volume 9

ISSUE 4

2021 dicembre

Editor in Chief Michele Meschi

Supervisor Editor Roberto Nardi

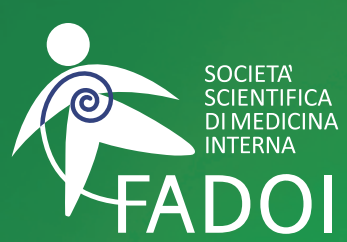

FEDERAZIONE

DELLE ASSOCIAZIONI

DEI DIRIGENTI

OSPEDALIERI

INTERNISTI

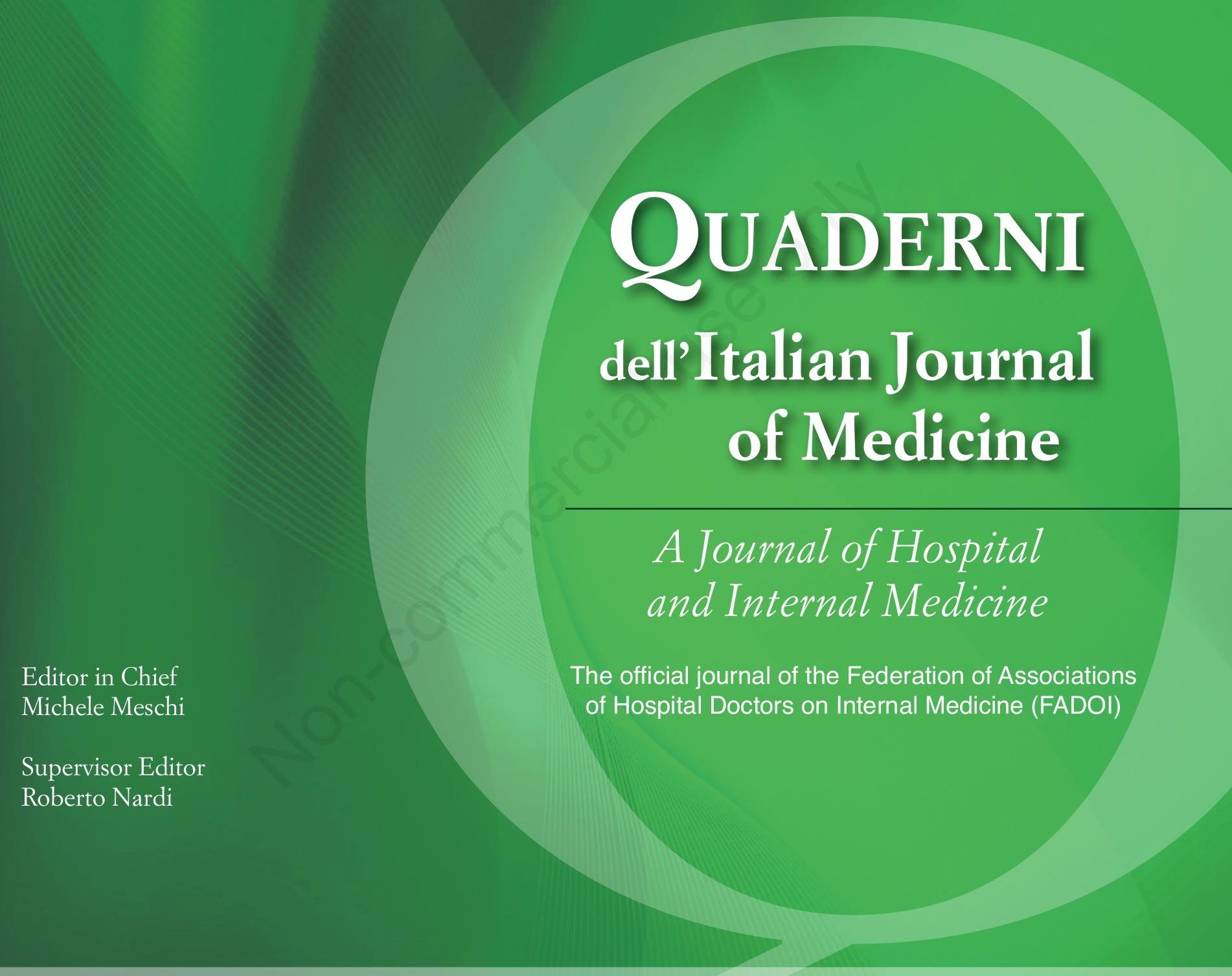

\title{
Gravidanza e malattie autoimmuni
}




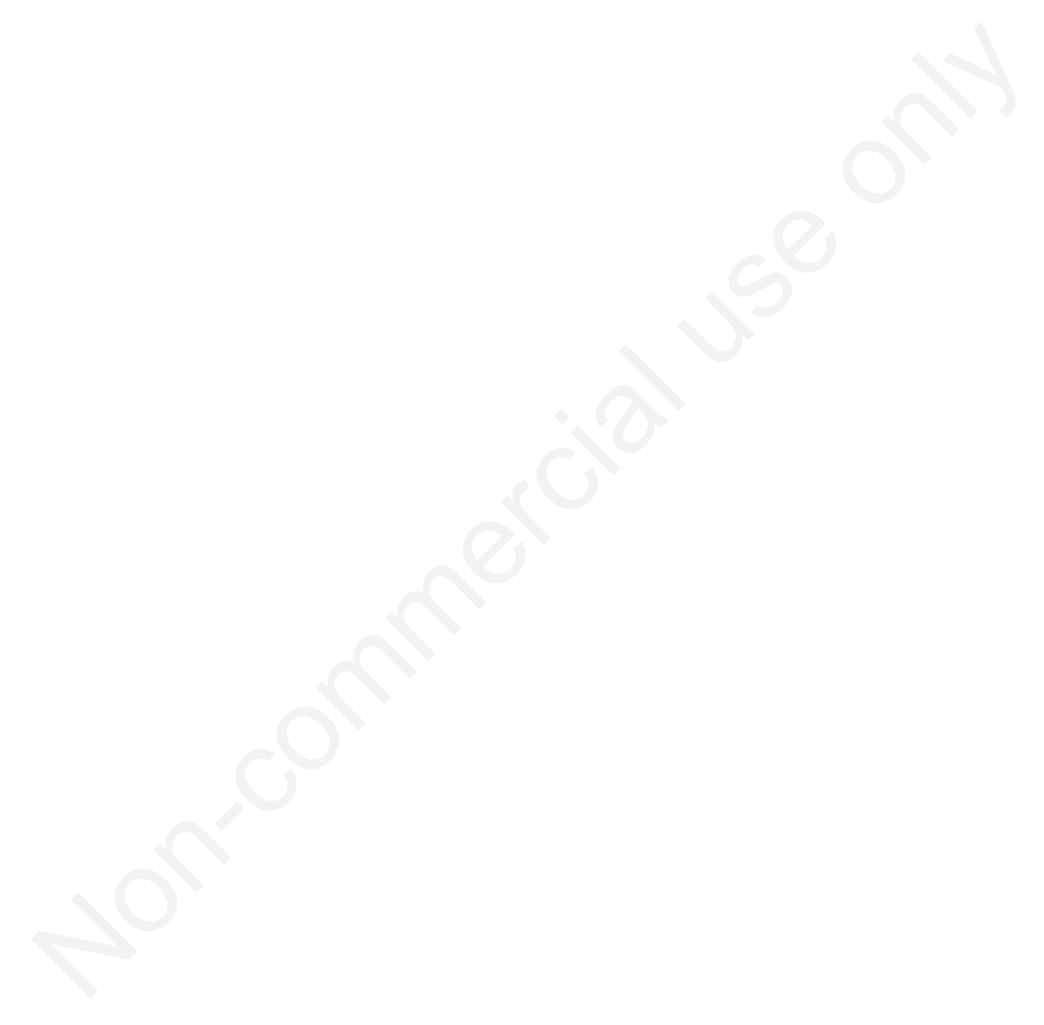


PRESIDENTE ELETTO

Francesco Dentali, Varese, Italy

\section{PAST PRESIDENT}

Andrea Fontanella, Napoli, Italy

\section{SEGRETARIO}

Paola Gnerre, Savona, Italy

\section{STAFF DI SEGRETERIA}

Lorenza Lenzi, Pomarolo (TN), Italy

Ada Maffettone, Napoli, Italy

Claudia Tieri, Bari, Italy

\section{TESORIERE}

Giorgio Ballardini, Rimini, Italy

\section{COORDINATORE COMMISSIONE GIOVANI}

Ombretta Para, Firenze, Italy

\section{RESPONSABILE RAPPORTI ISTITUZIONALI}

Claudio Santini, Roma, Italy

\section{RESPONSABILE RAPPORTI CON LE REGIONI}

Alberto Fortini, Firenze, Italy

\section{RESPONSABILE EVENTI E INIZIATIVE SPECIALI}

Mauro Campanini, Novara, Italy

EDITOR IN CHIEF ITALIAN JOURNAL OF MEDICINE

Giorgio Vescovo, Padova, Italy
RESPONSABILE DEI

QUADERNI DELL'ITALIAN JOURNAL OF MEDICINE EDIZIONI ON LINE

Michele Meschi, Borgo Val di Taro (PR), Italy

SUPERVISOR EDITOR DEI

QUADERNI DELL'ITALIAN JOURNAL OF MEDICINE

Roberto Nardi, Bologna, Italy

\section{RESPONSABILE SITO WEB E COMUNICAZIONE SOCIAL}

Salvatore Lenti, Arezzo, Italy

Giuseppe Oteri, Milano, Italy

WEB MANAGER E CONTENT EDITOR

Giuseppe Oteri, Milano, Italy

Davide Ghilardi, Milano, Italy

\section{RESPONSABILE SISTEMA GESTIONE QUALITÀ}

Franco Berti, Roma, Italy

DPO

Alba Sciascera, Magenta (MI), Italy

\section{CONSULTA DEI PRESIDENTI}

Sandro Fontana, Biella, Italy

Salvatore Di Rosa, Palermo, Italy

Ido Iori, Reggio Emilia, Italy

Antonino Mazzone, Legnano (MI), Italy

Carlo Nozzoli, Firenze, Italy

Mauro Campanini, Novara, Italy

Andrea Fontanella, Napoli, Italy 


\section{Italian Journal of Medicine}

A Journal of Hospital and Internal Medicine

\section{COORDINATORE}

David Terracina, Roma, Italy

\section{SEGRETARIO E RESPONSABILE SCIENTIFICO} DEL PROVIDER ECM

Andrea Montagnani, Grosseto, Italy

DIRETTORI DEL DIPARTIMENTO

DELLA RICERCA CLINICA FADOI

Filippo Pieralli, Firenze, Italy

Fulvio Pomero, Savigliano (CN), Italy

\section{DIRETTORI DIPARTIMENTO}

\section{PER LA FORMAZIONE E AGGIORNAMENTO}

Luigi Magnani, Voghera (PV), Italy

Roberta Re, Novara, Italy

\section{COORDINATORE SCIENTIFICO CENTRO STUDI FONDAZIONE FADOI}

Gualberto Gussoni, Milano, Italy

\section{DELEGATI SOCIETÀ SCIENTIFICHE COLLEGATE}

FISM Antonino Mazzone, Legnano (MI), Italy

SIF Luigi Magnani, Voghera (PV), Italy

Consulta Michele Stornello, Siracusa, Italy cardiovascolare

SIIA e ISO

Michele Stornello, Siracusa, Italy Arcangelo Iannuzzi, Pomigliano d'Arco (NA), Italy

EFIM

Antonio Brucato, Milano, Italy Lorenza Lenzi, Pomarolo (TN), Italy

Choosing wisely Roberto Frediani, Chieri (TO), Italy

\section{PROGETTI SPECIALI}

\section{AGGIORN@FADOI}

Giuliano Pinna

PROGETTO NUOVE TECNOLOGIE

Francesco Nasso, Flavio Tangianu

PROGETTO MEDICINA DI GENERE

Cecilia Politi

PROGETTO COMPETENCE

Flavio Tangianu

PROGETTO GOVERNANCE

Stefano De Carli, Andrea Montagnani, Fabrizio Colombo

PROGETTO HOSPITALIST

Francesco Orlandini

PROGETTO FINE VITA

Mauro Carbone, Fabio Gilioli

PROGETTO GASTROENTEROLOGIA e FEGATO

Luca Fontanella, Paola Piccolo, Franco Radaelli, Giancarlo Parisi PROGETTO NUTRIZIONE CLINICA

Roberto Risicato, Luciano Tramontano

PROGETTO MALATTIE INFETTIVE/ANTIBIOTICI

Claudio Santini, Massimo Giusti, Marco Falcone

PROGETTO ECOGRAFIA INTERNISTICA

Francesco Cipollini, Nicola Mumoli

PROGETTO MALATTIE RARE

Antonio Brucato, Antonella Paradiso

PROGETTO BPCO/NIV

Marco Candela, Giuseppe De Matthaeis, Francesco Ventrella

PROGETTO TROMBOSI

Mauro Silingardi, Matteo Giorgi Pierfranceschi, Pierpaolo Di Micco PROGETTO TRIAL

Giancarlo Agnelli, Antonio Ceriello, Leo Fabbri, Claudio Ferri,

Franco Radaelli, Paolo Verdecchia

\section{PRESIDENTE ANÍMO}

Gabriella Bordin, Castelfranco Veneto (TV), Italy 


\title{
QUADERNI - Italian Journal of Medicine
}

\author{
GRAVIDANZA E MALATTIE AUTOIMMUNI
}

Guest Editor: Paola Gnerre

Gravidanza e patologie autoimmuni

C. Politi, V. Donvito, A. Tincani

La contraccezione e la terapia estroprogestinica nelle donne con malattie autoimmuni.

M. Montesano, R. Picilli, G. Nova, M. Vignali

Gravidanza e monitoraggio fetale in pazienti con malattie reumatiche autoimmuni .

I. Cetin, R. Milazzo, L. Basili

Lupus eritematoso sistemico e gravidanza

M. Larosa, A. Doria

Artrite reumatoide

V.L. Ramoni

Sindrome da anticorpi anti-fosfolipidi in gravidanza e puerperio $\ldots . .36$ M.C. Gerardi, C. Nalli, D. Lini, A. Tincani

Gravidanza e sclerosi sistemica (sclerodermia) . . . . . . . . . . . 44

A. Brucato, M. Nivuori, A. Mazzone

Anticorpi anti-Ro/SSA, sindrome di Sjögren, lupus neonatale e blocco cardiaco congenito

C. Picchi, E. Tombetti, A.L. Brucato

Patologie della tiroide in gravidanza

S. De Carolis, E. Barbagelata, I. Ambrosino, S. Tabacco

Gestione della gravidanza nelle donne con malattia di Behçet e vasculiti .

M. Gerosa, M. Cornalba, A. Sinelli, R. Cimaz, R. Caporali

Sclerosi multipla

A. Protti, E.L. Susani, L. Saraceno, M.R. Marazzi, E.C. Agostoni

Malattie autoinfiammatorie ereditarie e gravidanza

L. Obici

Pericardite in gravidanza.

E. Barbagelata, I. Ambrosino, E. Bernero, A. Brucato

Fisiologia del rene in gravidanza. 


\section{QUADERNI - Italian Journal of Medicine}

Terapia con farmaci antireumatici in corso di gravidanza e allattamento . . 104 M.C. Gerardi, D. Lini, L. Andreoli

Il ruolo delle analisi di laboratorio nella gravidanza delle donne

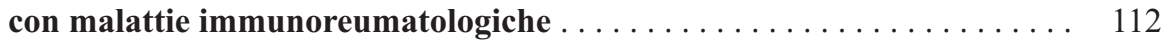
F. Bartoli, C.B. Chighizola

Fecondazione medicalmente assistita nelle malattie autoimmuni sistemiche. . . . . . . . . . . . . . . .

S. Truglia, S. Mancuso, F. Conti

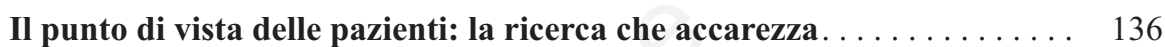
I. Galetti, S. Ostuzzi 


\title{
Gravidanza e patologie autoimmuni
}

\author{
Cecilia Politi, ${ }^{1}$ Valentina Donvito, ${ }^{2}$ Angela Tincani ${ }^{3}$ \\ ${ }^{1}$ U.O.C. Medicina Interna, P.O. F. Veneziale, Isernia; ${ }^{2}$ SSD Medicina Interna, Ospedale Sant'Anna - AOU Città della Salute e \\ della Scienza, Torino; ${ }^{3}$ U.O. Reumatologia e Immunologia Clinica, ASST-Spedali Civili di Brescia, Università degli Studi di \\ Brescia, Italia
}

\section{Introduzione}

\section{Medicina di genere, patologie autoimmuni e gravidanza}

In una medicina costruita su un modello sostanzialmente androcentrico in cui bambino era considerato un piccolo uomo, la donna fertile era sostanzialmente esclusa dagli studi clinici (così come il grande anziano), la attenzione alle differenze genere specifiche nelle malattie è iniziata dalla fine degli anni ' 90 , come una imprescindibile necessità culturale per poter assicurare cure appropriate a tutti i pazienti.

Valutando l'impatto del genere e di tutte le variabili che lo caratterizzano (biologiche, ambientali, culturali e socioeconomiche) sulla fisiologia, sulla fisiopatologia, sulle caratteristiche cliniche delle malattie, la medicina di genere (MDG) pone quindi l'attenzione sulle differenze nella prevenzione, nella diagnostica e nella risposta alla terapia delle malattie, non necessariamente quelle che prevalgono in uno dei due sessi o le patologie dell'apparato riproduttivo.

Il Ministero della Salute già nel $N^{\circ} 26$ dei Quaderni della Salute del 26 aprile 2016 'Il genere come determinante di salute', riconosce ufficialmente la MDG come necessaria per garantire l'equità e l'appropriatezza delle cure.

La 'Rete italiana per la medicina di genere' (Figura 1) vede l'Istituto Superiore di Sanità, le due Società di medicina di genere (Gruppo Italiano Salute e GenereGISeG e Centro Studi Salute e Medicina di genere) sotto l'egida della IGM (la Società internazionale di MDG), la FNOMCEO (Federazione degli Ordini dei

Corrispondente: Cecilia Politi, U.O.C. Medicina Interna, P.O. F. Veneziale, Isernia, Italia.

E-mail: cecilia.politi@asrem.org

Articolo pubblicato secondo la Creative Commons Attribution NonCommercial 4.0 License (CC BY-NC 4.0).

${ }^{\circ}$ Copyright: the Author(s), 2021

Licensee PAGEPress, Italy

QUADERNI - Italian Journal of Medicine 2021; 9(4):e1
Medici e degli Odontoiatri, e la presenza di FADOI (Federazione degli Internisti ospedalieri) accanto a SIMG (Società Italiana di medicina generale) con un ruolo sostanziale accanto alle molte società scientifiche con gruppi su specificità di genere.

L'Italia con il Piano attuativo per la applicazione e la diffusione della medicina di genere sul territorio nazionale, disposto ai sensi dell'art. 3 - comma 1- della Legge n. 3/2018, è oggi all'avanguardia in Europa e nel mondo, per fornire '.. un indirizzo coordinato e sostenibile per la diffusione della medicina di genere mediante divulgazione, formazione e indicazione di pratiche sanitarie che nella ricerca, nella prevenzione, nella diagnosi e nella cura tengano conto delle differenze derivanti dal genere, al fine di garantire la qualità e l'appropriatezza delle prestazioni erogate dal SSN in modo omogeneo sul territorio nazionale'.

Le donne nei paesi occidentali vivono più a lungo degli uomini ma, l'aspettativa di 'vita sana' è equivalente tra i due sessi. Gli anni di vantaggio nelle donne, infatti, sono spesso gravati da disabilità, principalmente correlata alle conseguenze determinate da malattie croniche e scarsa qualità della vita, con un impatto anche sulla spesa sanitaria.

Se la attenzione alla 'salute della donna' è stata a lungo relegata esclusivamente agli aspetti specifici legati alla riproduzione, dobbiamo ricordare che la prima causa di morte nella donna nel mondo industrializzato è l'infarto del miocardio. In Italia la mortalità cardio-cerebrovascolare nella donna è del $48.4 \%$ e nell'uomo è del $38.7 \%$.

Uomini e donne condividono fattori di rischio cardiovascolare tradizionali (diabete, fumo, obesità e sovrappeso, inattività fisica, ipertensione e dislipidemia), ma questi impattano in maniera diversa nei due sessi. Le donne, inoltre, accanto ai fattori di rischio tradizionali presentano fattori di rischio non tradizionali o emergenti (nascita pretermine, ipertensione in gravidanza, diabete gestazionale, malattie autoimmuni, trattamenti per neoplasia della mammella, depressione) che ne condizionano lo stato di salute o di malattia se non adeguatamente riconosciute, trattate e seguite nel tempo.

I bisogni sanitari delle donne sono quindi crescenti, differenti e di particolare complessità. 
Il Ministero già nel $\mathrm{N}^{\circ} 26$ dei quaderni, segnalava l'attenzione da porre alle differenze genere-specifiche nella risposta immunitaria e nelle malattie autoimmuni.

Se la risposta immunitaria sia umorale che cellulare è maggiore nella donna rispetto all'uomo (più efficace fagocitosi e presentazione antigenica, maggiore produzione di citochine in risposta alle infezioni, maggior numero di T linfociti, maggiori livelli di anticorpi circolanti sia a livello basale che in risposta a stimolazione, es: vaccinazioni), questo si traduce in una maggiore resistenza alle infezioni ma anche in una maggiore suscettibilità alle malattie autoimmuni. Le differenze principali tra uomini e donne nelle patologie autoimmuni inoltre non consistono solo in una diversa prevalenza, ma osserviamo diversità nella sintomatologia, decorso di malattia, risposta alla terapia e sopravvivenza.

La ricerca sulle differenze di genere in questo campo si focalizza quindi sull'effetto strettamente $l e-$ gato al sesso degli ormoni (antinfiammatorio/proinfiammatorio dose dipendente degli estrogeni, antinfiammatorio del progesterone ed immuno soppressivo degli androgeni) e sul ruolo dei cromosomi (in particolare del cromosoma $\mathrm{X}$ e la mancata inattivazione del secondo cromosoma X). Ma fondamentali sono i fattori correlati al genere, in primis l'esposizione occupazionale (es: effetto immunomodulatore di alcuni pesticidi specie nel maschio), nonché l'impatto della ormonoterapia (contraccettiva/sostitutiva) e degli stili di vita. Durante la gravidanza, inoltre, la risposta immunitaria si modifica per favorire l'impianto embrionale e la prosecuzione della stessa attraverso livelli elevati di estrogeni e progesterone che favoriscono la creazione di un ambiente antinfiammatorio ed immunosoppressivo. Oltre a ciò, nel dimorfismo della risposta immunitaria ha un ruolo anche il microbiota intestinale, la cui composizione si modifica in funzione degli ormoni sessuali e che a sua volta ne influenza la loro sintesi, mediante alcuni enzimi coinvolti (es: l'enzima di conversione dei glucocorticoidi in androgeni).

La Società Scientifica FADOI con la presentazione di una Monografia dei Quaderni dell'ITJM dedicata a Gravidanza e patologie autoimmuni, attraverso la condivisione di conoscenze da parte di esperti di varie discipline e la messa a punto e la proposizione di strategie di buona pratica sanitaria, attende alle raccomandazioni del Ministero della salute alle Società scientifiche (Legge 3/2018, art.1).

Questo sforzo di coordinamento delle attuali evidenze scientifiche su una così complessa e specifica tematica è perfettamente in linea con il percorso che FADOI ha intrapreso da anni e dichiarato anche con il VADEMECUM sulla MDG. ${ }^{1}$

\section{Quando è necessaria la gestione multidisciplinare}

Il numero delle gravidanze in donne affette da patologie croniche è in aumento negli ultimi decenni e la ragione di ciò è da attribuire ad una serie di fattori, di cui i principali sono: i) età delle donne al parto, che è in Italia in costante incremento. L'età materna media è di 34 anni, ma più del $30 \%$ ha un'età superiore ai 35 anni e circa il $6 \%$ delle donne in gravidanza ha più di

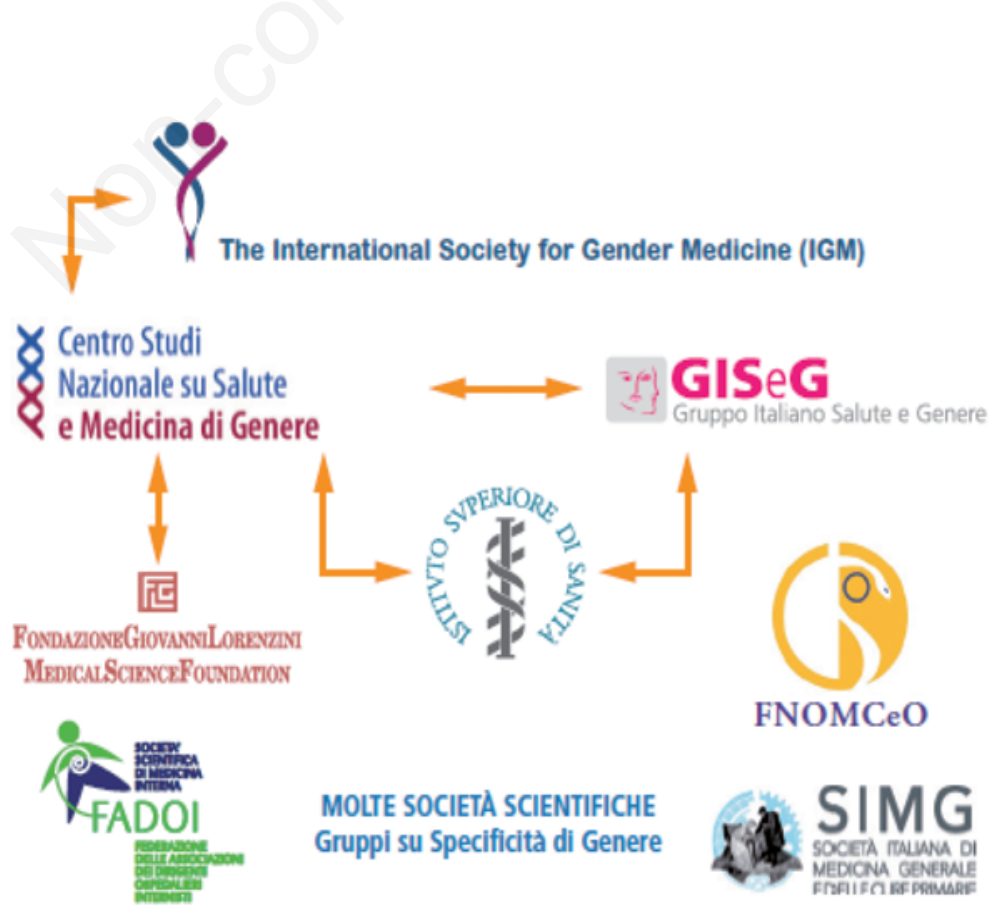

Figura 1. 'Rete italiana per la medicina di genere'. 
40 anni; ii) aumento delle donne con patologie croniche (malattie autoimmuni sistemiche, cardiopatie congenite operate, nefropatie, pazienti sottoposte a trapianto d'organo...) che raggiungono l'età fertile. Grazie ai progressi nella diagnosi precoce e nel trattamento chirurgico e farmacologico, queste donne possono ora desiderare ed affrontare una gravidanza, quando un tempo questa non era neanche ipotizzabile; iii) la presenza di donne migranti che nel loro territorio di origine hanno ricevuto una ridotta assistenza sanitaria, e che risultano portatrici di patologie misconosciute e/o sotto-trattate; iv) il ricorso sempre maggiore alle tecniche di Procreazione Medicalmente Assistita. Situazione questa in cui sono contemporaneamente presenti numerosi fattori di rischio per la gravidanza, quali l'età avanzata, la pregressa infertilità, la multigemellarità, l'incremento del rischio cardiovascolare e trombotico connesso ai trattamenti ormonali; v) la crescente prevalenza del sovrappeso e dell'obesità che costituisce un fattore di rischio emergente con cui sempre più si dovranno fare i conti.

È oggi ben noto che le malattie di interesse medico che complicano la gravidanza sono a livello mondiale una delle principali cause di mortalità e morbilità materna. Globalmente le 'cause indirette' sono responsabili di un terzo delle morti materne e nei soli paesi occidentali le cause mediche ne rappresentano quasi 1' $80 \%$. La presenza, Inoltre, di comorbilità aumenta anche il rischio di complicazioni e di morte materna da 'cause dirette' ostetriche (emorragia peripartum, eclampsia, embolia polmonare, sepsi grave, embolia amniotica).

Il dover affrontare gravidanze così complesse ha portato allo sviluppo di una nuova professionalità che trova la sua definizione in quella che gli anglosassoni chiamano 'Obstetric Medicine', fondata sulla gestione multidisciplinare/plurispecialistica di queste gravidanze. La Medicina Ostetrica serve ad ottimizzare la salute delle donne con patologie preesistenti rendendo possibile la gravidanza, nonché a prevenire o ridurre l'insorgenza di situazioni patologiche prevedibili e il numero di urgenze/emergenze a queste conseguenti. Il beneficio di un intervento appropriato sulla salute materna riduce il rischio di complicanze della gravidanza, incide sul benessere fetale e migliora gli outcomes a lungo termine ben oltre i 9 mesi della gravidanza e del parto.

Il ruolo delle équipes multidisciplinari è quindi centrale in ogni fase della programmazione e della gestione della gravidanza e del puerperio.

\section{Valutazione preconcezionale}

Il rischio materno e fetale sarà soppesato rispondendo a queste due domande: i) la malattia cronica può peggiorare per effetto della gravidanza? ii) in che misura la gravidanza e il benessere fetale sono a rischio a causa della patologia materna?

La stabilità della malattia e la presenza di danno d'organo dovranno essere valutate più in dettaglio rispondendo alle domande: i) è questo il momento migliore per iniziare una gravidanza? oppure ii) meglio attendere e curare ancora la paziente per consentire lo svolgimento della gravidanza in un momento più tranquillo?

E infine, ma cruciale per le patologie croniche, è l'utilizzo dei farmaci che richiede la duplice valutazione: i) è possibile sospendere il farmaco in uso? ii) è sicuro per la gravidanza proseguire quel farmaco?

\section{Gestione della gravidanza}

Fin dal primo trimestre la conoscenza dei fattori di rischio associati alla patologia materna e la presa in carico multidisciplinare, consentono di prevenire le complicanze precoci (es. rischio trombotico presente fin dalle prime settimane) e di diagnosticare senza ritardi le complicanze temute e preventivate (es. la preeclampsia nelle patologie autoimmuni).

È fondamentale in queste situazioni la tempestività della gestione multidisciplinare, che viene permessa da modelli organizzativi adeguati e adattati alle risorse dei diversi sistemi sanitari (ad esempio Day Service con disponibilità di esami, controlli ecografici e clinici in contemporanea da parte dei diversi specialisti)

L'interesse materno e quello fetale non sempre coincidono e spesso anche la decisione sul timing del parto deve essere presa dal team multidisciplinare. In molti casi può essere 'terapeutico' per la donna l'espletamento del parto, se l'epoca di gravidanza e le condizioni fetali lo consentono. In altri casi sarà più opportuno cercare di consentire la prosecuzione della gravidanza, attuando le opportune misure terapeutiche per migliorare il benessere materno e conseguentemente fetale. In casi estremi potrà essere necessario decidere per l'interruzione della gravidanza, nelle rare situazioni in cui il benessere materno e la sopravvivenza fetale risultino incompatibili.

\section{Puerperio}

Sappiamo che le problematiche di una donna con patologia cronica in gravidanza non finiscono con il parto. Nel periodo del puerperio, infatti, possono perdurare complicanze comparse in gravidanza oppure comparirne di nuove; pertanto, anche la sorveglianza a distanza dal parto deve essere gestita in modo multidisciplinare, con particolare attenzione alle riacutizzazioni, all'utilizzo dei farmaci in allattamento, alla contraccezione e alle complicanze a lungo termine, quali la maggiore incidenza di patologie cardiovascolari o metaboliche.

Gestione multidisciplinare in ambito ostetrico vuol dire quindi che: i) lo specialista e il ginecologo si abituano a lavorare insieme e, parlando lo stesso linguaggio, riescono a comprendersi quando devono 
confrontarsi sui casi più complessi o nell'urgenza; ii) lo specialista della patologia materna conosce anche un po' di ostetricia e viceversa; iii) la condivisione delle esperienze tra specialisti di formazione anche molto differente, e l'aggiornamento scientifico 'di gruppo' costituiscono un valore aggiunto per la crescita culturale individuale e del gruppo stesso.

Il miglioramento dell'outcome materno e fetale conseguente ad una gestione multidisciplinare fin dall'epoca preconcezionale è testimoniato, nelle gravidanze seguite per patologie autoimmuni, dalla riduzione delle riacutizzazioni di malattia nonché dai i tassi di nati vivi e di complicanze della gravidanza simili a quelli della popolazione generale.

\section{Il counselling}

Secondo la definizione della enciclopedia Treccani, in ambito sanitario il counselling (o counseling) è 'un'attività relazionale, svolta da personale specializzato (counselor), finalizzata a orientare, sostenere e sviluppare le potenzialità di persone momentaneamente in difficoltà, che può essere individuale o di gruppo, che promuove atteggiamenti attivi verso soluzioni possibili di una problematica ed aiuta a prendere decisioni e a attuare scelte dopo essere stata guidata a esaminare la situazione da diversi punti di vista'.

Sembra facile e naturale applicare questo concetto tutti i giorni ma forse almeno nel settore della riproduzione non è sempre così facile. In effetti le raccomandazioni delle Società Scientifiche internazionali invitano a interrogare le giovani pazienti con malattie reumatiche sulla progettualità nella loro vita familiare. Tuttavia, gli specialisti (siano essi reumatologi o internisti) che valutano le pazienti spesso trascurano questo aspetto e, a giudicare dalla letteratura, il problema non è soltanto Italiano. Infatti, i tempi brevi e talvolta contingentati delle visite non aiutano ad affrontare l'argomento. Discutere di questi temi potrebbe anche creare insicurezza e difficoltà nello specialista, abituato a gestire problemi diversi, fino ad impedirne la comunicazione.

Chi invece non ha problemi a parlarne sono i ginecologi e i medici di medicina generale che tuttavia potrebbero anche non essere esperti dei rapporti tra malattie autoimmuni e gravidanza o contraccezione. Nell'interesse delle pazienti è quindi necessario un consulto a più voci come sopra dettagliato.

Per comunicare a una giovane donna che già soffre di una malattia cronica come affrontare la gravidanza è necessario farle capire che la gravidanza non è una nuova malattia, e che lei continuerà a essere portatrice della sua malattia e che questa, pertanto, andrà 'curata' anche in questo periodo. Con qualche distinguo tra malattia e malattia, possiamo dire che tutte le malattie reumatiche/autoimmuni vanno trattate in gravidanza in quanto la attività di malattia, con la flogosi connessa, è dannosa, oltre che alla madre, alla crescita del feto e può causare parti pretermine e ritardi di crescita. È necessario, pertanto, far comprendere che i farmaci, quelli necessari, vanno assunti e lo specialista avrà cura di escludere tra questi quelli potenzialmente dannosi per il feto (che comunque sono fortunatamente pochi).

Il discorso 'farmaci' interessa anche pazienti di sesso maschile che desiderino diventare padri: in questo caso gli argomenti sono la paura di farmaci che possano causare malformazioni e quella di famaci che possano indurre sterilità e verranno dettagliati nel capitolo dedicato. Qui ci basta sottolineare come sia necessario aver presente il problema ed affrontarlo.

Per le pazienti donne, che non riescono ad iniziare la gravidanza, viene facilmente presa in considerazione la sterilità legata ai farmaci ma, dato che oggi questa situazione è ben definita e limitata, il problema appare più frequentemente legato alla età che avanza. Le donne negli ultimi anni, come dettagliato in precedenza, tendono a posticipare la gravidanza principalmente per problemi personali, e le nostre pazienti oltre a questi hanno i problemi legati alla malattia. È allora importante che lo specialista, qualche volta costretto a curare più aggressivamente la malattia (senza dimenticare in questa fase la necessaria contraccezione!), non perda di vista l'orologio biologico e metta in discussione il management della paziente ad ogni valutazione.

L'ultimo argomento da discutere è cosa accadrà dopo, una volta che il bimbo è nato. Accudire un neonato è certamente una gioia immensa ma è anche una fatica fisica non indifferente, soprattutto in presenza di problemi muscoloscheletrici. Avvertiamo le nostre neomamme che avranno bisogno di aiuto: questo non limita la loro funzione di madri che comincia al parto e dura comunque tutta la vita. Un discorso pratico e affettuoso su questo delicato argomento è necessario ad evitare la possibile depressione puerperale cui le nostre pazienti vanno incontro più frequentemente che le donne sane. ${ }^{2-7}$

\section{Bibliografia}

1. www.fadoi.org/news/vademecum-fadoi-per-la-medicina-di-genere

2. Narayan B, Nelson-Piercy C. Medical problems in pregnancy. Clin Med (Lond) 2017; 17:251-7.

3. Götestam Skorpen C, Hoeltzenbein M, Tincani A, et al. The EULAR points to consider for use of antirheumatic drugs before pregnancy, and during pregnancy and lactation. Ann Rheum Dis 2016;75:795-810.

4. Andreoli L, Bertsias GK, Agmon-Levin N, et al. EULAR recommendations for women's health and the management of family planning, assisted reproduction, pregnancy and menopause in patients with systemic lupus erythematosus and/or antiphospholipid syndrome. Ann Rheum Dis 2017;76:476-85. 
5. Chakravarty E, Cowse M, Pushparajah DS, et al. Family planning and pregnancy issues for women with systemic inflammatory diseases: patient and physician perspectives. BMJ Open 2014;4.

6. Andreoli L, Lazzaroni MG, Carini C, et al. 'Disease knowledge index' and perspectives on reproductive is- sues: a nationwide study on 398 women with autoimmune rheumatic diseases. Joint Bone Spine 2019;86: 475-81.

7. Birru Talabi M, Clowse MEB, Schwarz EB, et al. Family planning counseling for women with rheumatic diseases. Arthritis Care Res (Hoboken) 2018;70:169-74. 


\title{
La contraccezione e la terapia estroprogestinica nelle donne con malattie autoimmuni
}

\author{
Marzia Montesano, Roberta Picilli, Greta Nova, Michele Vignali \\ Ospedale Macedonio Melloni, ASST Fatebenefratelli Sacco, Milano, Italia
}

\section{Introduzione}

Per contraccezione si intende l'insieme dei dispositivi ormonali e non utilizzati per programmare o impedire il verificarsi di una gravidanza, proteggendo da gravidanze indesiderate e (a seconda del metodo utilizzato) da malattie a trasmissione sessuale.

Lo scopo è quello di controllare, in modo temporaneo e reversibile, il processo riproduttivo.

Le donne con malattie autoimmuni hanno particolari necessità ed esigenze in merito alla loro salute riproduttiva; la gravidanza, infatti, può accelerare la progressione della malattia in caso di lupus eritematoso sistemico (LES), sindrome anticorpi antifosfolipidi (APS) e vasculiti. ${ }^{1,2}$

Sono state descritte complicanze dovute alla gravidanza in caso di LES, artrite reumatoide (AR), sindrome di Sjögren e APS., ${ }^{2,3}$

Le malattie autoimmuni colpiscono donne e uomini con un rapporto di $2: 1 .^{4}$

Le donne in età fertile affette da malattie autoimmuni spesso vengono trattate con farmaci potenzialmente teratogeni, ${ }^{5}$ è importante in queste pazienti riuscire a programmare la gravidanza, riducendo il tasso di gravidanze indesiderate e ad alto rischio. Uno degli obiettivi principali nel counseling preconcezionale delle pazienti reumatologiche deve essere quello di pianificare una gravidanza in maniera tale che questa avvenga in un periodo di quiescenza da malattia o mentre la donna assume farmaci compatibili con la stessa.

I metodi contraccettivi si classificano sulla base della loro durata d'azione, della reversibilità e del

Corrispondente: Roberta Picilli e Greta Nova, Ospedale Macedonio Melloni, ASST Fatebenefratelli Sacco, Milano, Italia. E-mail: r.picilli@yahoo.com; nova.greta@gmail.com

Articolo pubblicato secondo la Creative Commons Attribution NonCommercial 4.0 License (CC BY-NC 4.0).

${ }^{\circ}$ Copyright: the Author(s), 2021

Licensee PAGEPress, Italy

QUADERNI - Italian Journal of Medicine 2021; 9(4):e2 meccanismo d'azione; possono essere distinti in ormonali e non.

Le malattie autoimmuni rispondono allo stimolo ormonale, in particolare degli ormoni sessuali steroidei; la gravidanza e l'utilizzo di metodi contraccettivi ormonali (pillole, cerotti, impianti o dispositivi intrauterini medicati) possono modificare il decorso della malattia.

Per questo motivo è importante valutare e scegliere il metodo contraccettivo più appropriato, considerando le possibili interazioni con la malattia e la possibilità di utilizzare contraccettivi ormonali e non. Frequentemente le donne con malattie reumatiche non utilizzano contraccettivi. ${ }^{6}$

I contraccettivi ormonali combinati hanno un effetto complesso sulle malattie autoimmuni: sono controindicati in pazienti con LES (con anticorpi antifosfolipidi positivi) e APS poiché possono peggiorare la sintomatologia, ${ }^{2}$ sono correlati a effetti avversi minori in pazienti con malattie intestinali croniche (RCU e morbo di Crohn), mentre non determinano alcun effetto significativo in pazienti con patologie tiroidee autoimmuni.

Gli estrogeni sono importanti immunomodulatori con effetti significativi sulla proliferazione cellulare, produzione di citochine e differenziazione delle cellule ematopoietiche.

Il sistema immunitario e gli ormoni interagiscono tra loro attraverso una serie di meccanismi d'azione e l'interazione tra questi sistemi può portare ad eventuali progressioni della malattia autoimmune.

L'utilizzo di metodi di barriera dovrebbe essere incoraggiato nelle giovani donne con malattie autoimmuni. L'utilizzo della contraccezione reversibile a lunga durata (LARC) può essere incoraggiato nella maggior parte di queste malattie. Le pillole a carattere solo progestinico sono sicure nella maggior parte dei casi, sebbene possano portare ad irregolarità del ciclo mestruale e dare quindi scarsa aderenza soprattutto nelle giovani donne affette. Le iniezioni intramuscolari di medrossiprogesterone Acetato eseguite circa ogni tre mesi sono un'ottima strategia di contraccezione, sebbene il loro uso prolungato sia correlato ad aumentato rischio di riduzione della densità minerale ossea.

In questo capitolo approfondiremo brevemente il 
corretto utilizzo della terapia contraccettiva nelle malattie autoimmuni più studiate e conosciute (Figura 1).

\section{Sindrome da anticorpi antifosfolipidi}

La sindrome da anticorpi antifosfolipidi (APS, antiphospholipid syndrome) è una patologia sistemica autoimmune definita da episodi di trombosi venose e arteriose spesso multiple e da patologie della gravidanza (aborti, morti fetali e parti prematuri), associate alla presenza di anticorpi antifosfolipidi (aPL). ${ }^{7} \mathrm{La}$ sindrome da anticorpi antifosfolipidi può essere diagnosticata in pazienti che non evidenziano alcun segno clinico né laboratoristico di altre sindromi autoimmuni (APS primaria) oppure può essere associata ad altre patologie, prevalentemente il LES.

Gli aPL, inoltre, possono essere riscontrati anche in altre patologie autoimmuni, talvolta durante infezioni in corso, patologie tumorali o in risposta ad alcuni farmaci; ${ }^{8}$ sono ad oggi riconosciuti come fattore di rischio acquisito indipendente per la trombofilia e causa frequente di aborti. Per tale motivo le gravidanze in giovani pazienti con APS si trovano in un setting clinicamente difficile che richiede una valutazione completa e una attenta assistenza medica multidisciplinare. $^{9}$

Il termine aPL comprende un gruppo eterogeneo di anticorpi quali il lupus anticoagulante (LAC), gli anticorpi anticardiolipina (aCL) e gli anticorpi antibeta2glicoproteina I (anti-b2GPI). ${ }^{10}$ Nonostante il nome, gli aPL non sono diretti contro i fosfolipidi, ma verso le proteine cationiche intravascolari, da soli o nel complesso di fosfolipidi anionici.

La APS è ben conosciuta come condizione protrombotica, ma, nonostante ciò, è tuttora limitata la capacità di predire il rischio di fenomeni tromboembolici per una paziente con anticorpi positivi ma asintomatica. ${ }^{11,12}$

L'associazione tra alte dosi di estrogeni e tromboembolismi venosi è nota da tempo, alcuni studi mostrano come gli estrogeni e il progesterone siano fattori rilevanti nella patogenesi di trombosi arteriose. ${ }^{13}$

La combinazione di aPL e l'utilizzo di una contraccezione orale combinata $(\mathrm{COC})$ potenzia il rischio di trombosi già presente in pazienti con APS, molte delle quali non sono a conoscenza del loro rischio genetico. ${ }^{12}$

Ulteriori fattori di rischio che possono aumentare la probabilità di eventi arteriosi come ictus e infarto in pazienti che soffrono di LES con aPL positivi, sono ad esempio l'emicrania complicata con aura, l'aterosclerosi e l'iperlipidemia. ${ }^{14}$

Alla luce di ciò, sono state espresse preoccupazioni considerevoli riguardanti la prescrizione di $\mathrm{COC}$ a queste donne, per cui sembra essere ragionevole evitare la $\mathrm{COC}$ in tutte le pazienti con positività ad aPL. ${ }^{12,14}$

Recenti revisioni sistematiche della letteratura e metanalisi sono state condotte per valutare il rischio di eventi tromboembolici venosi associati all'uso della contraccezione con solo progestinico. Diverse analisi hanno confermato un' associazione molto bassa, seppur non assente, tra il rischio tromboembolico venoso e la pillola con solo progestinico (POP) o il dispositivo intrauterino a rilascio progestinico. ${ }^{15}$

Le linee guida WHO (World Health Organization) considerano possibile l'uso del solo progestinico per il LES con positività per anticorpi aPL, così come le linee guida CDC (Center for Disease Control and Prevention). ${ }^{16,17}$

Le iniezioni di medrossiprogesterone acetato (DMPA) ogni tre mesi è un metodo contraccettivo ad alta efficacia e può essere un'alternativa valida alla COC nelle adolescenti con APS. Tra gli effetti collate-

SINDROME ANTICORPI ANTIFOSFOLIPIDI E LUPUS ERITEMATOSO

SISTEMICO:

- controindicati i COC

- alternative valide: IUD al rame, DMPA, IUD medicata al levonorgestrel, contraccettivi di barriera

ARTRITE REUMATOIDE:

- IUD e LARC

- COC non controindicati

SCLEROSI MULTIPLA:

- IUD e LARC in pazienti con ridotta motilità

TIROIDITI AUTOIMMUNI:

- COC non controindicati

Figura 1. Terapia contraccettiva nelle principali malattie autoimmuni. 
rali del DMPA sono note l'osteoporosi reversibile e il ritardo del recupero della fertilità dopo la sospensione. Le linee guida WHO e CDC consigliano il DMPA come metodo contraccettivo sicuro in donne con APS, il suo utilizzo è preferibile anche per poter sopprimere l'ovulazione, in modo tale da diminuire il rischio di un corpo luteo emorragico derivante dalla terapia anticoagulante assunta da queste pazienti. ${ }^{18}$

Il DMPA, così come lo IUD con levonorgestrel, determinano inoltre una diminuzione considerevole del flusso mestruale, dimostrando così di avere particolari benefici in pazienti in terapia con warfarin. ${ }^{12,19}$

\section{Lupus eritematoso sistemico}

Il lupus eritematoso sistemico è una malattia sistemica autoimmune. In più del $90 \%$ dei casi è colpito il sesso femminile, in particolare in età fertile.

Raccomandare un metodo anticoncezionale alle pazienti affette da LES è difficile, poiché i contraccettivi di barriera e le norme comportamentali hanno un alto tasso di fallimento. Gli studi pubblicati negli ultimi 40 anni hanno dimostrato un aumento delle esacerbazioni di LES nelle donne affette e trattate con contraccettivi orali combinati. ${ }^{20,21}$

Sebbene sia parte della pratica clinica sospendere la somministrazione dei COC non appena venga fatta diagnosi di LES, è importante considerare i loro potenziali effetti benefici, inclusa la contraccezione e la prevenzione dell'osteoporosi. Nel 2005 uno studio multicentrico ha valutato l'utilizzo dei COC vs placebo in pazienti affette da LES in forma inattiva o stabile. In entrambi i gruppi si sono verificate le riacutizzazioni severe della malattia senza differenze statisticamente significative e lo stesso è stato osservato in un altro studio multicentrico randomizzato in cui le pazienti venivano assegnate al gruppo $\mathrm{COC}$, solo progestinico e dispositivi intrauterini contenenti rame. ${ }^{22,23}$

Le pazienti dovrebbero essere edotte di quelli che sono i fattori di rischio individuali, generali (ipertensione, obesità, abitudine al fumo, storia familiare di tumori ormono-dipendenti) e correlati alla malattia, in particolare eventuali esacerbazioni e rischio trombotico (soprattutto se presente la positività per gli anticorpi antifosfolipidi).

I dispositivi intrauterini possono essere proposti a tutte le pazienti affette in assenza di controindicazioni ginecologiche.

Il dispositivo intrauterino contenente rame può essere utilizzato in tutte le pazienti, in quanto non modifica il decorso della malattia né sembra aumentare il rischio di infezioni severe,,$^{23}$ e pertanto deve essere considerato il metodo contraccettivo di scelta. Tal dispositivo non è indicato nelle pazienti che presentano una severa trombocitopenia poiché potrebbe aumentare la perdita ematica mestruale.
Il dispositivo intrauterino rilasciante levonorgestrel (progestinico di II generazione) dovrebbe essere considerato solo se i benefici dell'azione ormonale superino il rischio di trombosi (ad esempio nelle pazienti con mestruazioni eccessivamente abbondanti conseguenti alla terapia anticoagulante).

La sicurezza della terapia estroprogestinica combinata e del solo progestinico è stata dimostrata da trial randomizzati controllati in pazienti con LES in forma inattiva o stabile e in assenza di anticorpi antifosfolipidi. 22,23

In donne con aPL positivi (con o senza APS) la contraccezione ormonale combinata dovrebbe essere assolutamente controindicata (Medical Eligibility Criteria for contraceptive use - MEC 2015). Gli aPL conferiscono un significativo aumento del rischio tromboembolico in associazione al rischio preesistente di ogni COC.

In pazienti scoagulate con un profilo anticorpale a basso rischio, gli estrogeni dovrebbero essere considerati in quei casi di disordini ginecologici persistenti non altrimenti trattabili. Le composizioni di solo progestinici (pillole o impianti sottocutanei) possono essere utilizzate (sempre in assenza di anticorpi), sebbene il loro utilizzo debba essere ponderato sulla base del rischio di trombosi. La contraccezione d'emergenza invece non è controindicata in pazienti con LES (né con APS).

\section{Artrite reumatoide}

L'artrite reumatoide (AR) è una malattia infiammatoria sistemica che interessa diverse articolazioni, solitamente in modo simmetrico e causando spesso deformità articolari e disabilità.

$\mathrm{La} A R$ è da due a tre volte più frequente nelle donne rispetto agli uomini. Sono stati registrati, inoltre, livelli maggiori di attività di malattia nel sesso femminile. ${ }^{24}$

Nonostante ciò, la gravidanza in donne con artrite reumatoide ha generalmente outcomes buoni e diversi studi hanno dimostrato come non ci sia un aumento del rischio di aborto, anche se è possibile riscontrare un aumento del rischio di parto pretermine e basso peso alla nascita. ${ }^{25}$

È ben noto come la gravidanza, così come l'allattamento, tendano ad alleviare i segni e i sintomi dell'artrite reumatoide in circa il $75 \%$ delle donne, mentre la sintomatologia correlata alla patologia tende a peggiorare durante il periodo del post partum, in oltre il $90 \%$ delle pazienti. ${ }^{24-27}$

Uno studio più recente mostra variazioni della sintomatologia in gravidanza e nel post partum più modeste; probabilmente le nuove terapie utilizzate, che dimostrano una maggior efficacia, rendono più sottile la differenza con il beneficio determinato dalla gravidanza. ${ }^{28}$ 
Inoltre, dopo il parto, molte donne iniziano precocemente la terapia immunosoppressiva, prevenendo le note riacutizzazioni del post partum.

È importante notare che, nonostante ciò, in circa la metà della popolazione l'AR rimane attiva durante la gravidanza e in qualche caso va incontro a riacutizzazioni. ${ }^{25}$

È noto che i COC simulano lo stato gravidico e per questo il loro utilizzo in quest'ambito è oggetto di particolare interesse.

Nei modelli animali di artrite reumatoide gli estrogeni hanno effetti benefici, ritardando la progressione della malattia. Nell'uomo invece il ruolo degli estrogeni è meno chiaro poiché in letteratura sono stati riportati effetti sia pro che antinfiammatori. ${ }^{26}$ Come già accennato, se da un lato l'artrite reumatoide è più comune nelle donne, nelle quali è stato evidenziato anche un livello di attività maggiore rispetto al sesso maschile, dall'altro lato invece questa patologia tende a migliorare durante i periodi in cui il livello di estrogeni è alto, come ad esempio la gravidanza.

Diversi studi hanno evidenziato come a livello tissutale la concentrazione di estrogeni sia maggiore nel liquido sinoviale di pazienti con l'artrite reumatoide rispetto a campioni di pazienti sani. ${ }^{29}$ Uno studio recente ha evidenziato un aumento nella conversione dei precursori di estrogeni in metaboliti pro-infiammatori con conseguente aumento delle concentrazioni relative dei diversi metaboliti degli estrogeni biologicamente attivi, e alterazione dell'equilibrio dei processi pro e anti-infiammatori che caratterizzano l'AR. ${ }^{30}$

Una contraccezione efficace, sia ormonale che non, è fondamentale nelle pazienti giovani con artrite reumatoide in terapia con farmaci teratogeni, come il metotrexate e il leflunomide. Entrambi questi farmaci, infatti, sono stati classificati come categoria $X$ dalla FDA (Food and Drug Administration), indicando una evidente correlazione tra il farmaco e il rischio di anomalie fetali.

Tali rischi sono maggiori rispetto al potenziale beneficio del farmaco e per tale motivo è forte la raccomandazione a interrompere l'assunzione prima del concepimento.

Il leflunomide è associato a un tasso molto elevato di anomalie fetali, per tale motivo è raccomandata la valutazione del livello di leflunomide nel sangue prima della gravidanza e, nel caso in cui il livello sia maggiore di 2, deve essere somministrata la colestiramina per rimuovere completamente il leflunomide. ${ }^{25}$

In considerazione di ciò, si ritiene fondamentale un adeguato counselling con donne con l'artrite reumatoide per una buona comprensione dell'uso di metodi contraccettivi.

Alcuni medici raccomandano l'utilizzo di metodi contraccettivi reversibili e a lungo termine, come il dispositivo intrauterino o l'impianto sottocutaneo durante il periodo di assunzione di metotrexate e/o di fase attiva della malattia. ${ }^{31}$

Nonostante la dimostrata necessità della contraccezione nelle pazienti con AR, c'è ancora poca letteratura per quanto riguarda la sicurezza dei contraccettivi orali estro-progestinici.

Alcuni studi più recenti non hanno evidenziato una stretta correlazione tra COC e rischio di malattia. ${ }^{24}$

In conclusione, si può affermare che $i$ contraccettivi orali si possono utilizzare in modo sicuro per la contraccezione in pazienti con artrite reumatoide. Tuttavia, ad oggi, non esiste un'evidenza forte che raccomandi l'uso preventivo o terapeutico della contraccezione ormonale in presenza di questa patologia. ${ }^{26}$

\section{Sclerosi multipla}

La sclerosi multipla è una malattia infiammatoria autoimmune del sistema nervoso centrale che si manifesta con una perdita della sensibilità tattile, spasticità, perdita del controllo degli sfinteri, disfunzione sessuale, perdita dell'equilibrio, difficoltà nel parlare, tremori, disturbi visivi, debolezza, fino ad arrivare col tempo a difficoltà mnemoniche e perdita del giudizio. Le donne sono colpite da 1,4 a 2,8 volte più frequentemente rispetto agli uomini. La gravidanza non modifica l'andamento a lungo termine della malattia, si hanno abitualmente meno ricadute, in particolare nel corso del secondo e terzo trimestre.

I primi studi sugli effetti dei COC nella sclerosi multipla hanno portato a risultati contradditori: nessun effetto, risultati non statisticamente significativi in termini di aumento del rischio, effetto protettivo. ${ }^{32-34}$ Sebbene non esistano chiare evidenze è stata con il tempo sostenuta l'idea che i COC possano essere in parte responsabili dell'aumento dell'incidenza della sclerosi multipla nelle donne. ${ }^{35}$

In definitiva, la maggior parte dei metodi contraccettivi è sicura in donne affette da sclerosi multipla, l'unica eccezione va fatta per pazienti allettate o con problemi di motilità per l'aumentato rischio di eventi tromboembolici.

Laddove fosse presente una ridotta motilità va incoraggiato l'utilizzo di dispositivi intrauterini al rame e medicate o impianti sottocutanei (meno sicuro l'utilizzo di DMPA e di COC).

Non esistono trial controllati sugli effetti della contraccezione solo progestinica in pazienti con sclerosi multipla.

\section{Altre malattie autoimmuni}

Per quanto riguarda altre patologie autoimmuni, l'evidenza di un ruolo benefico o dannoso degli estrogeni e di altri ormoni sessuali è molto limitata e talvolta contradditoria. 


\section{Tiroiditi autoimmuni}

Ipertiroidismo e ipotiroidismo sono entrambi legati spesso a meccanismi autoimmuni. La più comune manifestazione di ipertiroidismo autoimmune è rappresentata dalla Malattia di Graves che comprende perdita di peso, tachicardia, aumento dell'appetito, nervosismo, irritabilità, tremori e sudorazioni profuse, così come gozzo, esoftalmo e mixedema. L'ipertiroidismo è più comune nelle donne che negli uomini con un rapporto di 5:1.

La più comune causa di ipotiroidismo, in aeree geografiche con sufficiente apporto di iodio, è la tiroidite cronica autoimmune (Hashimoto). L'ipotiroidismo è circa 5-8 volte più frequente nelle donne.

Numerosi studi hanno confermato che i COC moderni non influenzano dimensioni e funzione della ghiandola tiroidea in donne sane, i livelli di TSH non cambiano in maniera significativa e quelli di tiroxina libera non si modificano; non esistono evidenze significative sugli effetti dei COC sullo sviluppo dell'ipotiroidismo. ${ }^{36,37}$

\section{Sclerosi sistemica}

La malattia sclerodermica interessa prevalentemente le donne e in genere esordisce entro i 40 anni. Lo studio IMPRESS (Italian Multicentric Study on Pregnancy in Systemic Sclerosis) e i precedenti studi americani hanno confermato che la sclerosi sistemica tende a rimanere stabile nel corso della gravidanza, soprattutto per quanto riguarda i problemi muscolo-scheletrici, renali, cardiaci o polmonari, mentre i sintomi gastroesofagei possono peggiorare. Per contro il fenomeno di Raynaud può migliorare temporaneamente, così come l'ispessimento cutaneo, probabilmente per la vasodilatazione indotta dalle alterazioni ormonali della gravidanza, ma tende a peggiorare dopo il parto. ${ }^{25,38}$

Come per le altre malattie reumatiche autoimmuni, la gravidanza va affrontata solo in assenza di danno d'organo importante di base e va programmata aspettando preferibilmente tre anni dall'esordio della malattia e scegliendo un momento in cui la malattia non è attiva, con l'obiettivo di ridurre al minimo i rischi materno-fetali. A tal fine è fondamentale una corretta contraccezione: i metodi più consigliati sono i metodi di barriera, ma non ci sono particolari controindicazioni all'uso di dispositivi intrauterini e della pillola con solo progestinici. Per quanto riguarda le formulazioni contenenti anche estrogeni non c'è una chiara e univoca indicazione. $^{38}$

Due studi, infatti, suggeriscono il ruolo benefico degli estrogeni esogeni sulla funzione endoteliale nelle pazienti con sclerosi sistemica, mentre un altro studio descrive la progressione del fenomeno di Raynaud verso un quadro severo di sclerosi sistemica dopo l'utilizzo di contraccettivi orali. ${ }^{26,39,40}$

\section{Sindrome di Sjögren}

La sindrome di Sjögren (SS) è un disordine autoimmune che interessa soprattutto le donne di mezza età, è la seconda patologia autoimmune più comune e si manifesta con sintomi come xerostomia, xeroftalmia e ingrandimento delle ghiandole salivari. L'eziologia della SS non è del tutto conosciuta ma sappiamo che sono implicati diversi fattori, tra cui virali, ambientali, endocrinologici e ormonali.

In modelli animali la patologia è amplificata dall'uso di estrogeni, al contrario l'uso di androgeni per pazienti con SS allevia i sintomi. ${ }^{41}$

Sull'uomo, tuttavia, non ci sono studi di SS indotta in pazienti in terapia con estrogeni. Nello studio di Nagler e Pollack vengono descritti due casi di SS indotta in pazienti giovani altrimenti sane a cui è stata indotta l'ovulazione con l'utilizzo di estrogeni, evidenziando la possibilità che gli estrogeni slatentizzino una SS silente. Elevate dosi di estrogeni, associate a bassi livelli di androgeni possono essere dei fattori predisponenti significativi per la progressione della malattia. ${ }^{41}$

Alla luce di questi dati, i COC non vanno prescritti come prima scelta, tuttavia andrebbe incoraggiato l'utilizzo di contraccettivi di barriera e di dispositivi intrauterini.

\section{Vasculiti}

In letteratura ci sono pochissimi dati disponibili per quanto riguarda le vasculiti e la gravidanza per poter stabilire delle linee guida o raccomandazioni per la contraccezione e il concepimento.

La malattia di Behçet è una vasculite cronica multisistemica recidivante, con infiammazione delle mucose, è associata ad un aumentato rischio di trombosi. Alcuni studi hanno descritto casi di eventi trombotici severi e talvolta fatali associati all'utilizzo di contraccettivi orali in donne con la malattia di Behcet. ${ }^{42}$

Tenendo in considerazione quanto evidenziato da questi studi, l'uso di estro-progestinici orali deve essere evitato in queste pazienti. ${ }^{25,26}$

\section{Malattie infiammatorie intestinali}

\section{Malattia di Crohn}

La malattia di Crohn è una malattia infiammatoria del tratto gastroenterico. Caratterizzata tipicamente da affaticamento, diarrea e algie pelviche con o senza perdite ematiche, perdita di peso e febbre. Colpisce prevalentemente le donne con un picco di inizio tra i 15 e i 25 anni, suggerendo l'influenza degli ormoni sessuali sulla sua patogenesi.

Fino al 2017 più di 17 trials hanno valutato una possibile correlazione tra utilizzo di COC e sviluppo della malattia infiammatoria cronica, concludendo che questi possono avere un effetto negativo sulla condizione. ${ }^{37} \mathrm{E}$ stata riscontrata una correlazione tra utilizzo di $\mathrm{COC}$ e 
donne non fumatrici, in cui il rischio per malattia di Crohn aumenta. ${ }^{43}$

In definitiva tutti gli studi indicano che l'utilizzo dei COC portano ad un aumentato rischio, soprattutto nell'uso corrente, pertanto il loro utilizzo risulta non consigliato.

\section{Rettocolite ulcerosa}

La rettocolite ulcerosa è una malattia infiammatoria del colon. La combinazione dell'infiammazione e dell'ulcerazione può portare a discomfort e diarrea. È ugualmente distribuita tra uomini e donne.

Più di 14 studi hanno valutato una correlazione tra utilizzo di COC e rettocolite ulcerosa. ${ }^{37}$

Come per la malattia di Crohn, gli studi indicano un aumentato rischio correlato all'uso corrente di COC, pertanto il loro utilizzo risulta non consigliato.

\section{Bibliografia}

1. Clowse ME, Richeson RL, Pieper C, Merkel PA, for the Vasculitis Clinical Research Consortium. Pregnancy outcomes among patients with vasculitis. Arthritis Care Res (Hoboken) 2013;65:1370-4.

2. Ostensen M, Andreoli L, Brucato A, Cetin I, Chambers $\mathrm{C}$, Clowse ME, et al. State of the art: reproduction and pregnancy in rheumatic diseases. Autoimmun Rev 2015;14:376-86.

3. Martinez-Sanchez N, Robles-Marhuenda A, Alvarez-Doforno R, Viejo A, Antolin-Alvarado E, Deiros-Bronte L, et al. The effect of a triple therapy on maternal antiRo/SS-A levels associated to fetal cardiac manifestations. Autoimmun Rev 2015;14:423-8.

4. Hayter SM. Cook MC Updated assessment of the prevalence, spectrum and case definition of autoimmune disease. Autoimmun Rev 2012;11:754e65.

5. Flint J, Panchal S, Hurrell A, van de Venne M, Gayed M, Schreiber K, et al. BSR and BHPR guideline on prescribing drugs in pregnancy and breastfeeding. Part I: standard and biologic disease modifying anti-rheumatic drugs and corticosteroids. Rheumatology (Oxford) 2016;55:1693-7.

6. Julkunen HA, Kaaja R, Friman C. Contraceptive practice in women with systemic lupus erythematosus. $\mathrm{Br} \mathrm{J}$ Rheumatol 1993;32:227e30.

7. Miyakis S, Lockshin MD, Atsumi T, Branch DW, Brey $\mathrm{RL}$, Cervera R, et al. Internationalconsensus statement on an update of the classification criteria for definite antiphospholipid syndrome (APS). J Thromb Haemost 2006; 4(2): 295-306.

8. Bigioggero M. Meroni PL. The geoepidemiology of the antiphospholipid syndrome. Autoimmun Rev 2010; 9:!299-304

9. TincaniA, Bazzani C, Zingarelli S, Lojacono A, Lupus and the antiphospholipid syndrome in pregnancy and obstretics: clinical characteristics diagnosis, pathogenesis, and treatment. Semin Thromb Hemost 2008;34:267-73.

10. Pierangeli SS, De Groot PG, Dlott J, Favaloro E, Harris EN, Lakos G, et al. Criteria aPL tests: report of a task forse and preconference workshop at the 13th international Congress on antiphospholipid antibodies, Galveston, Texas, April 2010. Lupus 2011; (20):182-90.

11. Andreoli L, Fredi M, Nalli C, Reggia R, Lojacono A, Motta M, Tincani A. Pregnancy implications for systemic lupus erythematosus and the antiphospholipid syndrome. J of Autoimmunity 2012; 38:197-208.

12. Lourenco B, Kozu K, Leal G.N, Silva M.F, Fernandes E.G.C., Franca C.M.P, et al. Contraception for adolescents with chronic rheumatic diseases. Rivista Brasilera de Reumatologia , 2017;57(1):73-81.

13. Stageman BH, de Bastos M, Rosendaal FR, van Hylckama Vlieg A, Helmerhorst FM, Stijnen T, et al. Different combined oral contraceptives and the risk of venous thrombosis:systematic review and network meta-analysis. BMJ. 2013;347:5298.

14. Asherson RA, Harris EN, Hughes GRV, Farquharson RG. Complications of oral contraceptives and antiphospholipid antibodies. Arthritis Rheum. 1988;31:575-6.

15. Mantha S, Karp R, Raghavan V, Terrin N, Bauer A, Zwicker JI. Assessing the risk of venous thromboembolic events in women taking progestin-only contraception: a meta-analysis. BMJ. 2012;345:e4944.

16. WHO. Medical eligibility criteria for contraceptive use. 5th ed. geneva: WHO;2015. Available from: http//www. Who.int/reproductivehealth/publications/family-planning/Ex-summ-MEC-5/en

17. Centers for Disease Control and Prevention. Medical eligibility criteria for contraceptive use, 2010. Adapted from the World Health Organization medical eligibility criteria for contraceptive use,4th edition. MMWR.2010;59:1-86.

18. Yamakami LY, de Araujo DB, Silva CA, Baracat EC, de Carvalho JF. Severe hemorragic corpus luteum complicating anticoagulation in antiphospholipid syndrome. Lupus. 2011;20:523-6.

19. Schaedel ZE, Dolan G, Powell MC. The use of the levonorgestrel-releasing intrauterine system in the menagement of menorrhagia in women with hemostatic disorders. Am J Obstet Gynecol. 2005;193:1361-3.

20. Jungers P, Dougados M, Péelissier C, Kuttenn F, Tron F, Pertuiset N, et al. Effet de la contraception hormonale sur la nephropatie associée au lupus [Effect of hormonal contraception on the course of lupus nephropathy]. Nouv Presse Med 1982;18(11):3765e8.

21. Jungers P, Dougados M, Péelissier C, Kuttenn F, Tron F, Lesavre $\mathrm{P}$, et al. Influence of oral contraceptive therapy on the activity of systemic lupus erythematosus. Arthritis Rheum 1982;25:618e23.

22. Petri M, Kim MY, Kalunian KC, et al. Combined oral contraceptives in women with systemic lupus erythematosus. N Engl J Med 2005;353:2550-8.

23. Sánchez-Guerrero J, Uribe AG, Jiménez-Santana L, et al. A trial of contraceptive methods in women with systemic lupus erythematosus. N Engl J Med 2005;353:2539-49.

24. Williams W.V., BriaCell therapeutics Corporation, Havertown, PA, USA; and University of Pennsylvania, Philadelphia, PA, USA. Hormonal contraception and the development of autoimmunity: a review of the literature. The Linacre Quarterly 2017;84(3):275-295.

25. Clowse M.E.B, MD; MPH, Assistant Professor of Medicine. Managing contraception and pregnancy in the rheumatologic diseases. Best Practice and Reasearch Clinical Rheumatology 2010;24:373-385. 
26. Lateef A, Petri M. Hormone replacement and contraceptive therapy in autoimmune diseases. J of Autoimmunity 2012;38:170-176.

27. Ostensen M, Villiger PM. The remission of rheumatoid arthritis during pregnancy. Semin Immunopathol 2007 Jun;29(2):185-91.

28. De Man YA, Dolhain RJ, van de Geijn FE, et al. Disease activity of rheumatoid arthritis during pregnancy: results from nationwide prospective study. Arthritis Rheum 2008 Sep 15;59(9):1241-8.

29. Castagnetta LA, Carruba G, Granata OM, Stefano R, Miele M, Schmidt M, et al. Increased estrogen formation and estrogen to androgen ratio in the synovial fluid of patients with rheumatoid arthritis. J rheumatol 2003;30: 2597-605.

30. Schmidt M, Hartung R, Capellino S, Cutolo M, PfeiferLeeg A, Straub RH. Estrone/17beta-estradiol conversion to, and tumor necrosis factor inhibition by, estrogen metabolities in synovial cells of patients with rheumatoid arthritis and patients with osteoarthritis. Arthritis Rheum 2009;60:2913-22.

31. Ostensen M (2014). Contraception and pregnancy counselling in rheumatoid arthritis. Curr Opin Rheumatol 26(3):302-307.

32. Villard-Mackintosh L, Vessey MP. Oral contraceptives and reproductive factors in multiple sclerosis incidence. Contraception 1993;47:161e8.

33. Thorogood M, Hannaford PC. The influence of oral contraceptives on the risk of multiple sclerosis. Br J Obstet Gynaecol 1998;105:1296e9.

34. Hernan MA, Hohol MJ, Olek MJ, Spiegelman D, Ascherio A. Oral contraceptives and the incidence of multiple sclerosis.Neurology 2000;55:848e54.
35. Koch-Henriksen N, Sorensen PS. The changing demographic pattern of multiple sclerosis epidemiology. Lancet Neurol 2010;9:520e32.

36. Raps M, Curvers J, Helmerhorst FM, Ballieux BE, Rosing J, Thomassen S, et al. Thyroid function, activated protein Cresistance and the risk of venous thrombosis in users of hormonal contraceptives. Thromb Res 2014; 133:640e4.

37. William VW. Hormonal contraception and the development of autoimmunity: a review of the literature. Linacre Q 2017;84:275e95.

38. Lo Cuccio C, Ramoni V, Limonta M, Brucato A. Gravidanza, fertilità, Contraccezione e Menopausa nelle donne con sclerodermia. Rubrica medica di medicina interna e reumatologia, Ospedali riuniti di Bergamo.

39. Lekakis J, Papamichael C, Mavrikakis M, Voutsas A, Stamatelopoulos S. Effect of long term estrogen therapy on brachial arterial endothelium-dependent vasodilatation in women with Raynaud's phenomenon secondary to systemic sclerosis. Am J Cardiol 1998<,82:1555-7.A8.

40. Beretta L, Caronni M, ScorzaR. Systemic sclerosis following oral contraception. Clin Rheumatol 2005;24: 316-7.

41. Nagler R.M, Pollack S. Sjogren's Syndrome Induced by Estrogen Therapy. Semin Arthritis Rheum 2000; 30: 209-214.

42. Akbas T, Imeryuz N, Bayalan F, Baltacioglu F, Atagunduz P, Mulazimoglu L, et al. A case of Budd-Chiari syndrome with BeHormonal contraceptiveset's disease and oral contraceptive usage. Rheumatol Int 2007;28:83-6.

43. Katschinski B, Fingerle D, Scherbaum B, Goebell H. Oral contraceptive use and cigarette smoking in Crohn's disease. Dig Dis Sci 1993;38:1596e600. 


\title{
Gravidanza e monitoraggio fetale in pazienti con malattie reumatiche autoimmuni
}

\author{
Irene Cetin, ${ }^{1,2}$ Roberta Milazzo, ${ }^{1,2}$ Ludovica Basili1 ${ }^{1,2}$ \\ ${ }^{1}$ Dipartimento Donna, Mamma e Neonato, Ospedale dei Bambini 'V. Buzzi’, ASST Fatebenefratelli Sacco, Milano, Italia; \\ ${ }^{2}$ Dipartimento di Scienze Biomediche e Cliniche, Università degli Studi di Milano, Milano, Italia
}

\section{Introduzione}

Le malattie reumatiche autoimmuni colpiscono frequentemente le donne, più spesso in età fertile. Il principale obiettivo per queste pazienti è quello di poter superare le limitazioni che possono derivare da una malattia cronica e, dunque, di poter vivere una vita normale. Questo include anche la possibilità di una pianificazione familiare e quindi di poter affrontare una gravidanza, cosa che si è resa sempre più attuabile visto il progresso nella diagnosi precoce e nel trattamento delle malattie autoimmuni. Per molti anni, infatti, la gravidanza è stata controindicata alle donne con malattie autoimmuni sistemiche potenzialmente gravi. Ad oggi, con un'attenta gestione medica multidisciplinare e ostetrica, la maggior parte delle donne riesce a portare a termine una gravidanza.

Tuttavia, le malattie reumatiche differiscono notevolmente per quanto riguarda i rischi materni e fetali durante la gestazione.

Fattori importanti associati al rischio sono il tipo di malattia, l'attività della malattia al momento del concepimento e durante la gravidanza, il coinvolgimento sistemico degli organi, la presenza e il tipo di autoanticorpi specifici, le comorbilità della paziente e la terapia a cui è sottoposta. Come regola generale, l'estensione del processo immuno-infiammatorio, il coinvolgimento di organi vitali come rene, polmone e cuore e la terapia immunosoppressiva contribuiscono alle complicanze e ai possibili esiti avversi della gravidanza.

Corrispondente: Irene Cetin, Dipartimento Donna, Mamma e Neonato, Ospedale dei Bambini 'V. Buzzi', ASST Fatebenefratelli Sacco, Milano, Italia.

E-mail: irene.cetin@unimi.it

Articolo pubblicato secondo la Creative Commons Attribution NonCommercial 4.0 License (CC BY-NC 4.0).

${ }^{\circ}$ Copyright: the Author(s), 2021

Licensee PAGEPress, Italy

QUADERNI - Italian Journal of Medicine 2021; 9(4):e3

\section{Decorso della malattia reumatica in gravidanza}

Le malattie reumatiche non mostrano una risposta univoca alla gravidanza: alcune migliorano, altre rimangono invariate ma molte invece si aggravano. ${ }^{1} \mathrm{La}$ risposta della malattia alle modificazioni ormonali, immunologiche e biochimiche della gravidanza riflette la fisiopatologia delle diverse malattie autoimmuni. Ad esempio, l'artrite reumatoide (AR) è una malattia reumatica che migliora spontaneamente durante la gravidanza nella maggior parte delle pazienti, ${ }^{2} \mathrm{o}$ almeno in quelle che non presentano autoanticorpi come il fattore reumatoide o anticorpi anti-proteina citrullinata. ${ }^{3}$ Il miglioramento spontaneo inizia spesso già nel primo trimestre con una riduzione del dolore, della rigidità e del gonfiore articolare e raggiunge l'apice nel terzo trimestre. ${ }^{4} \mathrm{Al}$ contrario, le pazienti con anticorpi positivi hanno solo una probabilità del $40 \%$ di migliorare durante la gravidanza ${ }^{3}$. Il lupus eritematoso sistemico (LES) è il prototipo di malattia con coinvolgimento multiorgano caratterizzata da una importante produzione di autoanticorpi, il cui tasso di riacutizzazioni durante la gravidanza varia da sintomi lievi a moderati, molto spesso a livello cutaneo, articolare, gastroenterico ed ematologico. ${ }^{5}$ Le riacutizzazioni gravi coinvolgenti organi quali il rene, i polmoni o il sistema nervoso centrale si rilevano nell' $11-25 \%$ delle gravidanze. ${ }^{6}$ Lo stato di malattia attiva durante la gravidanza aumenta il tasso di esiti negativi da due a quattro volte. ${ }^{7}$

\section{Fisiopatologia e possibili esiti avversi della gravidanza}

Le complicanze della gravidanza associate a malattie autoimmuni hanno origine dal coinvolgimento dell'interfaccia materno-fetale e dall'alterazione dello sviluppo di un'adeguata funzione placentare (Figura 1).

Principalmente, le suddette complicanze sono rappresentate da aborti ripetuti, preeclampsia, restrizione di crescita fetale (IUGR) e morte endouterina fetale (MEF). Preeclampsia e IUGR contribuiscono anche 
ad aumentare il tasso di parto prematuro, e quindi sono associate ad alta morbilità neonatale, disabilità infantile a lungo termine e conseguenze nell'età adulta.

\section{Perdita di gravidanza}

L'incidenza di aborti e di MEF è significativamente aumentata nelle pazienti con LES, sindrome da anticorpi anti fosfolipidi (APS) e vasculiti, dato che riflette la presenza di autoanticorpi specifici che comportano danni materno-fetali e manifestazioni d'organo diffuse. ${ }^{8}$ Nel LES, il tasso di perdita fetale è annoverato tra $1{ }^{\prime} 11 \%$ e il $29 \%$, cioè $1,5-2,5$ volte più frequente rispetto alla popolazione generale. ${ }^{7,-12} \mathrm{La}$ nefrite lupica in fase attiva, la presenza di proteinuria e ipertensione, una precedente storia di MEF e la presenza di anticorpi anti fosfolipidi (aPL) si sono dimostrati fattori predittivi di perdita fetale nelle gravidanze in donne affette da LES. ${ }^{12}$ Le donne con APS hanno un'alta percentuale di perdita fetale durante la gravidanza nel primo trimestre ma oltre le 10 settimane di gestazione, in contrasto con la popolazione ostetrica generale in cui aborti sporadici o ricorrenti si verificano più comunemente nel periodo pre-embrionale ( $<6$ settimane di gestazione) o embrionale (tra 6-9 settimane di gestazione). Il tasso di nati morti è aumentato sia in pazienti con LES sia in pazienti con APS. ${ }^{12,13}$

\section{Restrizione di crescita fetalee preeclampsia}

Il corretto sviluppo della placenta è un requisito fondamentale per il buon esito della gravidanza. $\mathrm{Nu}-$ merosi studi hanno approfondito il meccanismo tramite il quale il trofoblasto interagisce con le cellule endometriali decidualizzate mediante una sequenza di eventi che, da un ambiente ipossico, permettono l'adeguato sviluppo della vascolarizzazione materno- fetale al fine di fornire un corretto scambio di nutrienti e garantire un adeguato apporto di ossigeno al feto. Quando questi processi falliscono o risultano inadeguati, le complicanze possono variare dall'aborto precoce alla morte del feto o possono determinare un inadeguato apporto di nutrienti e ossigeno al feto con restrizione della crescita fetale. Inoltre, la presenza di un ambiente avverso può portare al rilascio placentare, in modo sbilanciato, di fattori angiogenici e pro-infiammatori che danneggiano l'endotelio materno e contribuiscono allo sviluppo di preeclampsia. ${ }^{14}$

Negli ultimi anni, numerosi studi hanno descritto il fenotipo placentare associato a preeclampsia e IUGR e recentemente l'attenzione si è molto concentrata sulla presenza di fattori di stress ossidativo rilasciati dalla placenta, associati a livelli circolanti ridotti di fattore di crescita endoteliale vascolare (VEGF) e di fattore di crescita placentare (PlGF), fattori proangiogenici prodotti dalla placenta già $4-5$ settimane prima dello sviluppo della malattia. ${ }^{15}$

In particolare, la APS è la malattia autoimmune con il maggiore impatto sulla gravidanza.

Esistono diversi meccanismi patogenetici mediante i quali gli aPL possono avere effetti avversi sulla funzione placentare. Numerosi studi hanno infatti dimostrato che gli aPL hanno effetti diretti sulle cellule del trofoblasto riducendone la capacità di invasione, differenziazione e formazione del sinciziotrofoblasto. ${ }^{16,17} \mathrm{Le}$ proteine che legano i fosfolipidi, come la b2 glicoproteina 1 (b2GP1), sono necessarie per legare gli aPL alla cardiolipina. È stata dimostrata la presenza di b2GP1 sulle membrane cellulari del trofoblasto, spiegando in tal modo il trofismo degli aPL per la placenta: ${ }^{18}$ gli aPL legano b2GP1 aderendo ai fosfolipidi e sono responsabili dei difetti di placentazione.

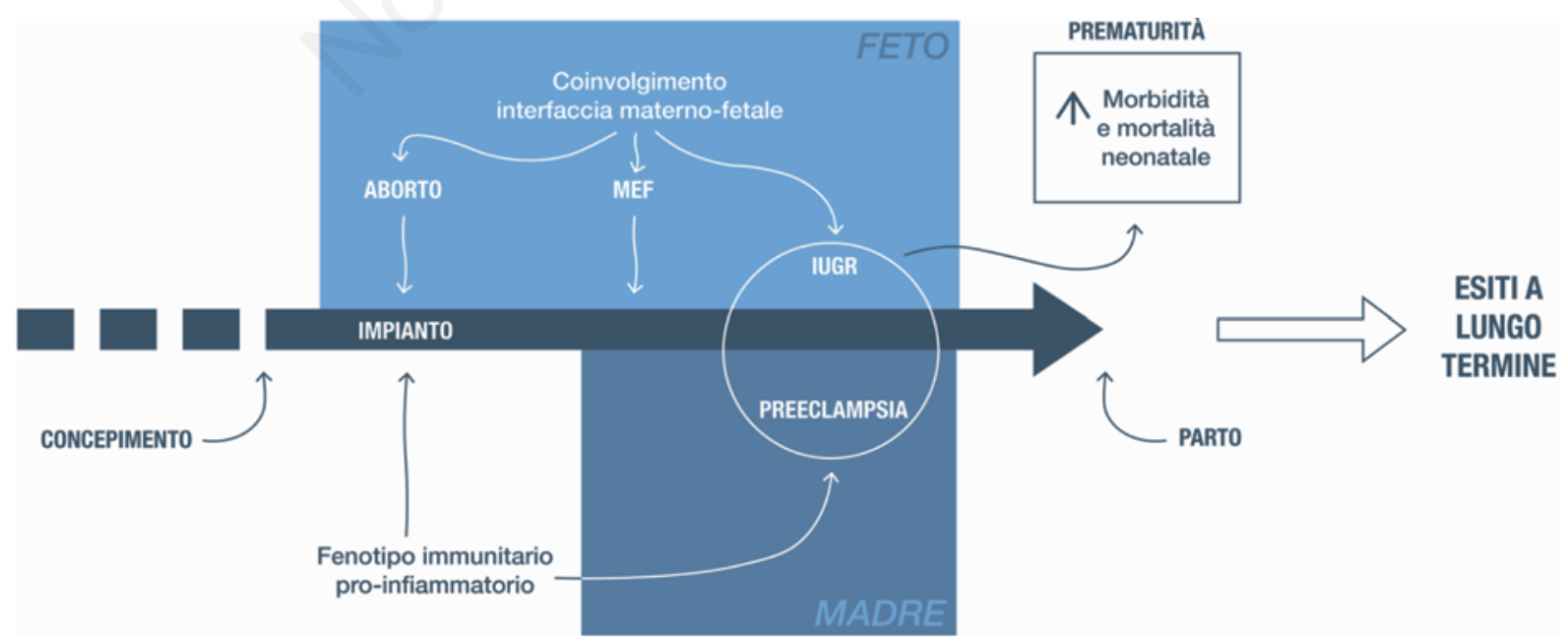

Figura 1. rappresentazione dei meccanismi coinvolti nello sviluppo di esiti avversi in gravidanze complicate da malattie reumatiche autoimmuni e dei loro effetti sul versante fetale e materno. Le complicanze della gravidanza correlate portano quindi a prematurità, aumento della morbilità e mortalità neonatale ed esiti a lungo termine. 
Inoltre, negli studi in vitro è stato riportato un effetto diretto degli aPL sull'angiogenesi endometriale. ${ }^{19}$ L'angiogenesi endometriale immediata è necessaria per il successo della placentazione e coinvolge il VEGF e i suoi recettori. Pertanto, gli aPL possono influenzare sia l'invasione del trofoblasto sia l'angiogenesi endometriale, processi necessari per stabilire una corretta interfaccia materno-fetale, che può portare potenzialmente all'aborto precoce o a complicazioni successive che implicano la morte del feto o restrizione di crescita e la preeclampsia. È ormai noto, infatti, che i meccanismi responsabili dello sviluppo di preeclampsia hanno origine dalle prime fasi dell'impianto, quindi un eventuale trattamento farmacologico dovrebbe essere avviato il prima possibile.

Nella preeclampsia, una circolazione uteroplacentare disfunzionale porta a una lesione ischemica da riperfusione e al rilascio di fattori pro-infiammatori da parte del trofoblasto, causando un'eccessiva risposta infiammatoria materna e la disfunzione endoteliale. ${ }^{20}$ In particolare, si ritiene che essa sia causata da un rilascio eccessivo del fattore anti-angiogenico sFLT-1 (soluble fms-like tyrosine kinase-1), recettore solubile del VEGF, da parte della placenta sottoposta a grave stress ossidativo. ${ }^{21}$ E stato riportato che la preeclampsia si verifica in circa un terzo delle pazienti con APS, spesso con esordio precoce prima di 34 settimane di gestazione. ${ }^{22}$ Il rischio di sindrome HELLP (Hemolysis Elevate Liver enzymes Low Platelet count) è aumentato nell'APS ed essa si manifesta spesso nel secondo trimestre di gravidanza. ${ }^{23,24}$ Sia la preeclampsia sia la sindrome HELLP hanno un esordio più precoce nelle gravidanze complicate da APS rispetto alla popolazione ostetrica generale.

Il tasso di IUGR è alto e varia dal 15 al $43 \%$ nell'APS, essendo indice di insufficienza placentare. ${ }^{25}$

\section{Parto prematuro}

Il tasso di parto prima delle 37 settimane di gestazione è più alto nelle pazienti con malattie autoimmuni rispetto alle donne sane. Il parto pretermine è associato a complicanze neonatali derivate dall'immaturità polmonare, a un ritardo nello sviluppo e complicanze a lungo termine. ${ }^{26}$ Per quanto riguarda le artriti infiammatorie, il tasso di esiti avversi per l'AR varia considerevolmente tra $i$ vari studi in letteratura. ${ }^{27-29}$ Uno studio basato sulla popolazione norvegese, ha messo a confronto gli esiti della gravidanza nelle donne con artriti infiammatorie croniche rispetto alle donne sane concludendo che il principale esito avverso in gravidanza nelle donne con AR era il parto prematuro, non rilevando invece un aumento del rischio di preeclampsia. Studi prospettici che includevano donne con AR ben controllata, cioè con bassa attività di malattia e sottoposte $\mathrm{a}$ terapia farmacologica blanda e follow-up regolare du- rante la gravidanza, hanno riscontrato che l'esito della gravidanza era simile a quello delle donne sane, , $^{2,830}$

Le percentuali di parto pretermine sono particolarmente elevate anche in LES, APS e sclerosi sistemica (SSc). ${ }^{12-13,31-34}$ Nelle donne con LES il parto pretermine è spesso la conseguenza di complicazioni cliniche materne come la nefrite lupica, l'insufficienza renale, l'ipertensione, la preeclampsia, o di rottura prematura delle membrane e compromissione fetale. ${ }^{12,32}$ Un marcatore predittivo di parto pretermine è rappresentato dall'attività di malattia durante la gravidanza. Altri fattori di rischio sono il trattamento con corticosteroidi ad alte dosi $(>15-20 \mathrm{mg}){ }^{35}$

\section{Esito neonatale e perinatale}

La morbilità e la mortalità perinatali risultano aumentate nei figli di pazienti affette da malattie reumatiche. ${ }^{8,36,37} \mathrm{Il}$ tasso di mortalità perinatale nei bambini nati da madri con diagnosi di artrite infiammatoria risulta tre volte più elevato rispetto a quello dei bambini di pazienti sane. ${ }^{27}$ La mortalità perinatale è aumentata anche nei bambini nati da madri con LES, fino al 5$20 \%$, o APS. . $^{13,36,38}$ Nell'APS è stata osservata una percentuale di morti perinatali fino al $54 \%$ principalmente a causa di preeclampsia severa o di sindrome HELLP associate di conseguenza a prematurità severa..$^{39}$

Numerosi studi sulle gravidanze di pazienti affette da AR hanno riscontrato che il peso alla nascita dei neonati rientrava nell'intervallo di normalità, ma risultava inferiore rispetto ai neonati di donne sane e ancor di più nei neonati di madri affette da AR con attività di malattia severa $\mathrm{o}$ in terapia prolungata con corticosteroidi. ${ }^{27,40,41}$ Nelle gravidanze di pazienti affette da $\mathrm{AR}$ con attività di malattia ben controllata $\mathrm{e}$ in terapia con basso dosaggio di prednisone, non è stato invece riscontrato alcun aumento nei tassi di prematurità o di neonati SGA (Small for Gestational Age). ${ }^{2,11}$ Il tasso di malformazioni congenite nei bambini di pazienti con malattie reumatiche non risulta aumentato, ad eccezione dei difetti alla nascita derivanti dall'esposizione nel primo trimestre a farmaci teratogeni come metotrexate e ciclofosfamide. ${ }^{27}$

\section{Pianificazione familiare e management della gravidanza}

\section{Pianificazione familiare e terapia farmacologica}

$\mathrm{Al}$ fine di perseguire gravidanze con esiti materni e neonatali favorevoli, è estremamente importante promuovere la pianificazione familiare nelle pazienti con malattie autoimmuni. Quest'ultima dovrebbe essere sostenuta in tutte le suddette pazienti se in età fertile, indipendentemente dal loro attuale desiderio di gravidanza. La decisione di affrontare una gravidanza ha infatti un forte impatto sul trattamento farmacolo- 
gico. L'obiettivo principale nella scelta della terapia per una paziente che desidera una gravidanza è quello di ottenere la remissione o almeno un basso grado di attività di malattia, poiché la maggior parte degli studi ha dimostrato che la malattia attiva al momento del concepimento è un fattore predittivo di esiti avversi in corso di gravidanza. ${ }^{42,43}$ In generale la programmazione di una gravidanza in uno stato di malattia in remissione stabile (almeno sei mesi) rappresenta una condizione favorevole per una gestazione con esito positivo.

La valutazione del rischio in relazione a possibili esiti avversi materni o fetali durante una futura gravidanza è essenziale per la consulenza individuale e, di conseguenza, per l'adeguamento della terapia di queste pazienti. ${ }^{8}$ I principali rischi materni sono rappresentati dall'attività di malattia al momento del concepimento, dalla riacutizzazione della malattia durante la gravidanza, dal concepimento in uno stadio di malattia caratterizzato dal coinvolgimento attivo sistemico o da danno d'organo grave, dalla presenza di aPL e di anticorpi anti Ro/SS-A e anti La/SS-B (Tabella 1).

L'insieme della valutazione clinica e degli esami di laboratorio consentirà di ottenere una stratificazione del profilo di rischio in elevato, moderato o lieve in base alla presenza dei suddetti fattori di rischio. L'adeguamento della terapia, nonché il tipo e la frequenza del monitoraggio materno-fetale saranno differenti in base al profilo di rischio della singola paziente.

Le pazienti in stato di malattia attiva o danno ad organi vitali come reni, polmoni o cuore dovranno essere scoraggiate nella ricerca immediata della gravidanza.
L'ipertensione polmonare sintomatica, la cardiopatia e funzionalità renale gravemente compromessa, nonché una storia pregressa di sindrome HELLP, sono associate ad un aumento della morbilità e mortalità materna. Le pazienti con recenti eventi trombotici (soprattutto ictus ischemico) o attuale malattia renale attiva o ipertensione arteriosa non controllata dovranno posporre la gravidanza (Tabella 2).

Le donne che pianificano una gravidanza spesso smettono di assumere farmaci per paura di danneggiare il feto, specialmente nel primo trimestre. La sospensione di una terapia efficace può portare tuttavia ad un aggravamento della malattia con effetti avversi sia sulla madre che sul feto ed è ormai chiaro che uno dei più temibili fattori di rischio in gravidanza è la riacutizzazione della malattia stessa. ${ }^{44} \mathrm{Dal}$ momento che la gravidanza si accompagna a importanti modificazioni del profilo ormonale, l'attività di malattia può risentirne talvolta in modo negativo con maggior rischio di riacutizzazione, in altri casi favorevolmente a seconda della tipologia di malattia reumatica e dei suoi meccanismi patogenetici. Pertanto, l'adeguamento della terapia deve essere discusso in tempo utile con le pazienti, in modo da evitare una sospensione inappropriata dei farmaci. È essenziale discutere con il team multidisciplinare coinvolto nella pianificazione familiare o nel follow-up durante la gravidanza ed individualizzare la terapia necessaria per la paziente prima del concepimento e durante la gestazione. Fornire indicazioni contraddittorie tra diversi specialisti coinvolti può essere disastroso,

Tabella 1. Check-list dei fattori da considerare nella stratificazione del rischio ostetrico durante il counselling preconcezionale di una donna affetta da una qualsiasi malattia reumatica.

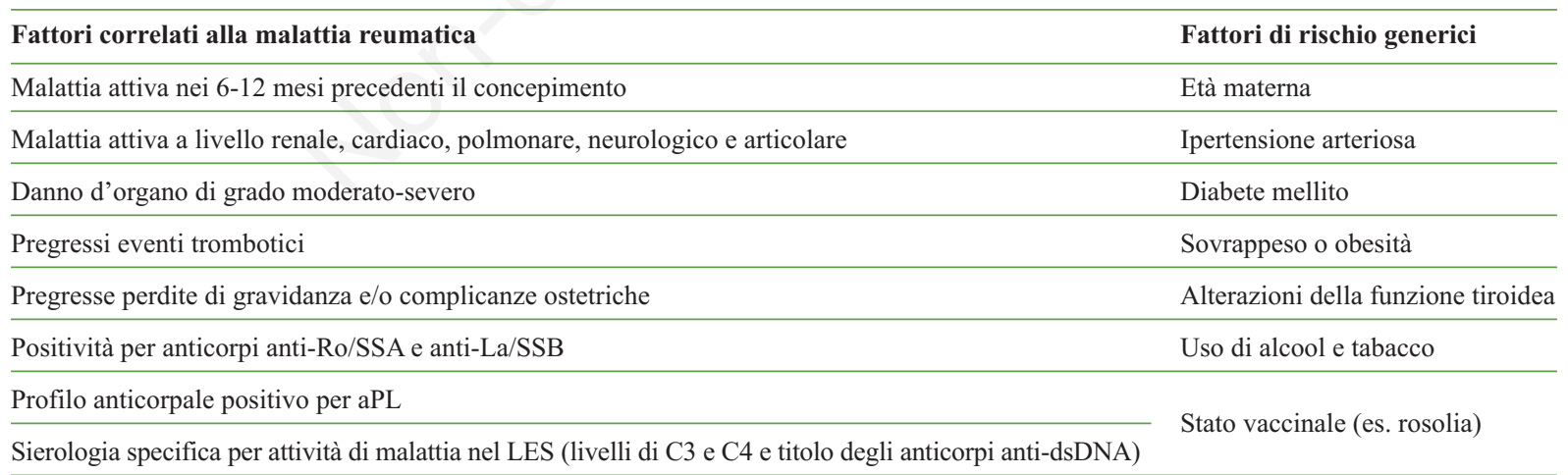

Tabella 2. Pianificazione della gravidanza in pazienti con malattie reumatiche autoimmuni.

Malattia in remissione o bassa e stabile attività o in trattamento stabile Adeguamento della terapia con farmaci compatibili con la gravidanza

Malattia in stadio precoce o danno d'organo in atto

Rinviare la gravidanza $\rightarrow$ raggiungere miglioramento o remissione con farmaci immunosoppressori o biologici o terapia di combinazione Se sostanziale miglioramento o remissione di malattia $\rightarrow$ pianificazione della gravidanza 
creando solo confusione alla paziente che non saprà di quale specialista fidarsi. Invece, fornire informazioni complete sugli effetti dei farmaci immunosoppressori, sui loro effetti collaterali e sulla loro sicurezza può aiutare la paziente a capire che un controllo efficace della malattia durante la gravidanza è importante per il normale decorso della stessa e per il benessere fetale. La paziente dovrebbe anche essere rassicurata sulla possibilità di intervenire in caso di riacutizzazione della malattia anche se fossero necessari corticosteroidi ad alte dosi o farmaci non usualmente approvati in corso di gestazione..$^{45}$ Infatti, una larga parte di farmaci immunosoppressori usati nelle malattie reumatiche autoimmuni non sono dannosi per il feto e possono dunque essere assunti in corso di gravidanza con tranquillità, tra questi: glucocorticoidi, idrossiclorochina, clorochina, azatioprina, ciclosporina A, tacrolimo, sulfasalazina, colchicina, immunoglobuline endovena. Tra i farmaci biologici, gli anti-TNF alfa sono quelli più studiati ed il loro utilizzo appare ragionevolmente sicuro nel primo e nel secondo trimestre di gravidanza. ${ }^{46}$.

Pochi e ben codificati sono i farmaci potenzialmente dannosi per il feto come micofenolato mofetile, metotrexate e ciclofosfamide, che dovranno essere sospesi con un intervallo di tempo sufficientemente lungo per poter garantire il completo wash out dall'organismo materno e quindi prevenirne gli effetti teratogeni. ${ }^{46}$.

I farmaci anti-infiammatori non steroidei e quelli biologici diversi dagli anti-TNF alfa sono invece soggetti a restrizioni cautelative a seconda del periodo gestazionale. ${ }^{46} \mathrm{Ai}$ farmaci anti-reumatici potranno poi essere affiancati, in relazione al rischio ostetrico, eventuali trattamenti preventivi. Tra i più utilizzati, singolarmente $o$ in associazione, l'acido acetilsalicilico a basso dosaggio per favorire un corretto sviluppo della placenta e ridurre il rischio di complicanze ostetriche quali la preeclampsia, e l'eparina sottocute che è parte integrante della profilassi antitrombotica. ${ }^{47}$

\section{Gravidanza e monitoraggio fetale: primo trimestre}

Non appena viene diagnosticata la gravidanza, è necessario effettuare una valutazione clinica e di laboratorio completa per monitorare l'attività di malattia. Le gravidanze ad alto rischio sono meglio monitorate da un team di specialisti multidisciplinare di cui faranno parte l'ostetrico, il reumatologo, l'internista e, in casi particolari, il pediatra, al fine di riconoscere precocemente e curare efficacemente complicanze cliniche e/o ostetriche.

Ad un attento monitoraggio ecografico maternofetale si assoceranno i consueti controlli in corso di gravidanza, che prevedono una visita mensile da parte del reumatologo e da parte del ginecologo, e degli esami di laboratorio, oltre al dosaggio dei livelli di an- ticorpi tipici e specifici della malattia reumatica autoimmune.

La frequenza delle visite dipenderà dalla gravità della malattia, dal tipo di terapia assunta dalla paziente e dalla settimana di gravidanza. I controlli durante la gravidanza devono essere programmati in base all'attività di malattia e alla presenza di fattori di rischio.

Nel corso del primo trimestre di gravidanza l'attenzione sarà quindi focalizzata sulla valutazione del benessere materno con la stratificazione del rischio relativo alla specifica patologia autoimmune da cui risulta affetta e con il conseguente, se necessario, adeguamento della terapia farmacologica in atto. Dal punto di vista specificamente ostetrico verrà eseguita una ecografia al fine di verificare l'impianto in sede intrauterina della camera gestazionale, il numero e la vitalità fetale, la datazione della gravidanza e la morfologia fetale. Saranno prescritti una serie di esami ematochimici ed infettivologici di routine come per tutte le gravidanze iniziali e, in aggiunta, quegli esami immunologici particolari e specifici della relativa malattia autoimmune. Verranno fornite informazioni sulla possibilità di effettuare test di screening e diagnostici per indagare l'eventuale presenza di anomalie cromosomiche fetali, sui corsi di accompagnamento alla nascita, sullo stile di vita da adottare e quindi sull'importanza di mantenere una alimentazione varia e sana e sulle norme igieniche per la prevenzione della toxoplasmosi, tutto ciò che viene comunemente consigliato e raccomandato anche nelle gravidanze fisiologiche.

\section{Gravidanza e monitoraggio fetale: secondo e terzo trimestre}

Dopo le 20 settimane devono essere eseguite frequenti valutazioni cliniche per il monitoraggio della pressione arteriosa materna e della proteinuria delle 24 ore. Nelle pazienti ad alto rischio di disordini ipertensivi e/o insufficienza placentare sarà fondamentale monitorare la conta piastrinica, la funzionalità renale ed epatica e il rapporto sFLT1/PlGF. ${ }^{47}$ Tre le 24 e le 28 settimane di gestazione verrà prescritta la curva da carico di glucosio, come avviene comunemente in gravidanza, al fine di diagnosticare un eventuale diabete gestazionale e mettere in atto le conseguenti misure dietetiche e il monitoraggio domiciliare della glicemia pre e post prandiale.

Dal secondo trimestre di gravidanza si dovrà anche proporre alla paziente la vaccinazione anti difterite, tetano e pertosse ed eventualmente il vaccino antinfluenzale. Per molto tempo è stata dibattuta la possibilità di sottoporre alla vaccinazione i pazienti con malattie reumatiche autoimmuni, indipendentemente dallo stato di gravidanza, per la paura di innescare o riattivare la mattia in seguito a stimolazione del sistema immunitario. Ad oggi questi timori risultano infondati, essendo questi eventi rari e privi di sicura 
correlazione con la somministrazione del vaccino. Invece, molte sono le raccomandazioni e linee guida inerenti alla vaccinazione in pazienti con malattie reumatiche autoimmuni, suggerendo con forza il ricorso alla vaccinazione antinfluenzale in questa categoria di pazienti che, proprio a causa della loro malattia, presentano una elevata suscettibilità alle infezioni. In generale, bisognerà porre attenzione nel vaccinare le pazienti preferenzialmente durante le fasi di inattività o stabilità della malattia, cosa che si auspica mantenere in corso di gravidanza, e non ci sono specifiche controindicazioni ai vaccini costituiti da microorganismi inattivati, a cui appartengono quelli sopracitati.

Per quanto concerne il monitoraggio ecografico, una valutazione regolare della crescita fetale può permetterci di individuare i feti più a rischio. Inoltre $\mathrm{a}$ quest'epoca verrà offerta l'ecografia ostetrica del secondo trimestre con lo scopo di studiare anche l'anatomia fetale. La velocimetria Doppler ci consentirà di valutare la funzionalità della circolazione uteroplacentare e fetale, consentendo di prevedere il possibile sviluppo di complicanze quali preeclampsia e IUGR. Il valore predittivo negativo della velocimetria Doppler delle arterie uterine è molto elevato, quindi un esame normale è considerato rassicurante. In particolare, le donne con una precedente storia di preeclampsia, con insufficienza placentare, con ipertensione, con nefropatia (anche se in remissione e con normale funzionalità renale) e con $\mathrm{aPL}$, nonché quelle con gravidanze multiple, sono candidate per lo studio della velocimetria Doppler a partire dalle 20 settimane di gestazione. Se l'ecografia e la velocimetria Doppler risulteranno normali, il controllo della crescita fetale potrà essere effettuato mensilmente. Qualora invece i parametri ecografici risultassero fuori dal range di normalità, $i$ controlli dovranno essere più frequenti, ogni due settimane $\mathrm{o}$ ancor più ravvicinati a seconda del grado di alterazione, fino alla necessità di un eventuale ricovero ospedaliero in caso di alterazioni della velocimetria Doppler fetale, per consentire il monitoraggio intensivo del benessere fetale.

L'ecocardiografia fetale seriata ogni due settimane tra 18 e 28 settimane è raccomandata per rilevare precocemente un eventuale blocco atrio-ventricolare (BAV) in feti di madri anti Ro/SS-A e anti La/SS-B positive. È da tale epoca infatti che gli anticorpi materni possono attraversare la placenta e quindi danneggiare il sistema di conduzione cardiaco fetale. Individuando precocemente le alterazioni iniziali del ritmo cardiaco fetale, è possibile intervenire tempestivamente con corticosteroidi sistemici per fermare o addirittura portare in remissione i disturbi cardiaci. Infatti, recenti studi suggeriscono che il trattamento antinfiammatorio durante il periodo di transizione da una frequenza cardiaca fetale normale al $\mathrm{BAV}$, che di per sé risulterebbe irreversibile, può arrestarne invece la progressione e ristabilire il ritmo sinusale. ${ }^{48-52}$

Tuttavia, la sorveglianza ecocardiografica fetale settimanale o bisettimanale solo raramente riesce ad individuare un BAV in tempo utile affinché il trattamento abbia successo, anche perché esso è di rapida insorgenza (meno di 24 ore)..$^{51,52} \mathrm{Il}$ monitoraggio giornaliero della frequenza cardiaca fetale in una struttura medica potrebbe invece aumentare le possibilità di individuare l'insorgenza precoce di alterazioni del ritmo cardiaco fetale. Tuttavia questo tipo di follow up risulta disagevole per le pazienti che dovrebbero recarsi giornalmente in ospedale e sottoporsi al controllo. Per questo motivo, dalla recente letteratura è stato proposto un metodo alternativo di monitoraggio della frequenza cardiaca fetale, portato avanti direttamente dalle pazienti nel loro contesto domiciliare. ${ }^{53-54} \mathrm{Per}$ far ciò, alle pazienti viene fornito un dispositivo Doppler ed esse vengono istruite sull'utilizzo di quest'ultimo. In questo modo la paziente potrà ascoltare la frequenza cardiaca fetale e registrarla quotidianamente scrivendo il risultato su un apposito diario che potrà poi essere controllato ad ogni successiva visita ostetrica. In caso di riscontro di ritmo fetale irregolare, frequenza cardiaca fetale inferiore a $110 \mathrm{o}$ superiore a 180 battiti al minuto, o in assenza di rilevazione del battito cardiaco fetale domiciliare, la donna potrà contattare il medico di riferimento per essere sottoposta ad una ecografia con ecocardiografia fetale in breve tempo rispetto alla rilevazione della frequenza cardiaca fetale anomala. ${ }^{53,54} \mathrm{Nel}$ caso in cui all'ecocardiografia fetale diagnostica si dovesse riscontrare la presenza di un BAV di secondo o terzo grado, alle pazienti potrà essere offerto il trattamento con desametasone, corticosteroide in grado di attraversare la barriera placentare, per il BAV incompleto in modo da impedirne la progressione verso un BAV di terzo grado completo o comunque per ripristinare la normale conduzione cardiaca. ${ }^{53,54}$ Gli studi presenti in letteratura confermano la semplicità del monitoraggio della frequenza cardiaca fetale domiciliare, affermando come questo metodo sia in realtà rassicurante per la donna e che non la ponga in uno stato d'ulteriore ansia. ${ }^{53,54}$

Nel terzo trimestre di gravidanza è necessaria una sorveglianza fetale supplementare attraverso la valutazione della biometria fetale, del liquido amniotico e della velocimetria Doppler nei casi di insufficienza placentare e IUGR. A termine di gravidanza, anche nel caso in cui non si siano riscontrate alterazioni nelle curve di crescita fetali nel corso della gestazione, $\mathrm{i}$ controlli del benessere fetale dovranno essere comunque intensificati, effettuando, settimanalmente o bisettimanalmente, il non stress test (NST) e/o il profilo biofisico a partire dalle 32 settimane di gestazione, soprattutto nelle donne affetta da quelle malattie autoimmuni note per l'aumentato rischio di morte endouterina fetale come il LES e l'APS ${ }^{47-54}$ (Figura 2). 


\section{Parto e post partum}

Durante il corso della gravidanza, dovrebbe essere anche discussa la possibile modalità di parto per dissipare ansie e dubbi della coppia prima della nascita. Diversi studi riportano un aumentato tasso di taglio cesareo (TC) nelle gravidanze di pazienti affette da malattie reumatiche autoimmuni, ${ }^{8,36}$ tuttavia la malattia reumatica non rappresenta di per sé, in genere, una indicazione al parto cesareo. La scelta della modalità del parto sarà quindi prettamente ostetrica e basata su condizioni materne o fetali che rappresentino una controindicazione al parto vaginale. In assenza di indicazioni mediche od ostetriche standard per un parto prima del termine, verrà programmato il timing del parto a 39 settimane per definire i tempi di interruzione dei farmaci antitrombotici.

La disfunzione placentare e la sproporzione fetopelvica costituiscono un terzo delle indicazioni al TC in pazienti con malattie reumatiche autoimmuni. ${ }^{27} \mathrm{Di}$ certo, indicazioni mediche o il desiderio della paziente possono essere motivo di esecuzione di TC elettivo in donne con malattie reumatiche. In realtà però, per quanto riguarda ad esempio le artriti infiammatorie, né l'infiammazione o l'anchilosi delle articolazioni sacro-iliache né la malattia estesa a livello spinale rappresentano un ostacolo meccanico al parto per via vaginale. Inoltre gli anestesisti spesso temono che l'analgesia spinale sia difficile da eseguire nelle pazienti con spondilite anchilosante (AS) a causa dell'anchilosi a livello della colonna lombare. Tuttavia, quest'ultima è rara nelle pazienti di sesso femminile con AS e si verifica solo dopo 3-4 anni dalla diagnosi di malattia. ${ }^{55}$

Le malattie reumatiche presentano, nel periodo successivo al parto, un aumentato rischio di riacutizzazione. Per questo si raccomanda una programmazione regolare di visite di controllo (almeno per i sei mesi successivi al parto) presso il proprio reumatologo che dovrà essere tempestivamente informato in caso di sintomatologia attiva. Il puerperio inoltre è un periodo ad aumentato rischio trombotico. Le pazienti con malattie reumatiche che presentano fattori di rischio, come ad esempio la presenza di aPL, dovrebbero ricevere un trattamento anti-trombotico con eparina a dosaggio profilattico per 4-6 settimane dopo il parto.

Per quanto riguarda l'allattamento al seno, la maggior parte dei farmaci anti-reumatici non sono controindicati durante l'allattamento e quindi non rappresentano motivo di rinuncia o sospensione.

Sono tuttavia considerati incompatibili con l'allattamento: metotrexate, leflunomide, ciclofosfamide e micofenolato mofetile. Inoltre l'allattamento non è correlato ad un aumentato rischio di riattivazione della malattia reumatica.

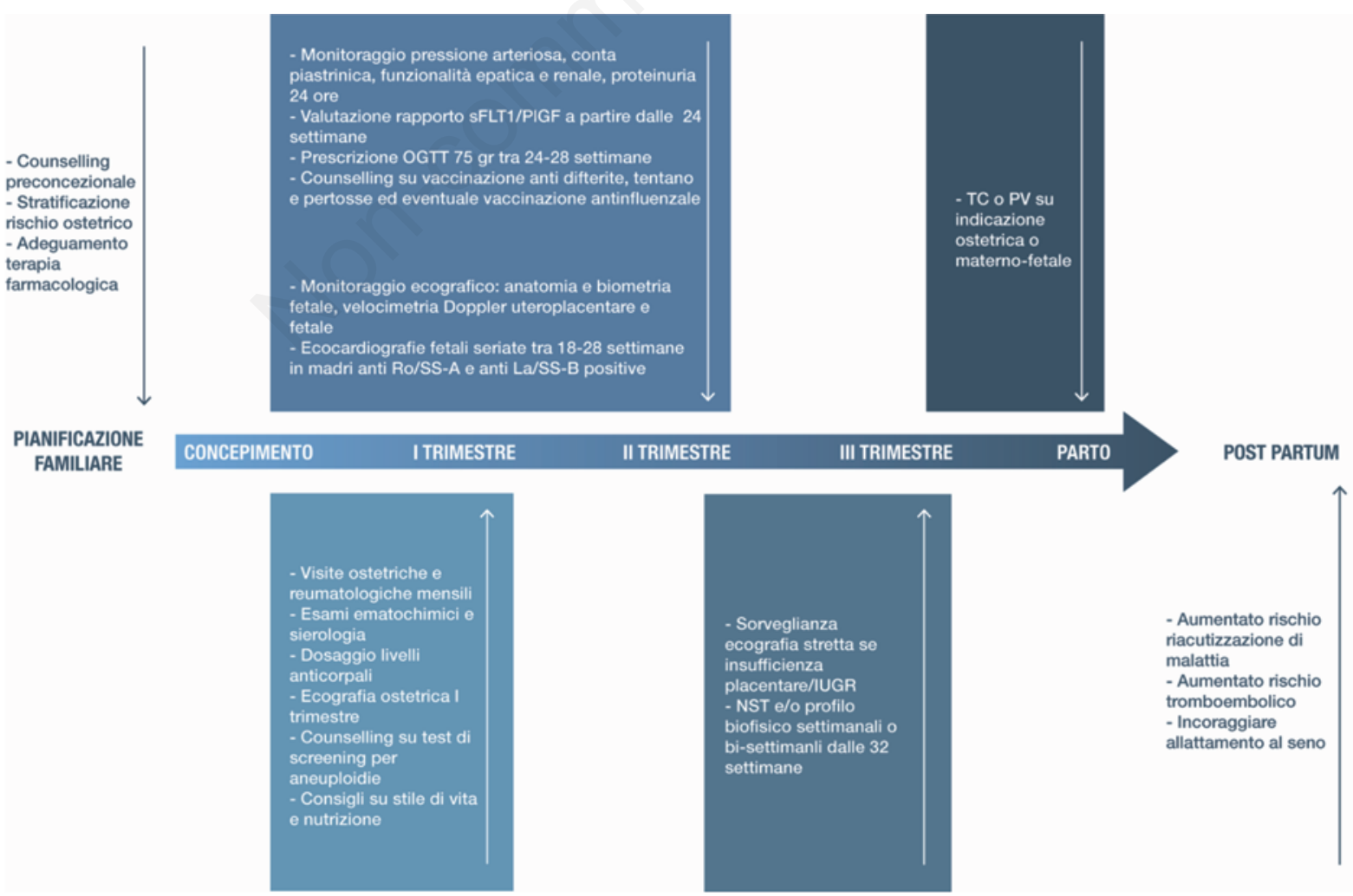

Figura 2. Linea del tempo del monitoraggio gravidanza nel I, II e III trimestre. 


\section{Bibliografia}

1. Østensen M, Villiger PM, Forger F. Interaction of pregnancy and autoimmune rheumatic disease. Autoimmun Rev 2012; 11: A437e46.

2. De Man YA, Dolhain RJ, van de Geijn FE, et al. Disease activity of rheumatoid arthritis during pregnancy: results from a nationwide prospective study. Arthritis Rheum 2008; 59:1241e8.

3. De Man YA, Bakker-Jonges LE, Goorbergh CM, et al. Women with rheumatoid arthritis negative for anticyclic citrullinated peptide and rheumatoid factor are more likely to improve during pregnancy, whereas in autoantibody-positive women autoantibody levels are not influenced by pregnancy. Ann Rheum Dis 2010; 69:420e3.

4. Forger F, Ostensen M, Schumacher A, et al. Impact of pregnancy on health related quality of life evaluated prospectively in pregnant women with rheumatic diseases by the SF-36 health survey. Ann Rheum Dis 2005; 64:1494e9.

5. Skomsvoll JF, Ostensen M, Irgens LM, et al. Pregnancy complications and delivery practice in women with connective tissue disease and inflammatory rheumatic disease in Norway. Acta Obstet Gynecol Scand 2000; 79:490-5.

6. Doria A, Cutolo M, Ghirardello A, et al. Steroid hormones and disease activity during pregnancy in systemic lupus erythematosus. Arthritis Rheum 2002; 47:202e9.

7. Clowse M, Magder LS, Witter F, et al. The impact of increased lupus activity on obstetric outcomes. Arthritis Rheum 2005; 52:514e21.

8. Østensen M, Dolhain R, Ruiz-Irastorza G. Obstetrics and pregnancy. In: Watts RA, Conaghan PG, Denton C, et al., editors. Oxford Textbook of Rheumatology 4e; 2013.

9. Clowse ME, Magder LS, Witter F, et al. Early risk factors for pregnancy loss in lupus. Obstet Gynecol 2006;107 (2 Pt 1):293ee9.

10. Molokhia M, Maconochie N, Patrick AL, et al. Crosssectional analysis of adverse outcomes in 1,029 pregnancies of Afro-Caribbean women in Trinidad with and without systemic lupus erythematosus. Arthritis Res Ther 2007; 9:R124.

11. Cortes-Hernandez J, Ordi-Ros J, Paredes F, et al. Clinical predictors of fetal and maternal outcome in systemic lupus erythematosus: a prospective study of 103 pregnancies. Rheumatology (Oxford) 2002; 41:643e50.

12. Smyth A, Oliveira GHM, Lahr BD, et al. A systematic review and meta-analysis of pregnancy outcomes in patients with systemic lupus erythematosus and lupus nephritis. Clin J Am Soc Nephrol 2010; 5:2060e8.

13. Cervera R, Serrano R, Pons-Estel GJ, et al. Morbidity and mortality in the antiphospholipid syndrome during a 10-year period: a multicentre prospective study of 1000 patients. Ann Rheum Dis 2014.

14. Redman CW, Sargent IL. Latest advances in understanding preeclampsia. Science 2005; 308:1592e4.

15. Redman CW, Sargent IL, Staff AC. IFPA Senior Award Lecture: making sense of pre-eclampsia - two placental causes of preeclampsia? Placenta 2014; 35(Suppl.): S20e5.

16. Di Simone N, Ferrazzani S, Castellani R, et al. Heparin and low-dose aspirin restore placental human chorionic gonadotropin secretion abolished by antiphospholipid antibody-containing sera. Hum Reprod 1997; 12:2061e5.

17. Di Simone N, Caliandro D, Castellani R, et al. Lowmolecular weight heparin restores in-vitro trophoblast invasiveness and differentiation in presence of immunoglobulin $\mathrm{G}$ fractions obtained from patients with antiphospholipid syndrome. Hum Reprod 1999; $14: 489 \mathrm{e} 95$

18. La Rosa L, Meroni PL, Tincani A, et al. Beta 2 glycoprotein I and placental anticoagulant protein I in placentae from patients with antiphospholipid syndrome. J Rheumatol 1994; 21:1684e93.

19. Di Simone N, Di Nicuolo F, D'Ippolito S, et al. Antiphospholipid antibodies affect human endometrial angiogenesis. Biol Reproduction 2010; 83:212e9.

20. Hung TH, Skepper JN, Burton GJ. In vitro ischaemiareperfusion injury in term human placenta as a model for oxidative stress in pathological pregnancies. Am J Pathol 2001; 159:1031e43.

21. Young BC, Levine RJ, Karumanchi SA. Pathogenesis of preeclampsia. Annu Rev Pathol 2010; 5:173e92.

22. Heilmann L, Schorsch M, Hahn T, et al. Antiphospholipid syndrome and pre-eclampsia. Semin Thromb Hemost 2011; 37:141e5.

23. Appenzeller S, Souza FH, Wagner Silva de Souza A, et al. HELLP syndrome and its relationship with antiphospholipid syndrome and antiphospholipid antibodies. Semin Arthritis Rheum 2011; 41:517e23.

24. Le Thi Thuong D, Tieuli_e N, Costedoat N, et al. The HELLP syndrome in the antiphospholipid syndrome: retrospective study of 16 cases in 15 women. Ann Rheum Dis 2005; 64:273e8.

25. Abou-Nassar K, Carrier M, Ramsay T, et al. The association between antiphospholipid antibodies and placenta mediated complications: a systematic review and meta-analysis. Thromb Res 2011; 128:77e85.

26. Dong Y, Yu JL. An overview of morbidity, mortality and long-term outcome of late preterm birth. World J Pediatr 2011; 7:199e204.

27. Wallenius M, Skomsvoll JF, Irgens LM, et al. Pregnancy and delivery in women with chronic inflammatory arthritides with a specific focus on first birth. Arthritis Rheum 2011; 63:1534e42.

28. Norgaard M, Larsson H, Pedersen L, et al. Rheumatoid arthritis and birth outcomes: a Danish and Swedish nationwide prevalence study. J Intern Med 2010; 268:329e37.

29. Barnabe C, Faris PD, Quan H. Canadian pregnancy outcomes in rheumatoid arthritis and systemic lupus erythematosus. Int J Rheumatol 2011; 2011:345727.

30. Østensen M, Fuhrer L, Mathieu R, et al. A prospective study of pregnant patients with rheumatoid arthritis and ankylosing spondylitis using validated clinical instruments. Ann Rheum Dis 2004; 63:1212e7.

31. Clark CA, Spitzer KA, Nadler JN, et al. Preterm deliveries in women with systemic lupus erythematosus. J Rheumatol 2003; 30:2127e32.

32. Imbasciati E, Tincani A, Gregorini G, et al. Pregnancy in women with pre-existing lupus nephritis: predictors of fetal and maternal outcome. Nephrol Dial Transplan 2009; 24:519e25.

33. Stagnaro-Green A, Akhter E, Yim C, et al. Thyroid dis- 
ease in pregnant women with systemic lupus erythematosus: increased preterm delivery. Lupus 2011; 20:690e9.

34. Clowse M, Wallace D, Weisman M, et al. Predictors of preterm birth in patients with mild systemic lupus erythematosus. Ann Rheum Dis 2013; 72:1536e9.

35. Empson M, Lassere M, Craig J, et al. Prevention of recurrent miscarriage for women with antiphospholipid antibody or lupus anticoagulant. Cochrane Database Syst Rev 2005; 2:CD002859.

36. Clowse ME, Jamison M, Myers E, et al. A National Study of the Complications of Lupus in Pregnancy. Am J Obstet Gynecol 2008; 199:127.e1e6.

37. Skomsvoll JF, Østensen M, Irgens LM, et al. Perinatal outcome in pregnancies of women with connective tissue disease and inflammatory rheumatic disease in Norway. Scand J Rheumatol 1999; 28:352e6.

38. Yasmeen S, Wilkins EE, Field NT, et al. Pregnancy outcomes in women with systemic lupus erythematosus. J Matern Fetal Med 2001; 10:91e6.

39. Hanouna G, Morel N, Le Thi Huong D, et al. Catastrophic antiphospholipid syndrome and pregnancy: an experience of 13 cases. Rheumatology (Oxford) 2013; 52:1635e41.

40. Motta M, Rodriguez-Perez C, Tincani A, et al. Neonates born from mothers with autoimmune disorders. Early Hum Dev 2009;85 (10 Suppl.): S67e70.

41. De Man YA, Hazes JM, van der HH, et al. Association of higher rheumatoid arthritis disease activity during pregnancy with lower birth weight: results of a national prospective study. Arthritis Rheum 2009; 60:3196e206.

42. Clowse M, Magder LS, Witter F, et al. The impact of increased lupus activity on obstetric outcomes. Arthritis Rheum 2005; 52:514-21.

43. Hansen AT, Kesmodel US, Juul S, et al. Increased venous thrombosis incidence in pregnancies after in vitro fertilization. Hum Reprod 2014 Mar; 29(3):611-7.

44. Forger F, Vallbracht I, Helmke K, et al. Pregnancy mediated improvement of rheumatoid arthritis. Swiss Med Wkly 2012; 142:w13644.

45. Ostensen M, Forger F. Management of RA medications in pregnant patients. Nat Rev Rheumatol 2009; 5: $382-90$.
46. Götestam Skorpen C, Hoeltzenbein M, Tincani A et al. The EULAR points to consider for use of antirheumatic drugs before pregnancy, and during pregnancy and lactation. Ann Rheum Dis. 2016 May; 75(5):795-810.

47. Andreoli L, Bertsias G K, Agmon-Levin N et al. EULAR recommendations for women's health and the management of family planning, assisted reproduction, pregnancy and menopause in patients with systemic lupus erythematosus and/or antiphospholipid syndrome. Ann Rheum Dis. 2017 Mar; 76(3):476-485.

48. Saleeb S, Copel J, Friedman D, Buyon JP. Comparison of treatment with fluorinated glucocorticoids to the natural history of autoantibody associated congenital heart block: retrospective review of the research registry for neonatal lupus. Arthritis Rheum 1999; 42:2335-45.

49. Askanase AD, Friedman DM, Copel J. Spectrum and progression of conduction abnormalities in infants born to mothers with anti- SSA/Ro/SSB-La antibodies. Lupus 2002; 11: 142-51.

50. Raboisson MJ, Fouron JC, Sonesson SE, et al. Fetal Doppler echocardiographic diagnosis and successful steroid therapy of Luciani-Wenckebach phenomenon and endocardial fibroelastosis related to maternal antiRo and anti-La antibodies. J Am Soc Echocardiogr 2005; 18:375-80.

51. Friedman DM, Kim MY, Copel JA, et al. Utility of cardiac monitoring in fetuses at risk for congenital heart block: the PR Interval and Dexamethasone Evaluation (PRIDE) prospective study. Circulation 2008; 117:485-93.

52. Cuneo BF, Ambrose SE, Tworetsky WT. Detection and successful treatment of emergent anti-SSA-mediated fetal atrioventricular block. Am J Obstet Gynecol 2016; 215:527-8

53. Cuneo BF, Moon-Grady AJ, Sonesson S-E, et al. Heart sounds at home: feasibility of an ambulatory fetal heart rhythm surveillance program for anti- SSA-positive pregnancies. J Perinatol 2017; 37: 226-30. 54

54. Cuneo BF, Sonesson SE, Levasseur S et al. Home Monitoring for Fetal Heart Rhythm During Anti-Ro Pregnancies. J Am Coll Cardiol. 2018 Oct 16;72(16): 1940-1951.

55. Gran JT, Ostensen M. Spondyloarthritides in females. Baillieres Clin Rheumatol 1998; 12:695e715. 


\title{
Lupus eritematoso sistemico e gravidanza
}

\author{
Maddalena Larosa, Andrea Doria \\ UOC Reumatologia, Dipartimento di Medicina (DIMED), Università degli Studi di Padova, Padova, Italia
}

\section{Introduzione}

Il lupus eritematoso sistemico (LES) è una malattia autoimmune sistemica il cui decorso è contraddistinto da periodi di riacutizzazioni alternati a remissione. ${ }^{1} \mathrm{Le}$ manifestazioni cliniche di malattia sono variabili e possono riguardare numerosi organi e apparati con gravità diverse, causando un danno irreversibile e molteplici comorbidità. ${ }^{1}$ Il 90\% dei pazienti affetti da LES esordisce in età giovanile e la malattia è più frequente nel sesso femminile, come la maggior parte delle malattie reumatiche. Il rapporto F/M varia da 10/1 negli adulti a 3-5/1 nei bambini ${ }^{2}$ e la malattia si manifesta prevalentemente tra i 15 e i 40 anni nel sesso femminile $\mathrm{e}$ in età più avanzata nel sesso maschile., ${ }^{3,4} \mathrm{I}$ fattori ormonali sembrano quindi avere un ruolo importante nello sviluppo del LES.

Considerati l'elevata incidenza della malattia in donne giovani, la gravidanza rappresenta un'evenienza relativamente comune e rappresenta un momento critico sia per le donne affette da lupus che per i reumatologi e gli internisti che le seguono. Il management del LES durante la gravidanza richiede, infatti, competenze multidisciplinari che devono attuarsi dal periodo pre-concezionale fino al puerperio. 5,6

La fertilità delle pazienti affette da LES in generale non è ridotta, ma durante la gravidanza le pazienti devono affrontare due principali criticità: gli effetti della malattia sulla prognosi materna e fetale e gli effetti della gravidanza sulla malattia. ${ }^{5,6}$

Ad oggi, non esistono biomarcatori affidabili che ci consentano di predire le riacutizzazioni di malattia durante la gestazione ed è quindi necessario una stretta

Corrispondente: Andrea Doria, UOC Reumatologia, Dipartimento di Medicina (DIMED), Università degli Studi di Padova, via Giustiniani 2, 35128 Padova, Italia.

E-mail: adoria@unipd.it

Articolo pubblicato secondo la Creative Commons Attribution NonCommercial 4.0 License (CC BY-NC 4.0).

${ }^{\circ}$ Copyright: the Author(s), 2021

Licensee PAGEPress, Italy

QUADERNI - Italian Journal of Medicine 2021; 9(4):e4 sorveglianza prima della gravidanza, dal periodo preconcezionale alla fine del post-partum. ${ }^{6}$

Secondo le ultime raccomandazioni EULAR, pubblicate nel $2016,{ }^{6}$ una malattia attiva al momento del concepimento o nei 6-12 mesi precedenti ha effetti sfavorevoli sul decorso della gravidanza ed aumenta il rischio di complicanze ostetriche come ritardo di crescita intra uterino (RCIU), parto pretermine ed insufficienza placentare. ${ }^{6,7}$

\section{Effetti della gravidanza sulla malattia: complicanze materne}

Durante la gravidanza delle pazienti affette da LES possono verificarsi riacutizzazioni di malattia con una frequenza variabile dal $25 \%$ al $65 \%$ dei casi. ${ }^{8} \mathrm{La}$ frequenza delle riacutizzazioni varia tuttavia a seconda degli studi: i risultati contrastanti dipendono dall'eterogeneità delle definizioni di riacutizzazione, dalla diversa natura degli studi (retrospettivi $v s$ prospettici), dalle caratteristiche delle pazienti e dalle difficoltà di diagnosi differenziale tra riacutizzazioni di malattia e cambiamenti fisiologici che avvengono durante il periodo gestazionale. ${ }^{9}$ Alcune anomalie di laboratorio possono verificarsi, infatti, anche nelle gravidanze di donne sane. Tra queste vi sono l'anemia moderata e talvolta una piastrinopenia, un aumento fisiologico della velocità di eritrosedimentazione (VES) e della proteinuria misurata nelle 24 ore. Anche i livelli sierici di complemento $(\mathrm{C} 3, \mathrm{C} 4, \mathrm{CH} 50)$ possono aumentare del $50 \%$ nelle pazienti con gravidanze non complicate. ${ }^{9}$ Quest'ultimo elemento può quindi rendere difficile il riconoscimento di una riacutizzazione di malattia durante la gestazione, dal momento che $\mathrm{C} 3$ e/o C4 possono risultare nei limiti di normali.'

L'influenza delle riacutizzazioni sull'esito gravidico dipende dal loro tipo e numero. Le riacutizzazioni renali sono infatti le più temibili e possono influenzare negativamente l'esito della gravidanza e determinare un danno irreversibile della funzione renale materna. ${ }^{10}$ Le riacutizzazioni renali possono verificarsi in qualsiasi trimestre, ma la frequenza più elevata è stata osservata nel primo e nel secondo trimestre; il rischio sembra inoltre rimanere elevata fino a circa 12 mesi dal parto. ${ }^{8}$ Il LES è una malattia prevalentemente $\mathrm{T}$ 
helper (Th)-2 mediata, caratterizzata da una 'disregolazione' dei linfociti T regolatori (Treg). Fisiologicamente in gravidanza si assiste a una diminuzione della bilancia Th1/Th2 e Th17/Treg. ${ }^{11}$ Nelle pazienti affette da LES, l'espansione della componente Th2 non è controbilanciata da un'adeguata espansione dei Treg espondendo le pazienti ad un rischio di riacutizzazioni durante la gestazione. ${ }^{12}$

Tra i fattori che favoriscono le riacutizzazioni di malattia vi è la malattia attiva nei 6-12 mesi che precedono il concepimento; ${ }^{6}$ al contrario, la remissione di malattia ${ }^{6}$ e l'assunzione di idrossiclorochina (HCQ) sono fattori protettivi. ${ }^{6}{ }^{13}$ In uno studio prospettico americano 'Predictors of Pregnancy Outcome: Biomarkers in Antiphospholipid Antibody Syndrome and Systemic Lupus Erythematosus ('PROMISSE')',13 Buyon et al. hanno dimostrato come una attività di malattia elevata (SLEDAI-2K $\geq 4$ ) al momento del concepimento si associa un aumentato rischio di riacutizzazioni durante la gravidanza. ${ }^{13}$ In questo studio il $65 \%$ delle pazienti arruolate assumeva $\mathrm{HCQ},{ }^{13}$ ma l'assunzione di HCQ non è risultata un fattore protettivo sulle riacutizzazioni.

La gravidanza rappresenta un periodo a 'rischio' anche per l'esordio della glomerulonefrite lupica (GLN) che può essere la prima manifestazione del LES in gravidanza e può condurre a insufficienza renale e/o complicazioni fetali gravi. ${ }^{6,14}$

Uno studio condotto su 103 gravidanze ${ }^{15}$ ha mostrato come un pregresso impegno renale è un fattore di rischio indipendente di riacutizzazioni durante la gravidanza. ${ }^{15}$

Altri predittori di riacutizzazioni di GLN in gravidanza sono stati identificati nei livelli ridotti di $\mathrm{C} 3 \mathrm{e} / \mathrm{o}$ $\mathrm{C} 4$ e/o nella positività degli anticorpi anti-DNA nativo (nDNA) al momento del concepimento, entrambi biomarcatori di attività di malattia. ${ }^{16} \mathrm{Al}$ contrario altri auto-anticorpi ancora in fase di studio come gli antipentrassina-3 (PTX3) sono risultati protettivi per l'impegno renale sia in modelli murini che umani. ${ }^{17}$

Dal momento che il rischio di sviluppare un danno d'organo irreversibile è più elevato nelle pazienti con danno d'organo già presente al concepimento, ${ }^{18}$ sono considerate controindicazioni alla gravidanza l'ipertensione polmonare grave (con una pressione stimata dell'arteria polmonare-pAPS $>50 \mathrm{mmHg}$ ), l'insufficienza renale (creatinina $>2,8 \mathrm{mg} / \mathrm{dL}$ ), la pneumopatia con deficit restrittivo (capacità vitale forzata-CVF $<1$ L), l'insufficienza cardiaca, la malattia attiva, in particolare in presenza di GLN e ictus cerebrale. ${ }^{19}$

Per quanto riguarda il puerperio, le riacutizzazioni sono frequenti in particolare nelle pazienti che hanno già avuto una riacutizzazione durante la gravidanza. In uno studio condotto su 144 gravidanze, il $15 \%$ delle pazienti che si riacutizzava nel post-partum aveva già sviluppato una riacutizzazione durante il periodo gestazionale. ${ }^{20}$ Inoltre, Buyon et al. analizzando i dati relativi al post-partum dello studio PROMISSE, hanno riportato una frequenza di riacutizzazione moderata e grave nel $12,7 \%$ e $3 \%$ dei casi, rispettivamente. Gli stessi Autori hanno anche sottolineato come le riacutizzazioni comparse nel puerperio siano sovrapponibili per frequenza a quelle osservate in gravidanza. ${ }^{21}$

Prevenire le riacutizzazioni di LES è di fondamentale importanza per ottenere un outcome fetale favorevole. Sappiamo infatti che le riacutizzazioni si associano ad una notevole riduzione nella percentuale di nati vivi ed aumenta il rischio di parto pretermine $\left(<37^{\mathrm{a}}\right.$ settimana di gestazione) e di RCIU. ${ }^{22}$

\section{Punti chiave}

- Le riacutizzazioni di malattia si verificano prevalentemente nel $1^{\circ}$ e $2^{\circ}$ trimestre di gravidanza.

- La remissione e la bassa attività di malattia al concepimento riducono il rischio di riacutizzazioni di LES in gravidanza e nel post-partum.

- Le riacutizzazioni di malattia in gravidanza possono essere lievi, moderate e gravi. Tra queste, la GLN rappresenta una riacutizzazione temibile in gravidanza.

- Durante le gravidanze non complicate di donne sane sono frequenti le seguenti alterazioni di laboratorio: VES aumentata, anemia, aumento di $\mathrm{C} 3 / \mathrm{C} 4$, lieve aumento della proteinuria-24 $\mathrm{h}$.

- Le controindicazioni assolute alla gravidanza nel LES includono: ipertensione polmonare grave (con una pressione stimata dell'arteria polmonarepAPS $>50 \mathrm{mmHg}$ ), insufficienza renale (creatinina $>2,8 \mathrm{mg} / \mathrm{dL}$ ), pneumopatia con deficit restrittivo (capacità vitale forzata-FVC $<1 \mathrm{~L}$ ), insufficienza cardiaca, malattia attiva, in particolare la presenza di GLN e ictus cerebrale (19).

\section{Effetti della malattia sulla gravidanza}

Durante la gravidanza le pazienti affette da LES possono sviluppare numerose complicanze ostetriche e fetali.

\section{Complicanze ostetriche}

Tra le più frequenti complicanze ostetriche si osservano le sindromi ipertensive che includono: ipertensione gestazionale, pre-eclampsia (PE), eclampsia (E), sindrome HELLP ed ematoma retroplacentare.

Secondo l'ultima definizione proposta dalle nuove linee guida dell'American College of Obstetricians and Gynecologists (ACOG) Committee 2020, ${ }^{23}$ la PE viene definita come un disordine tipico della gravidanza caratterizzato da una pressione arteriosa sistolica (PAS) $\geq 140 \mathrm{mmHg}$ o diastolica (PAD) $\geq 90 \mathrm{mmHg}$ 
che compare dopo la 20 settimana di gravidanza (SG) in una donna precedentemente normotesa, associate a proteinuria $\geq 300 \mathrm{mg} / 24 \mathrm{~h}$ o ad una proteinuria/creatininuria $\geq 0,3$.

La diagnosi di $\mathrm{PE}$ grave si basa sui seguenti criteri: PAS $\geq 160 \mathrm{mmHg}$ o $\mathrm{PAD} \geq 110 \mathrm{mmHg}$ in almeno 2 occasioni a distanza di 4 ore, mentre la paziente è a riposo; piastrinopenia (piastrine $<100.000 / \mathrm{uL}$ ); enzimi epatici elevati (almeno 2 volte il valore normale); dolore epigastrico persistente non responsivo a farmaci, insufficienza renale (creatininemia $>1,1 \mathrm{mg} / \mathrm{dL}$ ); edema polmonare; nuova insorgenza di emicrania non responsiva a farmaci e non spiegata da diagnosi alternative; turbe del visus. ${ }^{23}$

$\mathrm{La} \mathrm{PE}$ e/o la PE grave possono essere osservate fino al 35\% delle pazienti affette da LES in gravidanza, con una frequenza 10 volte superiore rispetto alla popolazione generale. ${ }^{7,24-26}$

La PE e la PE grave possono svilupparsi nel corso di una riacutizzazione di GLN da cui risulta difficile distinguerle. Infatti, la PE e la PE grave condividono con GLN alcune caratteristiche cliniche tra cui: aumento della proteinuria e/o diminuita funzione renale associate ad ipertensione, edemi declivi e piastrinopenia. ${ }^{9}$ In Tabella 1 sono riportati alcuni elementi utili per la diagnosi differenziale tra PE e GLN.

In questi casi, la biopsia renale è importante per la diagnosi differenziale, ma il suo utilizzo in gravi- danza è tutt'oggi limitato alla luce dei rischi legati alla procedura. La comune pratica clinica nei casi più critici suggerisce l'induzione del parto sia per evitare complicanze ostetriche che ulteriori complicanze materne.

In generale, le pazienti che hanno già avuto una $\mathrm{PE}$ sono più a rischio di sviluppare una nuova $\mathrm{PE}$ nelle gravidanze successive. ${ }^{27}$ In particolare, le pazienti con PE precoce (prima della $34^{\text {a }} \mathrm{SG}$ ) hanno un rischio 4 volte superiore di perdita fetale in una successiva gravidanza, mentre il rischio di PE è nettamente inferiore in caso di insorgenza dopo la $34 \mathrm{SG}^{27}$

Tra i fattori di rischio di PE vi sono fattori generali come diabete, ipertensione, nulliparità ed obesità e fattori legati al LES tra cui malattia attiva al concepimento o una GLN attiva nei 6 mesi precedenti la gravidanza, ${ }^{28}$ positività di anticorpi anti-fosfolipidi (aPL), compresi lupus anticoagulanti (LAC), anticardiolipina IgG o IgM, anti-beta2GPI IgG o IgM, riduzione di livelli sierici di complemento e piastrinopenia. ${ }^{7,9,29-31}$

Altri fattori di rischio di PE sono anomalie dell'arteria uterina all'eco-Doppler, ${ }^{32}$ aumento dei livelli sierici di fattori pro-angiogenetici (soluble endoglin, sEng; soluble fms-tyrosine kinase molecule-1, sFlt-1; placental growth factor, $\mathrm{PlGF})^{33,34} \mathrm{e}$ di PTX3, ${ }^{35,36}$

In letteratura sono state studiate alcune strategie terapeutiche per prevenire l'insorgenza di PE. Tra que-

Tabella 1. Caratteristiche cliniche e di laboratorio per la diagnosi differenziale tra preeclampsia e glomerulonefrite lupica nelle pazienti affette da lupus eritematoso sistemico in gravidanza.

\begin{tabular}{|c|c|c|}
\hline & $\mathrm{PE} / \mathrm{PE}$ grave & GLN \\
\hline Segni e sintomi clinici & $\begin{array}{l}\text { Ipertensione arteriosa ( } \geq 160 / 100 \mathrm{mmHg} \\
\text { nella PE grave) } \\
\text { Emicrania, perdita del visus, stroke, } \\
\text { dolore epigastrico } \\
\text { Decremento ponderale } \\
\text { Dispnea ed edema polmonare }\end{array}$ & $\begin{array}{l}\text { Ipertensione arteriosa } \\
\text { Astenia, edemi declivi, edemi peri-orbitari } \\
\text { Aumento ponderale } \\
\text { Eritema a farfalla e/o sinovite e/o altri segni } \\
\text { clinici di riacutizzazione di malattia }\end{array}$ \\
\hline Esami di laboratorio & $\begin{array}{l}\text { Proteinuria } \geq 300 \mathrm{mg} / 24 \text { ore } \\
\text { o proteinuria/creatinuria } \geq 0.3 \\
\text { Creatinina nella norma o aumentata } \\
\text { Aumento degli indici di citolisi } \\
\text { epatica } \\
\text { Moderata o grave trombocitopenia } \\
\text { Iperuricemia }\end{array}$ & $\begin{array}{l}\text { Proteinuria } \geq 300 \mathrm{mg} / 24 \text { ore } \\
\text { o proteinuria/creatinuria } \geq 0.3 \\
\text { Creatinina nella norma o aumentata } \\
\text { Sedimento attivo con ematuria } \\
\text { e/o piuria in caso di sindrome nefritica } \\
\text { Indici di citolisi epatica nella norma } \\
\text { Moderata o grave trombocitopenia } \\
\text { Acido urico nella norma (se non presente } \\
\text { insufficienza renale cronica avanzata) }\end{array}$ \\
\hline Marker sierologici & $\begin{array}{l}\text { Anti-DNAn nella norma } \\
\text { C3/C4 nella norma }\end{array}$ & $\begin{array}{l}\text { Anti-DNAn positivi } \\
\text { Diminuzione di C3/C4 (non sempre presente) }\end{array}$ \\
\hline Follow-up & $\begin{array}{l}\text { Pressione arteriosa, eco-Doppler uterino, } \\
\text { esame urine, proteinuria } 24 \mathrm{~h}\end{array}$ & $\begin{array}{l}\text { Pressione arteriosa, esame urine, } \\
\text { proteinuria } 24 \mathrm{~h}\end{array}$ \\
\hline Trattamento & $\begin{array}{l}\text { Glucocorticoidi, solfato di magnesio, } \\
\text { farmaci antipertensivi, induzione del parto } \\
\text { (specialmente in caso di complicanze fetali) }\end{array}$ & $\begin{array}{l}\text { Glucocorticoidi, immunosoppressori, } \\
\text { farmaci antipertensivi } \\
\text { Nei casi più gravi induzione del parto }\end{array}$ \\
\hline Prognosi & Mortalità sia materna che fetale & $\begin{array}{l}\text { Insufficienza renale cronica e danno renale } \\
\text { irreversibile }\end{array}$ \\
\hline
\end{tabular}

PE, preeclampsia; GLN, glomerulonefrite lupica; anti-DNAn, anti-DNA nativo; 24 h, 24 ore. 
ste, la somministrazione di aspirina $(60-100 \mathrm{mg} / \mathrm{die})$ sembra ridurre il rischio di PE e RCIU; ${ }^{37}$ resta tuttavia ancora incerto il 'timing' più opportuno per l'introduzione di questo farmaco nelle pazienti gravide. ${ }^{37}$

L'E è caratterizzata da crisi convulsive in una donna con PE e complica spesso i casi di PE grave. Non vi sono dati sulla prevalenza di tale condizione nelle pazienti affette da LES. In uno studio condotto da Kwok et al..$^{15}$ non sono stati osservati casi di $\mathrm{E}$ in 103 gravidanze lupiche.

La sindrome 'Hemolysis, Elevated Liver enzymes, Low Platelets count' (HELLP) può comparire nell' $80 \%$ delle pazienti lupiche con $\mathrm{PE}^{38}$ e può essere accompagnata ad altre complicanze fetali, quali parto cesareo, parto pretermine ed ematoma placentare. ${ }^{39}$

La PE rappresenta uno dei predittori della sindrome HELLP ed una elevata frequenza di questa sindrome è stata osservata nelle pazienti con LES e sindrome da anticorpi anti-fosfolipidi (APS), suggerendo che gli aPL potrebbero contribuire allo sviluppo di sindrome HELLP, microtrombosi e complicanze trombotiche in gravidanza. ${ }^{20}$

\section{Punti chiave}

- Il LES può essere associato ad alcune complicanze ostetriche, tra cui ipertensione gestazionale, PE/E e sindrome HELLP.

- Queste complicanze possono svilupparsi nelle pazienti con GLN attiva.

- Risulta difficile sostituire la GLN dalla PE.

- La sindrome HELLP si osserva più frequentemente in pazienti affette da LES e APS secondaria o nelle pazienti aPL carrier.

\section{Complicanze fetali}

Oltre alle complicanze ostetriche, anche il rischio di complicanze fetali nelle pazienti lupiche è più elevato rispetto alla popolazione generale. Tra queste vi sono il RCIU e neonato piccolo per età gestazionale (SGA), parto pretermine, morte fetale intrauterina, parto cesareo e lupus neonatale. ${ }^{18,40,41}$

La frequenza di RCIU varia dal $10 \%$ al $30 \%$ nelle gravidanze delle pazienti affette da LES $^{31,42}$ e può essere associata a lupus attivo, GLN e APS secondaria. ${ }^{40}$ In quest'ultimo caso, infatti, si verificano alterazioni placentari che possono condurre a ritardo di crescita e, nei casi più gravi, morte fetale. ${ }^{43}$

Il parto pretermine è la complicanza fetale più comune nelle pazienti affette da LES (fino al 33\% delle gravidanze) e la sua frequenza risulta essere più elevata rispetto alla popolazione generale ${ }^{44,45}$ raggiugnendo una prevalenza del $50 \%$ nelle pazienti affette da GLN. ${ }^{46,47}$

La frequenza di aborti e morti fetali si è notevolmente ridotta negli ultimi anni. ${ }^{45}$ I tassi di aborti spon- tanei (definiti come una perdita fetale prima della $10^{\mathrm{a}}$ SG) sono diminuiti dal $43 \%$ negli anni ' 60 - ' 70 al $17 \%$ negli anni $2000^{48}$ e il tasso di nati vivi è attualmente riportato tra $80 \%$ e $90 \%$ dei casi. ${ }^{38}$ Lo studio PROMISSE ha mostrato come il tasso di perdita fetale (definita come morte fetale dopo $12 \mathrm{SG}$ ) è più alto nelle donne afroamericane e ispaniche. ${ }^{13}$ È ragionevole quindi ritenere che fattori razziali ed etnici potrebbero influenzare il decorso del LES, così come l'esito delle gravidanze lupiche. Anche lo stato socioeconomico potrebbe contribuire alle morti fetali nelle pazienti con LES. ${ }^{49}$ Altri fattori predittivi di perdita fetale sono la malattia attiva, ${ }^{50}$ pregressa GLN,,${ }^{22}$ la positività di aPL e l'APS secondaria. ${ }^{9,51,52}$

Un'attenzione particolare merita il lupus neonatale, sindrome caratterizzata da diverse manifestazioni, tra cui dermatite, epatite, citopenie, miocardite e blocco atrioventricolare (BAV) che può essere irreversibile. Questa condizione è dovuta al passaggio transplacentare di anticorpi anti-Ro/SSA e/o anti$\mathrm{La} / \mathrm{SSB}$ dalla madre al feto ${ }^{9,12}$ a partire dalla $16^{\mathrm{a}} \mathrm{SG}$. Il BAV si manifesta nell' $1-2 \%$ dei bambini nati da donne con positività dell'anti-Ro/SSA e nel $20 \%$ dei bambini nati da donne con positività dell'anti$\mathrm{Ro} / \mathrm{SSA}$ e precedente figlio con BAV. ${ }^{27}$ Si pensa che il passaggio di anticorpi determini un danno del tessuto di conduzione cardiaco che si instaura tra la $16^{\mathrm{a}}$ $\mathrm{SG}$ e la $25^{\mathrm{a}} \mathrm{SG}$ e può evolvere fino al BAV di III grado. Nei casi più gravi può portare alla morte fetale o neonatale o richiedere l'impianto di un pacemaker alla nascita. A parte l'interessamento cardiaco, la maggior parte delle manifestazioni del lupus neonatale si risolve entro 6-9 mesi dalla nascita, quando gli anticorpi materni vengono eliminati dal circolo del bambino. ${ }^{9}$

Il monitoraggio ecocardiografico del feto durante la gravidanza in pazienti con anticorpi anti-SSA è stato recentemente messo in discussione da Costedoat-Chalumeau et al..$^{53}$ dal momento che non vi è ancora un gold standard per il trattamento del BAV. Anche i glucocorticoidi (GCs) fluorinati, infatti, non sembrano avere un'efficacia risolutiva nel trattamento di questa manifestazione.

\section{Punti chiave}

- Le complicanze fetali più frequenti nelle pazienti affette da LES in gravidanza sono rappresentate da parto pretermine, parto cesareo, RCIU e SGA.

- La frequenza di aborti e perdite fetali si è notevolmente ridotta negli ultimi anni.

- Il lupus neonatale rappresenta una sindrome caratterizzata da diverse manifestazioni, tra cui il BAV.

- Il BAV è raro: $1-2 \%$ dei bambini nati da donne con positività per anti-SSA/SSB e nel $20 \%$ dei bambini nati da donne con positività per anti-Ro/SSA e precedente figlio con BAV. 


\section{Terapia e farmaci in gravidanza}

Come accennato nei paragrafi precedenti, la remissione e/o la bassa attività di malattia al momento del concepimento sono elementi fondamentali per ridurre il rischio di riacutizzazioni del LES durante la gravidanza (e nel puerperio). Alcuni tra i farmaci abitualmente utilizzati al di fuori del periodo gestazionale (quali micofenolato e/o ciclofosfamide) sono infatti controindicati in questo periodo. Pertanto, il nostro armamentario terapeutico è decisamente ridotto in gravidanza.

Le prime 3-8 settimane dopo il concepimento (oppure le 5-10 dopo l'ultima mestruazione) sono considerate critiche per il processo di organogenesi in cui il feto è a rischio di teratogenicità da parte dei farmaci assunti dalla madre.$^{54}$ La maggior parte delle malformazioni fetali si sviluppa alla fine della $8^{\text {a }} \mathrm{SG}$, le anomalie genitali compaiono tra la ottava e la $12^{\mathrm{a}} \mathrm{SG}$ e le malformazioni a carico del sistema nervoso tra la ottava e $16^{\mathrm{a}} \mathrm{SG} .{ }^{54}$ Durante l'allattamento, i farmaci sono trasferiti nel latte materno tramite diffusione passiva. Nonostante solo una minima parte di farmaco raggiunga la circolazione fetale è comunque possibile che alcuni farmaci vengano assorbiti e persistano nella circolazione del neonato più a lungo rispetto a quanto non avviene nella madre a causa dell'immaturità del metabolismo epatico del neonato. ${ }^{55,56}$

I farmaci anti-infiammatori non steroidei (FANS), e in particolare gli inibitori della COX-2 ossigenasi possono essere utilizzati nel $1^{\circ}$ e $2^{\circ}$ trimestre ma dovrebbero essere evitati durante il $3^{\circ}$ trimestre a causa del rischio di chiusura prematura del dotto di Botallo, ipertensione polmonare, alterazione della funzionalità renale fetale e oligodramnios. ${ }^{54}$

I GCs si dividono in GCs fluorinati (betametasone e desametasone) e non fluorinati (prednisone/prednisolone, idrocortisone e metilprednisolone). I primi non sono metabolizzati dalla placenta e si trovano nella circolazione fetale; i secondi sono invece metabolizzati dalla placenta e si ritrovano nella circolazione fetale solo in minima parte (solo il 10\% del farmaco attivo raggiunge il feto). ${ }^{57}$ Per queste proprietà i GCs non fluorinati sono sicuri per il feto e possono essere utilizzati in ogni trimestre di gravidanza e nell'allattamento ${ }^{54}$ mentre i GCs fluorinati sono indicati solo quando si vuole intervenire sul feto, come ad esempio nell'induzione della maturità polmonare. ${ }^{57} \mathrm{La}$ somministrazione di GCs fluorinati si associa ad un maggior rischio di complicanze materne, tra cui diabete mellito gestazionale, ipertensione, osteoporosi (potenziata da un'eventuale terapia concomitante con eparina) e infezioni. In alcuni studi è stata dimostrata un'associazione tra assunzione di GCs non fluorinati (in particolare dosi superiori a $15-25 \mathrm{mg} /$ die di prednisone) e parto pretermine o rottura prematura delle membrane..$^{58}$ Tuttavia, in caso di riacutizzazione di malattia è possibile utilizzarli anche a dosi elevate.

La cardioaspirina può essere somministrata durante tutta la gravidanza fino alla $35^{\text {a }} \mathrm{SG}$, mentre la warfarina risulta essere controindicata alla luce del rischio di anomalie congenite se assunta tra la $6^{\mathrm{a}}$ e la $12^{\mathrm{a}} \mathrm{SG}$; la warfarina è però compatibile con l'allattamento.

Per quanto riguarda gli antipertensivi, gli ACE (angiotensin-coverting-enzyme) inibitori dovrebbero essere sostituiti da altri farmaci come labetalolo o nifedipina dopo la conferma di gravidanza.

Tra gli immunomodulanti e gli immunosoppressori possiamo distinguere due categorie di farmaci: quelli sicuri in gravidanza (e/o nell'allattamento) e quelli totalmente controindicati. È importante inoltre riconoscere quali trattamenti possono essere somministrati durante l'allattamento (Tabella 2).

Secondo le ultime raccomandazioni EULAR ${ }^{59} \mathrm{i}$ farmaci totalmente compatibili con la gravidanza sono: HCQ, clorochina, azatioprina, ciclosporina, tacrolimus e colchicina. Sono invece controindicati perché teratogeni metotrexate, micofenolato mofetile e ciclofosfamide.

Molti dei farmaci biotecnologici (b-DMARDS) possono essere somministrati nel primo trimestre perché il trasporto delle IgG1 inizia alla $16^{\mathrm{a}} \mathrm{SG}$. Tuttavia, su rituximab e belimumab non vi sono dati di sicurezza sufficienti per raccomandare il loro utilizzo durante la gravidanza. Pertanto, questi farmaci dovrebbero essere sostituti prima del concepimento con diverse tempistiche a seconda del loro meccanismo d'azione e proprietà farmacologiche.

\section{Conclusioni}

Sebbene la prevalenza delle complicanze materne, ostetriche e fetali si sia notevolmente ridotta rispetto al passato, la gravidanza nel LES continua ad essere una condizione ad esito incerto. ${ }^{60} \mathrm{La}$ definizione e la stratificazione del rischio in ciascuna paziente prima del concepimento rimangono un'operazione importante per ridurre la frequenza degli eventi avversi. ${ }^{60}$

Durante il counselling dovrebbero essere considerati alcuni fattori (Figura 1). Il primo è l'attività di malattia e il fenotipo clinico della paziente; per esempio, la GLN in atto o pregressa è un importante fattore di rischio di riacutizzazione della malattia durante la gravidanza. Di grande importanza è la terapia assunta dalla madre durante le prime fasi della malattia per la teratogenicità di alcuni farmaci impiegati nel LES. I GCs possono essere utilizzati in gravidanza purché a dosi moderate, mentre alcuni immunosoppressori quali ciclofosfamide, micofenolato e metotrexate devono essere evitati. Importante è anche il dosaggio di alcuni autoanticorpi come gli aPL che si associano al rischio di morte fetale e gli anti-SSA che si associano al rischio di BAV. 
Tabella 2. Farmaci nel trattamento del lupus eritematoso sistemico in gravidanza.

\begin{tabular}{|c|c|c|}
\hline & Gravidanza & Allattamento \\
\hline Glucocorticoidi & $\begin{array}{l}\text { GCs fluorinati: permessi (trattamento delle malattie } \\
\text { fetali) } \\
\text { GCs non fluorinati: permessi (trattamento delle } \\
\text { riacutizzazioni materne) }\end{array}$ & GC non fluorinati: permessi \\
\hline $\begin{array}{l}\text { Immunosoppressori \& } \\
\text { Immunomodulanti }\end{array}$ & $\begin{array}{l}\text { MTX: controindicato (stop almeno } 3 \text { mesi prima } \\
\text { del concepimento) } \\
\text { MMF: controindicato (stop almeno } 6 \text { settimane prima } \\
\text { del concepimento) } \\
\text { Ciclofosfamide: controindicato (stop almeno } 3 \text { mesi } \\
\text { prima del concepimento) } \\
\text { Talidomide: controindicata } \\
\text { AZA: permessa } \\
\text { CYC-A: permessa } \\
\text { TAC: permesso } \\
\text { Immunoglobuline endovena: permesse } \\
\text { Colchicina: permessa } \\
\text { HCQ: permessa }\end{array}$ & $\begin{array}{l}\text { MTX: controindicato } \\
\text { MMF: controindicato } \\
\text { Ciclofosfamide: controindicato } \\
\text { Talidomide: controindicata } \\
\text { AZA: permessa } \\
\text { CYC-A: permessa } \\
\text { TAC: permesso } \\
\text { Ig-ev: permesse } \\
\text { Colchicina: permessa } \\
\text { HCQ: permessa }\end{array}$ \\
\hline Farmaci biologici & $\begin{array}{l}\text { Belimumab: controindicato per mancanza di dati } \\
\text { Rituximab: controindicato per mancanza di dati }\end{array}$ & $\begin{array}{l}\text { Belimumab: controindicato per mancanza di dati } \\
\text { Rituximab: controindicato per mancanza di dati }\end{array}$ \\
\hline Altri & $\begin{array}{l}\text { Aspirina: permessa } \\
\text { EBPM: permessa } \\
\text { Warfarina: controindicata } \\
\text { FANS: controindicato nel } 3^{\circ} \text { trimestre }\end{array}$ & $\begin{array}{l}\text { Aspirina: permessa } \\
\text { EBPM: permessa } \\
\text { Warfarina: permessa } \\
\text { FANS: permesso (preferenzialmente ibuprofene) }\end{array}$ \\
\hline
\end{tabular}

GCs, glucorticoidi; MTX, methotrexate; MMF, micofelonato mofetil; AZA, azatioprina; CYC-A, ciclosporina-A; TAC, tacrolimus; HCQ, idrossiclorochina; EBPM, eparina a basso peso molecolare; FANS, farmaci anti-infiammatori non steroidei.

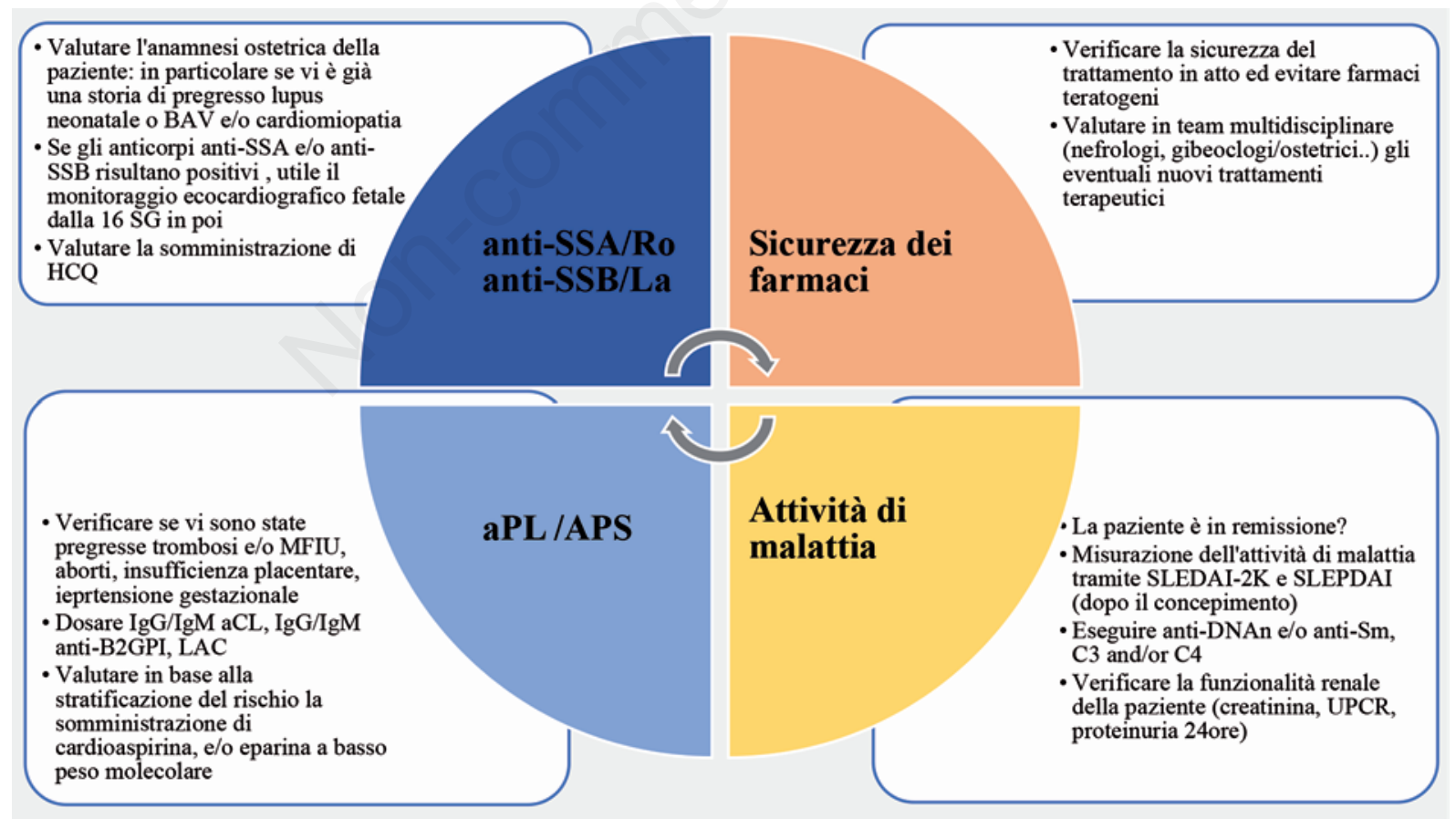

Figura 1. I quattro elementi caratterizzanti del 'counselling' pregravidico: 'PREGNA-RING'. BAV, blocco atrio-ventricolare; SG, settimana gestazionale; HCQ, idrossiclorochina; MFIU, morte fetale intra uterina, aCL, anti-cardiolipina; B2GPI, beta-2 glicoproteina I; LAC, lupus anticoagulanti; SLEDAI-2K, Systemic Lupus Erythematosus Disease Activity 2000; SLEPDAI, Systemic Lupus Erythematosus Pregnancy Disease Activity; anti-DNAn, anti-DNA nativo; UPCR, urine protein creatinine ratio. Figura adattata dalla referenz $a^{60}$. 


\section{Punti chiave}

- Il management del LES in gravidanza necessita di un team multidisciplinare che comprende reumatologo, ginecologo, neonatologo e nefrologo.

- La stratificazione del rischio nelle pazienti con LES prima del concepimento è fondamentale per ridurre la frequenza di eventi avversi materni e fetali.

- La valutazione dei farmaci assunti dalla madre, del profilo anticorpale (aPL e anti-SSA/anti-SSB), e la misurazione dell'attività di malattia al momento del concepimento e nei 6 mesi precedenti, sono i punti cardine del counselling preconcezionale.

\section{Bibliografia}

1. Gergianaki I, Bertsias G. Systemic Lupus Erythematosus in Primary Care: An Update and Practical Messages for the General Practitioner. Front Med; 2018;5:161.

2. Cattalini M, Soliani M, Caparello MC, Cimaz R. Sex Differences in Pediatric Rheumatology. Clin Rev Allergy Immunol. 2019; 56:293-307.

3. Rees F, Doherty M, Grainge MJ, Lanyon P, et al. The worldwide incidence and prevalence of systemic lupus erythematosus: a systematic review of epidemiological studies. Rheumatology; 2017; 56: 1945-61.

4. Tedeschi SK, Bermas B, Cotenbarder KH. Sexual disparities in the incidence and course of SLE and RA. Clin Immunol 2013; 149:211-18.

5. Lazzaroni MG, Dall' Ara F, Fredi M, et al. A comprehensive review of the clinical approach to pregnancy and systemic lupus erythematosus. J Autoimmun. 2016;74:106-17.

6. Andreoli L, Bertsias GK, Agmon-Levi N, et al. EULAR recommendations for women's health and the management of family planning, assisted reproduction, pregnancy and menopause in patients with systemic lupus erythematosus and/or antiphospholipid syndrome. Ann Rheum Dis. 2017; 76: 476-85.

7. Fischer-Betz R, Specker C. Pregnancy in systemic lupus erythematous and antiphospholipid syndrome. Best Pract Res Clini Rheumatol 2017; 31: 397-414.

8. Lateef A, Petri M. Systemic Lupus Erythematosus and Pregnancy. Rheum Dis Clin North Am. 2017; 43: 215-26.

9. Lateef A, Petri M. Managing lupus patients during pregnancy. Best Pract Res Clin Rheumatol 2013; 27: 435-47.

10. Ponticelli C, Moroni G. Flares in lupus nephritis: incidence, impact on renal survival and management. Lupus. 1998;7:635-38.

11. Tavakolpour S, Rahimzadeh G. New Insights into the Management of Patients with Autoimmune Diseases or Inflammatory Disorders During Pregnancy. Scand J Immunol. 2016; 84:146-49.

12. Knight CL, Nelson-Piercy C. Management of systemic lupus erythematosus during pregnancy: challenges and solutions. Open Access Rheumatol. 2017; 9: 37-53.

13. Buyon JP, Kim MY, Guerra MM, et al. Predictors of Pregnancy Outcomes in Patients With Lupus: A Cohort Study. Ann Intern Med. 2015; 163:153-63.

14. Kim SY, Lee JH. Prognosis of neonates in pregnant women with systemic lupus erythematosus. Yonsei Med J. 2008; 49: 515-20.

15. Kwok LW, Tam LS, Zhu TY, et al. Predictors of maternal and fetal outcomes in pregnancies of patients with systemic lupus erythematosus. Lupus 2011; 20: 829-36.

16. Moroni G, Doria A, Giglio E, et al. Maternal outcome in pregnant women with lupus nephritis. A prospective multicenter study. J Autoimmun. 2016;74:194-200.

17. Bassi N, Ghirardello A, Blank M, et al. IgG anti-pentraxin 3 antibodies in systemic lupus erythematosus. Ann Rheum Dis. 2010; 69:1704-1710.

18. Moroni G, Ponticelli C. Pregnancy in women with systemic lupus erythematosus (SLE). Eur J Intern Med. 2016;32:7-12.

19. Yamamoto Y, Aoki S. Systemic lupus erythematosus: strategies to improve pregnancy outcomes. Int J Womens Health. 2016; 8: 265-72.

20. Kroese SJ, Abheiden CNH, Blomjous BS, et al. Maternal and perinatal outcome in women with Systemic Lupus Erythematosus: A Retrospective Bicenter Cohort Study. J Immunol Res. 2017; 2017:8245879.

21. Davis-Porada J, Kim MY, Guerra MM, et al. Low frequency of flares during pregnancy and post-partum in stable lupus patients. Arthritis Res Ther. 2020; 19;22:52.

22. Wu J, Ma J, Zhang WH, Di W. Management and outcomes of pregnancy with or without lupus nephritis: a systematic review and meta-analysis. Ther Clin Risk Manag. 2018;14:885-901.

23. American College of Obstetricians and Gynecologists' Committee on Practice Bulletins - Obstetrics. Gestational Hypertension and Preeclampsia: ACOG Practice Bulletin, Number 222. Obstet Gynecol. 2020;135:237-60.

24. Borella E, Lojacono A, Gatto M, et al. Predictors of maternal and fetal complications in SLE patients: a prospective study. Immunol Res. 2014; 60: 170-76.

25. Julkunen H. Renal lupus in pregnancy. Scand J Rheumatol Suppl. 1998; 107: 80-83.

26. Dong Y, Yuan F, Dai Z, et al. Preeclampsia in systemic lupus erythematosus pregnancy: a systematic review and meta-analysis. Clin Rheumatol. 2020;39:319-25.

27. Hutcheon JA, Lisonkova S, Joseph KS. Epidemiology of pre-eclampsia and the other hypertensive disoerders of pregnancy. Best Pract Res Clin Obstet Gynaecol. 2011;25:391-403.

28. Smyth A, Oliveira GHM, Lahr BD, et al. A systematic review and meta-analysis of pregnancy outcomes in patients with systemic lupus erythematosus and lupus nephritis. Clin J Am Soc Nephrol. 2010; 5: 2060-68.

29. Tedeschi SK, Massarotti E, Guan H, et al. Specific systemic lupus erythematosus disease manifestations in the six months prior to conception are associated with similar disease manifestations during pregnancy. Lupus. 2015;24:1283-92.

30. Clowse ME, Magder LS, Witter F, et al. The impact of increased lupus activity on obstetric outcomes. Arthritis and rheumatism. 2005; 52: 514-21.

31. Bramham K, Hunt BJ, Bewley S, et al. Pregnancy outcomes in systemic lupus erythematosus with and without previous nephritis. J Rheumatol 2011; 38: 1906-13.

32. Rodríguez-Almaraz ME, Herraiz I, Gómez-Arriaga PI, et al. The role of angiogenic biomarkers and uterine artery Doppler in pregnant women with systemic lupus 
erythematosus or antiphospholipid syndrome. Pregnancy Hypertens. 2018;11:99-104.

33. Soh MC, Nelson-Piercy C. Biomarkers for Adverse Pregnancy Outcomes in Rheumatic Diseases. Rheum Dis Clin North Am. 2017; 43: 201-14.

34. Kim MY, Buyon JP, Guerra MM, et al. Angiogenic factor imbalance early in pregnancy predicts adverse outcomes in patients with lupus and antiphospholipid antibodies: results of the PROMISSE study. Am J Obstet Gynecol. 2016; 214:108.

35. Bassi N, Del Prete D, Ghirardello A, et al. PTX3 AntiPTX3, and Anti-C1q Autoantibodies in Lupus Glomerulonephritis. Clin Rev Allergy Immunol. 2015; 49: 217-26.

36. Gatto M, Ghirardello A, Luisetto R, et al. Immunisation with pentraxin 3 (PTX3) leads to anti-PTX3 antibody production and delayed lupus-like nephritis in NZB/NZW F1 mice. J Autoimmun. 2016; 74: 208-16.

37. Moroni G, Ponticelli C. Important considerations in pregnant patients with lupus nephritis. Expert Rev Clin Immunol. 2018;14:489-98.

38. Tufano A, Coppola A, Maruotti GM, et al. HELLP syndrome and its relation with the antiphospholipid syndrome. Blood Transfus 2014;12: 114-18.

39. Kongwattabakul K, Saksiriwuttho P, Chaiyarach S. et al. Incidence, characteristics, maternal complications, and perinatal outcomes associated with preeclampsia with severe features and HELLP syndrome. Int J Womens Health. 2018;10: 371-77.

40. Moroni G, Doria A, Giglio E, et al. Fetal outcome and recommendations of pregnancies in lupus nephritis in the 21 st century. A prospective multicenter study. J Autoimmun. 2016; 74: 6-12.

41. Nahal SK, Selmi C, Gershwin ME. Safety issues and recommendations for successful pregnancy outcome in systemic lupus erythematosus. J Autoimmun. 2018; 93 : 16-23.

42. Saavedra MA, Sanchez A, Morales S, et al. Primigravida is associated with flare in women with systemic lupus erythematosus. Lupus 2015; 24: 180-5.

43. Gladman DD, Tandon A, Ibañez D, et al. The effect of lupus nephritis on pregnancy outcome and fetal and maternal complications. J Rheumatol. 2010;37:754-8.

44. Clowse ME, Wallace DJ, Weisman M, et al. Predictors of preterm birth in patients with mild systemic lupus erythematosus, Annal. Rheum. Dis. 2013; 72:1536-39.

45. Clark CA, Spitzer KA, Nadler JN, et al. Preterm deliveries in women with systemic lupus erythematosus. J Rheumatol. 2003;30: 2127-32.

46. Clowse ME, Magder LS, Witter F, et al. Early risk factors for pregnancy loss in lupus.Obstet Gynecol. 2006;107:293-9.
47. Guettrot-Imbert G, Le Guern V, Morel N, et al. Systemic Lupus Erythematosus and antiphospholipid syndrome: How to manage pregnancy? Rev Med Interne. 2015; 36:173-81.

48. Clark CA, Spitzer KA, Laskin CA. Decrease in pregnancy loss rates in patients with systemic lupus erythematosus over a 40-year period . J Rheumatol, 2005;32; 1709-12.

49. Kaplowitz ET, Ferguson S, Guerra M, et al. Contribution of Socioeconomic Status to Racial/Ethnic Disparities in Adverse Pregnancy Outcomes Among Women With Systemic Lupus Erythematosus. Arthritis Care Res (Hoboken). 2018; 70: 230-35.

50. Marder W, Littlejohn EA, Somers EC. Pregnancy and autoimmune connective tissue diseases. Best Pract Res Clin Rheumatol. 2016; 30:63-80.

51. Chen D, Lao M, Zhang J, et al. Fetal and Maternal Outcomes of Planned Pregnancy in Patients with Systemic Lupus Erythematosus: A Retrospective Multicenter Study. J Immunol Res. 2018; 2018:2413637.

52. Jara LJ, Medina G, Saavedra MA, et al. Prolactin has a pathogenic role in systemic lupus erythematosus. Immunol Res. 2017; 65:512-23.

53. Costedoat-Chalumeau N, Morel N, Fischer-Betz R, et al. Routine repeated echocardiographic monitoring of fetuses exposed to maternal anti-SSA antibodies: time to question the dogma. Lancet Rheum. 2019; 1:187-93.

54. Bitencourt N, L. Bermas B. Pharmacological Approach to Managing Childhood-Onset Systemic Lupus Erythematosus During Conception, Pregnancy and Breastfeeding . Pediatric Drugs 2018; 20: 211-18.

55. Henderson E, Mackillop L. Prescribing in pregnancy and during breast feeding: using principles in clinical practice. Postgrad Med J. 1027;2011:349-54.

56. Rowe H, Baker T, Hale TW. Maternal medication, drug use, and breastfeeding. Pediatr Clin N Am. 2013;60: 275-94.

57. Tosounidou S, Gordon C. Medications in pregnancy and breatsfeeding. Best Practice \& Research Clincial Obst and Gynecol 2020; 64: 68-76.

58. Giles I, Yee CS, Gordon C. Stratifying management of rheumatic disease for pregnancy and breastfeeding. Nat Rev Rheumatol 2019;15:391-402.

59. Gotestam Skorpen C, Hoeltzenbein M, Tincani A, et al. The EULAR points to consider for use of antirheumatic drugs before pregnancy, and during pregnancy and lactation. Ann Rheum Dis 2016; 75: 795-810.

60. Larosa M, Del Ross T, Calligaro A, et al. Clinical outcomes and predictors of maternal and fetal complications in pregnancies of patients with systemic lupus erythematosus. Expert Rev Clin Immunol. 2019;15 (6):617-27. 


\title{
Artrite reumatoide
}

\author{
Véronique Laure Ramoni \\ U.O.C. Medicina Generale, Ospedale Maggiore di Lodi, A.S.S.T. Lodi, Italia
}

\section{Introduzione}

L'artrite reumatoide (AR) è una malattia reumatica predominante nel genere femminile (rapporto femmine:maschi 3:1) con un esordio che può avvenire anche nelle prime decadi di vita comprendendo pertanto il periodo fertile della donna. È quindi ragionevole aspettarsi di dover affrontare l'argomento del concepimento e della gestazione con le proprie pazienti. La letteratura presenta numerosi studi che hanno indagato gli aspetti riproduttivi, la gravidanza e l'allattamento nelle donne con artrite reumatoide ma anche il neonato esposto alla malattia materna è fonte di notevole interesse.

Con il termine di fertilità si definisce la capacità di concepire, mentre con subfertilità s'intende un tempo di attesa per il concepimento (Time to pregnancy, TTP) superiore a 12 mesi. La fecondità è invece la capacità di dare nascita ad un figlio vivo. A queste definizioni si aggiunge un altro parametro ovvero il numero medio di nati vivi per donna (Total fertility rate, TFR). ${ }^{1}$

L'AR ha sicuramente un impatto sulla sfera riproduttiva in generale, infatti in letteratura viene riportata per queste donne una dimensione famigliare ridotta rispetto a quanto osservato nella popolazione generale. Questa differenza era molto più marcata in passato mentre nelle ultime due decadi si è osservato un incremento del TFR da madri con malattie autoimmuni. ${ }^{2,3}$

Le scelte personali legate alla malattia ed alla paura di un suo peggioramento entrano sicuramente in gioco nella pianificazione famigliare, tuttavia da sole non giustificano la ridotta dimensione famigliare per queste malate. ${ }^{4}$ Esistono infatti anche problemi oggettivi di diminuzione della fertilità: nelle pazienti con AR è stata riscontrata una riduzione della riserva ovarica a cui si

Corrispondente: Véronique Laure Ramoni, U.O.C. Medicina Generale, Ospedale Maggiore di Lodi, A.S.S.T. Lodi, Italia. E-mail: v.ramoni@yahoo.it

Articolo pubblicato secondo la Creative Commons Attribution NonCommercial 4.0 License (CC BY-NC 4.0).

${ }^{\circ}$ Copyright: the Author(s), 2021

Licensee PAGEPress, Italy

QUADERNI - Italian Journal of Medicine 2021; 9(4):e5 accompagna la comparsa di menopausa precoce. Sono stati descritti livelli di ormone anti-mulleriano più bassi soprattutto nelle pazienti con artriti di lunga durata ${ }^{5} \mathrm{a}$ fronte di una normalità di tali livelli nelle donne con artriti iniziali, presupponendo pertanto che la riduzione della riserva ovarica sia secondaria al processo infiammatorio legato alla malattia. ${ }^{6}$ Esiste inoltre un problema di subfertilità osservato, a seconda delle casistiche esaminate, nel $25-43 \%$ delle pazienti rispetto al $9 \%$ nella popolazione generale. ${ }^{7,8}$ La subfertilità sembra essere la maggior causa di ridotto TFR nelle donne con AR mentre solo secondariamente entra in gioco una ridotta fecondità, a differenza di quanto osservato ad esempio nelle pazienti con lupus eritematoso sistemico, dove il TFR è influenzato prevalentemente dalla ridotta fecondità secondaria alla malattia attiva e ad aspetti farmacologici. ${ }^{7-9}$ L'influenza $^{\prime}$ di particolari fasi della malattia o di determinate terapie sulla fertilità è stata indagata anche nelle donne con AR. Dati provenienti da un Registro Olandese mostravano infatti che il $67 \%$ delle donne con una malattia attiva (disease activity score: DAS $28>5,1$ ) avevano un $T T P>12$ mesi rispetto a donne con malattia in remissione (DAS $28<2,6$ ) in cui l'attesa superiore all'anno si osservava solo nel $30 \%$ dei casi. ${ }^{7}$ Anche l'uso di farmaci antireumatici nel periodo pre-concezionale sembra avere un'influenza sul TTP: gli antiinfiammatori non steroidei, ad esempio, agiscono inibendo la produzione di prostaglandine coinvolte nell'ovulazione e nell'impianto della blastocist $\mathrm{i}^{10}$ mentre i corticosteroidi, soprattutto a dosaggio quotidiano superiore a $7,5 \mathrm{mg}$ di prednisone o equivalenti, hanno effetto sulla fertilità dovuto sia alla transitoria soppressione dell'asse ipotalamo-ipofisi-ovaio che all'effetto diretto sulla funzione ovarica e sull'endometrio. ${ }^{11,12}$

Uno stato di infertilità/subfertilità viene confermato anche da un maggior accesso a percorsi di procreazione medicalmente assistita in questo gruppo di donne come portato in evidenza dallo studio condotto da Jawaheer et al. ${ }^{13}$

L'outcome favorevole delle procedure di procreazione assistita, cioè l'evento nascita, è stato indagato nella popolazione danese da Nørgård e colleghi: ${ }^{14}$ questi autori hanno mostrato come anche attraverso la procreazione medicalmente assistita il numero di nati 
vivi per ciascun tranfert embrionario sia inferiore nella popolazione con AR rispetto ai controlli sani, ipotizzando che il problema possa risiedere nella fase di impianto dell'embrione poiché anche la sola gravidanza biochimica viene raggiunta in misura significativamente minore rispetto a quanto osservato nelle donne senza AR. È noto, infatti, che la ricettività endometriale sia uno degli elementi chiave per il successo di queste procedure ed è inoltre accertato che il sistema immunitario giochi un ruolo centrale nel predisporre alla recettività ed all'inizio di una gravidanza. Le terapie utili per migliorare la recettività endometriale sono tutt'oggi oggetto di studio. L'uso dello steroide pre-concezionale, anche se con evidenze da confermare, sembra una possibile opzione per migliorare gli outcomes di queste procedure. I corticosteroidi sono infatti tra i farmaci studiati per le loro potenti proprietà antinfiammatorie ed immunosoppressive anche se i risultati sulla loro reale efficacia nel periodo peri impianto non sono conclusivi. ${ }^{15}$

Restando in ambito farmacologico, il mantenimento della terapia con farmaci inibitori del TNF $\alpha$ sembra condizione favorente il concepimento. Shimada et al. ${ }^{16}$ hanno infatti studiato il TTP in due gruppi di pazienti con AR in terapia con farmaci anti $\mathrm{TNF} \alpha$ ma con diverso timing di sospensione: visita pre-concezionale e gravidanza accertata. Il primo gruppo sperimentava un TTP significativamente maggiorerispetto alle donne che avevano proseguito la terapia, a parità di attività di malattia sia alla visita pre-concezionale che al momento del concepimento. L'ipotesi alla base di questo risultato è che un intervento terapeutico che riduca l'assetto citochinico Th1, incluso il $\mathrm{TNF} \alpha$, possa modificare l'equilibrio Th1/Th2 verso una predominanza Th2, condizione a cui si assiste anche fisiologicamente in gravidanza, e che quindi potrebbe favorire la stessa.

Meno studiato è invece il genere maschile e meno conosciuto è l'impatto della malattia sulla fertilità maschile. I pazienti con AR sembrano avere un più basso livello di testosterone, il cui significato clinico non è tuttavia ancora noto. Certa è invece l'influenza di alcuni farmaci sulla fertilità: la sulfasalazina, ad esempio, può causare oligospermia, ridurre la motilità degli spermatozoi e incrementare le forme atipiche, condizione generalmente reversibile entro 2 mesi dalla sospensione del farmaco. ${ }^{17}$ Non ci sono invece evidenze che FANS, corticosteroidi, methotrexate e farmaci inibitori del TNF $\alpha$ abbiano un reale impatto sulla fertilità maschile; tuttavia, per quanto riguarda il methotrexate, non è stato ancora chiarito il reale impatto del farmaco sulla spermatogenesi e la reale influenza dell'esposizione paterna per quanto riguarda un possibile effetto teratogeno restando ancora valida la raccomandazione di interrompere tale farmaco 3 mesi prima del concepimento. ${ }^{18}$

\section{Outcome materno e gravidico}

Una volta iniziata la gravidanza le pazienti con AR vanno seguite periodicamente sia dal punto di vista ginecologico che da quello reumatologico in modo da valutare sia l'andamento della gravidanza che della malattia. Esiste una stretta correlazione tra queste due entità: in gravidanza, allo scopo di aumentare la tolleranza verso il feto non-self, si assiste ad uno shift dell'assetto immunologico con incremento della produzione di citochine di classe Th2 ed un'inibizione di quelle di classe Th1:19 questa variazione fisiologica porta alla riduzione delle citochine pro-infiammatorie tipiche dell'AR con conseguente tendenza della patologia a risentire positivamente della gravidanza. Studi retrospettivi precedenti gli anni ' 90 mostravano infatti un miglioramento dell'artrite in gravidanza in una percentuale variabile tra il 50-86\% delle donne; ${ }^{20}$ negli ultimi due decenni sono stati condotti diversi studi prospettici che hanno confermato il miglioramento dell'artrite anche se in percentuale nettamente inferiore. ${ }^{21,22}$ Una differenza sostanziale sta nel fatto che gli studi più recenti, oltre ad essere prospettici ed aver incluso pazienti con diversi gradi di attività di malattia, hanno introdotto l'uso di indici di attività di malattia utilizzabili in gravidanza. ${ }^{23}$ L'attività di malattia è stata infatti calcolata con il DAS 28 a tre variabili comprendenti il numero di articolazioni dolenti, il numero di articolazioni tumefatte e il valore di proteina $\mathrm{C}$ reattiva (PCR) ${ }^{24}$ Le variazioni fisiologiche che avvengono in gravidanza, infatti, influenzano sia la VES sia il global health $(\mathrm{GH})$ che pertanto non vanno considerati: la prima tende ad aumentare durante la gravidanza riducendosi nel post-partum mentre un incremento del GH si osserva sia nelle gestanti con artrite che nelle gestanti sane. Lo studio PARA di de Man et al. ${ }^{22}$ ha mostrato che il $48 \%$ di 52 pazienti con DAS28-CRP iniziale $<3,2$ è andato incontro ad un miglioramento durante la gravidanza. Il miglioramento è stato definito come una risposta buona o moderata. Nel terzo trimestre circa il 50\% di tutte le pazienti, incluse quelle con remissione o bassa attività di malattia all'inizio della gravidanza, avevano una malattia attiva (DAS28 $>3,2$ ), mentre il 27\% delle pazienti era in remissione (DAS28<2,6). Questi diversi livelli di miglioramento tra gli studi più recenti e quelli più datati, sono dovuti al fatto che attualmente grazie alle nuove opzioni terapeutiche ed all'approccio treat-to-target, la maggior parte delle pazienti con AR iniziano la gravidanza in una fase di bassa attività di malattia, pertanto anche il margine di miglioramento clinico legato all'effetto della gravidanza si è notevolmente ristretto. Sono stati poi studiati eventuali fattori predittivi di miglior risposta all'evento gravidanza in termini di miglioramento/remissione di malattia; da queste analisi è emerso che le forme di AR sieronegative sembrano andare più facil- 
mente incontro a remissione durante la gravidanza rispetto alle forme con presenza di positività per anticorpi anti citrullina (Anti-citrullinated protein antibodies, $A C P A s$ ) e fattore reumatoide (RA test). ${ }^{25}$

Gli ACPA sono gli autoanticorpi più specifici per l'AR ed il loro titolo non si modifica in corso di gravidanza. ${ }^{25}$ Gli studi approfonditi sui possibili meccanismi eziopatogenetici di questa diversa risposta clinica alla gravidanza si sono concentrati sui processi di galattosilazione degli ACPA IgG: tali processi indotti dalla gravidanza, sembrerebbero correlarsi direttamente ad una riduzione del DAS 28 -PCR. ${ }^{26}$

Il lavoro condotto da Harris et al. ${ }^{27}$ ha invece posto l'attenzione sulla correlazione tra attività di malattia rilevata dalla paziente e presenza di complicanze ostetriche. L'analisi dell'andamento della malattia materna è stata effettuata per mezzo di questionari di autovalutazione (HAQ, VAS dolore, VAS GH, SF36 e questionario di screening per la depressione) compilati da 63 gestanti con AR e 17 con artrite idiopatica giovanile che sono stati poi correlati all'outcome ostetrico. Il peggior stato di salute riportato dalle gestanti si correlava con la comparsa di complicanze ostetriche in particolare con parto pretermine con un odds ratio di 5,9 (CI 95\%, 1,5-23,9); analogamente il riscontro da parte del medico di una malattia attiva si associava alla comparsa di complicanze ostetriche quali parto pretermine e nascita di neonati piccoli per età gestazionale. Questa osservazione è molto interessante in quanto per la prima volta la valutazione della gestante confermava quella del medico e correlava con outcome negativo, diversamente con quanto osservato in altre patologie nelle quali solo la valutazione del medico correlava direttamente con l'outcome ostetrico.

Delicato e anche il periodo post partum: con la fine della gravidanza ed il ripristino del normale assetto immunologico ed ormonale, infatti, la donna può andare incontro ad una riattivazione dell'artrite: la percentuale di flare o riacutizzazione di malattia varia tra il $62 \% \mathrm{e}$ il $90 \%$ in diversi studi retrospettivi mentre sempre lo studio PARA evidenzia un flare post-partum nel 39\% delle pazienti, percentuale inferiore rispetto al passato, giustificata dalla precoce ripresa della terapia. ${ }^{22,28} \mathrm{E}$ interessante notare che anche in seguito ad un aborto si può osservare un flare di malattia in 1/3 delle pazienti. ${ }^{29}$ Il miglioramento dell'AR associato alla gravidanza e l'esacerbazione post-partum sono probabilmente il risultato di molteplici cambiamenti ormonali e immunologici, come già discusso, anche se i meccanismi esatti che sottendono questi fenomeni rimangono sconosciuti.

Una condotta utile per prevenire il flare post-partum potrebbe essere quella di riprendere dopo 1-2 settimane dal parto le terapie sospese nell'ultimo periodo di gravidanza, ad esempio gli inibitori del TNF $\alpha$ che andrebbero sospesi entro la $32^{\mathrm{a}}$ settimana di gestazione. ${ }^{30}$
Come la gravidanza può influenzare l'andamento della malattia, anche la malattia può avere un impatto sull'andamento della gravidanza stessa. L'esito della gravidanza nelle pazienti con AR è infatti leggermente meno favorevole, rispetto a quanto osservato nelle gestanti sane, soprattutto se la malattia è in fase attiva. Vi sono dati discordanti sull'incidenza dell'abortività nelle pazienti con AR. Secondo Brouwer e colleghi ${ }^{29}$ il rischio di un aborto spontaneo nelle donne con AR (17\%) risulterebbe paragonabile a quello osservato nella popolazione generale (11\%-22\%) tuttavia tali risultati sono stati ottenuti valutando una casistica di pazienti selezionate, con gravidanza adeguatamente programmata, libera da terapie potenzialmente teratogene preventivamente modificate. Dati più recenti derivano invece dal Registro Norvegese; in questo caso si osserva un leggero aumento del tasso di aborto nelle donne con AR rispetto alle donne senza una malattia infiammatoria, con un odds ratio di 1,32 (IC 95\%, 1,19-1,47). ${ }^{9}$ Anche il rischio di pre-eclampsia, complicanza relativamente poco frequente della gravidanza fisiologica $(3,4 \%)$, sembra aumentare invece nelle pazienti affette da AR $(5 \%) .{ }^{31}$ Per quanto riguarda invece il rischio di parto pre-termine, definito come nascita di un feto prima delle 37 settimana di gravidanza, risulta anch'esso aumentato nelle pazienti affette da AR $(9,2 \%-15,2 \%)$ rispetto a quanto osservato per le gestanti sane $(6,2 \%-7,8 \%)$ e tra i fattori associati alla prematurità ritroviamo la severità della malattia $\mathrm{e}$ l'utilizzo in gravidanza di glucocorticoidi. ${ }^{32}$ Infine anche la modalità di espletamento del parto risente della presenza della patologia materna: nelle gestanti con AR è stata infatti riscontrata un'incidenza maggiore di parto cesareo (26\%-34\%) rispetto al $16,5 \%$ della popolazione generale, incidenza che varia tuttavia da paese a paese. ${ }^{31}$ Fattore di rischio per l'espletamento del parto chirurgico sembra essere nuovamente l'attività di malattia: de Man et al. ${ }^{32}$ hanno infatti evidenziato che valori di DAS28PCR $>3,2$, indice di malattia attiva, si correlano ad un rischio di parto cesareo del $22 \%$ a fronte di un rischio del $10 \%$ nelle pazienti con più bassa attività di malattia (DAS28-PCR $<3,2$ ). Il mantenimento della terapia con bDMARDs, tipo anti TNF $\alpha$, durante tutta la gravidanza rispetto al loro utilizzo limitato al I trimestre si è mostrato vantaggioso in termini di ridotto rischio di riattivazione di malattia peri-partum o post-partum, senza aver evidenziato nella coorte di pazienti esaminate un aumento delle complicanze ostetriche e neonatali. ${ }^{33}$

Valutando infine il versante neonatale quello che è stato osservato è che i neonati di donne con $\mathrm{AR}$ sono più spesso piccoli per età gestazionale $(10 \%)$ rispetto ai nati da donne sane (3\%). ${ }^{31,34}$ Un più basso peso alla nascita, anche se ancora all'interno dei range di normalità, sembrerebbe nuovamente correlarsi all'attività di malattia materna durante la gravidanza. ${ }^{32}$ Shimada et al. ${ }^{16}$ hanno valutato la correlazione tra esposizione a bDMARDS e outcome ostetrico: su un seppur 
ristretto campione di gestanti con AR le pazienti che hanno eseguito la terapia fino al momento del concepimento hanno dato nascita a neonati con peso alla nascita superiore a quello rilevato nelle gestanti che avevano interrotto le terapia alla valutazione pre-concezionale. Non si sono evidenziate invece differenze in termini di abortività, parto pretermine, rottura prematura di membrane e neonati piccoli per età gestazionale (small for gestational age, SGA). L'esposizione a corticosteroidi si rivelava importante, infatti la dose media era significativamente più alta nelle donne che avevano avuto parto pretermine e neonati $S G A$ ( $\mathrm{P}=0,02$ e $\mathrm{P}<0,01$ rispettivamente). ${ }^{16}$

\section{Gestione farmacologica in ambito riproduttivo}

La pianificazione di una gravidanza così come la gestione della stessa non può prescindere dagli aspetti terapeutici. La terapia, infatti, deve essere attentamente valutata alla luce del desiderio di maternità considerando appunto il fatto che da una parte deve servire a controllare la malattia ma deve anche essere compatibile con la gravidanza. La sospensione della terapia al concepimento porta infatti con sé la possibilità di una riacutizzazione della malattia, con uno stato pro-infiammatorio che come già lungamente detto si associa ad un peggior outcome ostetrico.

Le opzioni terapeutiche compatibili con la gravidanza esistono e spaziano dai corticosteroidi, ad alcuni sDMARDs, ai farmaci biotecnologici in particolare gli inibitori del TNF $\alpha$. Numerose sono le linee guida a cui far riferimento per il loro corretto utilizzo: quelle della The British Society for Rheumatology (BSR) e dell'European League Against Rheumatism (EULAR). ${ }^{35,36}$

Alcuni farmaci, infatti, devono essere sospesi per i noti effetti teratogeni: primo tra tutti il methotrexato la cui sospensione deve avvenire 3 mesi prima del concepimento ma anche la leflunomide alla cui sospensione pre-concezionale, 2 anni, dovrebbe seguire anche il wash-out con colestiramina. L'aiuto più grande per la gestione delle artriti in gravidanza deriva dall'uso di idrossiclorochina, sulfasalazina, ciclosporina e dai farmaci biotecnologici anti-TNF $\alpha$. Questi ultimi sono in grado di controllare la malattia e vengono considerati compatibili con gravidanza ed allattamento. Il passaggio transplacentare di questi farmaci è stato studiato nel 2013 da Mahadevan et al. ${ }^{37}$ che hanno analizzato infliximab, adalimumab e certolizumab pegol in 31 gestanti affette da malattia infiammatoria cronica intestinale esposte a tali farmaci ricercando la loro concentrazione nel sangue cordonale, nel sangue del neonato e confrontandola con quella rilevata nella circolazione materna. Gli anticorpi materni, infatti, al fine di garantire un'immunità al neonato, sono trasportati attivamente attraverso i villi coriali per mezzo dai recettori neonatali per l'Fc. Le IgG1 sono la sottoclasse di immunoglobuline trasportate con più efficacia e la loro concentrazione aumenta in modo esponenziale dalla fine del secondo trimestre fino al parto, con la maggior parte degli anticorpi che passano nella circolazione fetale durante il terzo trimestre. La concentrazione nel sangue cordonale di infliximab e adalimumab è risultata superiore alla concentrazione degli stessi nella circolazione materna ( $160 \%$ e $179 \%$ rispettivamente) mentre tale concentrazione è risultata inferiore a quella materna per il Certolizumab pegol (3.9\%). Tale risultato è infatti giustificato dal fatto che mentre adalimumab ed infliximab sono entrambi anticorpi IgG1 completi e pertanto trasportati attivamente attraverso la barriera placentare, mentre Certolizumab pegol, privo del frammento Fc dell'immunoglobulina, viene trasferito alla circolazione fetale per diffusione passiva. Due studi di farmacocinetica, studio CRIB e studio CRADLE, hanno poi confermato rispettivamente che le concentrazioni plasmatiche di Certolizumab pegol erano al di sotto del limite di quantificazione in 13/14 campioni alla nascita e in tutti i campioni a 4 e 8 settimane dal parto e che il trasferimento della molecola dal plasma al latte materno si è rivelato trascurabile/assente, confermando la sicurezza di tale farmaco durante tutta la gravidanza e l'allattamento. ${ }^{38,39}$

Le linee guida internazionali consigliano quindi la sospensione di Adalimumab ed Etanercept alla fine del secondo trimestre mentre Infliximab entro la $16^{\text {a }}$ settimana di gestazione e la possibilità di proseguire invece con certolizumab pegol per tutta la gravidanza. Per quanto riguarda gli altri farmaci biotecnologici anti$\mathrm{TNF} \alpha$ le linee guida EULAR indicano la sospensione alla $32^{\mathrm{a}}$ settimana per etanercept mentre per golimumab possibile utilizzo in gravidanza ma sicurezza limitata dall'esiguità dei dati. Cautela per scarsità di dati anche per gli altri farmaci biotecnologici quali abatacept, tocilizumab, rituximab, sekukinumab, ustekinumab. ${ }^{36}$ Rituximab secondo linee guida andrebbe sospeso 6 mesi prima del concepimento mentre Tolicilizumab 3 mesi prima. Secondo linee guida EULAR invece la sospensione di tofacitinib dovrebbe avvenire 2 mesi prima del concepimento e tale farmaco deve essere evitato in allattamento. ${ }^{36}$ Non dimentichiamo tuttavia che anche i farmaci consentiti possono avere degli effetti collaterali anche sulla gravidanza come testimoniano i dati dello studio di Palmster et al. in cui la dose cumulativa di steroide assunta dal concepimento correla inversamente con la settimana gestazionale al parto a conferma del rischio di parto pretermine che può in parte essere legato alla patologia materna ma che può anche dipendere dalle terapie in corso. ${ }^{40}$

\section{Outcome neonatale}

Una delle domande frequenti che vengono poste al proprio medico reumatologo durante il colloquio pre- 
concezionale o durante la gravidanza riguarda il nascituro ed $i$ rischi per la sua salute in relazione alla malattia materna.

Lo studio di dati nazionali derivanti dal registro danese ha mostrato come i figli di madri con AR hanno un maggior rischio di sviluppare distiroidismi, epilessia durante l'infanzia e l'adolescenza e un aumentato rischio di sviluppare l'AR rispetto ai coetanei non esposti rispettivamente con un hazard ratio (HR) di 2,19 (95\% CI $1,14-4,21), 1,61(95 \%$ CI $1,16-2,25)$ e $2,89(95 \%$ CI $2,06-4,05) \cdot{ }^{41}$

Dallo stesso registro è stato studiato il possibile sviluppo dei disordini dello spettro autistico (autism spectrum disorder, ASD) su tutti i nati vivi tra il 1977 ed il 2008 da madri e/o padri affetti da artrite AR. La presenza della malattia in uno dei due genitori si associa ad un rischio del $30 \%$ di sviluppare un ASD con un HR da esposizione materna di 1,31 (95\% CI 1,06$1,63)$ e paterna di $1,33(95 \%$ CI $0,97-1,82)$ suggerendo che non solo l'esposizione in utero a fattori immunologici materni ma anche fattori genetici associati all'artrite possano essere coinvolti dal punto di vista eziopatogenetico nello sviluppo di questi disturbi. È stato infatti dimostrato che i soggetti con AR e ASD condividono un HLA-DRB01*04* quale predisposizione genetica comune. . $^{42-44}$

L'esposizione in utero a terapie, in particolare a farmaci anti $\mathrm{TNF} \alpha$, è stata indagata per verificare se tali terapie determinassero o meno uno stato immunosoppressivo nel neonato. L'analisi del numero di ospedalizzazione per eventi infettivi è stata analizzata in tre gruppi di neonati: nati da madri con AR esposti e non esposti in utero a terapia con anti TNFa, e neonati di gestanti sane. Nei primi 12 mesi di vita il numero di ospedalizzazioni non è risultato differente nei tre gruppi di neonati a testimoniare l'assenza di un franco rischio infettivo nei neonati esposti in utero a bDMARDs anti-TNF $\alpha .{ }^{45}$

Sempre correlato al rischio infettivo si ricorda il warning legato alla somministrazione di vaccini vivi attenuati nei neonati esposti in utero a bDMARDs antiTNFa: nel 2010 veniva infatti riportato il caso di un neonato esposto in utero ad infliximab per malattia infiammatoria cronica intestinale materna, nato sano e deceduto a causa di tubercolosi disseminata sviluppatasi dopo somministrazione di vaccino $\mathrm{BCG}$ al terzo mese di vita ${ }^{46} \mathrm{La}$ somministrazione di vaccini vivi attenuati va quindi posticipata a dopo il compimento del $7^{\circ}$ mese di vita del neonato.

In conclusione, la gravidanza nelle donne affette da $\mathrm{AR}$ è un evento possibile e non raro. Fondamentale è la sua pianificazione, che consiste soprattutto nell'attendere una fase di remissione/bassa attività di malattia ottenuta per mezzo di terapie compatibili con la gravidanza, terapie che non andranno interrotte ove possibile. Queste condizioni insieme ad una gestione multidisciplinare risultano fondamentali per il controllo della malattia materna e si correlano con un miglior outcome gestazionale.

\section{Bibliografia}

1. Zegers-Hochschild F, Adamson GD, Dyer S, et al. The International Glossary on Infertility and Fertility Care, 2017. Fertil Steril. 2017;108:393-406.

2. Wallenius M, Salvesen KA, Daltveit AK, et al. Reproductive trends in females with inflammatory joint disease. BMC Pregnancy Childbirth. 2016;16:123.

3. Wallenius M, Salvesen KÅ, Daltveit AK, et al. Secular trends of pregnancies in women with inflammatory connective tissue disease. Acta Obstet Gynecol Scand. 2015;94:1195-202.

4. Clowse ME, Chakravarty E, Costenbader KH, et al. Effects of infertility, pregnancy loss, and patient concerns on family size of women with rheumatoid arthritis and systemic lupus erythematosus. Arthritis Care Res (Hoboken) 2012;64:668-74.

5. Henes M, Froeschlin J, Taran FA, et al. Ovarian reserve alterations in premenopausal women with chronic inflammatory rheumatic diseases: impact of rheumatoid arthritis, Behcet's disease and spondyloarthritis on antiMullerian hormone levels. Rheumatology (Oxford) 2015;54:1709-12.

6. Brouwer J, Laven JS, Hazes JM, et al. Levels of serum anti-Mullerian hormone, a marker for ovarian reserve, in women with rheumatoid arthritis. Arthritis Care Res (Hoboken) 2013;65:1534-8.

7. Brouwer J, Hazes JM, Laven JS, et al. Fertility in women with rheumatoid arthritis: influence of disease activity and medication. Ann Rheum Dis 2015;74:1836-41.

8. Brouwer J, Fleurbaaij R, Hazes JMW, et al. Subfertility in Women With Rheumatoid Arthritis and the Outcome of Fertility Assessments. Arthritis Care Res (Hoboken) 2017;69:1142-9.

9. Wallenius M, Salvesen KA, Daltveit AK, et al. Miscarriage and stillbirth in women with Rheumatoid Arthritis. J Rheumatol 2015;42:1570-2.

10. Provost M, Eaton JL, Clowse ME. Fertility and infertility in rheumatoid arthritis. Curr Opin Rheumatol 2014;26:308-14.

11. Saketos M, Sharma N, Santoro NF. Suppression of the hypothalamic-pituitary-ovarian axis in normal women by glucocorticoids. Biol Reprod 1993;49:1270-6.

12. Whirledge S, Cidlowski JA. A role for glucocorticoids in stress-impaired reproduction: beyond the hypothalamus and pituitary. Endocrinology 2013;154:4450-68.

13. Jawaheer D, Zhu JL, Nohr EA, et al. Time to pregnancy among women with rheumatoid arthritis. Arthritis Rheum. 2011;63:1517-21.

14. Nørgård BM, Larsen MD, Friedman S, et al. Decreased chance of a live born child in women with rheumatoid arthritis after assisted reproduction treatment: a nationwide cohort study. Ann Rheum Dis. 2019;78:328-34.

15. Robertson SA, Jin M, Yu D, et al. Corticosteroid therapy in assisted reproduction-immune suppression is a faulty premise. Human reprod 2016;31:2164-73.

16. Shimada H, Kameda T, Kanenishi K, et al. Effect of bi- 
ologic disease-modifying anti-rheumatic drugs for patients with rheumatoid arthritis who hope to become mothers. Clin Rheumatol. 2019;38:1453-8.

17. O'Morain C, Smethurst P, Dore CJ, et al. Reversible male infertility due to sulphasalazine: studies in man and rat. Gut 1984;25:1078-84.

18. Gutierrez JC, Hwang K. The toxicity of methotrexate in male fertility and paternal teratogenicity. Expert Opin Drug Metab Toxicol. 2017;13:51-8.

19. Doria A, Iaccarino L, Arienti S. Th2 immune deviation induced by pregnancy: The two faces of autoimmune rheumatic diseases. Reprod Toxicol 2006;22:234-41.

20. Nelson JL, Ostensen M. Pregnancy and rheumatoid arthritis. Rheum Dis Clin North Am. 1997;23:195-212.

21. Barrett JH, Brennan P, Fiddler M, et al. Does rheumatoid arthritis remit during pregnancy and relapse post-partum? Results from a nationwide study in the United Kingdom performed prospectively from late pregnancy. Arthritis Rheum 1999;42:1219-27.

22. de Man YA, Dolhain RJ, van de Geijn FE, et al. Disease activity of rheumatoid arthritis during pregnancy: result from a nationwide prospective study. Arthritis Rheum 2008;59:1241-8.

23. Andreoli L, García-Fernández A, Gerardi MC, et al. The Course of Rheumatic Diseases During Pregnancy. IMAJ 2019;21:464-70

24. de Man YA, Hazes JM, van de Geijn FE, et al. Measuring disease activity and functionality during pregnancy in patients with rheumatoid arthritis. Arthritis Rheum 2007; 57:716-22.

25. de Man YA, Bakker-Jonges LE, Goorbergh CM, et al. Women with rheumatoid arthritis negative for anti-cyclic citrullinated peptide and rheumatoid factor are more likely to improve during pregnancy, whereas in autoantibody-positive women autoantibody levels are not influenced by pregnancy. Ann Rheum Dis 2010;69:420-3.

26. Bondt A, Hafkenscheid L, Falck D, et al. ACPA IgG galactosylation associates with disease activity in pregnant patients with rheumatoid arthritis, Ann Rheum Dis 2018;77:1130-6.

27. Harris N, Eudy A, Clowse MB. Patient-reported disease activity and adverse pregnancy outcomes in systemic lupus erythematosus and rheumatoid arthritis. Arthritis Care Res (Hoboken) 2019;71:390-7.

28. Ostensen M, Aune B, Husby G. Effect of pregnancy and hormonal changes on the activity of rheumatoid arthritis. Scand J Rheumatol 1983;12:69-72.

29. Brouwer J, Laven JS, Hazes JM, et al. Brief report: miscarriages in female rheumatoid arthritis patients: associations with serologic findings, disease activity, and antirheumatic drug treatment. Arthritis Rheumatol 2015;67:1738-43.

30. Clowse MEB. It Is Time to Modify Treatment to Enable More Women with Rheumatoid Arthritis to Have Successful Pregnancies. J Rheumatol 2019;46:223-5.

31. Norgaard M, Larsson H, Pedersen L, et al. Rheumatoid arthritis and birth outcomes: a Danish and Swedish nationwide prevalence study. J Intern Med 2010;268: 329-37.

32. de Man YA, Hazes JM, van der Heide H, et al. Association of higher rheumatoid arthritis disease activity during pregnancy with lower birth weight: results of a national prospective study. Arthritis Rheum 2009;60:3196-206.

33. Genest G, Spitzer KA, Laskin CA. Maternal and fetal outcomes in a cohort of patients exposed to tumor necrosis factor inhibitors throughout pregnancy. J Rheumatol.2018;45.1109-15.

34. Bharti B, Lee SJ, Lindsay SP, et al. Disease severity and pregnancy outcomes in women with rheumatoid arthritis: results from the organization of teratology information specialists autoimmune diseases in pregnancy project. $\mathrm{J}$ Rheumatol 2015;42:1376-82.

35. Flint J, Panchal S, Hurrell A, et al. on behalf of the BSR and BHPR Standards, Guidelines and Audit Working Group BSR and BHPR guideline on prescribing drugs in pregnancy and breastfeeding-Part I: standard and biologic disease modifying anti-rheumatic drugs and corticosteroids. Rheumatology (Oxford) 2016;55:1693-7.

36. Götestam Skorpen C, Hoeltzenbein M, Tincani A, et al. The EULAR points to consider for use of antirheumatic drugs before pregnancy, and during pregnancy and lactation. Ann Rheum Dis 2016;75:795-810.

37. Mahadevan U, Wolf DC, Dubinsky M, et al. Placental transfer of Anti-Tumor Necrosis Factor Agents in pregnant patients with inflammatory bowel disease. Clin Gastroenterol Hepatol. 2013;11:286-92.

38. Mariette X, Forger F, Abraham B, et al. Lack of placental transfer of certolizumab pegol during pregnancy: results from CRIB, a prospective, postmarketing, pharmacokinetic study. Ann Rheum Dis 2018;77:228-33.

39. Clowse MEB, Förger F, Hwang C, et al. Minimal to no transfer of certolizumab pegol into breast milk: results from CRADLE, a prospective, postmarketing, multicentre, pharmacokinetic study. Ann Rheum Dis 2017;76: 1890-6.

40. Palmsten K, Rolland M, Hebert MF, et al. Pharmacoepidemiol Drug Saf. 2018;27:430-8.

41. Jølving LR, Nielsen J, Kesmodel US, et al. Children Born by Women With Rheumatoid Arthritis and Increased Susceptibility for Chronic Diseases: A Nationwide Cohort Study. Arthritis Care Res 2018;70:1192-7.

42. Fries JF, Wolfe F, Apple R, et al. HLA-DRB1 genotype associations in 793 white patients from a rheumatoid arthritis inception cohort: frequency, severity, and treatment bias. Arthritis Rheum. 2002;46:2320-9.

43. Johnson WG, Buyske S, Mars AE, et al. HLA-DR4 as a risk allele for autism acting in mothers of probands possibly during pregnancy. Arch Pediatr Adolesc Med. 2009;163:542-6.

44. Rom AL, Wu CS, Olsen J, et al. Parental Rheumatoid Arthritis and Autism Spectrum Disorders in Offspring: A Danish Nationwide Cohort Study. J Am Acad Child Adolesc Psychiatry 2018;57:28-32.

45. Vinet E, De Moura C, Pineau CA et al. Serious infections in Rheumatoid Arthritis offspring exposed to tumor necrosis factor inhibitors: a cohort study. Arthritis Rheumatol. 2018.70:1565-71.

46. Cheent K, Nolan J, Shariq S, et al. Case report: fatal case of disseminated BCG infection in an infant born to a mother taking infliximab for Crohn's disease. J Crohns Colitis 2010;4:603-5. 


\title{
Sindrome da anticorpi anti-fosfolipidi in gravidanza e puerperio
}

\author{
Maria Chiara Gerardi, Cecilia Nalli, Daniele Lini, Angela Tincani
}

Unità Operativa di Reumatologia e Immunologia Clinica, ASST-Spedali Civili, Brescia; Dipartimento di Scienze Cliniche e Sperimentali, Università degli Studi di Brescia, Italia

\section{Introduzione}

La sindrome da anticorpi anti-fosfolipidi (APS) è una patologia autoimmune sistemica caratterizzata clinicamente da eventi trombotici (venosi e/o arteriosi) e/o perdite della gravidanza in associazione alla positività per gli anticorpi antifosfolipidi. I tre test raccomandati per la ricerca di tali anticorpi sono il lupus anticoagulante, gli anticorpi anti-cardiolipina e gli anticorpi anti32 Glicoproteina I. ${ }^{1}$ L'APS può essere primaria, in pazienti senza alcuna manifestazione clinica di altre patologie autoimmuni sistemiche, ${ }^{2}$ o secondaria se associata ad altra patologia reumatica, prima fra tutte il lupus eritematoso sistemico, con cui l'APS ha una stretta relazione dal punto di vista clinico, sierologico e genetico. ${ }^{3}$ In base alle manifestazioni cliniche prevalenti possiamo distinguere una APS trombotica in pazienti con precedenti eventi trombotici, una APS puramente ostetrica in pazienti con storia di complicanze ostetriche senza eventi trombotici e i cosiddetti aPL carriers, individui con persistente positività per uno o più $\mathrm{aPL}$ in assenza di manifestazioni cliniche della APS. ${ }^{4}$

La patologia ostetrica associata alla APS è costituita da: i) 3 o più aborti consecutivi prima della $10^{\mathrm{a}}$ settimana di gestazione; ii) 1 o più perdite fetali dopo la $10^{\text {a }}$ settimana di gestazione di un feto morfologicamente sano; iii) 1 o più parti pretermine di un neonato morfologicamente sano prima della $34^{\text {a }}$ settimana di gestazione per eclampsia o pre-eclampsia severa o per documentata insufficienza placentare.

Corrispondente: Angela Tincani, Unità Operativa di Reumatologia e Immunologia Clinica, ASST-Spedali Civili, Brescia, piazzale degli Spedali Civili 1, 25123 Brescia, Italia.

Tel.: +39.030.3995487; +39.030.3995488.

Fax: +39.030 .3995085$

E-mail: angela.tincanil@unibs.it

Articolo pubblicato secondo la Creative Commons Attribution NonCommercial 4.0 License (CC BY-NC 4.0).

${ }^{\circ}$ Copyright: the Author(s), 2021

Licensee PAGEPress, Italy

QUADERNI - Italian Journal of Medicine 2021; 9(4):e6
L'associazione tra aPL e complicanze ostetriche è comprovata da diversi studi epidemiologici e da modelli sperimentali nei quali il trasferimento passivo di aPL di classe IgG induce perdita fetale e ritardo di crescita intrauterino in topine gravide. ${ }^{5}$ Sono stati ipotizzati tre meccanismi che intervengono nella patogenesi delle complicanze ostetriche in pazienti con APS: trombosi della placenta, deficit di placentazione e infiammazione. L'espressione della $\beta 2$ GPI sulle membrane cellulari del trofoblasto spiega il trofismo degli anticorpi anti- $\beta 2$ GPI per la placenta. Essendo una proteina plasmatica cationica, la $\beta 2$ GPI è in grado di legare la fosfatidilserina espressa sulla membrana cellulare del trofoblasto che sta formando il sincizio. ${ }^{6}$ È oggi riconosciuto che il principale bersaglio degli aPL sia la $\beta 2 \mathrm{GPI}$, pertanto questa viene riconosciuta e legata dagli anticorpi alla superficie del trofoblasto. Conseguentemente, anche attraverso la attivazione dei meccanismi di flogosi scatenati dalla reazione anticorpale, gli aPL assumono un ruolo patogenetico nell' impedire lo sviluppo fisiologico del trofoblasto e causando, in ultima analisi, una alterata placentazione che può essere alla base delle complicanze ostetriche dell'APS.

Alla luce di quanto detto finora e dello stato trombofilico caratteristico della gravidanza e del puerperio anche nella popolazione generale, la gestione di questi periodi nelle pazienti con APS richiede una attenzione particolare. È importante che il reumatologo/internista affiancato dal ginecologo e dal neonatologo (ed eventualmente da altri specialisti) accompagnino la paziente dal counselling preconcezionale per tutta la gravidanza fino al puerperio e, se necessario, nel percorso attraverso le tecniche di riproduzione medicalmente assistita (PMA). ${ }^{7}$

\section{Counselling preconcezionale}

Nel momento stesso in cui una donna desidera avere un figlio, nasce in lei il desiderio che tutto proceda nel migliore dei modi e accanto a questo nascono preoccupazioni per il benessere del nascituro. Questo vale per qualunque donna intenda programmare una gravidanza, ma assume un significato del 
tutto particolare se questa stessa donna è affetta da APS, considerato l'aumentato rischio di complicanze ostetriche e di perdite della gravidanza legato a questa condizione. Diventa perciò fondamentale il counselling preconcezionale, che ha permesso negli ultimi anni di migliorare significativamente l'esito gestazionale di queste pazienti consentendoci, oggi, di trasmettere un messaggio ragionevolmente rassicurante alle future mamme.

Il primo passo è una stratificazione del rischio individuale a partire dal profilo anticorpale di ogni paziente (Tabella 1). Possiamo suddividere, infatti, le pazienti in due principali categorie di rischio a seconda della positività anticorpale: ${ }^{8}$ i) pazienti ad alto rischio: quando presente e persistente nel tempo positività per il LA, duplice positività (la positività di due test per gli aPL), la triplice positività per aPL (cioè positività di tutti e tre $\mathrm{i}$ test per la ricerca degli aPL), o la positività persistente per gli aPL ad alto titolo; ii) pazienti a basso rischio: isolata positività per gli $\mathrm{aCL}$ o gli anti- $\beta 2 \mathrm{GPI}$, soprattutto se transitori.

Attraverso l'anamnesi è importante distinguere tra pazienti con manifestazioni cliniche (trombotiche e/o ostetriche) e donne asintomatiche ma con persistente positività per gli aPL, le $a P L$ carriers. Tra le prime è bene definire numero, tempi e tipologia delle complicanze ostetriche e degli eventi trombotici, indagando anche eventuali manifestazioni non-criterio dell'APS (es. piastrinopenia, livaedo reticularis, valvulopatia). ${ }^{7,9}$ In tutte le pazienti, allo screening, sarà necessario indagare segni clinici e laboratoristici (un pannello completo per l'autoimmunità, inclusi i livelli delle frazioni $\mathrm{C} 3$ e C4 del complemento), per verificare se l'APS risulti associata ad altra patologia reumatica autoimmune o se presenta solo note di autoimmunità lupus-like. In caso di APS associata ad altra patologia reumatica andrà effettuata una attenta valutazione dell'attività di malattia materna. ${ }^{7}$

Ovviamente andranno considerati tutti gli altri eventuali fattori di rischio ostetrici, come la presenza di trombofilia congenita, coinvolgimento d'organo maggiore, tireopatie, età avanzata, stili di vita nocivi (fumo e consumo alcolico) e l'assunzione di eventuali farmaci potenzialmente teratogeni.

Il secondo passo consiste nel programmare un percorso di cura durante la gravidanza e il puerperio individuando strategie terapeutiche personalizzate. Entrambi gli aspetti dovrebbero essere specifici e condivisi con ogni paziente, considerando i rischi sopra elencati, sia personali che legati alla patologia. In associazione all'acido acetilsalicilico a basse dosi (low-dose aspirin, LDA) e all'eparina che saranno discussi in dettaglio nelle sezioni successive, in tutte le pazienti, come nella popolazione ostetrica generale, è raccomandata l'assunzione di acido folico dal pre-

Tabella 1. Stratificazione del rischio in una paziente con sindrome da anticorpi anti-fosfolipidi con desiderio di gravidanza o in gravidanza.

\section{Fattori di rischio materni}

Pregresse complicanze gravidiche:

Aborti, morti endouterine, pre-eclampsia/eclampsia, sindrome HELLP, parto pretermine, IUGR e neonati con SGA

Pregresse trombosi:

Numero, sede, venose o arteriose

Profilo aPL:

Isotipo e titolo del LA, aCL, anti- $\beta 2 \mathrm{GPI}{ }^{*}$

Profilo ad alto rischio': positività per il LA; 'duplice positività' - LA+aCL o LA+ anti- $\beta 2$ GPI o aCL+

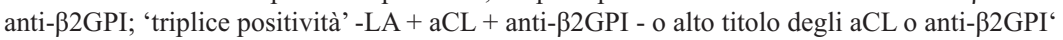
Profilo a basso rischio’: positività isolata, transitoria degli aCL o anti- $\beta 2 \mathrm{GPI}$ a basso-medio titolo

\begin{tabular}{ll}
\hline Manifestazioni non-criterio: & Trombocitopenia, anemia autoimmune \\
\hline Trombofilia congenita: & $\begin{array}{l}\text { Deficit proteina C, proteina S e antitrombina; fattore V Leiden, mutazione gene PT 20210 e MTHFR; } \\
\text { iperomocisteinemia }\end{array}$ \\
\hline Impegno d'organo maggiore: & $\begin{array}{l}\text { Impegno cardiaco, polmonare, renale, e del SNC (es. ipertensione polmonare severa, insufficienza renale } \\
\text { severa, attacco ischemico) }\end{array}$ \\
\hline Comorbilità materne: & Età avanzata, ipertensione arteriosa, diabete, tireopatie, sovrappeso/obesità \\
\hline Stili di vita nocivi: & Fumo, alcool e sostanze d'abuso \\
\hline Se associata ad altre patologie autoimmuni: \\
\hline Attività di malattia: & Paziente in remissione o malattia stabile nei 6-12 mesi precedenti \\
\hline Autoanticorpi: & Anti-Ro/SS-A e anti-La/SS-B \\
\hline Sierologia: & Valori sierici di C3/C4, titolo anti-dsDNA \\
\hline Farmaci teratogeni: & Metotressato, micofenolato, ciclofosfamide \\
\hline
\end{tabular}

aPL, anticorpi anti-fosfolipidi; sindrome HELLP, hemolysis, elevated liver enzyme levels, low platelet count; IUGR, intrauterine growth restriction - ritardo di crescita intrauterino; SGA, small-for-gestational-age - bambini piccoli per età gestazionale; LA, lupus anticoagulant; aCL, anticorpi anti-cardiolipina; anti- $\beta 2 \mathrm{GPI}$, anticorpi anti- $\beta 2 \mathrm{Gliproteina} \mathrm{I;} \mathrm{PT,} \mathrm{pro-}$ trombina; MTHFR, metilenetetraidrofolato reduttasi; SNC, sistema nervoso centrale. 
concezionale, e di calcio e vitamina $\mathrm{D}$ durante la gravidanza. ${ }^{7}$ Alcune situazioni, come un recente evento trombotico (specialmente se arterioso) o una malattia reumatica attiva, possono esporre la paziente a un aumentato rischio di complicanze materno-fetali per cui in questi casi è bene consigliare di posticipare la gravidanza di almeno 6 mesi. ${ }^{10}$ In presenza, invece, di impegno d'organo severo (ipertensione polmonare severa, insufficienza renale severa, interstiziopatia polmonare severa) la gravidanza potrebbe essere controindicata per il rischio aumentato di complicanze materne anche fatali. ${ }^{10,11}$

\section{Gestione della gravidanza}

È importante che durante la gravidanza la paziente sia seguita collegialmente da un gruppo multidisciplinare che includa oltre ai reumatologi/internisti anche i ginecologi ed eventuali altri specialisti di volta in volta necessari. Il parto dovrebbe essere programmato fin da subito in un centro dotato di terapia intensiva neonatale per la nota alta frequenza di possibili parti pretermine.

Il management della gravidanza prevede controlli clinici/laboratoristici possibilmente mensili non solo da parte degli ostetrici ginecologi ma anche da parte dei reumatologi/internisti. Tra gli esami da rivalutare almeno trimestralmente andrebbe incluso anche il dosaggio delle frazioni del complemento, i cui livelli sierici aumentano fisiologicamente in gravidanza. Il mancato incremento fisiologico di $\mathrm{C} 3 \mathrm{e} / \mathrm{o} \mathrm{C} 4$ è stato associato, infatti, al verificarsi di eventi ostetrici indesiderati. ${ }^{12}$

Anche lo screening ecografico ai vari trimestri di gestazione appare imprescindibile e va eventualmente integrato nel terzo trimestre con una valutazione Doppler, mensile, delle arterie uterine e della arteria ombelicale. Questo esame è indispensabile per valutare eventuali ritardi di crescita intrauterina (IUGR) e poter così decidere con la paziente la tempistica del parto più corretta.

Ovviamente in tutte le pazienti va attentamente monitorata la pressione arteriosa che, unitamente al controllo della proteinuria nelle 24 ore diventa imprescindibile nelle pazienti con coinvolgimento renale di malattia e/o disordini ipertensivi. ${ }^{7}$

Il trattamento della gravidanza nelle donne positive per gli aPL andrà individualizzato in base al profilo laboratoristico (profilo aPL a basso o alto rischio) e clinico (complicanze ostetriche, trombosi, associazione con altre patologie autoimmuni, manifestazioni non-criterio). In base a tali fattori nelle sezioni successive discuteremo della gestione della gravidanza nelle pazienti con o-APS, t-APS, APS associata ad altre patologie autoimmuni e nelle donne aPL carriers.

\section{o-sindrome da anticorpi anti-fosfolipidi}

Le gravidanze delle pazienti con APS possono complicarsi con aborti precoci ricorrenti o perdite fetali tardive. Va precisato però che gli aborti precoci, avvenuti entro la $10^{\mathrm{a}}$ settimana di gestazione, sono comuni anche nella popolazione ostetrica generale, con una frequenza stimata del 10-15\%. Circa il 6\% delle pazienti che vanno incontro ad aborto precoce sono portatrici di aPL. ${ }^{13}$ Prima di attribuire la poliabortività precoce alla presenza degli autoanticorpi è necessario escludere altre cause più frequenti, come le anomalie cromosomiche, le anomalie anatomiche uterine, l'insufficienza luteale, le infezioni cervicali e le disfunzioni tiroidee materne. ${ }^{14}$ Le perdite fetali tardive, oltre la $10^{\mathrm{a}}$ settimana di gestazione, sono manifestazioni più̀ specifiche per la definizione della APS. ${ }^{14}$ Le donne che presentano positività per gli aPL possono avere gravidanze complicate dall'insufficienza placentare e dalla pre-eclampsia, entrambe responsabili di IUGR e parto pretermine. La pre-eclampsia precoce (prima della $34^{a}$ settimana) e severa, è considerata una complicanza tipica della APS e come tale rientra nei criteri classificativi della sindrome; da tempo è stata sottolineata la sua associazione in particolare con gli anticorpi anti$\beta 2$ GPI. ${ }^{15}$ Lo sviluppo della sindrome HELLP è più precoce nelle pazienti con APS rispetto alla popolazione generale, presentandosi prevalentemente nel secondo trimestre. La pre-eclampsia e l'insufficienza utero-placentare con conseguente IUGR possono spiegare l'alta percentuale di parti pretermine nelle pazienti con APS. La prematurità, infatti, sembra essere la più frequente complicanza neonatale delle gravidanze. ${ }^{16} \mathrm{Di}$ qui la già citata necessità di parto in centri attrezzati per i prematuri. Oggi, grazie all'introduzione della terapia combinata con LDA ed eparina, la maggior parte delle gravidanze ha un esito favorevole anche se le complicanze ostetriche legate all'APS non sono state cancellate. ${ }^{17}$ Nelle pazienti con o-APS (in assenza di eventi trombotici) si raccomanda eparina a dosaggio profilattico (eparina non frazionata, unfractionated heparin - UFH- o eparina a basso peso molecolare, low molecular weight heparin - LMWH) in associazione a LDA (100 mg/die) ${ }^{7,8}$ Per ragioni pratiche, si preferisce, quando possibile, la $\mathrm{LMWH} .{ }^{7,8} \mathrm{La}$ LDA deve essere preferibilmente iniziata nel periodo preconcezionale e la UFH/LMWH dovrà essere iniziata non appena sia confermata la gravidanza. L'interruzione del trattamento con LDA è più controversa e dipende dai protocolli locali, dall'anestesia epidurale e dalla tipologia di parto. In molti centri si sospende alla $36-37^{\text {a }}$ settimana per ridurre il rischio di emorragie peri-/post-parto. Prima dell'induzione del parto, del taglio cesareo o dell' anestesia epidurale andrà sospesa la terapia eparinica: quando possibile, con un intervallo di 4-6 ore per la UFH e di 24 ore per la LMWH. ${ }^{18}$ Nelle donne con o-APS ricorrente nono- 
stante terapia di combinazione con LDA ed eparina, si possono considerare come opzioni terapeutiche: l'eparina a dosaggio terapeutico sempre in associazione a LDA; la associazione di eparina, LDA e idrossiclorochina (HCQ) per tutta la durata della gravidanza (la HCQ è preferenzialmente da iniziare dal preconcezionale); l'associazione alla terapia convenzionale di prednisone $(10 \mathrm{mg} / \mathrm{die})$ nel primo trimestre $(0-14$ settimane di gestazione) e/o di immunoglobuline endovena (IVIG). ${ }^{8}$ L'HCQ è una terapia consolidata per il LES grazie ai suoi effetti antinfiammatori e immunomodulatori. In recenti studi sperimentali, l'HCQ riduce il legame degli aPL e ripristina l'espressione dell'annessina V sulle cellule del sinciziotrofoblasto umane in coltura, prevenendo in tal modo il danno placentare dovuto agli anticorpi. ${ }^{19,20}$ Nell'uomo in due studi retrospettivi, la HCQ sembrerebbe ridurre le complicanze gravidiche legate all'APS se aggiunta alla terapia convenzionale, ${ }^{21,22}$ in particolare se somministrata al dosaggio di $400 \mathrm{mg} /$ die e iniziata prima del concepimento. ${ }^{23}$ Trials clinici multicentrici valuteranno l'efficacia dell'HCQ in aggiunta alla terapia standard nelle donne con APS nel prevenire lo sviluppo di complicanze della gravidanza. ${ }^{24,25} \mathrm{Un}$ recente piccolo studio caso-controllo ha evidenziato il potenziale ruolo della pravastatina $(20 \mathrm{mg} / \mathrm{die})$ nel migliorare l'esito gestazionale nelle donne con APS complicata da pre-eclampsia/IUGR nonostante l'uso di LDA ed eparina. Questo farmaco assunto subito dopo il riscontro di pre-eclampsia e/o IUGR fino alla fine della gravidanza sembra migliorare il flusso placentare. ${ }^{26}$ Lo studio IMPACT, invece, sta valutando l'efficacia del certolizumab, un inibitore del TNF $\alpha$ che non attraversa la placenta, ${ }^{27}$ nel ridurre il rischio di complicanze nell'APS. ${ }^{28}$

\section{t-sindrome da anticorpi anti-fosfolipidi}

Le pazienti con precedenti trombosi con o senza complicanze ostetriche presentano un aumentato rischio di sviluppare nuovi eventi trombotici in quanto la gravidanza è un periodo di per sé a rischio elevato anche nella popolazione generale. ${ }^{29,30}$ Pertanto, il trattamento della t-APS in corso di gravidanza si basa sulla prevenzione secondaria delle recidive trombotiche mediante l'uso di farmaci antitrombotici e su strategie terapeutiche per ridurre al minimo le possibili complicanze gravidiche legate agli aPL.

Sebbene non vi siano studi clinici sulla gestione della t-APS durante la gravidanza, si raccomanda, non appena la gravidanza sia confermata, prima di tutto di sospendere il warfarin a causa della sua nota embriotossicità che si verifica tra la $6^{\mathrm{a}}$ e la $12^{\mathrm{a}}$ settimana di gestazione che può provocare gravi malformazioni e ritardi di crescita. ${ }^{31}$ In sostituzione al warfarin va introdotta UFH/LMWH a dosaggio terapeutico in associazione a LDA. ${ }^{8,32,33}$ La LDA e l'eparina dovranno essere sospese prima del parto come descritto nella sezione precedente.

Le donne con t-APS possono trarre beneficio da un parto programmato, in modo che la LMWH possa essere sostituita con UFH per via endovenosa; quest'ultima, infatti, può essere continuata fino a 4-6 ore prima del parto o dell'anestesia epidurale. ${ }^{34}$

\section{Sindrome da anticorpi anti-fosfolipidi associata ad altre patologie autoimmuni}

Nel parlare di gestione della gravidanza nelle donne con APS e altre malattie autoimmuni, focalizzeremo la nostra attenzione soprattutto sul LES, poiché la maggior parte degli studi riguarda tale patologia ed è quella più frequentemente associata. Come per tutte le patologie reumatiche, un buon controllo della malattia di base è fondamentale per un buon esito della gravidanza, poiché una malattia materna attiva durante il concepimento aumenta il rischio di riacutizzazioni e di complicanze gravidiche. ${ }^{35,36}$

Inoltre, è importante considerare che le pazienti con patologia autoimmune sistemica presentano un aumentato rischio trombotico non completamente attribuibile ai tradizionali fattori di rischio cardiovascolare. Tutti questi dati dovrebbero essere presi in considerazione nella valutazione del rischio di una paziente con APS o anche solo con aPL nell'ambito di una malattia autoimmune. ${ }^{7}$

Il trattamento in queste pazienti prevede l'utilizzo di LDA, LMWH e HCQ. La dose di LMWH (profilattica o terapeutica) dipende dalle manifestazioni cliniche (o-APS o t-APS). La LDA e la LMWH dovrebbero essere introdotte e sospese come indicato nei paragrafi precedenti.

Nelle pazienti affette da LES e profilo aPL ad alto rischio (in assenza di trombosi o patologia ostetrica) è raccomandata LDA in corso di gravidanza, mentre in quelle a profilo aPL a basso rischio l'utilizzo di LDA andrà valutato da caso a caso. ${ }^{8}$

È poi fondamentale proseguire la terapia con $\mathrm{HCQ}^{37}$ e con eventuali altri farmaci immunosoppressori già in atto, ovviamente compatibili con la gravidanza, per controllare l'attività di malattia ed evitare riacutizzazioni. ${ }^{7}$ La terapia con farmaci immunosoppressori dovrà essere adattata prima del concepimento sospendendo quelli teratogeni (ad es. metotressato, micofenolato mofetile) e iniziando farmaci compatibili con la gravidanza (ad es. azatioprina, ciclosporina) $)^{38}$ (Vedi capitolo Terapia con farmaci antireumatici in corso di gravidanza e allattamento).

\section{aPL carriers}

Gli aPL in assenza di manifestazioni cliniche trombotiche e/o ostetriche sono frequentemente identificati nel corso di indagini diagnostiche per altre malattie 
autoimmuni, in donne con manifestazioni APS noncriterio, in donne con problemi di infertilità, prima dell'inizio della terapia con contraccettivi orali o semplicemente per caso in donne sottoposte a screening della coagulazione per procedure chirurgiche. Anche se non esistono dati univoci, gli studi hanno stimato che la prevalenza degli aPL nella popolazione generale possa oscillare tra $11 \%$ e il $5 \%$, con un titolo anticorpale generalmente basso. ${ }^{39}$

Sebbene non sia ancora noto il rischio di complicanze ostetriche nelle aPL carriers, considerato il ruolo patogenetico degli aPL, una stratificazione del rischio dovrebbe essere fatta prendendo in considerazione gli stessi fattori di rischio sopra menzionati per le pazienti con sindrome definita.

Pochi studi hanno indagato l'esito gestazionale in queste donne. ${ }^{40-43}$ I dati finora pubblicati sono contraddittori. Una revisione sistematica di 5 studi condotti su 154 gravidanze ha concluso che la profilassi primaria con LDA non migliora l'esito gestazionale nelle aPL carriers asintomatiche. ${ }^{44}$ In un ampio studio osservazionale retrospettivo, il tasso di perdite fetali, età gestazionale al momento del parto e il peso alla nascita non era diverso tra le donne aPL positive trattate LDA e quelle non trattate. ${ }^{40}$ Gli stessi dati sono stati confermati in un'altra grande coorte di 73 aPL carriers in stato di gravidanza (per lo più LA isolati). ${ }^{41}$

Dall'altra parte, in uno studio multicentrico internazionale, condotto su 200 donne arruolate tra il $2000 \mathrm{al}$ 2014, con positività confermata per gli aPL durante la gravidanza, la frequenza di complicanze gravidiche è stata riscontrata nel $17,9 \%$ delle $a P L$ carriers, analogamente alle pazienti con o-APS $(18,7 \%)$ e a quelle con t-APS $(24,2 \%)$. La triplice positività per gli aPL era associata alle complicanze gravidiche anche nelle $a P L$ carriers trattate con LDA e LMWH. ${ }^{41}$ Questi risultati hanno portato allo sviluppo di uno studio multicentrico successivo volto a indagare l'approccio terapeutico e gli esiti gestazionali nelle $a P L$ carriers. ${ }^{43}$ Complicanze ostetriche sono state osservate nel 9\% di queste donne e i fattori di rischio associati erano: fattori di rischio tradizionali acquisiti, manifestazioni APS non-criterio o manifestazioni lupus-like e la triplice positività per gli aPL. Le complicanze gravidiche sono state osservate nonostante il trattamento combinato con LDA e LMWH a dosaggio profilattico, suggerendo che le $a P L$ carriers con più fattori di rischio e un profilo aPL ad alto rischio potrebbero aver bisogno di un trattamento aggiuntivo, ad esempio LMWH a dosaggio terapeutico o di un farmaco immunmodulante come l'HCQ.

Le ultime raccomandazioni EULAR suggeriscono una terapia con LDA nelle aPL carriers con un profilo aPL ad alto rischio. ${ }^{8}$ La LDA è d'altronde utilizzata anche nelle donne senza aPL per la prevenzione della pre-eclampsia, complicanza che si riscontra con frequenza aumentata nelle gravidanze di donne con aPL. ${ }^{45}$
Nelle pazienti con aPL e manifestazioni cliniche non-criterio dovrebbe essere considerata una terapia con LDA, in monoterapia o in associazione a LMWH a seconda del profilo di rischio della donna (profilo aPL, precedenti gravidanze con nato vivo e ulteriori fattori di rischio per complicanze ostetriche o trombosi). ${ }^{7}$ In una recente analisi del registro europeo sulla o-APS (EUROAPS), le donne con complicanze ostetriche che non soddisfacevano i criteri per una o-APS definita presentavano outcomes ostetrici simili alle donne con o-APS definita quando trattate con la terapia standard con LDA + LMWH. ${ }^{46}$

Recentemente, è stato ipotizzato un possibile ruolo della HCQ nella prevenzione delle complicanze gravidiche anche nelle donne $a P L$ carriers. ${ }^{47,48}$ Lo studio clinico randomizzato, HYPATIA, valuterà il ruolo di HCQ nella prevenzione primaria delle complicanze ostetriche anche nelle aPL carriers. ${ }^{25}$

\section{Gestione del puerperio}

La nascita di un figlio - evento di per sé straordinario e ricco di speranze - comporta anche una serie di profondi e delicati sconvolgimenti biologici, ormonali, fisici, psicologici, sociali per la donna. È un periodo di estrema fragilità per la donna che richiede una cura e attenzione particolare da parte della famiglia per il necessario supporto pratico oltre che psicologico e da parte dello specialista per i problemi di salute.

L'incidenza di tromboembolismo venoso aumenta fino $\mathrm{a} \geq 20$ volte nelle prime 12 settimane dopo il parto ${ }^{19}$. Nelle donne con APS bisogna tener presente che tale rischio va a sommarsi al rischio legato alla patologia.

Nel puerperio sia la LMWH che l'UFH possono essere reintrodotte non appena raggiunta l'emostasi (generalmente circa 6 ore dopo il parto vaginale e 12 ore dopo un parto cesareo). ${ }^{19}$

Alle donne con o-APS (senza storia di trombosi) si consiglia di assumere LMWH o UFH a dosaggio profilattico fino a 6 settimane dopo il parto. ${ }^{8}$

Le donne con t-APS potranno continuare la LMWH a dosaggio terapeutico o reintrodurre il warfarin. Sia l'eparina che il warfarin sono compatibili con l'allattamento. ${ }^{49}$ Qualora si preferisse reintrodurre il warfarin subito dopo il parto, sarà necessario embricarlo per i primi giorni con eparina: la prima dose potrà essere somministrata il giorno dopo il parto in associazione all'eparina fino al raggiungimento di un INR $>2$ in due occasioni consecutive. ${ }^{19}$

Anche le donne aPL carriers asintomatiche dovranno essere trattate con LMWH a dosaggio profilattico per almeno 6 settimane dopo il parto. ${ }^{8}$

Inoltre, è di estrema importanza in tutte queste donne evitare l'immobilità e indossare calze a compressione graduata. 


\section{Infertilità e tecniche di procreazione medicalmente assistita}

Le malattie reumatiche di per sé non sono causa di infertilità femminile. Solo alcune particolari situazioni possono condizionare una ridotta fertilità: malattia attiva; insufficienza renale cronica; utilizzo di farmaci che riducano la riserva ovarica (ciclofosfamide); utilizzo cronico di FANS che possa indurre la cosiddetta 'unruptured follicle syndrome' con conseguente assenza di ovulazione. ${ }^{50}$ Secondo dati sperimentali, gli aPL potrebbero compromettere la fertilità femminile interferendo con la decidualizzazione endometriale e quindi con l'impianto. La positività per aPL è stata riportata con frequenza aumentata tra le donne sterili. Tuttavia, i dati finora disponibili sono pochi per trarre delle conclusioni definitive. ${ }^{51}$ In una donna con APS che presenti problemi di infertilità (definita come mancato concepimento dopo almeno 12 mesi di rapporti sessuali non protetti) andranno indagati sia i fattori di rischio associati alla malattia, sia quelli generali, e verrà studiato anche il partner.

La procreazione medicalmente assistita può essere una opzione per le pazienti con APS. La PMA si avvale di tecniche di base o I livello (inseminazione intrauterina - IUI), semplici e poco invasive, e di tecniche avanzate o di II e III livello (fecondazione in vitro e trasferimento dell'embrione - FIVET; microiniezione intracitoplasmatica dello spermatozoo - ICSI), complesse e più invasive. Tutte queste tecniche possono essere eseguite su ciclo spontaneo (quindi senza alcuna terapia di stimolazione ovarica) o con induzione farmacologica dell'ovulazione. Inoltre, le tecniche di II e III livello possono essere eseguite con embrioni a fresco o con embrioni congelati. Studi osservazionali hanno mostrato come la PMA sia relativamente sicura nelle donne con APS, se opportunamente profilassate e seguite. ${ }^{52,53}$ Inoltre, il tasso di successo sembra essere simile a quello delle donne senza APS (fino al 30\%). Anche nel caso in cui una paziente con APS decida di intraprendere questo percorso, un adeguato counselling prima di qualsiasi procedura è da ritenersi necessario al fine di ottenere il miglior risultato possibile. Attualmente, non esistono linee guida ufficiali sulla profilassi più corretta da effettuarsi nelle pazienti con APS che si sottopongano a tecniche di PMA. In ogni caso appare necessario stratificare il rischio per ogni singola paziente in base all'assetto anticorpale, alle manifestazioni cliniche, all'eventuale danno d'organo e all'attività di malattia.

Nel caso di stimolazione ormonale e cicli con embrioni a fresco nelle pazienti con t-APS (già in terapia con warfarin), all'inizio della stimolazione ormonale la terapia anticoagulante con warfarin andrà sospesa e verrà introdotta la LMWH a dosaggio terapeutico: quest'ultima andrà poi sospesa 12 ore prima del prelievo degli oociti e reintrodotta lo stesso giorno del prelievo se non insorgono emorragie; la LDA andrà invece introdotta al momento del trasferimento embrionale. Le pazienti con o-APS e le aPL carriers ad alto rischio (già in terapia con LDA) sospenderanno l'LDA 5-7 giorni prima del prelievo degli oociti e la reintrodurranno due giorni dopo; a partire dalla stimolazione ormonale inizieranno poi la LMWH a dosaggio profilattico che andrà sospesa 12 ore prima del prelievo degli oociti e reintrodotta lo stessa giorno, sempre in assenza di complicanze emorragiche. In caso di cicli con embrioni congelati, le pazienti con tAPS al test di gravidanza positivo sospenderanno il warfarin e introdurranno LMWH a dosaggio terapeutico in associazione a LDA. Le pazienti con o-APS e le $a P L$ carriers ad alto rischio (già in LDA) introdurranno LMWH a dosaggio profilattico al test di gravidanza positivo. ${ }^{51,54} \mathrm{Al}$ fine di evitare complicanze come la sindrome da iperstimolazione ovarica, esistono opzioni più sicure come, ad esempio, l'utilizzo di estrogeni o progestinici naturali, una stimolazione ovarica a dosaggi più bassi o il trasferimento di un solo embrione. ${ }^{55}$

\section{Conclusioni}

La gravidanza e il puerperio nelle pazienti con APS devono essere considerati periodi ad alto rischio per cui è necessaria una stretta sorveglianza e terapie mirate per ridurre al minimo il rischio di complicanze materno-fetali. L'attuale standard di cura dell'APS materna si basa sulle manifestazioni cliniche e sul profilo di rischio individuale. Una terapia di associazione con LDA ed eparina costituisce il trattamento convenzionale in corso di gravidanza. Tuttavia, nel $20 \%$ dei casi ci possono essere complicanze nonostante la terapia, per cui queste donne necessitano di opzioni terapeutiche ulteriori, come la somministrazione durante il primo trimestre di steroide a medie dosi e/o le immunoglobuline per via endovenosa. Inoltre, terapie più maneggevoli come la HCQ sembrano avere effetti benefici, in particolare se somministrato a dosaggio terapeutico. Sono necessari ulteriori studi per valutare il ruolo della pravastatina nella cura dei pazienti con APS che sviluppano pre-eclampsia o IUGR. E ulteriori dati sono fondamentali per capire qual è la migliore gestione delle aPL carriers e nelle pazienti con manifestazioni non-criterio al fine di migliorarne l'esito gestazionale. Le poche linee guida disponibili basate sulla revisione sistematica della letteratura sono state analizzate nell'ambito di ERN ReCONNET (rete di riferimento europea sulle malattie rare e complesse del tessuto connettivo e delle malattie muscoloscheletriche), un'iniziativa finanziata dalla Comunità Europea con l'obiettivo di migliorare la assistenza di questi pazienti attraverso l'identificazione di bisogni insoddisfatti nella diagnosi e gestione della malattia. 
Recentemente anche l'EULAR (European League Against Rheumatism) ha pubblicato le raccomandazioni per il trattamento della APS negli adulti riscontrando le stesse aree di incertezza. ${ }^{8}$

Pertanto, nonostante il significativo costante miglioramento del management e dell'outcome gravidico che ha caratterizzato questi ultimi anni, la gestione della gravidanza, le manifestazioni cliniche incomplete o non-criterio e la profilassi primaria rimangono aree di incertezza che dovrebbero essere prese in considerazione per lo sviluppo di future linee guida. ${ }^{56}$

\section{Bibliografia}

1. Miyakis S, Lockshin Md, Atsumi T, et al. International consensus statement on an update of the classification criteria for definite antiphospholipid syndrome (APS). J Thromb Haemost. 2006; 4: 295-306.

2. Alarcón-Segovia D, Sanchez-Guerrero J. Primary antiphospholipid syndrome. J Rheumatol. 1989;16:482-8.

3. Meroni PL, Tsokos GC. Editorial: Systemic Lupus Erythematosus and Antiphospholipid Syndrome. Front Immunol. 2019;10:199.

4. Ruiz-Irastorza G, Cuadrado Mj, Ruiz-Arruza I, et al. Evidence-based recommendations for the prevention and long-term management of thrombosis in antiphospholipid antibody-positive patients: report of a task force at the 13th International Congress on antiphospholipid antibodies. Lupus 2011; 20:206-18.

5. Bakimer R, Fishman P, Blank M, et al. Induction of primary antiphospholipid syndrome in mice by immunization with a human monoclo- nal anticardiolipin antibody (H-3). J Clin Investig 1992;89:1558-63.

6. Meroni PL, Borghi MO, Raschi E, Tedesco F. Pathogenesis of antiphospholipid syndrome: understanding the antibodies. Nat Rev Rheumatol. 2011; 7:330-9.

7. Andreoli L, Bertsias Gk, Agmon-Levin N, et al. EULAR recommendations for women's health and the management of family planning, assisted reproduction, pregnancy and menopause in patients with systemic lupus erythematosus and/or antiphospholipid syndrome. Ann Rheum Dis. 2017; 76: 476-85.

8. Tektonidou MG, Andreoli L, Limper M, et al. EULAR recommendations for the management of antiphospholipid syndrome in adults. Ann Rheum Dis. 2019;78: 1296-1304.

9. Mekinian A, Carbillon L, Nicaise-Roland P, et al. Mothers' antiphospholipid antibodies during pregnancy and the relation to offspring outcome. Clin Exp Rheumatol. $2014 ; 32: 446$.

10. Østensen M. Preconception Counseling. Rheum Dis Clin North Am. 2017;43:189-199.

11. Sliwa K, Van Hagen Im, Budts W, et al. Pulmonary hypertension and pregnancy outcomes: data from the Registry Of Pregnancy and Cardiac Disease (ROPAC) of the European Society of Cardiology. Eur. J. Heart Fail. 2016; 18:1119-28.

12. Buyon JP, Kim MY, Guerra MM, et al. Predictors of Pregnancy Outcomes in Patients With Lupus: A Cohort Study. Ann Intern Med. 2015;163:153-63.
13. Andreoli L, Chighizola CB, Banzato A, et al. Estimated frequency of antiphospholipid antibodies in patients with pregnancy morbidity, stroke, myocardial infarction, and deep vein thrombosis: a critical review of the literature. Arthritis Care Res (Hoboken). 2013;65:1869-73.

14. Tincani A, Bazzani C, Zingarelli S, et al. Lupus and the antiphospholipid syndrome in pregnancy and obstetrics: clinical characteristics, diagnosis, pathogenesis, and treatment. Semin Thromb Hemost. 2008;34:267-73.

15. Faden D, Tincani A, Tanzi P, et al. Anti-beta 2 glycoprotein I antibodies in a general obstetric population: preliminary results on the prevalence and correlation with pregnancy outcome. Anti-beta2 glycoprotein I antibodies are associated with some obstetrical complications, mainly preeclampsia-eclampsia. Eur J Obstet Gynecol Reprod Biol. 1997;73:37-42.

16. Tincani A, Rebaioli CB, Andreoli L, et al. Neonatal effects of maternal antiphospholipid syndrome. Curr Rheumatol Rep. 2009;11:70-76.

17. de Jesus GR, Agmon-Levin N, Andrade CA, et al. 14th International Congress on Antiphospholipid Antibodies Task Force report on obstetric antiphospholipid syndrome. Autoimmun Rev 2014;13:795-813.

18. Marshall AL. Diagnosis, treatment, and prevention of venous thromboembolism in pregnancy. Postgrad Med. 2014; 126: 25-34

19. Wu XX, Guller S, Rand JH. Hydroxychloroquine reduces binding of antiphospholipid antibodies to syncytiotrophoblasts and restores annexin A5 expression. Am. J. Obstet. Gynecol. 2011; 205:576.e7-14.

20. Bertolaccini M1, Contento G, Lennen R, et al. Complement inhibition by hydroxychloroquine prevents placental and fetal brain abnormalities in antiphospholipid syndrome. J Autoimmun. 2016; 75: 30-8.

21. Sciascia S, Hunt Bj, Talavera-Garcia E, et al. The impact of hydroxychloroquine treatment on pregnancy outcome in women with antiphospholipid antibodies. Am. J. Obstet. Gynecol. 2016; 214:273.e1-273.e8.

22. Mekinian A, Lazzaroni MG, Kuzenko A, et al. The efficacy of hydroxychloroquine for obstetrical outcome in anti-phospholipid syndrome: data from a European multicenter retrospective study. Autoimmun Rev. 2015; 14:498-502.

23. Ruffatti A, Tonello M, Hoxha A, et al. Effect of Additional Treatments Combined with Conventional Therapies in Pregnant Patients with High-Risk Antiphospholipid Syndrome: A Multicentre Study. Thromb Haemost. 2018; 118:639-46.

24. Schreiber K, Breen K, Cohen H, et al. HYdroxychloroquine to improve pregnancy outcome in women with AnTIphospholipid Antibodies (HYPATIA) protocol: a multinational randomized controlled trial of hydroxychloroquine versus placebo in addition to standard treatment in pregnant women with antiphospholipid syndrome or antibodies. Semin. Thromb. Hemost. 2017; 43:562-71.

25. Belizna C, Pregnolato F, Abad S, et al. HIBISCUS: Hydroxychloroquine for the secondary prevention of thrombotic and obstetrical events in primary antiphospholipid syndrome. Autoimmun Rev. 2018;17:11531168.

26. Lefkou E, Mamopoulos A, Dagklis T, et al. Pravastatin improves pregnancy outcomes in obstetric antiphospho- 
lipid syndrome refractory to antithrombotic therapy. J Clin Invest. 2016; 126:2933-40.

27. Mariette X, Förger F, Abraham B, et al. Lack of placental transfer of certolizumab pegol during pregnancy: results from CRIB, a prospective, postmarketing, pharmacokinetic study. Ann Rheum Dis. 2018; 77:228-33.

28. https://clinicaltrials.gov/ct2/show/NCT03152058? term $=$ CERTOLIZUMAB\&cond=APS\&draw=2\&rank=1.

29. Eichinger S, Evers Jlh, Glasier A, et al. Venous thromboembolism in women: A specific reproductive health risk. Human Reproduction Update 2013; 19: 471-82.

30. Da Silva Saraiva S, De Moraes Mazetto B, Quinteiro Tobaldine $\mathrm{L}$, et al. The impact of antibody profile in thrombosis associated with primary antiphospholipid syndrome. Am J Hematol. 2017; 92:1163-9.

31. Greer IA. Thrombosis in pregnancy: updates in diagnosis and management. Hematology Am Soc Hematol Educ Program. 2012; 2012: 203-07.

32. Bates Sm, Greer Ia, Middeldorp S, et al. VTE, thrombophilia, antithrombotic therapy, and pregnancy: Antithrombotic Therapy and Prevention of Thrombosis, 9th ed: American College of Chest Physicians EvidenceBased Clinical Practice Guidelines. Chest. 2012; 14:e691S-e736S.

33. Chighizola $\mathrm{Cb}$, Ubiali $\mathrm{T}$, Meroni Pl. Treatment of Thrombotic Antiphospholipid Syndrome: The Rationale of Current Management-An Insight into Future Approaches. J Immunol Res. 2015:951424.

34. Marshall AL. Diagnosis, treatment, and prevention of venous thromboembolism in pregnancy. Postgrad Med. 2014; 126: 25-34.

35. Rose HL, Ho WK. Management of very high risk pregnancy with secondary anti-phospholipid syndrome and triple positivity to the antiphospholipid antibodies. J Thromb Thrombolysis. 2014; 38:453-6.

36. Ruffatti A, Tonello M, Visentin Ms, et al. Risk factors for pregnancy failure in patients with anti-phospholipid syndrome treated with conventional therapies: a multicenter, case-control study. Rheumatology 2011; 50: 1684-1689).

37. Sciascia S, Hunt Bj, Talavera-Garcia E, Et al. The impact of hydroxychloroquine treatment on pregnancy outcome in women with antiphospholipid antibodies. Am. J. Obstet. Gynecol. 2016; 214:273.e1-273.e8.

38. Götestam Skorpen C, Hoeltzenbein M, et al. The EULAR points to consider for use of antirheumatic drugs before pregnancy, and during pregnancy and lactation. Ann Rheum Dis. 2016;75:795-810.

39. Schreiber K, Sciascia S, De Groot PG, et al. Antiphospholipid syndrome. Nat Rev Dis Primers. 2018; 25; 4 : 18005.

40. Del Ross T, Ruffatti A, Visentin MS, et al. Treatment of 139 pregnancies in antiphospholipid-positive women not fulfilling criteria for antiphospholipid syndrome: a retrospective study. J. Rheumatol. 2013; 40:425-9.

41. Soh MC, Pasupathy D, Gray G, et al. Persistent antiphospholipid antibodies do not contribute to adverse pregnancy outcomes. Rheumatology (Oxford). 2013; $52: 1642-7$.
42. Fredi M, Andreoli L, Aggogeri E, et al. Risk Factors for Adverse Maternal and Fetal Outcomes in Women With Confirmed aPL Positivity: Results From a Multicenter Study of 283 Pregnancies. Front Immunol. 2018;9:864.

43. Lazzaroni MG, Fredi M, Andreoli L, et al. Triple Antiphospholipid (aPL) Antibodies Positivity Is Associated With Pregnancy Complications in aPL Carriers: A Multicenter Study on 62 Pregnancies. Front Immunol. 2019;10:1948.

44. Amengual O, Fujita D, Ota E, et al. Primary prophylaxis to prevent obstetric complications in asymptomatic women with antiphospholipid antibodies: a systematic review. Lupus. 2015; 24:1135-42.

45. Roberge R, GiguèRe Y, Villa $P$, et al. Early administration of low-dose aspirin for the prevention of severe and mild preeclampsia: a systematic review and meta-analysis. Am. J. Perinatol. 2012; 29:551-6.

46. Alijotas-Reig J, Esteve-Valverde E, Ferrer-Oliveras R, et al. Comparative study of obstetric antiphospholipid syndrome (OAPS) and non-criteria obstetric APS (NCOAPS): report of 1640 cases from the EUROAPS registry. Rheumatology (Oxford). 2019 Oct 3. [Epub ahead of print].

47. Meroni PL. Prevention \& treatment of obstetrical complications in APS: Is hydroxychloroquine the Holy Grail we are looking for? J. Autoimmun. 2016; 75:1-5.

48. Abd Rahman R, Dekoninck P, Murthi P, et al. Treatment of preeclampsia with hydroxychloroquine: a review. J. Matern. Fetal. Neonatal. Med. 2018; 31:525-9.

49. Flint J, Panchal S, Hurrell A, et al. BSR and BHPR Standards, Guidelines and Audit Working Group. BSR and BHPR guideline on prescribing drugs in pregnancy and breastfeeding-Part II: analgesics and other drugs used in rheumatology practice. Rheumatology (Oxford). 2016;55:1698-702.

50. Østensen M. Sexual and reproductive health in rheumatic disease. Nat Rev Rheumatol. 2017;13:485-493.

51. Chighizola CB, Raimondo MG, Meroni PL. Does APS Impact Women's Fertility? Curr Rheumatol Rep. 2017;19:33.

52. Orquevaux P, Masseau A, Le Guern V, et al. In vitro fertilization and systemic lupus erythematosus or antiphospholipid syndrome: an update. Rev Med Interne 2015; 36:154-8.

53. Orquevaux P, Masseau A, Le Guern V, et al. In Vitro Fertilization in 37 Women with Systemic Lupus Erythematosus or Antiphospholipid Syndrome: A Series of 97 Procedures. J Rheumatol. 2017; 44:613-8.

54. Costedoat-Chalumeau N. Assisted reproduction techniques: what can we tell to women with rheumatic diseases? Ann Rheum Dis 2019; 78:A45.

55. Bellver J, Pellicer A. Ovarian stimulation for ovulation induction and in vitro fertilization in patients with systemic lupus erythematosus and antiphospholipid syndrome. Fertil Steril. 2009; 92: 1803-10.

56. Limper M, Scirè CA, Talarico R, et al. Antiphospholipid syndrome: state of the art on clinical practice guidelines. RMD Open. 2018;4:e000785. 


\title{
Gravidanza e sclerosi sistemica (sclerodermia)
}

\author{
Antonio Brucato, ${ }^{1}$ Mariangela Nivuori, ${ }^{2}$ Antonino Mazzone ${ }^{3}$ \\ ${ }^{1}$ Dipartimento di Scienze Biomediche e Cliniche 'L. Sacco', Università degli Studi di Milano, Ospedale Fatebenefratelli, Mi- \\ lano; ${ }^{2}$ Medicina Interna, Ospedale Fatebenefratelli, Milano; ${ }^{3}$ Ospedale Civile di Legnano (MI), Italia
}

\section{Introduzione}

La sclerosi sistemica ( $\mathrm{SSc}$ ) è una malattia autoimmune cronica sistemica ad eziologia sconosciuta dal carattere progressivo. $\mathrm{E}$ caratterizzata sul piano morfologico da 3 ordini di alterazioni: la disregolazione del sistema immunitario (con infiltrazione linfocitaria perivascolare ad espansione oligoclonale, produzione di autoanticorpi e rilascio di citochine), la vasculopatia obliterativa a carico del microcircolo ed ipertroficoostruttiva con formazione di neo-intima a carico delle piccole arterie muscolari associata ad episodi vasospastici, il diffuso accumulo di collagene di tipo 1 nell'interstizio della cute e degli organi bersaglio con conseguente disfunzione degli stessi.

Si distinguono due principali sottotipi clinici sulla base dell'estensione dell'impegno cutaneo: una malattia diffusa ( $\mathrm{dcSSc}$ ) con ispessimento cutaneo prossimale a gomiti e ginocchia ed una malattia limitata $(\mathrm{lcSSc})$ con ispessimento cutaneo distale a gomiti e ginocchia.

La SSc colpisce il sesso femminile in misura nettamente maggiore rispetto al maschile (sex-ratio F:M 3$8 / 1$ ), con un'età media all'esordio di circa 40 anni. Dato che negli ultimi decenni si sta assistendo ad un progressivo ritardo nell'età di concepimento, almeno la metà delle pazienti potrebbe andare incontro ad una gravidanza dopo che la diagnosi è stata posta. Per tale ragione la gravidanza si configura come un evento sempre meno raro nelle donne affette da SSc.

Fino a circa 30 anni fa la gravidanza era fortemente sconsigliata alle donne sclerodermiche perché ritenuta un fattore di rischio di complicanze materno-fetali. Era idea comune, infatti, che potesse accelerare la progres-

Corrispondente: Mariangela Nivuori, Medicina Interna, Ospedale Fatebenefratelli, piazza Principessa Clotilde 3, 20121 Milano, Italia.

E-mail: mariangela.nivuori@asst-fbf-sacco.it

Articolo pubblicato secondo la Creative Commons Attribution NonCommercial 4.0 License (CC BY-NC 4.0).

${ }^{\circ}$ Copyright: the Author(s), 2021

Licensee PAGEPress, Italy

QUADERNI - Italian Journal of Medicine 2021; 9(4):e7 sione della malattia materna (fino all'eventuale exitus) e che, d'altro canto, la malattia potesse inficiare il normale sviluppo fetale. ${ }^{1}$ Alla base della reticenza dei medici ad autorizzare la gravidanza in queste donne vi erano numerose segnalazioni., ${ }^{2,3} \mathrm{Nel}$ 1989, Maymon et al analizzarono i reports relativi a 94 gravidanze in donne sclerodermiche; ben 14 casi (circa 10\%) si conclusero con un exitus (ascrivibile in più della metà dei casi ad una crisi renale sclerodermica o ad un deterioramento della funzionalità cardio-polmonare) ${ }^{4}$

Qualche anno dopo, Steen et al. condussero due studi, di cui uno retrospettivo ed un altro prospettico, che hanno contribuito a rivoluzionare radicalmente l'approccio della specialista nella gestione e nella presa in carico delle donne gravide sclerodermiche. I due lavori, infatti, conclusero per risultati incoraggianti e sovrapponibili: nella maggior parte dei casi la malattia si mantiene stabile nel corso della gravidanza e solo una piccola percentuale dei casi va incontro ad evoluzione.,

Ad oggi è opinione comune che il momento ideale in cui avere una gravidanza è funzione dello stato di attività di malattia, della sua durata, delle terapie in atto, dell'assetto anticorpale e della severità dell'impegno viscerale. Da qui emerge la necessità di un accurato counselling pregravidico. La gravidanza resta del tutto controindicata in caso di ipertensione arteriosa polmonare, insufficienza renale cronica di grado severo, cardiomiopatia con $\mathrm{FE}<30 \%$, ed alta attività di malattia. ${ }^{7,8}$

\section{La sessualità in corso di sclerosi sistemica}

La sclerodermia ha un impatto notevole sulla qualità della vita, sulle relazioni interpersonali e sulla sfera sessuale delle donne che ne sono affette. La compromissione dell'attività sessuale relata a questa patologia così come ad altre malattie croniche ${ }^{9}$ non viene abitualmente indagata dal medico, che spesso si mostra riluttante nei confronti della problematica. Ciò rende ragione della sottostima della reale incidenza del problema.

La disfunzione sessuale nelle donne affette da SSc è più frequente che nella popolazione generale $\mathrm{e}^{10,11} \mathrm{e} \mathrm{ri-}$ conosce come meccanismi scatenanti sia fattori fisici che psicologici. La patologia spesso si associa a secchezza vaginale ed a ridotta lubrificazione che sono una 
frequente causa di dispareunia. Possono concorrere al dolore anche il fenomeno di Raynaud, le ulcere digitali, il coinvolgimento muscolo-scheletrico, oltre che l'astenia e la ridotta capacità all'esercizio fisico. Per ciò che concerne l'aspetto psicologico, non vanno trascurate la sindrome ansioso-depressiva e la distorsione dell'immagine corporea, sebbene uno studio abbia dimostrato che l'insoddisfazione per il proprio aspetto fisico impatta sulla disfunzione sessuale in misura di gran lunga minore rispetto al dolore cronico. ${ }^{12}$

Tuttavia, nonostante quanto premesso, da una survey su 101 donne con SSc è emerso che il $61 \%$ di esse è sessualmente attiva. Inoltre, tra le pazienti non attive sessualmente, solo il $17 \%$ attribuisce la propria inattività sessuale alla SSc, mentre tra le principali motivazioni addotte vi sono età, scelta personale ed assenza di partner. ${ }^{11}$

Uno scenario differente è stato prospettato dallo studio multicentrico condotto su 547 donne sclerodermiche: solo il $17 \%$ delle pazienti arruolate non lamenta disturbi nella sfera sessuale. Il $41 \%$ delle donne è sessualmente attiva e tra queste il $58 \%$ riferisce una compromissione della sessualità relata alla patologia. La maggior parte delle donne riporta quale principale disturbo il dolore vaginale. ${ }^{13}$

I report presenti in letteratura confermano che non vi è alcuna relazione tra attività di malattia e disfunzione sessuale, così come non sembrano esserci differenze nella compromissione della vita sessuale di donne affette da forma diffusa e limitata. ${ }^{14}$ Nella pratica clinica quotidiana, lo specialista di riferimento dovrebbe valutare anche questo aspetto della situazione clinica della malattia. ${ }^{10}$

Al fine di migliorare il confort delle donne sclerodermiche durante un rapporto sessuale si potrebbe proporre loro di utilizzare dei lubrificanti, riscaldare l'ambiente circostante ed evitare di consumare i pasti nel periodo immediatamente antecedente in caso di disturbi gastrointestinali. ${ }^{15}$ Oggi risultati interessanti sulla secchezza vaginale sembrano ottenersi con laserterapia locale.

\section{La fertilità in corso di sclerosi sistemica}

Negli scorsi decenni si è ritenuto che la SSc fosse una causa di ipo o di infertilità. Tuttavia, la maggior parte delle donne aveva già avuto dei figli prima della diagnosi di SSc, il che costituiva un bias considerevole nell'interpretazione del dato. ${ }^{16}$ Nello studio retrospettivo di Englert et al. in cui sono state analizzate le gravidanze antecedenti alla diagnosi di SSc, le pazienti ritardavano di un anno il concepimento rispetto ai controlli sani (il che lasciava supporre una sottesa diminuita fertilità), ma il risultato era sovrapponibile a quello ottenuto in una coorte affetta da fenomeno di Raynaud primitivo. ${ }^{17}$ Inoltre, una causa ginecologica come un'o- struzione tubarica o un'endometriosi era identificabile in un caso su 2. Il tasso di infertilità per ragioni indeterminate nelle sclerodermiche è di fatto risultato pari a quello dei controlli sani; ${ }^{18}$ in caso di anamnesi positiva per poliabortività è necessario fare un'analisi completa delle possibili cause e soprattutto di quelle potenzialmente reversibili, tanto nella paziente (es. anticorpi antifosfolipidi) quanto nel partner.

Risultati analogamente confortanti sono stati riportati da Steen che ha confrontato un gruppo di pazienti sclerodermiche con malattia conclamata con un gruppo di donne con artrite reumatoide ed un gruppo di controlli sani. Il tasso di nulliparità è maggiore nelle sclerodermiche $(21 \% \mathrm{SSc}$ rispetto al $12 \%$ controlli sani, $\mathrm{P}<0.05$ ), ma la significatività statistica del dato scompare dopo aver corretto il risultato per alcuni fattori quali il numero di donne sessualmente inattive, non sposate o che hanno deciso di non avere figli. ${ }^{6}$

Meritano particolare attenzione due problematiche strettamente relate alla fertilità: la contraccezione e la possibile interferenza del trattamento immunosoppressivo assunto. Nelle sclerodermiche, soprattutto in caso di negatività degli anticorpi antifosfolipidi, non ci sono specifiche controindicazioni alla contraccezione (anche con estrogeni, oltre che con progestinici e dispositivi intra-uterini). Tra gli agenti immunosoppressori utilizzati, la ciclofosfamide si distingue per l'alta percentuale di amenorrea ed infertilità determinata, che è funzione della dose cumulativa somministrata. ${ }^{19,20}$

\section{L'aborto in corso di sclerosi sistemica}

I primi studi retrospettivi volti ad individuare differenze nel tasso di aborti nelle donne affette da SSc rispetto alle sane hanno dimostrato un più alto numero di aborti nelle donne sclerodermiche sia prima che dopo la diagnosi di malattia. ${ }^{18,21}$ In alcune case-series, però, $i$ criteri di inclusione non erano stringenti; venivano pertanto arruolate poche donne e con molteplici fattori di rischio per aborto, in aggiunta alla malattia di base. ${ }^{22}$ Englert trovò un aumento del numero di aborti prima dell'esordio della malattia ed ipotizzò che fossero proprio queste gravidanze infruttuose a determinare un passaggio transplacentare di cellule fetali che sarebbe poi culminato in una malattia da rigetto (chronic graft versus host disease), ritenuta come possibile meccanismo patogenetico della SSc. ${ }^{17}$

Il dato non è stato confermato da Steen et al. Il tasso di aborto nelle gravide sclerodermiche appare uguale a quello della popolazione generale. La frequenza di aborto è significativamente maggiore nelle donne affette da una forma diffusa e con una durata di malattia superiore ai 4 anni ( $42 \%$ rispetto al $13 \%$ negli altri gruppi). ${ }^{6,23}$

Lo studio IMPRESS (Italian Multicentric study on Pregnancy in Systemic Sclerosis) è uno studio retrospettico multicentrico in cui tra il 2000 ed il 2011 sono state 
arruolare 99 donne affette da SSc per un totale di 109 gravidanze. Nello studio IMPRESS, sono descritti aborti prima della decima settimana nel $4 \%$ dei casi, aborti dopo la decima settimana nel $2 \%$ dei casi, aborti volontari/terapeutici nel $4 \%$ dei casi. Anche in questo caso i risultati appaiono sovrapponibili a quelli ottenuti nel gruppo di controllo normale ${ }^{24}$ (Tabella 1).

È in corso lo studio IMPRESS 2, multicentrico prospettico internazionale, che sta valutando in modo prospettico 100 gravidanze in donne sclerodermiche.

\section{Nati prematuri o nati piccoli per l'età gestazionale}

L'Organizzazione Mondiale della Sanità definisce pretermine il bambino nato prima della $37^{\circ}$ settimana di gestazione a partire dalla comparsa dell'ultimo ciclo mestruale. ${ }^{25}$ La definizione di prematurità è stata stabilita attraverso due criteri: l'età gestazionale (EG), corrispondente alla settimana compiuta al momento del parto, ed il peso alla nascita (PN). Entrambi costituiscono importanti parametri per la valutazione dello stato del nato prematuro, in quanto l'EG è indice della maturazione neurologica, mentre il PN lo è del buon funzionamento degli organi del neonato. I bambini prematuri rappresentano circa il $7 \%$ di tutti i nati ed hanno aumentate morbilità e mortalità rispetto ai neonati a termine a causa della loro prematurità. L'incidenza e la gravità delle complicanze della prematurità aumentano con la diminuzione dell'età gestazionale e del peso alla nascita e sono funzione dell'immaturità degli organi.

Nelle donne gravide affette da SSc (come osservato in tutte le donne affette da patologie autoimmuni) vi è un aumentato rischio di prematurità rispetto ai controlli sani, anche nelle gravidanze intercorse prima della diagnosi di malattia. Le cause della prematurità possono essere molteplici e vanno dal sanguinamento placentare alla rottura prematura delle membrane, alla crisi renale ed alla pre-eclampsia. In media i bambini nascono alla 34,9 settimana gestazionale con un peso di $2250 \mathrm{gr}^{6,23}$

Nel 2006 uno studio retrospettivo su 20 gravidanze in 13 donne affette da SSc e connettivite mista ha evidenziato un tasso di prematurità del $40 \%$ ed un tasso di nati piccoli per l'età gestazionale del $50 \%{ }^{26}$ Una probabile spiegazione per questo risultato è che le donne arruolate nella coorte avevano un'alta prevalenza di anticorpi anti-cardiolipina, che potrebbero aver concorso alla vasculopatia placentare.

Tabella 1. Gli outcomes gravidici delle donne affette da sclerosi sistemica arruolate nello studio IMPRESS (Italian Multicentric study on Pregnancy in Systemic Sclerosis).

\begin{tabular}{|c|c|c|c|}
\hline & SSc & lcSSc & deSSc \\
\hline Gravidanze complessive, $n$ & 109 & 54 & 48 \\
\hline Età materna media (anni) al concepimento $(\mathrm{SD})$ & $31.8(5.3)$ & $31.8(5.8)$ & $32(4.0)$ \\
\hline Nati vivi, $\mathrm{n}(\%)$ & $98(90 \%)$ & $48(89 \%)$ & $44(92 \%)$ \\
\hline Aborti $(<10$ settimana), n $(\%)$ & $4(4 \%)$ & $1(2 \%)$ & $2(4 \%)$ \\
\hline Morte fetale ( $\geq 10$ settimana), $\mathrm{n}(\%)$ & $2(2 \%)$ & $1(2 \%)$ & $1(2 \%)$ \\
\hline Aborti volontari e terapeutici, $\mathrm{n}(\%)$ & $5(4 \%)$ & $4(7 \%)$ & $1(2 \%)$ \\
\hline Parti complessivi, $n$ & 98 & 48 & 44 \\
\hline Gravidanze gemellari, $\mathrm{n}(\%)$ & $3(3 \%)$ & $2(4 \%)$ & $1(2 \%)$ \\
\hline Restrizione della crescita fetale $\left(<5^{\circ}\right.$ percentile $), \mathrm{n}(\%)$ & $6(6 \%)$ & $1(2 \%)$ & $5(11 \%)$ \\
\hline Rottura prematura delle membrane, $\mathrm{n}(\%)$ & $6(6 \%)$ & $3(6 \%)$ & $2(4 \%)$ \\
\hline Parto prematuro <37 settimana, $\mathrm{n}(\%)$ & $25(25 \%)$ & $10(20 \%)$ & $14(32 \%)$ \\
\hline Parto prematuro $<34$ settimana, $\mathrm{n}(\%)$ & $10(10 \%)$ & $4(8 \%)$ & $5(11 \%)$ \\
\hline Parto cesareo, n (\%) & $51(52 \%)$ & $22(46 \%)$ & $25(57 \%)$ \\
\hline Ipertensione gestazionale, $\mathrm{n}(\%)$ & $2(2 \%)$ & $1(2 \%)$ & $1(2 \%)$ \\
\hline Pre-eclampsia, n (\%) & $0(0 \%)$ & $0(0 \%)$ & $0(0 \%)$ \\
\hline Eclampsia, n (\%) & $0(0 \%)$ & $0(0 \%)$ & $0(0 \%)$ \\
\hline Totali neonati, $n$ & 101 & 49 & 45 \\
\hline Peso alla nascita molto basso ( $<1500 \mathrm{gr}), \mathrm{n}(\%)$ & $5(5 \%)$ & $1(2 \%)$ & $4(8 \%)$ \\
\hline Piccoli per età gestazionale $\left(<10^{\circ}\right.$ percentile $), \mathrm{n}(\%)$ & $14(14 \%)$ & $5(10 \%)$ & $9(20 \%)$ \\
\hline
\end{tabular}

Rottura prematura delle membrane: rottura delle membrane prima della $37^{\circ}$ settimana gestazionale. Ipertensione gestazionale: ipertensione dopo la $20^{\circ}$ settimana in assenza di proteinuria. Pre-eclampsia: ipertensione dopo la $20^{\circ}$ settimana con proteinuria $\geq 300 \mathrm{mg} / 24 \mathrm{~h}$. Eclampsia: convulsioni generalizzate e/o coma in un Quadro di pre-eclampsia in assenza di altre condizioni neurologiche. Piccolo per età gestazionale: peso alla nascita $<10^{\circ}$ percentile per età gestazionale. 
Più recentemente lo studio IMPRESS ha confermato un tasso di prematurità maggiore nelle donne sclerodermiche piuttosto che nella popolazione controllo ( $25 \%$ vs $12 \%)$. Tanto l'analisi univariata quanto l'analisi multivariata identificano l'assunzione dello steroide nel corso della gravidanza quale fattore di rischio.

In IMPRESS i tagli cesarei sono risultati più frequenti nelle pazienti con SSc che nel gruppo controllo (52\% vs 31\%). Venti cesarei sono stati eseguiti come emergenza ( 9 per ragioni ostetriche, 11 per sofferenza fetale) e 31 in elezione, 14 dei quali in seguito ad indicazione ostetrica, in assenza di una reale motivazione clinica, per timore della malattia materna. ${ }^{24} \mathrm{Un}$ altro studio di coorte ha confermato che le sclerodermiche sono sottoposte a parto cesareo nel $64 \%$ dei casi, a fronte del $28 \%$ riportato nella popolazione generale. ${ }^{27}$

È definito come nato piccolo per l'età gestazionale (SGA) il neonato con peso alla nascita inferiore al $10^{\circ}$ percentile per l'età gestazionale ed il sesso.

Un ritardo di crescita intrauterino è più frequente nelle sclerodermiche piuttosto che nelle donne affette da Raynaud primitivo e nei controlli sani ( $10 \%$ vs $4 \%$ vs $2 \%) .{ }^{28}$ Sorprendentemente, circa 10 anni più tardi, la stessa équipe ha rimesso in discussione i dati precedenti mediante uno studio prospettico da cui è emerso che nessuno dei 48 bambini nati da madri sclerodermiche era piccolo per l'età gestazionale (peso medio alla nascita di 3220 gr). Una delle possibili spiegazioni è che il più ampio uso dei calcio antagonisti verificatosi negli anni successivi abbia contribuito al miglioramento della perfusione placentare.

Anche lo studio IMPRESS non ha riscontrato un aumento dei neonati con SGA nelle donne affette da sclerodermia rispetto alla popolazione controllo. ${ }^{24}$

\section{L'effetto della gravidanza sull'impegno viscerale in corso di sclerosi sistemica}

Può essere difficile discriminare le manifestazioni cliniche indotte dalla gravidanza in corso di scleroder- mia, in quanto gravidanza fisiologica e sclerosi sistemica condividono alcuni sintomi.

Attualmente si è concordi nel ritenere che la gravidanza non influisca negativamente sul decorso della malattia, la quale, in funzione del tipo di coinvolgimento d'organo e delle manifestazioni cliniche, si manterrà stabile nel $61 \%$ dei casi, migliorerà nel $20 \%$ dei casi e peggiorerà nel $20 \%$ dei casi. ${ }^{7,23}$

Non è stata ritrovata alcuna differenza statisticamente significativa tra gli outcomes gravidici nelle donne con forma limitata di malattia rispetto alle donne con forma diffusa, sebbene nello studio IMPRESS si sia delineato in modo chiaro un trend circa la maggiore prevalenza di esiti peggiori (SGA, prematurità e taglio cesareo) nelle forme diffuse (Tabella 2).

\section{Ipertensione arteriosa polmonare}

L'ipertensione arteriosa polmonare (PAH) costituisce tutt'ora una controindicazione assoluta alla gravidanza nelle donne con SSc. Colpisce circa il 10\% degli individui affetti da SSc, generalmente nelle fasi più avanzate di malattia ed in caso di positività degli anticorpi anti-centromero ed antiRNP. Uno studio retrospettivo condotto dal centro di riferimento francese per la PAH e pubblicato nel 2005 ha mostrato una mortalità materna del $36 \%$ in 14 donne affette da PAH di grado severo (nessun caso di SSc analizzato), soprattutto nel peri-partum, nonostante la gestione ottimale. ${ }^{29}$ Una più recente metanalisi ha evidenziato una mortalità del 33\% nel sottogruppo di pazienti affetti da PAH secondaria non legata a cardiopatia (di cui un caso di SSc). ${ }^{30} \mathrm{~L}$ 'aumentata mortalità nel peripartum è verosimilmente ascrivibile alla riduzione delle resistenze periferiche ed all'aumento dell'output cardiaco dal 30 al $50 \%$ con conseguente ripercussione sulle pressioni polmonari, mentre l'aumentata mortalità nel post-partum è riconducibile alla repentina riduzione della gittata con aumento delle resistenze periferiche e possibilità di collasso circolatorio e morte improvvisa.

Tabella 2. Gli effetti della gravidanza sulla sclerosi sistemica.

\begin{tabular}{ll}
\hline Coinvolgimento d'organo in corso di SSc & Cambiamenti indotti dalla gravidanza \\
\hline Complessivo & La malattia si mantiene stabile nella stragrande maggioranza dei casi \\
\hline Fenomeno di Raynaud & Temporaneo miglioramento soprattutto nel secondo e nel terzo trimestre di gestazione \\
\hline Cute & Possibile peggioramento del mRSS nell'immediato post-partum \\
\hline Apparato muscoloscheletrico & Artromialgie frequenti, analogamente alle gravidanze della popolazione generale \\
\hline Apparato gastroenterico & $\begin{array}{l}\text { Reflusso gastroesofageo e stipsi frequenti, analogamente alle gravidanze della popolazione } \\
\text { generale }\end{array}$ \\
\hline Apparato cardiopolmonare & $\begin{array}{l}\text { Outcomes sovrapponibili a quelli di donne affetti da altre patologie con analogo performance } \\
\text { status }\end{array}$ \\
\hline Rene & $\begin{array}{l}\text { Rischio di crisi renale sclerodermica maggiore in caso di subset diffuso ed esordio di malattia } \\
\text { inferiore ai } 4 \text { anni, indipendentemente dalla concomitante gravidanza }\end{array}$ \\
\hline
\end{tabular}

mRSS, Rodnan Skin Score. 
Nello studio IMPRESS, nessuna delle donne arruolate era affetta da $\mathrm{PAH}$, ma si è assistito ad un caso di PAH esordito 9 mesi dopo il parto in una donna affetta da una forma limitata, Anti-topoisomerasi +, con ipertensione arteriosa e severo impegno polmonare (FVC $37 \%$ e DLCO 23\%). ${ }^{24}$

Pur se la PAH resta una controindicazione assoluta alla gravidanza, alcune donne affrontano la gravidanza anche in questa situazione molto pericolosa. In alcuni casi clinici è stato descritto l'uso riuscito di epoprostenolo e sildenafil durante la gravidanza e raccomandata l'anticoagulazione con eparina a basso peso molecolare per ridurre il rischio di tromboembolia. ${ }^{31,32}$

\section{Crisi renale sclerodermica}

La crisi renale sclerodermica è la complicanza più temuta in corso di gravidanza. È definita dalla comparsa improvvisa di un'ipertensione arteriosa severa e/o di un'insufficienza renale rapidamente progressiva associata ad una contrazione della diuresi, in assenza di altre plausibili cause scatenanti oltre alla SSc. Fattori di rischio comuni sono: la durata di malattia inferiore ai 4 anni, il subset diffuso con rapida evoluzione dell'estensione dell'impegno cutaneo, la positività degli anticorpi antiRNPIII, la terapia steroidea $>15 \mathrm{mg} /$ die nei 3 mesi antecedenti. . $33,34^{3}$

La diagnosi differenziale con la pre-eclampsia è difficile e può ritardare l'avvio di una terapia congrua. Infatti, l'ipertensione severa, l'emolisi meccanica con trombocitopenia e l'insufficienza renale sono comuni alle due malattie. In caso di crisi renale sclerodermica, però, non ci saranno alterazioni della funzionalità epatica né dell'uricemia e l'incremento della creatinina seguirà una cinetica rapida; inoltre, si assisterà ad un aumento dei livelli di renina plasmatica legato all'ischemia reno-corticale. ${ }^{35}$ Per l'individuazione della preeclampsia in fase precoce è stato proposto un nuovo marker; si tratta del rapporto tra la tirosin kinasi-1 fms like (sFIt-1) ed il fattore di crescita placentare (PIGF). ${ }^{36}$

Non è chiaro se il tasso di pre-eclampsia sia aumentato oppure no nelle donne con SSc. ${ }^{24}$

Contrariamente a quanto si verifica nell'eclampsia, il cesareo urgente non migliora l'outcome in corso di crisi renale, non avendo alcun impatto sulla pressione e sull'insufficienza renale. La terapia ha come caposaldo il ricorso agli ACE inibitori, che ne hanno drasticamente modificato la prognosi, affermandosi come l'unica classe di antipertensivi in grado di controllare il quadro clinico e di ridurre la mortalità dal $75 \%$ al $16 \% .{ }^{37}$ Gli ACE inibitori, sebbene normalmente contro-indicati in gravidanza perché responsabili di malformazioni d'organo nel feto (quali atresia renale, ipoplasia polmonare), devono essere subito somministrati in caso di crisi renale sclerodermica, indipendentemente dalla settimana gestazionale.
D'altro canto, in una case-series su 10 donne gravide non sclerodermiche con un'ipertensione di grado severo trattate con captopril a basso dosaggio (25 $\mathrm{mg} / \mathrm{die}$ ) non sono state riportate malformazioni fetali, né complicanze neonatali e si è ottenuto un controllo soddisfacente della pressione arteriosa. ${ }^{38}$

Una precedente crisi renale non costituisce una controindicazione assoluta alla gravidanza; è fondamentale, però, che la pressione arteriosa sia perfettamente controllata e che gli ACE inibitori siano stati interrotti da tempo nella fase di programmazione della gravidanza, mantenendo lo stesso un adeguato controllo della situazione generale di malattia. Ad oggi non è noto se l'interruzione dell'ACE inibitore in queste donne le esponga ad un maggior rischio di sviluppare una crisi renale nel corso della nuova gravidanza.

Steen et al. hanno descritto 5 gravidanze di donne sclerodermiche con precedente crisi renale; 4 donne hanno portato a termine la gravidanza mentre una donna ha avuto un aborto precoce. Nell'ambito di 91 gravide sclerodermiche 2 hanno sviluppato una crisi renale (entrambe con una forma diffusa ad esordio recente e pertanto ad alto rischio di crisi renale indipendentemente dalla gravidanza), per cui in un caso si è proceduto ad un aborto terapeutico alla 20esima settimana al fine di controllare la crisi, nell'altro caso è stato impostato il trattamento dialitico e con ACE inibitore e si è avuto un parto prematuro. ${ }^{23}$ A riprova del fatto che non fosse la gravidanza di per sé ma il fenotipo clinico ad essere predittivo di crisi renale, Steen ha confrontato queste pazienti gravide con donne affette da dcSSc in fase precoce ma non gravide e non ha riscontrato alcun aumento dell'incidenza di crisi renale in corso di gravidanza.

Nello studio IMPRESS non si è assistito a nessuna crisi renale in corso di gravidanza; una donna anti-topoisomerasi + ha sviluppato una crisi renale un mese dopo la nascita di un neonato SGA. ${ }^{24}$

\section{L'impegno cardiopolmonare}

Le donne sclerodermiche non hanno outcomes cardiopolmonari peggiori rispetto ad altre donne incinte con analogo performance status cardiopolmonare. Lo stress cardiovascolare indotto dalla gravidanza può smascherare un danno miocardico subclinico, soprattutto se si ricorre ai beta-agonisti come tocolitici in caso di minaccia di parto pretermine (in queste pazienti sono preferibili i calcio-antagonisti).

Nello studio IMPRESS una donna anti-topoisomerasi + con una malattia ad esordio recente $(18$ mesi) ha sviluppato una miocardite 6 mesi dopo un parto pretermine.

La gravidanza in queste pazienti, inoltre, non si associa ad un'evoluzione del quadro di fibrosi polmonare. Al contrario Steen et al. nel 1999 hanno descritto la gra- 
vidanza di 5 casi di fibrosi polmonare: in 3 casi c'è stato un parto prematuro, in un caso un exitus in seguito ad una polmonite da inalazione e in un caso un'interruzione di gravidanza nel primo trimestre. ${ }^{23}$

Nelle donne con impegno cardiopolmonare è mandatorio uno stretto follow-up, soprattutto nel terzo trimestre, quando la distensione dell'utero, l'elevazione delle cupole diaframmatiche e la formazione di microatelettasie alle basi polmonari possono determinare ipossia (che si somma al fisiologico aumento del consumo di ossigeno in gravidanza), necessitante di supporto di ossigeno.

\section{L'impegno gastrointestinale}

I disturbi gastrointestinali, quali il reflusso gastroesofageo, la dispepsia, la costipazione, sono comuni a tutte le gravidanze. In particolare, il reflusso si accentua nel secondo e nel terzo trimestre di gravidanza per via della riduzione del tono dello sfintere esofageo inferiore e dell'aumento della pressione intra-addominale. Le sclerodermiche lamentano abitualmente questi disturbi, che rientrano nel corteo sintomatologico della patologia e che possono accentuarsi durante la gravidanza. Dallo studio IMPRESS, infatti, emerge che la pirosi peggiora nel $19 \%$ dei casi, mentre le alterazioni dell'alvo compaiono in circa il $9 \%$ delle donne. ${ }^{24}$

\section{L'impegno cutaneo}

Nello studio condotto da Steen, in 7 donne su 59 si è assistito ad un peggioramento dell'impegno cutaneo dopo il parto; si è ipotizzato che ciò possa essere riconducibile alla sospensione della terapia immunosoppressiva prima della gravidanza. ${ }^{23}$

Il dato è stato confermato dallo studio IMPRESS, in cui si è visto che il mRSS è peggiorato nel $15 \%$ delle donne dopo il parto (passando da una media di $7,7$ a 15$){ }^{24}$

\section{Il fenomeno di Raynaud}

Il fenomeno di Raynaud e le ulcere digitali migliorano nel secondo e nel terzo trimestre di gravidanza in virtù dell'aumento della gittata cardiaca, per poi peggiorare nuovamente subito dopo il parto. Sono stati segnalati pochi casi di necrosi digitale acuta nell'ultima fase della gravidanza in donne in terapia con beta-bloccanti o in corso di stati settici. ${ }^{6}$

\section{Vasculopatia placentare}

L'interessamento vascolare è tipico della SSc, e può coinvolgere anche la vascolarizzazione placen- tare. Esami istopatologici di un numero limitato di casi hanno evidenziato vasculopatia della decidua con fibrosi stromale, displasia mesenchimale e infarti ischemici. Queste anomalie sono simili a quelle osservate nelle gravidanze complicate da ipertensione gravidica e possono essere la base fisiopatologica di ritardo di crescita fetale, prematurità, ipertensione arteriosa. ${ }^{39}$

\section{Il parto}

Al momento del parto specifici accorgimenti possono essere il riscaldamento adeguato della sala parto, della superficie cutanea e degli eventuali liquidi perfusi al fine di prevenire un'esacerbazione del fenomeno di Raynaud (Tabella 3). L'anestesia regionale (in particolare il blocco epidurale) è consigliata al momento del parto perché induce vasodilatazione periferica, con conseguente incremento della perfusione cutanea. Eisele consiglia di usare dosaggi di anestetici inferiori perché le donne affette da SSc spesso riportano un blocco sensitivo-motorio di lunga durata dopo il parto. ${ }^{40}$

Qualunque sia il quadro di impegno cutaneo, non si è evidenziato un ritardo di cicatrizzazione in caso di taglio cesareo o di episiotomia, se la ferita viene accudita con cura. $^{23}$

\section{Il counselling pre-concezionale}

Prima di avviare una gravidanza è fondamentale un counseling pre-concezionale adeguato, al fine di valutare diversi aspetti (Tabella 3), quali:

- L'attività di malattia, l'entità ed il tipo di coinvolgimento d'organo. Un importante danno d'organo (polmonare, cardiaco, renale, intestinale, etc) controindica la gravidanza. La PAH, in conformità con le raccomandazioni ESC/ERS del 2015 è controindicazione assoluta alla gravidanza. Va ricordato che le donne con sclerodermia all'esordio (durata di malattia inferiore ai 4 anni) e positività anticorpale per gli anti-topoisomerasi e gli anti RNApolIII hanno generalmente una malattia più aggressiva rispetto alle donne con positività anticorpale per gli anti-centromero e malattia di lunga durata, per cui le prime potrebbero essere a maggior rischio di progressione durante la gravidanza e nell'immediato post-partum sebbene dagli studi ad oggi condotti non sia emersa una differenza negli outcomes gravidici tra le forme limitate e le diffuse $^{37,38}$. L'optimum sarebbe che la donna decidesse di intraprendere una gravidanza in una fase quiescente di malattia, ma questo non sempre avviene.

- L'assetto anticorpale, valutando gli anticorpi che possono influenzare la gravidanza, quali gli anticorpi anti-fosfolipidi (anti-cardiolipina, anti- 
Tabella 3. Gestione delle pazienti durante la gravidanza, il parto ed il post-partum.

Counselling pre-concezionale

1. Valutare il subset di malattia, il tipo di coinvolgimento viscerale, l'assetto auto anticorpale e stadiare la malattia

2. Sospendere preferibilmente tre mesi prima della gravidanza i possibili farmaci teratogeni (bosentan, macitentan, micofenolato mofetile, methotrexate, ciclofosfamide)

3. Iniziare l'acido folico ed eventualmente la cardioaspirina

In corso di gravidanza

1. Stretto follow-up ostetrico-ginecologico-internistico

2. Non controindicato 1'uso di inibitori di pompa protonica, bloccanti dell'istamina o bloccanti dei canali del calcio per problemi gastrointestinali e vascolari

3. Evitare gli alti dosaggi di steroidi se non strettamente indicati per il rischio di prematurità

4. Monitoraggio della crescita intrauterina ed eventuale monitoraggio della velocimetria materno-fetale dalla XXIV settimana gestazionale in caso di positività degli AntiSSA

5. Monitoraggio materno della pressione arteriosa; in caso di ipertensione intraprendere prontamente una terapia antipertensiva efficace, qualunque sia la causa

6. Evitare gli agonisti dei recettori beta-adrenergici come tocolitici in caso di parto pretermine

\section{Parto}

1. Optare per l'anestesia locale

2. Riscaldare la sala parto ed i fluidi infusi per ridurre la vasocostrizione periferica

3. Posizionare un valido accesso venoso

\section{Post-partum}

1. Proseguire un attento monitoraggio con ripristino precoce dei farmaci teratogeni eventualmente sospesi e trattamento aggressivo dell'ipertensione se è presente

beta2glicoproteina I, LAC) e gli anticorpi antiRo/SSA.

- La terapia assunta, tenendo presente che bosentan, macitentan, micofenolato mofetile, ciclofosfamide e methotrexate sono teratogeni e vanno interrotti prima del concepimento (preferenzialmente 3 mesi prima). Gli inibitori della pompa protonica e gli anti-istaminici $\mathrm{H} 2$ sono sicuri. Se necessari, i calcio antagonisti possono essere somministrati. I cortisonici vanno adoperati il meno possibile e alle minime dosi efficaci. In caso di crisi renale sclerodermica vanno utilizzati gli ACE-inibitori anche durante la gravidanza.

- La supplementazione con acido folico, che va iniziata sin da prima del concepimento per risultare efficace nella prevenzione della spina bifida.

- L'uso di bassi dosi di aspirina, al fine di ridurre rischio di pre-eclampsia nelle donne a rischio.

- La pianificazione del successivo follow-up con visite mensili.

- Il monitoraggio della pressione arteriosa.

Il counseling si configura come il momento in cui da un lato si informerà la paziente degli eventuali rischi relati alla patologia, dall'altro spesso la si rassicurerà, in quanto la gravidanza può essere affrontata con ragionevole serenità qualora le condizioni di base della donna siano buone, senza danni d'organo di rilievo, il concepimento si collochi in una fase quiescente di malattia, i farmaci teratogeni siano stati sospesi ed eventualmente sostituiti da farmaci più sicuri.

È necessaria una gestione multidisciplinare coordinata tra internista/immunologo/reumatologo, ginecologo, anestesista e neonatologo per impostare un monitoraggio e una terapia cucita sulla specifica paziente, garantendo il monitoraggio più congruo alle differenti fasi della gravidanza e minimizzando il rischio di complicanze.

\section{Bibliografia}

1. Tincani A, Dall'Ara F, Lazzaroni MG et al. Pregnancy in patients with autoimmune disease: a reality in 2016 . Autoimmunity Reviews 1016;15(10), 975-7.

2. Scarpinato L, Mackenzie AH. Pregnancy and progressive systemic sclerosis. Case report and review of the literature. Cleve Clin Q. 1985;52:207-11.

3. Black CM, Stevens WM. Scleroderma. Rheum Dis Clin North Am 1989;15:193-212.

4. Maymon R, Fejgin M. Scleroderma in pregnancy. Obstet Gynecol Surv 1989; 44 (7): 530-4.

5. Steen VD. Scleroderma and pregnancy. Rheum Dis Clin North Am 1997; 23(1):133-47.

6. Steen VD, Medsger TA. Fertility and pregnancy outcome in women with systemic sclerosis. Arthritis Rheum 1999;42(4):763-8.

7. Steen VD. Pregnancy in scleroderma. Rheum Dis Clin North Am 2007;33:345-58.

8. Østensen M, Brucato A, Carp H et al. Pregnancy and reproduction in autoimmune rheumatic diseases. Rheuma tology 2010; 50(4):657-64.

9. Nusbaum MR, Hamilton C, Lenahan C. Chronic illness and sexual functioning. Am Fam Physician 2003;67:34754.

10. Schouffoer AA, van der Marel J, ter Kuile MM et al. Impaired sexual function in women with systemic sclerosis: a cross-sectional study. Arthritis Rheum 2009; 61(11): 1601-8.

11. Impens AJ, Rothman J, Schiopu E et al. Sexual activity and functioning in female scleroderma patients. Clin 
Exp Rheumatol 2009; 27(3 Suppl. 54):38-43.

12. Knafo R, Haythornthwaite JA, Heinberg L et al. The association of body immage dissatisfaction and pain with reduced sexual function in women with systemic sclerosis. Rheumatology 2011;50(6):1125-30.

13. Levis B, Hudson M, Knafo R et al. Rates and correlates of sexual activity and impairment among women with systemic sclerosis. Arthritis Care Res 2012;64(3)340-50.

14. Guerriere JA et al. Quality of life and sexual function in women with systemic sclerosis. Arthritis Rheum 2001; 44 Suppl:S328.

15. Knafo R, Thombs BD, Jewett L et al. (Not) talking about sex: a systematic comparison of sexual impairment in women with systemic sclerosis and other chronic disease samples. Rheumatology 2009;48:1300-3.

16. Ballou SP, Morley JJ, Kushner I. Pregnancy and systemic sclerosis. Arthritis Rheum 1984;27(3):295-8.

17. Englert H, Brennan P, McNeil D et al. Reproductive function prior to disease onset in women with scleroderma. J Rheumatology 1992;19:1575-9.

18. Giordano M, Valentini G, Lupoli S et al. Pregnancy and systemic sclerosis. Arthritis Rheum 1985;28(2):237-8.

19. Østensen M, Khamashta M, Lockshin M et al. Anti-inflammatory and immunosuppressive drugs and reproduction. Arthritis Res Ther. 2006;8(3):209.

20. Betelli M, Breda S, Ramoni V et al. Pregnancy in systemic sclerosis JSRD 2018;4:21-29.

21. Silman AJ and Black C. Increased incidence of spontaneous abortion and infertility in women with scleroderma before disease onset: a controlled study. Ann Rheum Dis. 1988;47:441-444.

22. Slate WG and Graham AR. Scleroderma and pregnancy. Am J Obstet Gynecol 1968;101(3):335-41.

23. Steen VD. Pregnancy in women with systemic sclerosis. Obstet Gynecol. 1999;94:15-20.

24. Taraborelli M, Ramoni V, Brucato A et al. Brief Report: Successful pregnancies but a higher risk of preterm births in patients with systemic sclerosis: An Italian multicenter study. Arthritis Rheum 2012;64(6)1970-1977.

25. Beck S, Wojdyla D, Say L et al. The worldwide incidence of preterm birth: a systematic review of maternal mortality and morbidity. Bull World Health Organ 2010;88:31-38.

26. Chung L, Flyckt RLR, Colon I et al. Outcome of pregnancies complicated by systemic sclerosis and mixed connective tissue disease. Lupus 2006;15:595-9.

27. Chen JS et al. Pregnancy Outcomes in Women With Rare Autoimmune Diseases. Arthritis Rheum 2015;67 (12), 3314-23.
28. Steen VD, Conte C, Day N et al. Pregnancy in women with systemic sclerosis. Arthritis Rheum. 1989;32 (2):151-7

29. Bonnin M, Mercier FJ, Sitbon O et al. Severe pulmonary hypertension during pregnancy: mode of delivery and anesthetic management of 15 consecutive cases. Anesthesiology 2005;102, 1133-7.

30. Bedard E, Dimopoulos K, Gatzoulis MA. Has there been any progress made on pregnancy outcomes among women with pulmonary arterial hypertension? Eur Heart J 2009;30:256-65.

31. Martin SR and Edwards A. Pulmonary hypertension and pregnancy. Obstet Gynecol 2019;134(5):974-87.

32. Ladoucer M. Pregnancy and pulmonary arterial hypertension. Presse Med 2019; 48(12):1422-1430.

33. Steen VD. Scleroderma renal crisis. Rheum Dis Clin North Am 2003;29(2):315-33.

34. Teixeira L, Mahr A, Berezné A et al. Scleroderma renal crisis, still a life-threatning complication. Ann N Y Acad Sci 2007.

35. Friedman SA, Bernstein MS, Kitzmiller JL. Pregnancy complicated by collagen vascular disease. Obstet Gynecol Clin North Am. 1991;18:213-236.

36. Zeisler H, Llurba E, Chantraine F et al. Predictive Value of the sFlt-1: PlGF Ratio in Women With Suspected Preeclampsia. N Eng J Med 2016;374:13-22.

37. Steen VD. Long-term outcomes of scleroderma renal crisis. Ann Intern Med. 2000;133:600-603.

38. Easterling TR, Carr DB, Davis C et al. Low-dose, shortacting, angiotensin-converting enzyme inhibitors as a rescue therapy in pregnancy. Obstet Gynecol 2000;96 (6):956-61.

39. Ibba-Manneschi L, Manetti M, Milia AF et al. Severe fibrotic changes and altered expression of angiogenic factors in maternal scleroderma: placental findings. Ann Rheum Dis 2010;69(2):458-61.

40. Eisele JH, Reitan JA. Scleroderma, raynaud's phenomenon and local anesthetics. Anesthesiology 1971;34 (4):386-7.

41. Rueda de Leon Aguirre A, Ramirez Calvo JA, Rodriguez Reyna TS. Comprehensive approach to systemic sclerosis patients during pregnancy. Reumatol Clin 2015;11:99-107.

42. Ostensen M, Andreoli L, Brucato A et al. State of the art: reproduction and pregnancy in rheumatic diseases. Autoimmun Rev 2015;14:376-86.

43. Rolnik DL, Wright D, Poon LC, et al. Aspirin versus placebo in pregnancies at high risk for preterm preeclampsia. N Engl J Med. 2017;377(7):613-622. 


\title{
Anticorpi anti-Ro/SSA, sindrome di Sjögren, lupus neonatale e blocco cardiaco congenito
}

\author{
Chiara Picchi, ${ }^{1}$ Enrico Tombetti, ${ }^{2}$ Antonio Luca Brucato ${ }^{3}$
}

${ }^{1}$ U.O. Medicina Interna, Ospedale Fatebenefratelli e Presidio Ospedaliero Macedonio Melloni, Milano; ${ }^{2}$ Dipartimento di Scienze Biomediche e Cliniche 'L. Sacco', Università degli Studi di Milano, Milano; ${ }^{3}$ U.O. Medicina Interna, Ospedale Fatebenefratelli e Presidio Ospedaliero Macedonio Melloni e Dipartimento di Scienze Biomediche e Cliniche 'L. Sacco', Università degli Studi di Milano, Milano, Italia

\section{Introduzione}

Gli Ab anti-Ro/SSA e anti-La/SSB possono essere presenti nel siero di donne sane asintomatiche e nel siero di donne con molteplici condizioni cliniche, in particolare con patologie autoimmuni. Si ritrovano infatti, con frequenza via via decrescente, in donne con sindrome di Sjögren (SS), pazienti affette da lupus eritematoso sistemico (LES), pazienti con connettivite indifferenziata e in donne con artrite reumatoide (AR). Il lupus neonatale (LN) è una patologia rara causata dal passaggio transplacentare degli anti Ro/SSA dal circolo materno al circolo fetale, a partire dalla 16 settimana e con un picco dalla 18 alla 24 settimana di gestazione. Una donna con positività per gli anti-Ro/SSA presenta un rischio pari all' $1-2 \%$ di avere un figlio affetto da LN, mentre il rischio aumenta al $15-20 \%$ in caso di precedente gravidanza con LN. Le manifestazioni cliniche del LN possono coinvolgere principalmente la cute, ma anche fegato e vie biliari, sistema emopoietico e cuore. Il coinvolgimento cardiaco si manifesta, in assenza di cardiopatie congenite, con un blocco cardiaco congenito (BCC) di vario grado, fibroelastosi endocardiaca della giunzione atrioventricolare e con una cardiomiopatia dilatativa (CMD). Contrariamente alle altre manifestazioni che sono transitorie, l'interessamento cardiaco è definitivo ed è associato ad alta mortalità e morbidità.

Il monitoraggio ecocardiografico fetale, utile per

Corrispondente: Chiara Picchi, U.O. Medicina Interna, Ospedale Fatebenefratelli e Presidio Ospedaliero Macedonio Melloni, piazza Principessa Clotilde 3, Milano, Italia.

E-mail: chiara.picchi@asst-fbf-sacco.it

Articolo pubblicato secondo la Creative Commons Attribution NonCommercial 4.0 License (CC BY-NC 4.0).

${ }^{\circ}$ Copyright: the Author(s), 2021

Licensee PAGEPress, Italy

QUADERNI - Italian Journal of Medicine 2021; 9(4):e8 la ricerca di eventuali anomalie che possono condurre al $\mathrm{BCC}$, viene effettuato ogni una o due settimane, a partire dalla 16 settimana di gestazione. In caso di anamnesi ostetrica positiva per $\mathrm{LN}$, invece il monitoraggio è più serrato, una volta a settimana. Vista la rapidità evolutiva del $\mathrm{BCC}$ da incompleto a completo, potrebbe essere utile un monitoraggio domiciliare da parte delle madri tramite un dispositivo portatile in grado di rilevare anomalie del battito cardiaco fetale.

La terapia si basa classicamente sull'utilizzo di steroidi fluorinati; studi recenti hanno sperimentato l'utilizzo di desametasone, aferesi e Ig ev per la prevenzione dell'evoluzione in BCC completo e in caso di segni di scompenso, idrope fetale, miocardite. L'utilizzo di idrossiclorochina (HCQ) risulta ad oggi l'unica strategia profilattica supportata da dati scientifici per le donne a rischio di sviluppare LN; è inoltre stato osservato che l'utilizzo di HCQ diminuisce il rischio di recidiva all' $8 \%$ in caso di anamnesi ostetrica positiva per LN.

\section{Gli antigeni Ro/SSA e La/SSB e sindrome di Sjögren}

Ro/SSA e La/SSB sono due antigeni noti per rappresentare un possibile bersaglio di reazioni autoimmuni. La duplice nomenclatura con cui questi antigeni sono conosciuti ha ragioni storiche, quando furono identificati come bersagli di autoanticorpi in due coorti indipendenti di pazienti lupici (rispettivamente nei pazienti 'Ro' e 'La') di pazienti con sindrome di Sjögren (SS).

L'antigene Ro/SSA è un complesso ribonucleoproteico formato da due proteine (Ro52 e Ro60, rispettivamente di 52 e $50 \mathrm{kDa}$ ) e piccoli RNA non codificanti della classe degli YRNA. In particolare, Ro60 contiene un dominio di legame con gli RNA, ${ }^{1}$ mentre Ro52 ha un'azione di E3-ubiquitina ligasi che regola le risposte immuni mediate dall'interferon regulatory factor. ${ }^{2} \mathrm{Al}$ contrario, l'antigene La/SSB è una proteina di $48 \mathrm{kDa}$ 
che agisce come fattore di terminazione della trascrizione svolta della RNA polimerasi III. ${ }^{3}$

Gli anticorpi anti-Ro/SSa e anti-La/SSB sono presenti nel siero di pazienti con molteplici condizioni cliniche, in particolare con malattie sistemiche autoimmuni. In questo caso la prevalenza degli anti-Ro/SSA è maggiore rispetto agli anti-La/SSB; gli anti-SSB tendono infatti ad essere presenti solamente in un sottogruppo, che rappresenta circa il $30-60 \%$ dei pazienti con anti-Ro/SSA. Inoltre, pazienti con malattie autoimmuni sistemiche presentano anti-Ro/SSA con frequente specificità per-Ro60. ${ }^{4}$

Da un punto di vista clinico, gli autoanticorpi antiRo/SSA e anti-La/SSB sono associati in primo luogo alla SS, connettivite caratterizzata da un attacco autoimmune nei confronti delle ghiandole esocrine e di cui questi anticorpi sono un importante marcatore diagnostico. Nel $50 \%$ dei casi la SS è primitiva ed è caratterizzata da xeroftalmia e xerostomia, mentre nel $50 \%$ dei casi è associata ad altre patologie autoimmuni (AR $30 \%$, LES $10 \%$, sclerodermia $1 \%$, patologie autoimmuni della tiroide, epatite cronica, disordini del sistema linfatico). La SS è frequentemente associata alla presenza di anticorpi anti-Ro/SSA (70-80\%). Con frequenza via via più bassa, gli anti-Ro/SSa e anti-La/SSB sono riscontrabili nei pazienti con LES (40\%) e lupus eritematoso subacuto cutaneo, sclerosi sistemica (SSC) e altre connettiviti e artrite reumatoide (AR). Sono descritte positività per anti-Ro/SSA in corso di epatopatie autoimmuni e malattia celiaca, con prevalente specificità per anti-Ro52. Esistono inoltre soggetti con positività per anti-Ro/SSA o anti-La/SSB che non presentano malattie immunomediate, ma che possono presentare neoplasie solide o ematologiche, mentre altri (che rappresentano fino allo $0,5 \%$ della popolazione generale) possono essere completamente asintomatici. In molti casi si tratta di giovani donne in età fertile, che quindi prima o poi potrebbero affrontare una gravidanza.

\section{Gravidanza in donne con anti-Ro/SSA o anti-La/SSB: il lupus neonatale}

La positività materna per anti-Ro/SSA e anti$\mathrm{La} / \mathrm{SSB}$ in corso di gravidanza assume particolare rilevanza perché espone al rischio di sviluppare il lupus neonatale (LN), condizione causata dalla trasmissione transplacentare nel circolo fetale di autoanticorpi materni. Il nome 'lupus neonatale' deriva dall'iniziale osservazione di tale fenomeno nei figli di donne lupiche e dalla sua somiglianza clinica con alcune manifestazioni del lupus eritematoso dell'adulto.

$\mathrm{Si}$ è successivamente compreso che il fattore materno necessario per lo sviluppo di LN non è la diagnosi di LES, bensì la positività per anti anti-Ro/SSA e/o anti$\mathrm{La} / \mathrm{SSB}$ o, più raramente, per anti U1-RNP. Circa il $20 \%$ delle madri di figli con LN è affetto da SS, il 15\% da LES, il 15\% sia da SS che LES, 1'1\% da AR, il 25\% da altre condizioni autoimmuni o da connettiviti indifferenziate; nel $25 \%$ dei casi invece sono donne asintomatiche con positività anticorpale ma senza storia di malattie autoimmuni sistemiche (la metà di queste ultime, tuttavia, sviluppa manifestazioni cliniche autoimmuni entro i successivi tre anni). ${ }^{5-8}$

Fortunatamente, il LN è molto raro e la maggioranza delle donne a rischio per profilo autoanticorpale non presenterà figli affetti da altre patologie. Il rischio di una madre con anti-Ro/SSA di avere figli con LN è infatti circa del 1-2\%, che aumenta al 3,1\% in caso di positività anche per anti-La/SSB e si riduce allo $0.9 \%$ in caso di negatività di questi ultimi. ${ }^{9}$

\section{Manifestazioni cliniche del lupus neonatale}

Le manifestazioni cliniche del lupus neonatale possono coinvolgere il cuore (circa $25 \%$ dei casi), la cute ( $40 \%$ dei casi), il sistema emopoietico (35\% dei casi), il fegato ( $35 \%$ dei casi) e, più raramente, il sistema nervoso centrale. Talvolta alcuni aspetti clinici come l'interessamento cutaneo possono non essere presenti alla nascita, ma in generale essi compaiono entro il terzo mese di vita. La clearance degli anticorpi materni dalla circolazione del lattante comporta la naturale risoluzione delle manifestazioni infiammatorie del lupus neonatale entro il primo anno di vita, con tuttavia possibili esiti cicatriziali permanenti, specie a livello cardiaco o cutaneo. Il tipico interessamento cutaneo ricorda clinicamente le manifestazioni subacute del lupus eritematoso sistemico del paziente adulto. Esso è caratterizzato da macule e macchie eritematose talvolta con caratteristiche annulari o policlicliche, più spesso sulle aree fotoesposte. ${ }^{10}$ Generalmente sono manifestazioni transitorie, anche se sono possibili esiti permanenti discromici o atrofici.

Le manifestazioni ematologiche, quali anemia, neutropenia, piastrinopenia e raramente anemia aplastica, ${ }^{5}$ e quelle epatobiliari, come l'elevazione delle transaminasi, degli indici di colestasi o epatomegalia, sono reversibili e presentano prognosi buona. Raramente alcuni neonati affetti da $\mathrm{LN}$ possono mostrare macrocefalia, con o senza idrocefalo.

Dal punto di vista clinico e prognostico, l'aspetto più rilevante del $\mathrm{LN}$ è rappresentato dall'interessamento cardiaco. La complicanza cardiaca più frequente è rappresentata dalla comparsa di blocco cardiaco congenito (BCC), definito come un blocco atrioventricolare (BAV) insorto in utero o entro il primo mese di vita e che tipicamente colpisce cuori che non presentano anomalie strutturali. Altre manifestazioni possibili sono la miocardite, cardiomiopatia dilatativa e fibroelastosi endocardica. ${ }^{11,12}$ Il LN è la causa dell $180 \%$ dei casi di BCC in cuori strutturalmente sani. 
Dal punto di vista istologico, l'aspetto più tipico è la fibrosi del nodo $\mathrm{AV}$ e del sistema di conduzione distale, ma è descritto anche un coinvolgimento fibrotico del nodo seno-atriale e del fascio di His. Il BCC si può manifestare con BAV di I, II o III grado e generalmente insorge fra la $16^{\circ}$ e la $24^{\circ}$ settimana gestazionale, con un picco intorno alla $18^{\circ}$ settimana. L'evoluzione è spesso acuta, con rapida progressione verso un BAV completo nel giro di poche ore o giorni.

I BAV avanzati possono determinare bradicardia fetale già evidente in utero (es 40-100 bpm), condizionante scompenso cardiaco ed ipoperfusione nella vita intrauterina e/o postnatale. , $^{5,13,14}$

In circa il 5-10\% dei casi di LN si sviluppa una cardiomiopatia, che può essere ricondotta al $\mathrm{BCC}$, agli esiti del pacing ventricolare ed alla conseguente asincronia, ${ }^{5}$ alla miocardite o alla fibroelastosi endocardica. ${ }^{11}$ Talvolta, lo sviluppo di cardiomiopatia dilatativa può avvenire tardivamente, nel periodo neonatale 0 , più raramente, durante l'infanzia. ${ }^{15}$

È stato ipotizzato che il LN possa associarsi a bradicardia sinusale, prolungamento dell'intervallo QT ed anomalie strutturali del cuore o delle valvole; questi aspetti però sono clinicamente meno rilevanti e mancano dati significativi in merito.

\section{Patogenesi del lupus neonatale}

La patogenesi del LN si basa sul passaggio transplacentare nel circolo fetale di autoanticorpi materni della classe $\mathrm{IgG}$, a partire dalla $11-12^{\circ}$ settimana gestazionale. La maggioranza delle madri $(80 \%)$ di feti affetti da LN presenta positività per autoanticorpi antiRo/SSA, anti-La/SSB o più raramente anti-U1-RNP. Ciò non esclude che altri autoanticorpi materni possano svolgere un ruolo ancillare in presenza dei tre sopra citati.

Alcuni aspetti clinico-epidemiologici sono rilevanti dal punto di vista patogenetico. Infatti, le madri dei neonati con $\mathrm{BCC}$ non presentano un BAV, nonostante sia descritta l'aritmogenicità degli antiRo/SSA ${ }^{16}$ e sia stato osservato un allungamento dell'intervallo QT in alcune coorti di adulti positivi per tali autoanticorpi. Inoltre, solo una ristretta minoranza (1-2\%) delle donne con anti-Ro/SSA e/o anti$\mathrm{La} / \mathrm{SSB}$ ha progenie affetta da BCC. Questo rischio aumenta al $15-20 \%$ in caso di precedente gravidanza con BCC..$^{17,18}$

Queste osservazioni suggeriscono una particolare vulnerabilità del tessuto di conduzione cardiaco fetale agli autoanticorpi ed una patogenesi multifattoriale, in cui la presenza degli anticorpi patogenetici è fattore necessario ma non sufficiente allo sviluppo di BCC. Per spiegare l'insorgenza del LN solo in una stretta minoranza di gravidanze potenzialmente a rischio, si è ipotizzato che solamente alcuni autoanticorpi anti-
$\mathrm{Ro} / \mathrm{SSA}$ o La/SSB abbiano in realtà un ruolo patogenetico, in base agli epitopi riconosciuti. Studi condotti in vivo su ratti hanno evidenziato che gli anticorpi che riconoscono la porzione gli aminoacidi 200-239 di Ro52 (p200) inducono BAV di I grado e bradicardia sinusale, a differenza degli anticorpi diretti contro altre porzioni dell'antigene Ro/SSA. Tuttavia, il BAV di I grado non è sempre indice di patologia, poiché può risolversi spontaneamente. Inoltre, ulteriori studi epidemiologici non hanno dimostrato una specificità anticorpale univocamente legata all'insorgenza di LN o di BCC. $4 ., 9,14,19$

Attualmente due sono i meccanismi ritenuti potenzialmente responsabili del danno a livello del nodo AV e dello sviluppo di BCC (Figura 1).

Questi meccanismi non sono mutualmente esclusivi e vengono riportati di seguito:

1) Mimetismo molecolare con i canali del calcio. Gli autoanticorpi materni anti-Ro/SSA sono stati descritti cross-reagire con i canali del calcio di tipo $\mathrm{L}^{20}$ espressi nel cuore fetale, responsabili dell'accoppiamento eccitazione/contrazione e dello sviluppo del nodo AV. Il legame antigene-anticorpo porterebbe all'internalizzazione del canale e a una maggiore suscettibilità all'apoptosi. Ciò sarebbe supportato dall'osservazione in modelli murini che l'overespressione dei canali del calcio limita la bradicardia sinusale e il deterioramento della conduzione AV indotte dall'infusione di autoanticorpi. ${ }^{21}$

2) Apoptosi 'infiammatoria'. Durante il processo di rimodellamento tissutale in corso di organogenesi, alcuni cardiomiociti vanno normalmente incontro ad apoptosi. Durante questo processo vengono esposti sulla superficie cellulare gli antigeni $\mathrm{Ro} / \mathrm{SSA}$ e La/SSB altrimenti confinati nello spazio intracellulare. Il conseguente legame antigene-anticorpo avviene sui corpi apoptotici e inibisce la normale efferocitosi dei miocardiociti apoptotici. ${ }^{22}$ L'accumulo di miocardiociti apoptotici ricoperti da autoanticorpi indurrebbe un programma pro-infiammatorio nei macrofagi, ${ }^{23}$ tramite l'attivazione dei recettori per l'Fc presenti sulla membrana dei macrofagi e l'attivazione toll-like receptors (TLR) intracellulari (ad TLR7) da parte degli RNA presenti nei complessi Ro/SSA fagocitati insieme ai miocardiociti apoptotici. La risultante risposta infiammatoria porterebbe nuova apoptosi e una stimolazione della produzione di trasforming growth factor (TGF)-beta, una delle principali proteine pro-fibrosanti, che induce la differenziazione dei fibroblasti a miofibroblasti e fibrosi a livello del nodo $\mathrm{AV}$ e del miocardio in generale. È stato proposto per la beta2 glicoproteina I un possibile ruolo protettivo, che si baserebbe sulla la capacità di antagonizzare il legame antigene-anticorpo a livello dei corpi apoptotici, 
In parallelo a questi due meccanismi di azione degli autoanticorpi materni, è verosimile che fattori genetici ed ambientali abbiano un ruolo nel determinare l'insorgenza e l'evoluzione della malattia. Polimorfismi genetici nel feto potrebbero influenzare sia la formazione del legame antigene-anticorpo, sia il tipo di risposta conseguente al legame. Studi con approccio gene-candidato hanno mostrato una significativa associazione fra i polimorfismi genetici del TGF-beta. ${ }^{24}$ Uno studio di associazione genome-wide ha mostrato un' associazione tra la regione HLA e l'interessamento cardiaco nel LN. ${ }^{25}$ L'associazione più stretta era con loci vicini agli MHC di classe III. Si sono osservate anche altre associazioni con polimorfismi vicini a loci che regolano l'apoptosi e l'infiammazione, ma nessuna raggiungeva una significatività 'genome-wide'. Bisogna tuttavia considerare che gli studi genetici sono limitati dall'effetto dell'ereditarietà materna e dall'influenza genetica sulla malattia materna e/o sulla produzione di anticorpi patogenetici da parte della madre. È inoltre interessante osservare che le gravidanze gemellari monozigoti hanno feti e neonati più spesso discordanti circa la presenza o meno del LN, suggerendo che cofattori ambientali o stocastici hanno una rilevanza importante per lo sviluppo del fenotipo di malattia.
Per quanto riguarda i fattori genetici, alla base delle manifestazioni non-cardiache, gli studi suggeriscono una comune suscettibilità genetica fra LN cutaneo e le forme di lupus subacuto cutaneo, dovuta all'aplotipo tumor necrosis factor (TNF)-alfa A308/HLA-DRB $1 * 03 .{ }^{26} \mathrm{Si}$ ipotizza che tale aplotipo conduca a una maggiore espressione di TNF-alfa da parte dei cheratinociti esposti ai raggi ultravioletti della luce solare, con conseguente stimolazione di apoptosi e infiammazione. Tuttavia, i due loci (TNFalfa e HLA-DRB1) sono in linkage disequilibrium nella popolazione caucasica e gli studi non permettono di distinguere con chiarezza il ruolo individuale di questi due polimorfismi.

\section{Prognosi e storia naturale del lupus neonatale}

Il principale fattore prognostico in caso di LN è l'interessamento cardiaco. In caso di BCC la mortalità è stimata all'incirca del $17 \%$, di cui un terzo dei casi è intrauterina. ${ }^{11}$ Fattori prognostici quoad vitam sono: l'età gestazionale di insorgenza del BAV, la bradicardia spiccata, lo sviluppo di idrope fetale, cardiomiopatia dilatativa o fibroelastosi endocardica. ${ }^{11}$ Il posizionamento di PM è necessario nel $70 \%$ dei casi
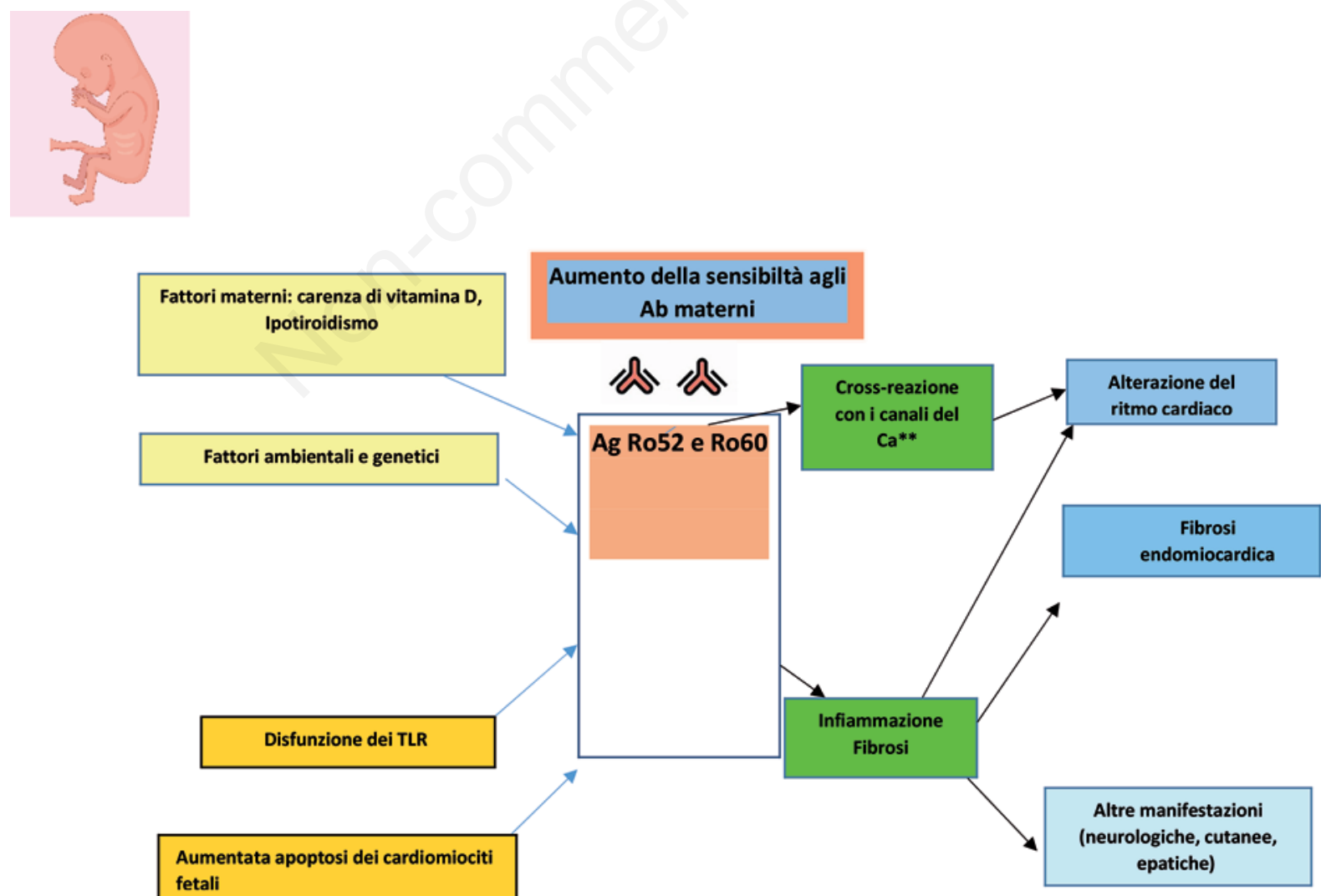

Figura 1. Patogenesi del blocco cardiaco congenito nel lupus neonatale. 
di interessamento cardiaco e permette a chi sopravvive di condurre una vita normale. Nel caso di interessamento cutaneo possono esitare aree atrofiche o discromiche a livello delle sedi interessate. Durante lo sviluppo e la vita adulta il rischio del bambino di sviluppare LES o un'altra patologia autoimmunità sembra essere dovuto alla familiarità, piuttosto che al fatto di avere sviluppato o meno LN.

La storia naturale del BCC non è ben definita, anche se è ragionevole pensare che ci sia un'evoluzione progressiva del BAV fino al blocco completo. Ciò apre una finestra di opportunità per le terapie che mirano ad identificare i casi di BCC prima che si instauri una condizione irreversibile. Tuttavia, esistono vari punti che richiedono di essere chiariti:

a) l'identificazione di marcatori specifici ma precoci di malattia sarebbe utile da un lato come outcome surrogato per studi clinici e patogenetici, dall'altro come biomarker diagnostico precoce per guidare le terapie. Ad oggi si considera il BAV di II grado specifico ma non precoce per BCC, poiché non sempre le terapie sono efficaci in tale circostanza. Tramite monitoraggio ecografico non invasivo è possibile valutare anche il ritardo fra la sistole atriale e quella ventricolare, e stimare di conseguenza l'intervallo PR, identificando i casi con allungamento significativo dello stesso (BAV di I grado). Sfortunatamente, l'utilizzo del BAV di I grado come marcatore precoce di malattia è oggetto di disputa. Infatti, uno studio basato sul monitoraggio ecografico ha mostrato la reversibilità spontanea del BAV di I grado in 6-8 feti, mentre due soggetti sono andati incontro in un caso a progressione fino al BAV completo e nell'altro caso a BAV di II grado (con regressione a BAV di primo I grado dopo terapia steroidea) ${ }^{27}$ Più recentemente, il medesimo gruppo ha mostrato che BAV di I grado nei feti potenzialmente a rischio spesso non evolvevano verso un BAV di grado più avanzato. ${ }^{28}$ Non solo la specificità del BAV di I grado è oggetto di disputa, ma anche la sua sensibilità nei confronti di un successivo BAV di grado avanzato. A tal riguardo, è ragionevole attendersi che i risultati siano dipendenti dalla frequenza dell'intervallo PR stimato ecograficamente. Un recente studio basato su uno screening settimanale ha evidenziato un variabile grado di ritardo di conduzione nei $2 / 3$ dei feti che successivamente hanno sviluppato un BAV di II o di III grado. ${ }^{28}$

b) la velocità di progressione verso blocchi avanzati, che pare essere variabile da soggetto a soggetto. Tale variabile è fondamentale per poter fornire raccomandazioni circa la frequenza ottimale di uno screening al fine di evidenziare precocemente il BCC. Storicamente si consigliava uno screening a cadenza settimanale, ma ci sono casi segnalati in cui la transizione da ritmo sinusale a BAV completo è occorsa in meno di 24 ore. ${ }^{29,30}$

c) la reversibilità dopo terapia. Il BAV completo è considerato virtualmente irreversibile e pertanto non rappresenta un'indicazione ad un trattamento immunologico, tranne nel caso in cui sia di recente insorgenza. Al contrario, il BAV di II grado è considerato potenzialmente reversibile con la terapia, e rappresenta ad oggi la principale finestra di opportunità in cui effettuare una terapia immunologica.

\section{Trattamento del lupus neonatale}

L'approccio terapeutico classico al BBC prevede l'utilizzo degli steroidi fluorinati, come il betametasone e il desametasone $(4-8 \mathrm{mg} / \mathrm{die})$, solo parzialmente inattivati dalla placenta e in grado quindi di avere buona biodisponibilità nel feto. Nonostante vengano utilizzati da vari decenni, i dati pubblicati riguardo l'uso degli steroidi fluorinati nei casi di interessamento cardiaco da LN sono di qualità limitata, considerato il disegno osservazionale degli studi e la loro incompleta concordanza. La letteratura meno recente suggerisce una riduzione della mortalità in caso di BCC conclamato. ${ }^{31}$ Successivi studi osservazionali (non randomizzati) non sono riusciti a confermare la riduzione della mortalità nei figli delle donne trattate con steroidi fluorinati, anche se ciò potrebbe essere dovuto a un bias di allocazione, in cui i casi più gravi vengono avviati al trattamento. ${ }^{11,32} \mathrm{Nel}$ caso di riscontro intrauterino di BAV di II grado, il pooling dei dati dei maggiori studi mostra un trend statistico verso il miglioramento del blocco (normalizzazione della conduzione o regressione a BAV di I grado, $35 \%$ vs $6 \%) .{ }^{11,32}$ Una recente metanalisi ha mostrato una maggiore probabilità di miglioramento del BAV ma un simile tasso di mortalità o necessità di impianto di PM, nei casi trattati con steroidi fluorinati rispetto a quelli non trattati. ${ }^{33} \mathrm{~L}$ ' utilizzo degli steroidi fluorinati in caso di BCC conclamato rimane pertanto controverso. ${ }^{34}$ Recentemente sono stati avviati studi in merito all'effetto negativo che gli steroidi fluorinati utilizzati nel periodo prenatale eserciterebbero sullo sviluppo neuropsicologico del bambino. Il problema riguarderebbe soprattutto il desametasone rispetto al betametasone, che pertanto andrebbe preferito nella scelta terapeutica. Mancano però prove conclusive a tal riguardo, dal momento che anche gli anti-Ro/SSA potrebbero avere un'azione dannosa sullo sviluppo neurospicologico. Inoltre, studi condotti su piccole coorti di pazienti non hanno mostrato una riduzione del quoziente intellettivo (QI). ${ }^{35}$ Nonostante sia quindi ragionevole pensare che non vi siano importanti effetti sullo sviluppo neurocognitivo da parte degli steroidi fluorinati somministrati in età fetale, si suggerisce una 
certa cautela nella somministrazione. L'utilizzo degli steroidi come profilassi nelle gravidanze a rischio non viene suggerito fino a quando mancheranno biomarkers specifici di sviluppo di LN.

Come alternativa terapeutica è stato proposto l'utilizzo di immunoglobuline endovenose (Ig ev) ad alte dosi, sulla base del profilo di sicurezza e dell'efficacia terapeutica delle stesse nei confronti di altre patologie anticorpo-mediate. Le Ig ev saturano i recettori per le Fc senza esercitare cross-link, di fatto limitando le risposte pro-infiammatorie dovute al riconoscimento di complessi antigene-anticorpo. Inoltre, esse stimolano l'espressione di recettori per le $\mathrm{Fc}$ ad azione inibitoria a scapito di quelli attivatori. ${ }^{36}$ Due trials osservazionali prospettici non randomizzati hanno valutato l'utilizzo profilattico delle Ig ev $(400 \mathrm{mg} / \mathrm{kg}$ ogni 3 settimane a partire dalla $12^{\circ}$ settimana gestazionale) nelle gravidanze a rischio di LN. Entrambi gli studi sono stati interrotti precocemente perché non hanno mostrato un'efficacia preliminare nelle prime gravidanze reclutate (rispettivamente 18 e 15 donne ad alto rischio per $\mathrm{LN}$ nelle gravidanze precedenti). ${ }^{37,38} \mathrm{Al}$ contrario, uno studio non controllato ha valutato l'uso delle Ig ev in associazione agli steroidi fluorinati nelle forme più gravi, associate a cardiomiopatia o fibroelastosi endocardica. ${ }^{39}$ I risultati sono stati incoraggianti, con una mortalità osservata pari al $20 \%$, più bassa rispetto ai dati precedenti in cui risultava compresa tral' $80 \%$ e il $25 \%$. $^{11,15,40-42}$

Sulla base della sua attività nel LES e della capacità di inibire il TLR7 (un TLR intracellulare che riconosce acidi nucleici) e il TLR8, è stato proposto l'uso profilattico di idrossiclorochina (HCQ) nelle gravidanze a rischio di LN. Studi preliminari retrospettivi $^{11}$ avevano mostrato una riduzione del 65\% dell'incidenza di BBC in donne gravide anti-Ro/SSA positive trattate con HCQ. Un recente studio prospettico a singolo braccio di fase II ha valutato l'azione profilattica dell'HCQ (400 mg die a partire dalla $10^{\circ}$ settimana gestazionale) in donne in fase gestazionale con precedente gravidanza complicata da BCC. I risultati hanno mostrato l'efficacia profilattica dell'HCQ: su 54 gravidanze reclutate, i casi di BAV di II grado o totale sono stati 4 (pari al $7.4 \%$, significativamente più bassi dell'atteso di circa $18 \%$ ).

In conclusione nei casi di LN con interessamento cardiaco conclamato (escludendo quindi i BAV di I grado), è razionale seguire il seguente approccio: nei BAV di II grado e in quelli completi insorti recentemente, in presenza di segni di miocardite, cardiomiopatia dilatativa, idrope/scompenso fetale, insufficienza valvolare atrioventricolare almeno lieve o sospetta fibroelastosi, si può discutere con la paziente circa l'uso gli steroidi fluorinati (betametasone $8 \mathrm{mg}$ per qualche giorno, con successivo decalage a $4 \mathrm{mg}$ per 4-6 settimane), eventualmente associando Ig ev. Nei casi più gravi (segni di idrope/scompenso cardiaco, miocardite) si può considerare la plasmaferesi. Il già citato recente studio di Sonesson et al. ${ }^{28}$ ha suggerito che le terapie impostate entro la prima settimana dall'insorgenza di un BCC completo fetale possano favorire lo sviluppo di un ritmo ventricolare più efficace anche in assenza di ripresa della conduzione $\mathrm{AV}$, migliorando la prognosi e posticipando la necessità di impianto di PM nella vita post-natale. In caso di grave bradicardia fetale, possono essere utili gli agonisti beta- 2 adrenergici come il salbutamolo ( $2 \mathrm{mg} \mathrm{6-10} \mathrm{volte} \mathrm{die)} \mathrm{come}$ terapia 'a ponte' verso un parto cesare. Per quanto possibile in base alle condizioni fetali ed al persistente trasferimento di autoanticorpi materni al feto, si cerca di posticipare il parto, al fine di ridurre il rischio di prematurità dei neonati e di ritardare l'incremento delle resistenze vascolari del post-partum condizionante un maggior lavoro cardiaco materno.

\section{Gestione della gravidanza a rischio di lupus neonatale}

Le pazienti con patologia autoimmune nota (LES, Sjögren, connettivite) che desiderano una gravidanza, pazienti con anamnesi positiva per pregressa morte endouterina fetale e le pazienti ANA positive con desiderio di maternità dovrebbero essere sottoposte in fase preconcezionale a screening per anticorpi anti-ro/SSA e la/SSB. La gestione multidisciplinare tra Ginecologo e Internista/Reumatologo/Immunologo della donna gravida con malattie autoimmuni deve iniziare infatti ancora prima del concepimento, al fine di minimizzare i rischi legati alla gravidanza e migliorare gli outcomes materni e fetali. Risulta di fondamentale importanza il counselling preconcezionale, mirato all'identificazione dei fattori che possono influire negativamente sul decorso della gravidanza e alla scelta di un adeguato trattamento immunosoppressivo compatibile con la gestazione. La malattia autoimmune materna in fase attiva è infatti il principale fattore di rischio per l'insorgenza di complicanze materno fetali. Il timing ottimale per il concepimento è quello in cui la malattia si presenta in fase quiescente o stabile. $\mathrm{Si}$ raccomanda un periodo di almeno sei mesi libero da malattia attiva prima del concepimento.

Viene inoltre valutata in fase preconcezionale l'eventuale terapia immunosoppressiva in atto e la sua compatibilità con il periodo gestazionale; se necessario viene effettuato uno switch a farmaci sicuri per una adeguata crescita del feto, con attento monitoraggio dell'efficacia terapeutica e della sicurezza. Viene inoltre raccomandata l'assunzione di acido folico ancora prima dell'inizio della gravidanza. Come già discusso in precedenza, l'unica terapia profilattica ad oggi supportata da dati scientifici per le donne gravide a rischio di LN è quella con HCQ. In fase preconcezionale le 
donne con malattie autoimmuni che desiderano una gravidanza saranno sottoposte a una valutazione reumatologica, in cui la donna viene tranquillizzata circa gli outcomes materno fetali favorevoli e alle nuove e sicure strategie terapeutiche. Verrà quindi effettuato un esame clinico e valutazione dei parametri vitali, esecuzione di esami ematochimici di routine quali emocromo, funzionalità renale, funzionalità epatica, esame urine e proteinuria, ricerca anti-ro/SSA e $\mathrm{La} / \mathrm{SSB}$, anticorpi antifosfolipidi, dosaggio C3 e C4, anticorpi anti-DNA, ANA.

Tutte le donne con malattie autoimmuni in gravidanza dovrebbero essere sottoposte a follow up ostetrico e reumatologico mensile, che prevede monitoraggio clinico e terapeutico, esami ematochimici di routine e monitoraggio di eventuali anticorpi antifosfolipidi precedentemente rilevati.

In caso di positività per gli anti-Ro il monitoraggio gestazionale inizia normalmente a partire dalla 16 settimana tramite ecocardiografia del cuore fetale, con lo scopo di individuare i soggetti a rischio di $\mathrm{LN}$ con segni precoci di interessamento cardiaco e un eventuale intervallo terapeutico efficace. ${ }^{43}$ Esistono ancora dubbi sulla frequenza con cui il monitoraggio andrebbe condotto. In caso di anamnesi ostetrica positiva per pregresso LN, il monitoraggio ecocardiografico fetale deve avvenire una volta a settimana. Non esiste invece un consensus definitivo sulla frequenza con cui debba essere effettuato in caso di positività anticorpale ma anamnesi ostetrica muta. Attraverso l'esame strumentale, viene misurato il ritardo fra sistole atriale e ventricolare e si può stimare la durata dell'intervallo PR. Tuttavia, la comparsa o l'evoluzione verso un $\mathrm{BAV}$ di grado avanzato può avvenire in poche ore o giorni, e gli studi hanno mostrato che il monitoraggio fetale ecocardiografico effettuato una o due volte alla settimana solo raramente riesce ad individuare casi di $\mathrm{BCC}$ in una finestra temporale favorevole per una terapia efficace. ${ }^{44} \mathrm{Si}$ è pertanto proposto di aumentare la frequenza del monitoraggio, associando alle valutazioni ecocardiografiche fetali ambulatoriali ogni sette o quindici giorni, l'utilizzo di sistemi portatili attraverso cui le madri possano valutare al domicilio la frequenza cardiaca fetale ogni 12 ore. Le madri richiedere una rivalutazione ecocardiogramma fetale in caso di incapacità ad identificare al domicilio il ritmo fetale, riscontro di irregolarità dello stesso o di bradicardia o di tachicardia fetale. Nel 2018 è stato pubblicato uno studio canadese multicentrico prospettico condotto su 315 donne con positività per gli anti-Ro, in cui è stato impiegato un dispositivo chiamato Sondine B (FDA-approved e acquistabile su Amazon al costo di circa 50 dollari) per la misurazione del battito e del ritmo fetale a domicilio, due volte al giorno tra la 18 e la 24 settimana. ${ }^{30}$ Dallo studio è emerso che delle 315 donne, 21 madri $(6,7 \%)$ hanno registrato al domi- cilio un'alterazione del ritmo fetale: 18 feti presentavano alterazioni cardiache benigne e 3 feti presentavano un BAV di II o di III grado. In 1 caso di BAV di II grado fu intrapresa terapia con desametasone $8 \mathrm{mg}$ e Ig ev entro le 12 ore dalla rilevazione dell'alterazione, con successivo ripristino del ritmo sinusale. Negli altri 2 casi il trattamento è stato intrapreso 32 ore dopo l'ultima rilevazione di un ritmo cardiaco fetale normale, senza efficacia, e con necessità di impianto di PM alla nascita. Nonostante la persistenza del blocco AV completo nei due casi segnalati, è interessante notare che con questo tipo di monitoraggio combinato, e la conseguente rapida somministrazione delle terapie, non ci sono stati casi di mortalità o cardiomiopatia dilatativa. Attraverso la misurazione domiciliare del ritmo cardiaco fetale inoltre è stato possibile diagnosticare tutti i BAV e monitorare i feti potenzialmente a rischio di aritmia. Ulteriori studi sono necessari a riguardo dell'utilità del monitoraggio domiciliare, ma è probabile che esso possa rappresentare il nuovo standard per le gravidanze a rischio.

I casi di blocco AV avanzato si giovano dell'impianto di PM, che risulta necessario nei primi dieci anni di vita in circa il 70-80\% dei casi di BCC, spesso già a partire dal periodo neonatale (in tal caso, utilizzando uno stimolatore epicardico). Le indicazioni per il posizionamento del PM sono rappresentate da: BAV III grado con QRS slargato o disfunzione ventricolare o BAV III grado con FC ventricolare $<55 \mathrm{bpm}$ o $<70$ bpm in caso di anomalie congenite. L'isoproterenolo è talvolta utilizzato come transitoria terapia cronotropa positiva. Le manifestazioni cutanee possono giovarsi dell'evitamento dai raggi solari e, nei casi gravi, da terapia topica steroidea. Le manifestazioni cliniche epatobiliari ed ematologiche di solito non richiedono trattamento perché transitorie.

\section{Bibliografia}

1. Greidinger EL, Zang Y, Martinez L, Jaimes K, Nassiri $\mathrm{M}$, Bejarano $\mathrm{P}$, et al. Differential tissue targeting of autoimmunity manifestations by autoantigen-associated $\mathrm{Y}$ RNAs. Arthritis Rheum. 2007 May;56(5):1589-97.

2. Fayyaz A, Kurien BT, Scofield RH. Autoantibodies in Sjögren's Syndrome. Rheum Dis Clin North Am. 2016;42(3):419-34.

3. Hernández-Molina G, Leal-Alegre G, Michel-Peregrina M. The meaning of anti-Ro and anti-La antibodies in primary Sjögren's syndrome. Autoimmun Rev. 2011 Jan;10(3):123-5.

4. Defendenti C, Atzeni F, Spina MF, Grosso S, Cereda A, Guercilena G, et al. Clinical and laboratory aspects of Ro/SSA-52 autoantibodies. Autoimmun Rev. 2011 Jan;10(3):150-4.

5. Vanoni F, Lava SAG, Fossali EF, Cavalli R, Simonetti GD, Bianchetti MG, et al. Neonatal Systemic Lupus Erythematosus Syndrome: a Comprehensive Review. Clin Rev Allergy Immunol. 2017 Dec;53(3):469-76. 
6. Teixeira AR, Rodrigues M, Guimarães H, Moura C, Brito I. Neonatal lupus - case series of a tertiary hospital. Acta Reumatol Port. 2017;42(4):318-23.

7. Morel N, Lévesque K, Maltret A, Baron G, Hamidou M, Orquevaux $\mathrm{P}$, et al. Incidence, risk factors, and mortality of neonatal and late-onset dilated cardiomyopathy associated with cardiac neonatal lupus. Int J Cardiol. 2017 Dec 1;248:263-9.

8. Rivera TL, Izmirly PM, Birnbaum BK, Byrne P, Brauth JB, Katholi M, et al. Disease progression in mothers of children enrolled in the Research Registry for Neonatal Lupus. Ann Rheum Dis. 2009 Jun;68(6):828-35.

9. Brucato A, Cimaz R, Caporali R, Ramoni V, Buyon J. Pregnancy outcomes in patients with autoimmune diseases and anti-Ro/SSA antibodies. Clin Rev Allergy Immunol. $2011 \mathrm{Feb}$;0(1):27-41.

10. Moretti D, Cimaz R, Vannucci G, Marino A, De Martino M, Greco A. Cutaneous neonatal lupus: a case report and review of the literature. Int J Dermatol. 2014 Dec;53 (12):1508-12.

11. Izmirly PM, Saxena A, Kim MY, Wang D, Sahl SK, Llanos C, et al. Maternal and fetal factors associated with mortality and morbidity in a multi-racial/ethnic registry of anti-SSA/Ro-associated cardiac neonatal lupus. Circulation. 2011 Nov 1;124(18):1927-35.

12. Brucato A, Jonzon A, Friedman D, Allan LD, Vignati G, Gasparini M, et al. Proposal for a new definition of congenital complete atrioventricular block. Lupus. 2003;12(6):427-35.

13. Brito-Zerón P, Izmirly PM, Ramos-Casals M, Buyon JP, Khamashta MA. The clinical spectrum of autoimmune congenital heart block. Nat Rev Rheumatol. 2015 May;11(5):301-12.

14. Wainwright B, Bhan R, Trad C, Cohen R, Saxena A, Buyon J, et al. Autoimmune-mediated congenital heart block. Best Pract Res Clin Obstet Gynaecol. 2019 Oct 8;

15. Moak JP, Barron KS, Hougen TJ, Wiles HB, Balaji S, Sreeram N, et al. Congenital heart block: development of late-onset cardiomyopathy, a previously underappreciated sequela. J Am Coll Cardiol. 2001 Jan;37(1):238-42.

16. Boutjdir M, Chen L, Zhang ZH, Tseng CE, DiDonato F, Rashbaum W, et al. Arrhythmogenicity of IgG and anti52-kD SSA/Ro affinity-purified antibodies from mothers of children with congenital heart block. Circ Res. 1997 Mar;80(3):354-62.

17. Lee LA. The clinical spectrum of neonatal lupus. Arch Dermatol Res. 2009 Jan 17;301(1):107-10.

18. Buyon JP, Clancy RM. Neonatal Lupus: Basic Research and Clinical Perspectives. Rheum Dis Clin North Am. 2005 May 1;31(2):299-313.

19. Izmirly PM, Buyon JP, Saxena A. Neonatal lupus: advances in understanding pathogenesis and identifying treatments of cardiac disease. Curr Opin Rheumatol. 2012 Sep;24(5):466-72.

20. Xiao GQ, Hu K, Boutjdir M. Direct inhibition of expressed cardiac l- and t-type calcium channels by igg from mothers whose children have congenital heart block. Circulation. 2001 Mar 20;103(11):1599-604.

21. Karnabi E, Boutjdir M. Role of calcium channels in congenital heart block. Scand J Immunol. 2010 Sep;72(3):226-34.

22. Clancy RM, Neufing PJ, Zheng P, O'Mahony M, Nimmerjahn F, Gordon TP, et al. Impaired clearance of apop- totic cardiocytes is linked to anti-SSA/Ro and -SSB/La antibodies in the pathogenesis of congenital heart block. J Clin Invest. 2006 Sep;116(9):2413-22.

23. Miranda-Carús ME, Askanase AD, Clancy RM, Di Donato F, Chou TM, Libera MR, et al. Anti-SSA/Ro and anti-SSB/La autoantibodies bind the surface of apoptotic fetal cardiocytes and promote secretion of TNF-alpha by macrophages. J Immunol. 2000 Nov 1;165(9): 5345-51.

24. Clancy RM, Backer CB, Yin X, Kapur RP, Molad Y, Buyon JP. Cytokine polymorphisms and histologic expression in autopsy studies: contribution of TNF-alpha and TGF-beta 1 to the pathogenesis of autoimmune-associated congenital heart block. J Immunol. 2003 Sep 15;171(6):3253-61.

25. Clancy RM, Marion MC, Kaufman KM, Ramos PS, Adler A, International Consortium on Systemic Lupus Erythematosus Genetics H, et al. Identification of candidate loci at 6p21 and 21q22 in a genome-wide association study of cardiac manifestations of neonatal lupus. Arthritis Rheum. 2010 Nov;62(11):3415-24.

26. Clancy RM, Backer CB, Yin X, Chang MW, Cohen SR, Lee LA, et al. Genetic association of cutaneous neonatal lupus with HLA class II and tumor necrosis factor alpha: implications for pathogenesis. Arthritis Rheum. 2004 Aug;50(8):2598-603.

27. Sonesson S-E, Salomonsson S, Jacobsson L-A, Bremme K, Wahren-Herlenius M. Signs of first-degree heart block occur in one-third of fetuses of pregnant women with anti-SSA/Ro 52-kd antibodies. Arthritis Rheum. 2004 Apr;50(4):1253-61.

28. Sonesson S-E, Ambrosi A, Wahren-Herlenius M. Benefits of fetal echocardiographic surveillance in pregnancies at risk of congenital heart block: single-center study of 212 anti-Ro52-positive pregnancies. Ultrasound Obstet Gynecol. 2019 Jul;54(1):87-95.

29. Cuneo BF, Ambrose SE, Tworetzky W. Detection, and successful treatment of emergent anti-SSA-mediated fetal atrioventricular block. Am J Obstet Gynecol. 2016 Oct;215(4):527-8.

30. Cuneo BF, Sonesson S-E, Levasseur S, Moon-Grady AJ, Krishnan A, Donofrio MT, et al. Home Monitoring for Fetal Heart Rhythm During Anti-Ro Pregnancies. J Am Coll Cardiol. 2018;72(16):1940-51.

31. Jaeggi ET, Fouron J-C, Silverman ED, Ryan G, Smallhorn J, Hornberger LK. Transplacental fetal treatment improves the outcome of prenatally diagnosed complete atrioventricular block without structural heart disease. Circulation. 2004 Sep 21;110(12):1542-8.

32. Eliasson H, Sonesson S-E, Sharland G, Granath F, Simpson JM, Carvalho JS, et al. Isolated atrioventricular block in the fetus: a retrospective, multinational, multicenter study of 175 patients. Circulation. 2011 Nov 1;124(18):1919-26.

33. Michael A, Radwan AA, Ali AK, Abd-Elkariem AY, Shazly SA, Middle-East Obstetrics and Gynecology Graduate Education (MOGGE) Foundation Research Group. Use of antenatal fluorinated corticosteroids in management of congenital heart block: Systematic review and meta-analysis. Eur J Obstet Gynecol Reprod Biol X. 2019 Oct;4:100072.

34. Brucato A, Tincani A, Fredi M, Breda S, Ramoni V, Morel N, et al. Should we treat congenital heart block 
with fluorinated corticosteroids? Autoimmun Rev. 2017;16(11):1115-8.

35. Brucato A, Astori MG, Cimaz R, Villa P, Li Destri M, Chimini L, et al. Normal neuropsychological development in children with congenital complete heart block who may or may not be exposed to high-dose dexamethasone in utero. Ann Rheum Dis. 2006 Nov;65(11): 1422-6.

36. Chang C. The pathogenesis of neonatal autoimmune and autoinflammatory diseases: a comprehensive review. J Autoimmun. 2013 Mar;41:100-10.

37. Friedman DM, Llanos C, Izmirly PM, Brock B, Byron $\mathrm{J}$, Copel J, et al. Evaluation of fetuses in a study of intravenous immunoglobulin as preventive therapy for congenital heart block: Results of a multicenter, prospective, open-label clinical trial. Arthritis Rheum. 2010 Apr;62(4):1138-46.

38. Pisoni CN, Brucato A, Ruffatti A, Espinosa G, Cervera R, Belmonte-Serrano M, et al. Failure of intravenous immunoglobulin to prevent congenital heart block: Findings of a multicenter, prospective, observational study. Arthritis Rheum. 2010 Apr;62(4):1147-52.

39. Trucco SM, Jaeggi E, Cuneo B, Moon-Grady AJ, Silverman E, Silverman N, et al. Use of intravenous gamma globulin and corticosteroids in the treatment of maternal autoantibody-mediated cardiomyopathy. J Am Coll Cardiol. 2011 Feb 8;57(6):715-23.

40. Nield LE, Silverman ED, Taylor GP, Smallhorn JF, Mullen JBM, Silverman NH, et al. Maternal anti-Ro and anti-La antibody-associated endocardial fibroelastosis. Circulation. 2002 Feb 19;105(7):843-8.

41. Nield LE, Silverman ED, Smallhorn JF, Taylor GP, Mullen JBM, Benson LN, et al. Endocardial fibroelastosis associated with maternal anti-Ro and anti-La antibodies in the absence of atrioventricular block. J Am Coll Cardiol. 2002 Aug 21;40(4):796-802.

42. Guettrot-Imbert G, Cohen L, Fermont L, Villain E, Francès $\mathrm{C}$, Thiebaugeorges $\mathrm{O}$, et al. A new presentation of neonatal lupus: 5 cases of isolated mild endocardial fibroelastosis associated with maternal Anti-SSA/Ro and AntiSSB/La antibodies. J Rheumatol. 2011 Feb;38 (2):378-86.

43. Rosenthal D, Druzin M, Chin C, Dubin A. A new therapeutic approach to the fetus with congenital complete heart block: preemptive, targeted therapy with dexamethasone. Obstet Gynecol. 1998 Oct;92(4 Pt 2):689-91.

44. Friedman DM, Kim MY, Copel JA, Davis C, Phoon CKL, Glickstein JS, et al. Utility of cardiac monitoring in fetuses at risk for congenital heart block: the PR Interval and Dexamethasone Evaluation (PRIDE) prospective study. Circulation. 2008 Jan 29;117(4):485-93. 


\title{
Patologie della tiroide in gravidanza
}

\author{
Sara De Carolis, ${ }^{1,2}$ Elena Barbagelata, ${ }^{3}$ Imma Ambrosino, ${ }^{4}$ Sara Tabacco ${ }^{5}$ \\ ${ }^{1}$ UOC di Patologia Ostetrica, Dipartimento Scienze della Salute della Donna, del Bambino e di Sanità Pubblica, Fondazione \\ Policlinico Universitario A. Gemelli IRCCS, Roma; ${ }^{2}$ Istituto di Clinica Ostetrica e Ginecologica, Università Cattolica del Sacro \\ Cuore, Roma; ${ }^{3}$ Dipartimento di Medicina Interna, Sestri Levante (GE); ${ }^{4}$ Libero Professionista in Geriatria, ASL Maglie (LE); \\ ${ }^{5}$ Dipartimento di Ginecologia e Ostetricia, Università La Sapienza, Roma, Italia
}

\section{Introduzione}

Le patologie della tiroide, ipertiroidismo e ipotiroidismo, sono da 5 a 10 volte più frequenti nelle donne rispetto agli uomini. La maggior parte dei distiroidismi richiede un trattamento cronico che va pertanto continuato durante la gravidanza.

La gravidanza ha un profondo impatto sulla tiroide e sulla sua funzione. ${ }^{1}$ Durante la gravidanza il volume della ghiandola aumenta del $10 \%$ nei paesi con un quantitativo sufficiente di iodio e dal 20 al $40 \%$ nei paesi con carenza iodica. La produzione degli ormoni tiroidei, tiroxina (T4) e triiodotironina (T3), aumenta di circa il $50 \%$ e si verifica un incremento delle proteine leganti la tiroxina (TBG), in particolare le concentrazioni di TBG e T4 aumentano dalla 7 settimana di gestazione e raggiungono il picco intono alla 16 settimana. ${ }^{2}$ Aumenta, inoltre, di circa il $50 \%$ il fabbisogno giornaliero di iodio e la sua escrezione renale, pertanto la Organizzazione Mondiale della Sanità (WHO) raccomanda un apporto giornaliero di iodio pari a 250 $\mu \mathrm{g}$ nelle donne in gravidanza e durante l'allattamento. ${ }^{3}$ In molti paesi le donne che stanno programmando una gravidanza dovrebbero iniziare una supplementazione orale di iodio (150 $\mu \mathrm{g}$ pro die) almeno 3 mesi prima. Non c'è alcuna necessità di supplementazione iodica nelle donne trattate per ipertiroidismo o che assumono levo-tiroxina (LT4).

Infine, nel primo trimestre, la gonadotropina corionica umana placentare (hCG) stimola il recettore del

Corrispondente: Elena Barbagelata, Dipartimento di Medicina Interna, Sestri Levante (GE), Italia.

E-mail: elenabarbagelata@yahoo.it

Articolo pubblicato secondo la Creative Commons Attribution NonCommercial 4.0 License (CC BY-NC 4.0).

${ }^{\circ}$ Copyright: the Author(s), 2021

Licensee PAGEPress, Italy

QUADERNI - Italian Journal of Medicine 2021; 9(4):e9
TSH con conseguente aumento della secrezione degli ormoni tiroidei e riduzione della concentrazione sierica dell'ormone tireotropo (TSH). ${ }^{4,5}$

Per tali modifiche fisiologiche, le donne gravide hanno concentrazioni sieriche di TSH più basse, infatti, rispetto alle donne sane, fino al 15\% delle donne nel primo trimestre della gravidanza mostrano un valore del TSH più basso del limite inferiore pari a $0,4 \mathrm{mU} / \mathrm{L} \cdot{ }^{6,7} \mathrm{Il}$ range di riferimento del TSH nelle donne in gravidanza presenta una riduzione del limite inferiore di circa $0,1-$ $0,2 \mathrm{mU} / \mathrm{L}$ e del limite superiore di circa $0,5-1,0 \mathrm{mU} / \mathrm{L}$ rispetto al range di riferimento delle donne non gravide. In caso di riscontro di TSH oltre il range di normalità, va determinata la quota libera di tiroxina (fT4) e dosati gli autoanticorpi, in particolare gli anticorpi anti-perossidasi (TPO Ab che rappresentano un marker specifico della tiroidite autoimmune; l'ecografia tiroidea può essere utile per la valutazione dell'ecostruttura e la presenza di noduli.

Inoltre, una percentuale che va dal 2 al 17\% delle donne in gravidanza mostra una positività per gli anticorpi anti-perossidasi (TPOAb) e anti-tireoglobulina $(\operatorname{TgAb})$ ed il titolo auto-anticorpale risulta più elevato nel primo trimestre. ${ }^{8-10}$

Diversi studi hanno evidenziato un'associazione della positività auto-anticorpale con l'aborto spontaneo ${ }^{11,12}$ il parto pretermine, ${ }^{13,14}$ la depressione post-partum $^{15}$ e la sindrome da distress respiratorio del neonato. ${ }^{16}$ L'assunzione di selenio non è raccomandata nei pazienti con positività per TPO Ab.

\section{Ipotiroidismo}

L'ipotiroidismo è comune nelle donne in età riproduttiva e costituisce la disfunzione tiroidea più frequente in gravidanza.

L'ipotiroidismo fuori gravidanza ha un picco di incidenza intorno alla IV-VI decade ed è più frequente nelle donne con un rapporto maschi/femmine pari a 1/15. La diagnosi di ipotiroidismo viene fatta con il dosaggio degli ormoni tiroidei, che risultano diminuiti, e con la valutazione dei livelli plasmatici del TSH, che 
risultano aumentati. È possibile distinguere, inoltre, un ipotiroidismo subclinico (subclinical hypothyroidism, $\mathrm{SCH}$ ), in cui c'è un aumento di TSH, senza variazioni degli ormoni tiroidei, da un ipotiroidismo conclamato (overt hypothyroidism, $\mathrm{OH}$ ) in cui si riscontra un'alterazione di entrambi i parametri. Alcune alterazioni della sfera riproduttiva come l'amenorrea, la menorragia e la presenza di cicli anovulatori coesistono con l'ipotiroidismo, riducendo la fertilità.

La prevalenza di ipotiroidismo in gravidanza si aggira intorno all' $1 \%$ e la tiroidite cronica autoimmune di Hashimoto risulta essere la causa più frequente di ipotiroidismo in gravidanza. ${ }^{1}$

Il sospetto di un ipotiroidismo in gravidanza e l'indicazione alla sua ricerca sono: un ipotiroidismo noto (tiroidite di Hashimoto, precedente ablazione con iodio 131 o chirurgica, irradiazioni del collo, mixedema idiopatico, lesioni ipofisarie o ipotalamiche), una storia personale o familiare di malattie autoimmuni tiroidee, presenza di diabete mellito di tipo 1 o di altra malattia autoimmune; anche la celiachia può, infatti, essere associata a patologie tiroidee. Molti clinici attualmente sono orientati ad effettuare lo screening per ipotiroidismo in tutte le gravidanze, analogamente allo screening per il diabete gestazionale.

Le pazienti ipotiroidee che non vengono trattate o non sono adeguatamente trattate hanno un rischio maggiore di: aborto spontaneo, pre-eclampsia, abruptio placentae, anemia e cardiopatie fetali, atonia uterina, basso peso alla nascita, morte fetale, malformazioni congenite e compromissione dello sviluppo del sistema nervoso centrale. Il neonato può invece manifestare un ipotiroidismo transitorio, un'aumentata incidenza di deficit neurologici, anche in caso di ipotiroidismo sub-clinico, con un QI-score di 4-7 punti inferiore alla norma. ${ }^{17-20}$ (Tabella 1).

̇̀ stato anche evidenziato che l'SCH aumenta il rischio di complicanze durante la gravidanza nelle pazienti con positività per gli anticorpi anti-TPO. ${ }^{21}$
Diversi studi ${ }^{22-24}$ hanno dimostrato che l'SCH si associa ad infertilità nella donna, pertanto si raccomanda la valutazione dei livelli sierici di TSH nello screening della donna infertile e la terapia con levotiroxina (LT4) nella donna con SCH che viene sottoposta a procreazione medicalmente assistita (PMA). Lo scopo del trattamento è di raggiungere un livello sierico del TSH $<2,5 \mathrm{mU} / \mathrm{L}$. ${ }^{1}$

Le linee guida dell'American Thyroid Association ${ }^{25}$ hanno stabilito che il limite superiore della concentrazione sierica del TSH in gravidanza deve essere: i) 2,5 $\mathrm{mU} / \mathrm{L}$ nel primo trimestre; ii) $3 \mathrm{mU} / \mathrm{L}$ nel secondo e terzo trimestre.

Nel caso di ipotiroidismo conclamato si raccomanda il trattamento farmacologico con LT4 durante la gravidanza. ${ }^{25}$

In caso di ipotiroidismo subclinico si raccomanda di valutare la presenza di autoanticorpi anti-tireoperossidasi (TPO Ab) e di procedere nel modo seguente:

A. la terapia con LT4 è raccomandata in caso di:

- positività di TPO Ab e valore sierico del TSH superiore al range di riferimento;

- negatività di TPO $\mathrm{Ab}$ e valore sierico del $\mathrm{TSH}>10$ $\mathrm{mU} / \mathrm{L}$.

B. la terapia con LT4 può essere presa in considerazione in caso di:

- positività di TPO Ab e valore sierico del TSH >2,5 $\mathrm{mU} / \mathrm{L}$ o comunque al di sopra del limite superiore del range di riferimento;

- negatività di TPO Ab e valore del TSH sierico compreso tra il limite superiore del range di riferimento e $10 \mathrm{mU} / \mathrm{L}$.

C. La terapia con LT4 non è raccomandata per le donne con:

- negatività di TPO Ab e valore sierico del TSH nel range di riferimento. ${ }^{25}$

Nelle donne con ipotiroidismo conclamato o con ipotiroidismo subclinico (trattato o non trattato) o a rischio di ipotiroidismo (pazienti eutiroidee con positività

Tabella 1. Complicanze delle patologie tiroidee in gravidanza.

\begin{tabular}{ll}
\hline Ipotiridoismo & Ipertiroidismo \\
\hline Aborto spontaneo & Aborto spontaneo \\
\hline Preecalmpsia & Parto prematuro \\
\hline Aburptio placentae & Basso peso alla nascita \\
\hline Anemia & Malformazione congenite \\
\hline Cardiopatie & Morte perinatale \\
\hline Atonia uterina & Tireotossicosi materna \\
\hline Basso peso alla nascita & Scompenso cardiaco materno \\
\hline Morte fetale & Craniosinostosi \\
\hline Malformazione congenite & Ipotiroidismo transitorio fetale \\
\hline Compromissione del sistema nervoso centrale & Epatosplenomegalia fetale
\end{tabular}


auto-anticopale, oppure tiroidectomizzate, oppure trattate con terapia radiometabolica) il livello sierico del TSH dovrebbe essere monitorato ogni 4 settimane fino alle $16^{\mathrm{a}}-20^{\mathrm{a}}$ settimana di gestazione ed un'ultima volta tra la $26^{\mathrm{a}}$ e la $32^{\mathrm{a}}$ settimana. $^{26}$

Nelle donne con ipotiroidismo noto trattate con LT4 che stanno programmando una gravidanza dovrebbe essere valutato il livello sierico del TSH nel periodo preconcenzionale ed il dosaggio della LT4 deve essere aggiustato in modo da avere un valore del TSH compreso tra il limite inferiore di riferimento e 2,5 mU/L. ${ }^{1}$ Nelle pazienti ipotiroidee in trattamento con LT4 in cui è sospettato o accertato lo stato gravidico, solitamente è necessario un incremento del dosaggio del $25-30 \%$ in seguito alle modifiche fisiologiche ad esso correlate. ${ }^{26}$ Si verifica, infatti, un'aumentata degradazione placentare del T4 in inattivo reverse T3; inoltre, si verifica un aumento della clearance renale di T4, nonché una diminuzione della T4 legata sia al suo al passaggio al feto che ad un aumento della TBG. In pratica è buona pratica clinica, incrementare il dosaggio alla positività del test di gravidanza ed educare la paziente già nota ad effettuare tale incremento.

Dopo il parto, il dosaggio della LT4 dovrebbe essere ridotto alla dose che assumeva la paziente prima del concepimento e la funzionalità tiroidea dovrebbe essere rivalutata 6 settimane dopo il parto. Uno studio condotto da Galofre ha dimostrato che più del $50 \%$ delle donne con tiroidite di Hashimoto richiede un incremento del dosaggio della terapia sostitutiva nel post-partum, rispetto alla dose assunta prima della gravidanza, probabilmente a causa di un'esacerbazione della patologia autoimmune nel periodo successivo al parto. ${ }^{27}$

Per quanto concerne le pazienti in cui la terapia sostitutiva è stata iniziata durante la gravidanza, in alcuni casi non è necessaria alcuna terapia dopo il parto, in altri casi potrebbe essere necessaria una sospensione temporanea della terapia, soprattutto quando il dosaggio dell'LT4 assunto dalla paziente è $\leq 50 \mu \mathrm{g} / \mathrm{d}$; in seguito, a tale sospensione si dovrà rivalutare la funzionalità tiroidea dopo 6 settimane.

Per favorire un assorbimento ottimale della L-tiroxina, l'assunzione dovrebbe avvenire a distanza di almeno quattro ore da quella del ferro e di integratori contenenti ferro, di calcio e latte di soia.

\section{Ipertiroidismo}

L'ipertiroidismo al di fuori della gravidanza ha un picco d'incidenza tra la III-IV decade di vita con una prevalenza di 2,5-3\%. In gravidanza, la prevalenza dell'ipertiroidismo conclamato è dello $0,2 \%{ }^{28}$

Gran parte degli ipertiroidismi (90\%) riconosce come causa il morbo di Basedow; altre cause sono la malattia di Plummer, il gozzo multinodulare tossico, la tiroidite di De Quervain, la tiroidite di Hashimoto, il carcinoma follicolare tiroideo, la mola vescicolare ed il corioncarcinoma, una precedente ablazione chirurgica ed un'eccessiva assunzione di ormoni tiroidei.

Le manifestazioni cliniche, in parte sovrapponibili ai comuni disturbi riferiti nella normale gravidanza, sono: lieve tachicardia, palpitazioni, ipersudorazione, intolleranza al caldo, iperemesi, astenia, ansia. Sono invece aspetti clinici più specifici per tireotossicosi la perdita di peso, severa tachicardia, gozzo, oftalmopatia, mixedema pretibiale. Le indicazioni specifiche alla ricerca dell'ipertiroidismo in gravidanza possono essere: storia di ipertiroidismo nei nati precedenti, la presenza di eutiroidismo dopo ablazione, il riscontro di tachicardia fetale o di gozzo fetale durante gli accertamenti diagnostici in gravidanza.

La diagnosi di ipertiroidismo è fatta attraverso il dosaggio dei livelli plasmatici di FT3 e FT4, che risultano aumentati, mentre i livelli di TSH appaiono molto diminuiti.

La malattia di Basedow in gravidanza ha una prevalenza di circa $0.5 \%$. Solitamente peggiora nel primo trimestre a causa dell'effetto tireostimolante dell'hCG sul recettore del $\mathrm{TSH}$, mentre migliora nella seconda metà della gravidanza come risultato dell'effetto benefico indotto dalla gravidanza stessa sul sistema immune. ${ }^{29,30}$ Quando si sospetta un morbo di Basedow, la diagnosi deve essere confermata attraverso la determinazione degli anticorpi antitiroide (thyroid-stimulating immunoglobulin, TSI). Circa il 3\% dei neonati da madre con M. di Basedow sviluppa un ipertiroidsmo neonatale secondario al passaggio di anticorpi anti-recettore del TSH dalla madre al feto. Tale condizione di solito insorge dopo 7-10 giorni dalla nascita ed è autolimitante (sei-dodici settimane); richiede usualmente un trattamento antitiroideo farmacologico di breve durata.

Durante la gravidanza l'ipertiroidismo non trattato può causare outcome ostetrici sfavorevoli.

Le complicanze materne possono essere ipertensione gestazionale, preeclampsia, abruptio placentae, scompenso cardiaco, anemia. infezioni, scarso incremento ponderale, crisi tireotossica e riacutizzazione della malattia nel post-partum.

I rischi fetali dovuti all'ipertiroidismo materno sono: aborto spontaneo, parto pretermine (10- 25\%), basso peso alla nascita, mortalità perinatale $(10 \%$ circa), scompenso cardiocircolatorio, craniosinostosi, esoftalmo, epatosplenomegalia, gozzo da tionamidi $(10 \%)$ e ipotiroidismo transitorio (1-5\%). Uno dei rischi più gravi è rappresentato dallo sviluppo della tireotossicosi neonatale, la cui comparsa non dipende, comunque, dall'attività o dalla gravità della patologia tiroidea materna (Tabella 1).

Nel feto l'ipertiroidismo si manifesta in genere con tachicardia e iposviluppo, ma può anche essere presente una ipertrofia ghiandolare tiroidea che, in alcuni 
casi, può determinare problemi al parto ostacolando la respirazione neonatale. L'ipertiroidismo neonatale è legato al passaggio transplacentare di immunoglobuline stimolanti la tiroide. Tale condizione è generalmente transitoria: normalmente, dopo 3-12 settimane, viene raggiunta una condizione di eutiroidismo. L'ipertiroidismo congenito è associato, nei casi più gravi, ad una mortalità del $15-25 \%$.

L'ipertiroidismo neonatale si può evidenziare alla nascita con ittero, tremori, diarrea, tachicardia $(>200$ bpm), insufficienza cardiaca, epatosplenomegalia, gozzo ed esoftalmo. Sono descritte rare complicanze neonatali a lungo termine, come la craniosinostosi e minime disfunzioni cerebrali.

Anche se durante la gravidanza non sono evidenti i segni e i sintomi dell'ipertiroidismo fetale, per ogni bambino nato da madre affetta da morbo di Basedow, si impone uno screening accurato per valutare il possibile stato ipertiroideo e, se la madre ha assunto farmaci antitiroidei, il controllo deve essere ripetuto anche dopo le prime due settimane di vita.

Il controllo dell'ipertiroidismo con la terapia antitiroidea si accompagna ad una riduzione della frequenza di queste complicanze che è tanto maggiore quanto più precoce è l'inizio del trattamento nel corso della gestazione. ${ }^{31}$

I migliori risultati si ottengono quando l'ipertiroidismo viene diagnosticato e corretto prima dell'inizio della gravidanza. È importante informare i genitori che il rischio di una qualsiasi malformazione fetale in corso di trattamento con tionamidi è di 1,5 volte, pari allo $0,02 \%$ rispetto al totale delle gravide; mentre il rischio malformativo associato all'ipertiroidismo non trattato è di circa 20 volte. ${ }^{32}$

Il trattamento dell'ipertiroidismo in gravidanza pone alcuni problemi perché ogni scelta terapeutica deve tener conto della presenza del feto e del passaggio transplacentare dello iodio e dei farmaci impiegati. Le tionamidi (propiltiouracile e metimazolo) rappresentano la terapia di prima scelta; l'uso dello iodio radioattivo é assolutamente controindicato in gravidanza, ${ }^{33}$ mentre il ricorso all'intervento chirurgico è limitato a casi eccezionali.

Il raggiungimento dell'eutiroidismo nelle pazienti ipertiroidee trattate con tionamidi richiede di solito dalle 2 alle 6 settimane. I fattori che influenzano la rapidità di risposta sono i livelli iniziali degli ormoni tiroidei, l'attività della malattia e l'entità dei depositi ormonali intratiroidei.

L'obiettivo terapeutico consigliato ${ }^{34,35}$ è ottenere e mantenere valori di fT4 ai limiti superiori della norma, usando la dose minima possibile di farmaco antitiroideo. Infatti, diversi dati di letteratura dimostrano che l'ipertiroidismo subclinico non si associa a complicanze materno/fetali; inoltre mantenere il più basso possibile il dosaggio di tireostatico riduce la quota di farmaco che passa al feto e conseguentemente diminuisce il rischio di ipotiroidismo fetale/neonatale. ${ }^{36}$ L'uso di propiltiouracile (PTU) è associato, anche in gravidanza, ad un rischio aumentato di epatotossicità, mentre l'assunzione di metimazolo (MMI) nel primo trimestre si associa ad un rischio aumentato di malformazioni congenite. ${ }^{37}$ Tuttavia è stato chiaramente dimostrato che è più frequente e severo il rischio di complicazioni dell'ipertiroidismo non trattato in gravidanza che i potenziali eventi avversi legati all'uso delle tionamidi. ${ }^{38}$ Inoltre, benché anche PTU possa causare malformazioni congenite (situs inversus \pm destrocardia, agenesia renale isolata, cardiopatia congenita), queste di solito si verificano singolarmente; invece, l'uso di MMI può causare una sindrome specifica detta embriopatia da metimazolo caratterizzata da atresia delle coane e esofagea, aplasia cutis, onfalocele, dismorfismi facciali. ${ }^{39-41}$

Di conseguenza le principali e più autorevoli linee guida (American Thyroid Association e Endocrine Society) raccomandano l'uso di PTU nel primo trimestre e di metimazolo nel secondo e terzo trimestre., ${ }^{1,42}$

Tuttavia, poiché i due farmaci hanno diversa farmacocinetica e diverso dosaggio è possibile che il passaggio dall'uno all'altro possa causare la perdita di controllo sull'ipertiroidismo con potenziali effetti negativi materno-fetali. ${ }^{43}$

Una gravissima complicanza dell'ipertiroidismo a carico della madre è la crisi tireotossica. È un'emergenza medica che si presenta con il quadro clinico di febbre, disidratazione, tachicardia, alterazione dello stato mentale, diarrea, nausea, vomito e scompenso cardiaco. È associata ad una mortalità materna del $25 \%$. Diverse possono essere le cause che portano alla crisi tireotossica, quali un'infezione, un intervento chirurgico o il parto. Il trattamento deve essere rapidamente instaurato ai primi sintomi, somministrando liquidi, ossigeno, antipiretici e farmaci antitiroidei. ${ }^{44}$

La terapia chirurgica è da preferirsi quando la madre presenta complicanze all'uso delle tionamidi (agranulocitosi) o quando l'ipertiroidismo viene controllato con dosi quotidiane di PTU $>300 \mathrm{mg}$ o con dosi di metimazolo $>30 \mathrm{mg}$, tali da aumentare il rischio di ipotiroidismo fetale. Per diminuire il rischio che l'intervento chirurgico possa scatenare una crisi tireotossica, lo stato ipertiroideo della paziente deve essere ben controllato con terapia medica prima dell'operazione.

La tireotossicosi gestazionale transitoria è, invece, una condizione, diagnosticata in 1-3\% di tutte le gravidanze e caratterizzata da TSH soppresso e alto fT4, transitoria che si manifesta nel primo trimestre della gravidanza quando aumenta molto il valore dell'hCG ed è caratterizzata da vomito severo, diminuzione di peso, disidratazione, chetonuria, iperemesi gravidica. È una condizione che ha una maggiore frequenza nelle 
gravidanze gemellari. Nella maggioranza dei casi si risolve spontaneamente intorno alla 18-20 settimana di gestazione parallelamente al declino dei valori di $\mathrm{hCG}$ e non necessita di terapia con tionamidi; generalmente è sufficiente una terapia dietetica ed antiemetica. ${ }^{45}$

Il management della gravidanza prevede, quindi, controlli tiroidei seriati, il controllo della crescita fetale e di eventuali segni di patologia tiroidea fetale. Non essendoci un approccio terapeutico completamente sicuro per l'ipertiroidismo in gravidanza, sarebbe preferibile che la donna raggiungesse uno stato eutiroideo prima di iniziare la gravidanza. Tale condizione può essere raggiunta sia farmacologicamente, ma non può essere esclusa una riacutizzazione in gravidanza, sia mediante ablazione della ghiandola, con iodio radioattivo o chirurgicamente. Molte di queste donne necessitano successivamente di terapia sostitutiva con levotiroxina (L-tiroxina).

\section{Noduli tiroidei}

È stata evidenziata una maggiore incidenza di noduli tiroidei nella gravida rispetto alla nullipara, ma l'esatto ruolo degli ormoni riproduttivi nella genesi dei noduli tiroidei è sconosciuto. Inoltre, il $15-40 \%$ dei noduli tiroidei insorti durante la gravidanza potrebbe essere maligno.

La certezza diagnostica si ha con l'agoaspirato; questo esame raggiunge un'alta sensibilità e specificità diagnostica e, vista l'impossibilità di eseguire la scintigrafia, è l'esame di prima scelta in gravidanza. ${ }^{46}$

Qualora venga evidenziata una citologia sospetta o certa per tumore, si dovrà valutare se procedere alla rimozione chirurgica della tiroide durante la gravidanza oppure, in caso sia possibile, ritardare la tiroidectomia al postpartum. ${ }^{47}$

È comunque importante sottolineare che una corretta gestione della paziente si basa su un approccio multidisciplinare che vede coinvolti il ginecologo, l'endocrinologo, il chirurgo, il radiologo e l'anatomopatologo.

\section{Conclusioni}

La valutazione delle gravidanze con tireopatia si basa su un corretto counselling preconcezionale e su un attento monitoraggio durante la gravidanza, al fine di trasformare una gravidanza ad alto rischio in una a rischio medio. È descritto che i due terzi della popolazione dell'Europa occidentale e centrale sono a rischio di deficit di iodio, tale deficit, anche se moderato, influenza negativamente la funzione tiroidea della madre e del feto e lo sviluppo mentale del neonato. Sembra opportuno, perciò, sottolineare che le donne che programmano una gravidanza o sono in gravidanza do- vrebbero ricevere una supplementazione di iodio (circa $150 \mu \mathrm{g} / \mathrm{die}$ ) e alcuni integratori di uso in gravidanza contengono tale quota. ${ }^{48} \mathrm{Va}$, comunque, sottolineato che gli effetti a lungo termine di tale supplementazione non sono noti.

È importante effettuare lo screening per patologie tiroidee prima e all'inizio della gravidanza, per individuare precocemente forme subcliniche ed intervenire con la terapia nei casi selezionati.

\section{Bibliografia}

1. Alexander EK, Pearce EN, Brent GA, et al Guidelines of the American Thyroid Association for the Diagnosis and Management of Thyroid Disease during Pregnancy and the Postpartum. Thyroid Volume 27, Number 3, 2017.

2. Weeke J, Dybkjaer L, Granlie K, Eskjaer Jensen S, Kjaerulff E, Laurberg P, Magnusson B 1982 A longitudinal study of serum TSH, and total and free iodothyronines during normal pregnancy. Acta Endocrinologica 101:531.

3. Berghout A, Wiersinga W 1998 Thyroid size and thyroid function during pregnancy: an analysis. Eur J Endocrinol 138:536-542.

4. Glinoer D 1997 The regulation of thyroid function in pregnancy: pathways of endocrine adaptation from physiology to pathology. Endocr Rev 18:404-433.

5. Baloch Z, Carayon P, Conte-Devolx B, Demers LM, Feldt-Rasmussen U, Henry JF, LiVosli VA, Niccoli-Sire P, John R, Ruf J, Smyth PP, Spencer CA, Stockigt JR, Guidelines Committee, National Academy of Clinical Biochemistry 2003 Laboratory medicine practice guidelines. Laboratory support for the diagnosis and monitoring of thyroid disease. Thyroid 13:3-126.

6. Soldin OP, Tractenberg RE, Hollowell JG, Jonklaas J, Janicic N, Soldin SJ 2004 Trimester-specific changes in maternal thyroid hormone, thyrotropin, and thyroglobulin concentrations during gestation: trends and associations across trimesters in iodine sufficiency. Thyroid 14:1084-1090.

7. Kahric-Janicic N, Soldin SJ, Soldin OP, West T, Gu J, Jonklaas J 2007 Tandem mass spectrometry improves the accuracy of free thyroxine measurements during pregnancy. Thyroid 17:303-311.

8. Pearce EN, Oken E, Gillman MW, Lee SL, Magnani B, Platek D, Braverman LE 2008 Association of firsttrimester thyroid function test values with thyroperoxidase antibody status, smoking, and multivitamin use. Endocr Pract 14:33-39.

9. Moleti M, Lo Presti VP, Mattina F, Mancuso A, De Vivo A, Giorgianni G, Di Bella B, Trimarchi F, Vermiglio F 2009 Gestational thyroid function abnormalities in conditions of mild iodine deficiency: early screening versus continuous monitoring of maternal thyroid status. Eur J Endocrinol 160:611-617.

10. McElduff A, Morris J 2008 Thyroid function tests and thyroid autoantibodies in an unselected population of women undergoing first trimester screening for aneuploidy. Aust N Z J Obstet Gynaecol 48:478-480.

11. Chen L, Hu R 2011 Thyroid autoimmunity and miscarriage: a meta-analysis. Clin Endocrinol (Oxf) 74: 513-519. 
12. Thangaratinam S, Tan A, Knox E, Kilby MD, Franklyn J, Coomarasamy A 2011 Association between thyroid autoantibodies and miscarriage and preterm birth: metaanalysis of evidence. BMJ 342:d2616.

13. Negro R 2011 Thyroid autoimmunity and pre-term delivery: brief review and meta-analysis. J Endocrinol Invest 34:155-158.

14. He X, Wang P, Wang Z, He X, Xu D, Wang B 2012 Thyroid antibodies and risk of preterm delivery: a metaanalysis of prospective cohort studies. Eur J Endocrinol 167:455-464.

15. Groer MW, Vaughan JH 2013 Positive thyroid peroxidase antibody titer is associated with dysphoric moods during pregnancy and postpartum. J Obstet Gynecol Neonatal Nurs 42:E26-E32.

16. Negro R, Schwartz A, Gismondi R, Tinelli A, Mangieri T, Stagnaro-Green A 2011 Thyroid antibody positivity in the first trimester of pregnancy is associated with negative pregnancy outcomes. J Clin Endocrinol Metab 96:E920-E924.

17. FIGO Working Group on Good Clinical Practice in Maternal-Fetal Medicine. Good clinical practice advice: Thyroid and pregnancy. Int J Gynaecol Obstet. 2019 Mar;144(3):347-351.

18. Zhou M, Wang M, Li J, Luo X, Lei M. Effects of thyroid diseases on pregnancy outcomes. Exp Ther Med. 2019; 18(3):1807-1815.

19. Casey BM, Dashe JS, Wells CE, McIntire DD, Leveno KJ, Cunningham FG. Subclinical hyperthyroidism and pregnancy outcomes. Obstet Gynecol. 2006; 107: 337-341.

20. Allan WC, Haddow JE, Palomaki GE, et al. Maternal thyroid deficiency and pregnancy complications: Implications for population screening. J Med Screen. 2000; 7: $127-130$.

21. Negro R, Schwartz A, Gismondi R, Tinelli A, Mangieri T, Stagnaro-Green A 2010 Increased pregnancy loss rate in thyroid antibody negative women with TSH levels between 2.5 and 5.0 in the first trimester of pregnancy. J Clin Endocrinol Metab 95:E44-E48.

22. Abalovich M, Mitelberg L, Allami C, Gutierrez S, Alcaraz G, Otero P, Levalle O 2007 Subclinical hypothyroidism and thyroid autoimmunity in women with infertility. Gynecol Endocrinol 23:279-283.

23. Lee YJ, Kim CH, Kwack JY, Ahn JW, Kim SH, Chae HD, Kang BM 2014 Subclinical hypothyroidism diagnosed by thyrotropin-releasing hormone stimulation test in infertile women with basal thyroid-stimulating hormone levels of 2.5 to $5.0 \mathrm{mIU} / \mathrm{L}$. Obstet Gynecol Sci 57:507-512.

24. Arojoki M, Jokimaa V, Juuti A, Koskinen P, Irjala K, Anttila L 2000 Hypothyroidism among infertile women in Finland. Gynecol Endocrinol 14:127-131.

25. Stagnaro-Green A, Abalovich M, Alexander E, et al. Guidelines of the American Thyroid Association for the diagnosis and management of thyroid disease during pregnancy and postpartum. Thyroid. 2011;21(10): 1081-1125.

26. FIGO Working Group on Good Clinical Practice in Maternal-Fetal Medicine. Good clinical practice advice: Thyroid and pregnancy. Int J Gynaecol Obstet. 2019 Mar;144(3):347-351.

27. Galofre JC, Haber RS, Mitchell AA, Pessah R, Davies
TF. 2010 Increased postpartum thyroxine replacement in Hashimoto's thyroiditis. Thyroid 20:901-908.

28. Dong AC, Stagnaro-Green A. Differences in diagnostic criteria mask the true prevalence of thyroid disease in pregnancy: a systematic review and meta-analysis. Thyroid 2018;29:278e89.

29. Luton D, Le Gac I, Vuillard E, et al. Management of Graves' disease during pregnancy: the key role of fetal thyroid gland monitoring. J Clin Endocrinol Metab. 2005; 90, no. 11:6093-6098.

30. Tonacchera M, Chiovato L, Bartalena L, et al. Treatment of Graves' hyperthyroidism with thionamides: a position paper on indications and safety in pregnancy. J Endocrinol Invest. 2019 Nov 29.

31. Delitala AP, Capobianco G, Cherchi PL, et al. Thyroid function and thyroid disorders during pregnancy: A review and care pathway. Arch Gynecol Obstet 299: 327 338, 2019.

32. Lazarus JH. Thyroid function in pregnancy. Br Med Bull 2011; 97:137-48.

33. Sapin R, d'Herbomez M. Free thyroxine measured dialysis and nine immunoassays in sera with various serum thyroxine-binding capacities. Clin Chem 2003; 49: 1531-5.

34. De Groot L, Abalovich M, Alexander EK, Amino N, Barbour L, Cobin RH, Eastman CJ, Lazarus JH, Luton D, Mandel SJ, Mestman J, Rovet J, Sullivan S: Management of thyroid dysfunction during pregnancy and postpartum: an Endocrine Society clinical practice guideline. J Clin Endocrinol Metab 2012; 97: 2543-2565.

35. Stagnaro-Green A, Abalovich M, Alexander E, Azizi F, Mestman J, Negro R, Nixon A, Pearce EN, Soldin OP, Sullivan S, Wiersinga W: Guidelines of the American Thyroid Association for the diagnosis and management of thyroid disease during pregnancy and postpartum. American Thyroid Association Taskforce on Thyroid Disease during Pregnancy and Postpartum. Thyroid 2011; 21:1081-1125.

36. Wing DA, Millar LK, Koonings PP, et al. A comparison of propylthiouracil versus methimazole in the treatment of hyperthyroidism in pregnancy. Am J Obstet Gynecol.1994; 170:90-95.

37. Hackmon R, Blichowski M, Koren G. The safety of methimazole and propylthiouracil in pregnancy: A systemic review. J Obstet Gynaecol Can. 2012;34:1086.

38. Millar LK, Wing DA, Leung AS, Koonings PP, Montoro $\mathrm{MN}$, Mestman JH. Low birth weight and preeclampsia in pregnancies complicated by hyperthyroidism. Obstet Gynecol. 1994;84:946-949.

39. Clementi M, Di Gianantonio E, Cassina M, et al. Treatment of hyperthyroidism in pregnancy and birth defects. J Clin Endocrinol Metab. 2010;95:E337-41.

40. Yoshihara A, Noh J, Yamaguchi T, et al. Treatment of graves' disease with antithyroid drugs in the first trimester of pregnancy and the prevalence of congenital malformation. J Clin Endocrinol Metab. 2012;97:2396-2403.

41. Song R, Lin H, Chen Y, Zhang X, Feng W. Effects of methimazole and propylthiouracil exposure during pregnancy on the risk of neonatal congenital malformations: A meta-analysis. PLoS One 2017; 12.

42. De Groot L, Abalovich M, Alexander EK, Amino N, Barbour L, Cobin RH, Eastman CJ, Lazarus JH, Luton D, Mandel SJ, Mestman J, Rovet J, Sullivan S: Management 
of thyroid dysfunction during pregnancy and postpartum: an Endocrine Society clinical practice guideline. J Clin Endocrinol Metab 2012; 97: 2543-2565.

43. Earl R, Crowther CA, Middleton P. Interventions for hyperthyroidism pre-pregnancy and during pregnancy. The Cochrane Collaboration. Published by JohnWiley \& Sons, Ltd. 2013.

44. Chiha M, Samarasinghe S, Kabaker AS. Thyroid storm: an updated review. J Intensive Care Med 2015; 30:131.

45. Yeo CP, Khoo DH, Eng PH, et al. Prevalence of gestational thyrotoxicosis in Asian women evaluated in the 8th to 14th weeks of pregnancy: correlations with total and free beta human chorionic gonadotrophin. Clin Endocrinol (Oxf) 2001; 55:391.

46. Burch HB, Burman KD, Cooper DS, et al. A 2015 Survey of Clinical Practice Patterns in the Management of Thyroid Nodules. J Clin Endocrinol Metab 2016; 101:2853.

47. Nam KH, Yoon JH, Chang HS, Park CS. Optimal timing of surgery in well-differentiated thyroid carcinoma detected during pregnancy. J Surg Oncol 2005; 91:199.

48. Leung AM, Pearce EN, Braverman LE. Iodine content of prenatal multivitamins in the United States. N Engl J Med 2009; 360:939. 


\title{
Gestione della gravidanza nelle donne con malattia di Behçet e vasculiti
}

\author{
Maria Gerosa, Martina Cornalba, Alessandro Sinelli, Rolando Cimaz, Roberto Caporali \\ Dipartimento di Scienze Cliniche e di Comunità, Università degli Studi di Milano, ASST PINI-CTO, Milano, Italia
}

\section{Introduzione}

Il termine 'vasculiti sistemiche' include un gruppo eterogeneo di patologie, caratterizzate da un danno infiammatorio della parete dei vasi. A seconda del tipo, delle dimensioni e della localizzazione dei vasi interessati, le manifestazioni cliniche possono essere molto diverse e avere un andamento variabile, quale autolimitante, remittente-recidivante o cronico. $\mathrm{Si}$ tratta in genere di patologie gravi, talvolta fatali, che richiedono un rapido riconoscimento e una terapia aggressiva, e il cui esatto meccanismo patogenetico è sconosciuto. ${ }^{1}$

La più comune classificazione delle vasculiti è fondata principalmente sulla dimensione dei vasi coinvolti ed è stata revisionata durante la International Chapel Hill Consensus Conference (CHCC) del 2012 (Tabella 1). Si possono distinguere vasculiti dei grossi vasi, quali l'arterite di Takayasu e l'arterite gigantocellulare, vasculiti interessanti vasi di medio calibro, come la poliarterite nodosa e la malattia di Kawasaki, o di piccolo calibro, come le vasculiti ANCA-associate. Inoltre, alcune forme di vasculite (es. malattia di Behçet) non coinvolgono in maniera predominante vasi di specifiche dimensioni e, pertanto, vengono classificate come vasculiti interessanti vasi di calibro variabile. $^{2}$

Negli ultimi anni, la diagnosi precoce e un adeguato controllo di malattia hanno permesso una riduzione della mortalità e della morbidità di questi pazienti; il conseguente miglioramento della qualità di

Corrispondente: Maria Gerosa, Dipartimento di Scienze Cliniche e di Comunità, Università degli Studi di Milano, ASST PINI-CTO, Milano, Italia.

E-mail: maria.gerosa@unimi.it

Articolo pubblicato secondo la Creative Commons Attribution NonCommercial 4.0 License (CC BY-NC 4.0).

${ }^{\circ}$ Copyright: the Author(s), 2021

Licensee PAGEPress, Italy

QUADERNI - Italian Journal of Medicine 2021; 9(4):e10 vita ha consentito alle giovani donne affette da queste patologie la possibilità di portare a termine con successo una o più gravidanze. ${ }^{1-12}$ Nonostante ciò, la gravidanza in corso di vasculite rimane un evento non comune, a causa dell'estrema rarità di queste malattie nelle donne in età fertile. ${ }^{1}$ I dati riguardanti gli esiti delle gravidanze sono ancora limitati, e le conoscenze relative al rischio gestazionale sono principalmente ottenute da case reports o piccole case series e da studi retrospettivi, con possibili bias osservazionali. ${ }^{12}$ In considerazione dell'età media di insorgenza più precoce, la maggior parte della letteratura si concentra su gravidanze in donne affette da arterite di Takayasu e malattia di Behçet; casi di gravidanze in vasculiti ANCA-associate sono comunque riportati. ${ }^{4-12}$ In linea generale, da quanto emerge dalla letteratura, la gravidanza non sembra avere un effetto significativo sull'attività di malattia; al contrario, una eventuale riacutizzazione può condurre a severe complicanze. ${ }^{4-13}$ Gli studi fino ad ora condotti dimostrano chiaramente come una attenta programmazione della gravidanza, in una fase di completa remissione di malattia, e uno stretto monitoraggio da parte del reumatologo/internista e ginecologo, siano fondamentali per ridurre al minimo il rischio di complicanze materne e fetali nelle donne con vasculite sistemica. In particolare, un aspetto di estrema rilevanza riguarda il trattamento di queste pazienti: da un lato, la terapia di fondo delle vasculiti merita particolare attenzione a causa della fetotossicità di numerosi farmaci utilizzati; dall'altro, la scelta di farmaci compatibili con la gravidanza è necessaria per garantire un adeguato controllo della patologia di base. ${ }^{1-11}$

\section{Malattia di Behçet}

La malattia di Behçet è un disordine infiammatorio multisistemico cronico recidivante, interessante arterie e vene di qualsiasi dimensione, caratterizzato da manifestazioni muco-cutanee, oculari, vascolari, articolari, gastrointestinali e/o del sistema nervoso centrale., ${ }^{3,4,12}$

Nessun indice di attività di malattia è stato al momento attuale validato in gravidanza. Le riacutizzazioni 
sono normalmente definite dall'esordio di nuovi sintomi o dal peggioramento di segni di patologia già presenti, che richiedono modifiche terapeutiche. Rispetto ad altri tipi di vasculite, $i$ dati disponibili in letteratura riguardanti la gravidanza in corso di malattia di Behçet sono più abbondanti, in relazione alle caratteristiche epidemiologiche di questa malattia. I diversi studi hanno preso in considerazione le condizioni cliniche della donna (età, coinvolgimento d'organo, trattamenti in corso e pregressi), le complicanze materne (ipertensione arteriosa, pre-eclampsia, necessità di incremento della dose di glucocorticoidi), e l'outcome fetale/neonatale (prematurità, basso peso alla nascita, mortalità perinatale, accesso alla terapia intensiva neonatale). ${ }^{4}$

Dagli studi disponibili emerge che la malattia di Behçet in più della metà dei casi rimane stabile o migliora durante la gravidanza. ${ }^{4-12}$ Tuttavia, nella stessa donna, la malattia può risultare ben controllata in una

Tabella 1. Nomenclatura delle vasculiti adottata dalla International Chapel Hill Consensus Conference nel 2012.

\begin{tabular}{l}
\hline Vasculiti dei grossi vasi \\
Arterite di Takayasu \\
Arterite a cellule giganti \\
\hline Vasculiti dei medi vasi \\
Poliarterite nodosa \\
Malattia di Kawasaki \\
\hline Vasculiti dei piccoli vasi \\
Vasculiti ANCA-associate \\
Poliangioite microscopica (MPA) \\
$\quad$ Granulomatosi con poliangioite (GPA) \\
Granulomatosi eosinofila con poliangioite (EGPA) \\
Vasculiti da immunocomplessi \\
Malattia da anticorpi anti-membrana basale glomerulare \\
Vasculite crioglobulinemica \\
$\quad$ Vasculite da IgA (Schonlein-Henoch) \\
$\quad$ Vasculite orticarioide ipocomplementemica \\
\hline Vasculiti di vasi di dimensioni variabili \\
Malattia di Behçet \\
Sindrome di Cogan \\
\hline Vasculite di singoli organi \\
Angioite cutanea leucocitoclastica \\
Arterite cutanea \\
Vasculite primaria del sistema nervoso centrale \\
Aortite isolata \\
Altre \\
\hline Vasculiti associate a malattie sistemiche \\
Vasculite da lupus \\
Vasculite reumatoide \\
Vasculite da sarcoidosi \\
Altre \\
\hline Vasculite associata a probabile eziologia \\
Vasculite crioglobulinemica associata a virus da epatite C \\
Vasculite associata a virus da epatite B \\
Aortite associata a sifilide \\
Vasculite da immunocomplessi da farmaci \\
Vasculite ANCA associata da farmaci \\
Vasculite associata a neoplasia \\
Altre \\
\hline
\end{tabular}

gravidanza, mentre può riacutizzarsi nella successiva. Fino ad oggi, non sono stati identificati segni predittivi per una riattivazione di patologia nel corso di gravidanza. ${ }^{9}$ La prevalenza di riacutizzazione durante la gestazione è stimata intorno al $30 \%$ : più frequentemente è caratterizzata dalla comparsa di ulcere orali $(50 \%$ $66.7 \%)$ e genitali (25\%-55.6\%), seguite da lesioni cutanee $(8,3-33,3 \%)$ e infiammazione oculare $(0-25 \%)$. Di particolare rilevanza clinica, per l'elevata morbilità ad essa associata, è l'aumentata incidenza di eventi materni tromboembolici interessanti vasi di qualsiasi calibro, come trombosi venosa cerebrale, della vena cava superiore o embolia polmonare; inoltre, la sindrome di Budd-Chiari o una trombosi venosa profonda e intracardiaca sono risultate più frequenti durante il puerperio. ${ }^{3,7,9,12}$ Non esistono dati che dimostrino che una terapia trombo-profilattica in gravidanza possa ridurre il rischio di queste temibili complicanze e uno stretto controllo di malattia sembra rappresentare, come al di fuori della gestazione, la migliore strategia per ridurre il rischio di trombosi nelle pazienti affette da Behçet.

La malattia non sembra avere un effetto rilevante sull'outcome materno-fetale. I dati riguardanti circa 225 gravidanze in donne affette da malattia di Behçet riportano una frequenza di eventi avversi solo lievemente più alta di quella osservata nella popolazione generale: le complicanze più comuni sono state un lieve incremento dell'abortività (con incidenza fino al $20,8 \%$ ), ritardo di crescita intrauterino, parto pretermine, diabete gestazionale e ipertensione., ${ }^{3,7,9,12} \mathrm{E}$ interessante notare come l'aumento del rischio di aborto sia stato associato ad un pregresso coinvolgimento venoso: è stato ipotizzato che tale associazione sia correlata ad un possibile effetto di interferenza sull'impianto del trofoblasto, nelle pazienti con manifestazioni venose, attraverso un meccanismo non ancora completamente chiarito.

In conclusione, le donne affette da Behçet hanno un rischio intorno al $30 \%$ di riacutizzazione, che però, nella maggior parte dei casi, è di modesta entità. La complicanza più temibile in queste pazienti è la comparsa di eventi trombotici, associata ad una elevata morbilità. Il rischio di complicanze sulla gravidanza è solo lievemente più alto della popolazione generale ed uno stretto monitoraggio durante la gestazione può ridurlo in maniera significativa.

\section{Arterite di Takayasu}

L'arterite di Takayasu è una vasculite granulomatosa che coinvolge primariamente i grossi vasi, quali l'aorta, le sue branche principali e le arterie polmonari. ${ }^{3-12}$ Queste lesioni sono spesso asintomatiche, finché non avviene una dissezione, una rottura o lo sviluppo di un aneurisma. ${ }^{14}$ 
Al momento non esiste ancora uno strumento clinico validato per valutare l'attività di malattia in gravidanza. Uno degli indici di attività più utilizzati per la malattia, il Kerr/NIH Index, che prende in considerazione sintomi costituzionali, rialzo della VES, alterazioni ischemiche e caratteristiche angiografiche indicative di vasculite, è di difficile applicazione in gravidanza, in quanto il rialzo della VES e i sintomi costituzionali possono essere da questa influenzati, anche in assenza di malattia in fase di attività.

Gli studi riguardanti la gravidanza in pazienti affette da arterite di Takayasu hanno preso in considerazione le caratteristiche generali del soggetto (età, tipo di coinvolgimento arterioso, parità, precedenti complicanze ostetriche), lo stato di salute materno (necessità di incremento della dose di glucocorticoidi, rialzo di VES e PCR, ipertensione arteriosa, preeclampsia, interessamento renale e cardiaco, eventi cardiovascolari) e del feto (ridotta crescita fetale, prematurità, peso alla nascita, mortalità perinatale, Apgar score a 5 minuti). ${ }^{4}$

L'esordio di malattia solitamente avviene prima dei 30 anni di età; pertanto questa patologia è più comunemente osservata in gravidanza rispetto ad altre forme di vasculite. ${ }^{3-12}$ Studi recenti hanno dimostrato come nella maggior parte dei casi la gravidanza non abbia un effetto significativo sul decorso di malattia. Tuttavia, sebbene rare, le complicanze materne descritte possono avere un impatto devastante, essendo rappresentate da aneurisma aortico, infarto miocardico, insufficienza aortica o dissezione. .,4,12 $^{4}$

La maggior parte delle gravidanze in donne affette da arterite di Takayasu è portata a termine con successo, se ben programmata. ${ }^{3-12}$ Le complicanze più frequenti sono correlate all'elevata incidenza di ipertensione arteriosa di cui questa malattia è gravata. In particolare, è descritta una prevalenza di ipertensione gestazionale e pre-eclampsia di cinque volte maggiore rispetto alla popolazione generale. Altre complicanze descritte includono morte intrauterina, ritardo di crescita intrauterino e basso peso alla nascita, parto pretermine e perdita fetale. Il rischio è stato correlato alle caratteristiche di aggressività della malattia. ${ }^{3,12,14}$

\section{Vasculiti ANCA-associate}

Le vasculiti ANCA-associate sono un gruppo di vasculiti necrotizzanti interessanti principalmente vasi di piccolo calibro delle vie respiratorie, dei polmoni, del rene e del sistema nervoso periferico, caratterizzate da positività per anticorpi specifici per mieloperossidasi (MPO-ANCA) o proteinasi 3 (PR3-ANCA).,

Le principali varianti clinico-patologiche includono la poliangioite microscopica (MPA), la granulomatosi con poliangioite (GPA, nota anche come granulomatosi di Wegener) e la granulomatosi eosinofila con poliangioite (EGPA o sindrome di Churg Strauss). Sebbene l'età media d'esordio sia più avanzata, per ciascuna di queste forme di vasculite sono stati descritti casi di gravidanza. Gli scarsi dati di letteratura suggeriscono che la gravidanza possa essere gravata da un elevato rischio di complicanze severe fino all'exitus, in caso di malattia in fase attiva. ${ }^{3,4}$ Esistono inoltre diversi case reports che descrivono un esordio di malattia acuta ed aggressiva proprio durante la gestazione. ${ }^{1,3}$

La poliangioite microscopica (MPA) è una vasculite necrotizzante pauci-immune interessante principalmente capillari, venule e arteriole, che si manifesta comunemente come glomerulonefrite necrotizzante e/o capillarite polmonare, con positività per $\mathrm{ANCA}$ in più del $90 \%$ dei pazienti. I dati riguardanti le gravidanze in questa forma di vasculite sono scarsi e suggeriscono che, se la gravidanza si instaura in una fase di remissione di malattia, il rischio di riacutizzazione è intorno al $40 \%$. Nel caso in cui, invece, la gravidanza sia intrapresa durante la fase attiva, le complicanze possono essere molto gravi, fino a casi descritti di exitus materno. Le complicanze fetali descritte sono basso peso alla nascita e prematurità anche severa; esiste poi il rischio di insorgenza di una sindrome MPAlike nel neonato. ${ }^{3,4,12}$ Nonostante il passaggio placentare degli anticorpi, il trattamento della madre con terapia immunosoppressiva (corticosteroidi e azatioprina) potrebbe prevenire l'esordio della MPA-like syndrome nel neonato. ${ }^{12}$

La granulomatosi con poliangioite (GPA) è una rara vasculite necrotizzante che coinvolge principalmente le alte vie respiratorie, il polmone e il rene, con picco d'esordio oltre i 40 anni di età, con positività per gli ANCA in più del $80 \%$ dei pazienti. ${ }^{5,6,12}$ Come per la MPA, il rischio di complicanze materne e di peggioramento di malattia è elevato in caso di concepimento durante una fase di attività di malattia. Esistono diversi casi descritti in letteratura di esordio della vasculite proprio durante la gravidanza, con comparsa di manifestazioni molto severe di malattia, prevalentemente renali o polmonari, compresa la stenosi subglottica, che in alcuni casi hanno portato a morte materna. ${ }^{5,6,12}$ Dal punto di vista ostetrico, le complicanze materno-fetali più comuni sono il parto pretermine (con una frequenza del $35 \%$ ), preeclampsia, rottura prematura delle membrane, aborto spontaneo, emorragia pre-parto ed ematoma retroplacentare.

La granulomatosi eosinofila con poliangioite (Sindrome di Churg-Strauss - EGPA) è una vasculite necrotizzante che interessa in maniera predominante vasi di piccolo e medio calibro. Le principali manifestazioni cliniche sono la comparsa di granulomi necrotizzanti extravascolari, eosinofilia periferica, vasculite polmonare e dei piccoli vasi, in pazienti affetti da ri- 
nosinusite cronica ed asma, con età media di insorgenza intorno ai 48 anni e positività per ANCA nel $40 \%$ dei casi. ${ }^{3,4-12}$ Come nella GPA, il parto pretermine è la complicanza più frequente, ma sono comunque osservati casi di perdita fetale e ritardo di crescita intrauterino..$^{3,4-12}$

Al momento non ci sono strumenti clinici specifici per valutare l'attività di malattia durante la gravidanza. Nella maggior parte degli studi in donne gravide affette da vasculite ANCA associata, l'attività di malattia viene valutata utilizzando il Birmingham Vasculitis Activity Score (BVAS), mentre il danno dovuto alla malattia attraverso il Vasculitis Damage Index (VDI). ${ }^{5,6}$ Inoltre, molti studi si fondano su dati riguardanti le caratteristiche delle pazienti (età, tipo di vasculite, coinvolgimento d'organo, positività anticorpale, terapie precedenti e in atto), lo stato di salute materno (funzionalità renale, ipertensione arteriosa, preeclampsia), fetale e neonatale (ritardo di crescita intrauterino, parto pretermine, basso peso alla nascita, mortalità perinatale) e il tipo di parto.,

Nel complesso, i dati che riguardano la gravidanza nelle vasculiti ANCA associate suggeriscono che, se la gravidanza viene attentamente programmata in una fase di remissione di malattia, il rischio di complicanze materne e fetali è abbastanza basso, anche se una stima precisa di tale rischio risulta difficile a causa dell'esiguo numero di casi descritti. Al contrario, in caso di malattia in fase attiva, la gravidanza può determinare un peggioramento della vasculite, che a sua volta può avere un effetto negativo sull'outcome gravidico. ${ }^{3,4}$

\section{Gestione delle vasculiti in gravidanza}

La necessità di intraprendere la gravidanza in fase di remissione di malattia implica un'attenta valutazione della terapia, soprattutto per le donne in età fertile. Le vasculiti, nel loro complesso, rappresentano un gruppo di patologie complesse, con andamento variabile, ma che possono avere manifestazioni molto severe, che richiedono un trattamento aggressivo, talvolta con farmaci potenzialmente teratogeni, che in genere deve essere proseguito a lungo termine. ${ }^{11}$ Inoltre, un'infiammazione sistemica da vasculite attiva può aumentare il rischio di aborto, ritardo di crescita fetale e nascita pretermine. ${ }^{3}$

Tra le terapie comunemente utilizzate per il trattamento delle vasculiti, corticosteroidi, colchicina, immunoglobuline endovena, ciclosporina e azatioprina sono considerati sicuri al momento del concepimento e durante la gravidanza; pertanto, per limitare il rischio di riattivazione di malattia, questi farmaci non devono assolutamente essere interrotti. ${ }^{11}$

Tra i farmaci inclusi nell'armamentario terapeutico delle vasculiti ne esistono alcuni con un chiaro poten- ziale teratogeno: tra questi, quelli più utilizzati sono metotrexate (MTX), micofenolato mofetile (MMF) e ciclofosfamide (CYC). Secondo le ultime raccomandazioni EULAR sull'utilizzo di farmaci immunosoppressori in gravidanza, questi dovrebbero essere interrotti prima di una programmazione di concepimento, con uno switch a farmaci a più basso rischio per la gravidanza. Se il concepimento avviene in corso di queste terapie, il farmaco deve essere immediatamente interrotto e la paziente indirizzata al ginecologo per discutere il rischio fetale..$^{3-11,15}$

Nonostante molti reumatologi preferiscano prescrivere glucocorticoidi in gravidanza, questi non sono sempre la scelta migliore, in quanto determinano un incremento del rischio di nascite pretermine e limitano significativamente la crescita fetale. Inoltre, si riscontra più frequentemente un aumento del rischio di diabete gestazionale, ipertensione arteriosa e incremento ponderale materno, tutte manifestazioni associate a complicanze a breve e lungo termine per la donna e il neonato. Pertanto, risulta preferibile usare farmaci immunosoppressori non teratogeni per controllare l'attività di malattia prima e durante la gravidanza, limitando lo steroide alle riacutizzazioni. ${ }^{3}$

L'azatioprina (AZA) ha il più elevato numero di dati che supportano la sua compatibilità in gravidanza, seguita da ciclosporina e tacrolimus; si tratta di farmaci che possono essere introdotti prima del concepimento e continuati durante la gravidanza e l'allattamento.

La ciclofosfamide (CYC) è un noto farmaco teratogeno quando utilizzato durante il concepimento e il primo trimestre di gravidanza; in letteratura, il trattamento combinato con glucocorticoidi durante il secondo e terzo trimestre ha dimostrato il raggiungimento di una remissione in circa la metà delle pazienti, ma spesso con un esito gravidico sfavorevole per riscontro di preeclampsia, parto pretermine e basso peso alla nascita. ${ }^{11}$

Elevati livelli di citochine quali IL-6 e TNFalfa possono essere particolarmente deleteri in queste pazienti, e studi preliminari hanno dimostrato l'efficacia di farmaci anti-IL6 o anti-TNFalfa in donne refrattarie ad altre terapie immunosoppressive. ${ }^{14}$ Diversi studi hanno ormai chiaramente evidenziato che i farmaci anti-TNF possono essere continuati durante la gravidanza e l'allattamento; essi attraversano la placenta a partire dalla 14esima settimana di gestazione con un incremento delle concentrazioni materne in prossimità del parto, in particolare infliximab e adalimumab. Le raccomandazioni EULAR suggeriscono pertanto che questi ultimi debbano essere sospesi tra la 30esima e la 32esima settimana di gestazione, per evitare effetti potenzialmente avversi sulla risposta immunitaria del neonato. Tra gli anti-TNF, certolizumab pegol ha dimostrato essere probabilmente il farmaco anti-TNF 
più sicuro. Studi recenti hanno infatti evidenziato che questa molecola, non possedendo la porzione $\mathrm{Fc}$, presenta un passaggio attraverso la placenta e nel latte materno trascurabile, e non deve pertanto essere sospeso né in prossimità del parto né durante l'allattamento. ${ }^{3,15}$

Un altro farmaco biologico di interesse è rituximab (RTX). Sulla base di due studi randomizzati controllati, infatti, la Food and Drug Administration ha recentemente approvato l'utilizzo di RTX in combinazione con glucocorticoidi per il trattamento delle vasculiti ANCA associate. Dati sull'utilizzo di RTX durante la gravidanza sono piuttosto limitati, ma sembrano essere promettenti. ${ }^{8}$ Numerosi autori, infatti, non hanno riportato un aumento di malformazioni in feti esposti a tale farmaco, anche se sono stati descritti casi di transitoria deplezione di linfociti B nel feto, ma ripristino degli stessi entro 6 mesi dalla nascita senza effetti avversi. Per tale motivo RTX deve essere rigorosamente evitato negli ultimi mesi di gravidanza, mentre alcuni autori ipotizzano che l'infusione nei mesi precedenti al concepimento o nel primo trimestre potrebbe essere un approccio accettabile per il trattamento delle vasculiti in fase di attività o ad alto rischio di riattivazione senza terapia di mantenimento. ${ }^{3,15} \mathrm{Ul}-$ teriori studi sono tuttavia necessari per chiarire in maniera incontrovertibile se e come RTX possa essere utilizzato in maniera sicura durante la gestazione.

Recentemente, in casi con esordio di malattia durante la gravidanza, è stata utilizzata con successo anche la terapia con immunoglobuline endovena, con beneficio sulla patologia e nascita di neonati sani. ${ }^{12} \mathrm{La}$ plasmaferesi può essere considerata in casi severi di vasculite ANCA-associata.

La colchicina è considerata un farmaco a basso rischio in gravidanza in studi di donne affette da Malattia di Behçet, garantendo un ridotto utilizzo di steroide. ${ }^{10}$

L'ipertensione è un sintomo comune in donne gravide affette da arterite di Takayasu e può condurre a complicanze materne e fetali; pertanto, è raccomandato uno stretto monitoraggio della pressione arteriosa e l'utilizzo precoce di farmaci antipertensivi in caso di necessità. In tale situazione, il farmaco di prima scelta è rappresentato da alfametildopa, mentre l'utilizzo di calcio-antagonisti o beta-bloccanti potrebbe essere preso in considerazione in caso di ipertensione non controllata, dopo la $12^{\circ}$ settimana di gestazione.

In letteratura sono descritti anche casi di vasculite esordita nel periodo post-partum, per cui si raccomanda stretto monitoraggio anche nelle successive 612 settimane. Il trattamento, se continuato durante la gravidanza, non deve essere interrotto troppo rapidamente e, in caso di ulteriore peggioramento clinico, dovrebbe essere considerata una terapia più aggressiva dopo il parto. La vasculite non è generalmente una pa- tologia ereditaria, sebbene vi sia una predisposizione genetica, tuttavia rari casi di manifestazioni vasculitiche transitorie sono stati descritti in neonati di madri affette. ${ }^{11}$

\section{Fertilità}

Un aspetto interessante per i pazienti affetti da vasculite è il potenziale impatto sulla fertilità, che spesso non viene inizialmente considerato. Al contrario, questo argomento dovrebbe essere precocemente trattato soprattutto in previsione di alcuni trattamenti, ed eventualmente ridiscusso in caso di desiderio di gravidanza, in quanto sia l'età avanzata che l'incremento della dose di CYC incidono negativamente sulla fertilità. Vasculiti quali GPA o malattia di Behçet raramente coinvolgono gli organi riproduttivi femminili. Una disregolazione funzionale neuroendocrina dell'asse ipotalamo-ipofisi-gonadi è possibile come in ogni situazione di stress, ma è solitamente transitoria. Nell'uomo, un'orchite o epididimo-orchite è una classica manifestazione della poliarterite nodosa (PAN), ma può essere osservata anche in corso di GPA, malattia di Behçet o porpora di Schonlein-Henoch. L'infiammazione testicolare è solitamente reversibile con terapia, senza ulteriori conseguenze, ma è possibile riscontrare casi di necrosi ischemica testicolare.

La CYC è il più potente farmaco utilizzato per il trattamento delle vasculiti, ma è associato ad incrementato rischio di infertilità o sub fertilità nel 20-85\% di donne in età fertile, sulla base della dose cumulativa ricevuta e dell'età della paziente. La dose cumulativa di CYC associata ad insufficienza ovarica precoce si riduce all'aumentare dell'età della paziente; in particolare, 20,4 g in donne tra i 20 e 30 anni, 9,3 g tra i 30 e 40 anni e solo 5,2 $\mathrm{g}$ in donne oltre i 40 anni. Questo riscontro è dovuto al ridotto numero di ovociti vitali al momento della terapia. I livelli di ormone antimulleriano $(\mathrm{AMH})$ sono stati recentemente valutati come un potenziale marcatore di riserva ovarica in donne con subfertilità; in particolare, alterazioni di AMH sono inversamente correlate alla dose cumulativa di CYC. L'impatto dannoso della CYC sulla fertilità è una preoccupazione anche per l'uomo, in quanto sterilità, sub fertilità e oligo-azoospermia sono osservati nel $50-90 \%$ di uomini precedentemente trattati con CYC. Esiste un'associazione tra età ed impatto reversibile della CYC, in quanto uomini al di sotto dei 40 anni sembrano in grado di migliorare la fertilità dopo l'interruzione della terapia. Altri farmaci utilizzati per il trattamento delle vasculiti non sembrano responsabili di sub fertilità o infertilità; questi farmaci includono corticosteroidi, colchicina, AZA, MMF, leflunomide (LEF), anti-TNFalfa o RTX. Qualche riferimento all'utilizzo di MTX in patologie diverse dalle vasculiti riferisce casi di oligospermia reversi- 
bile. ${ }^{11}$ In caso di pazienti di sesso maschile, la criopreservazione dello sperma dovrebbe essere suggerita prima del trattamento con CYC; per le giovani donne, la criopreservazione degli ovociti, del tessuto ovarico e dell'embrione sono potenziali opzioni. In ogni caso, le pratiche descritte sono costose e ristrette a pochi centri specializzati; inoltre, spesso non si può ricorrere alla criopreservazione prima dell'inizio della terapia con CYC a causa dell'urgenza di trattare la vasculite. L'utilizzo di progesterone, sotto forma di medrossiprogesterone acetato e pillola contraccettiva orale combinata, almeno durante la fase di vasculite attiva e nelle iniziali fasi di trattamento, potrebbe ridurre il rischio di infertilità indotto dalla CYC. Analoghi del $\mathrm{GnRH}$ (gonadotropin-releasing hormone) potrebbero essere utili nell'interrompere, almeno in parte, i cicli mestruali e limitare la diffusione della CYC a livello ovarico, con conseguente aiuto per la preservazione della riserva ovarica, a discapito di effetti collaterali quali sintomi menopausali e depressione. Antagonisti del GnRH sono un'opzione, in quanto competono direttamente con il GnRH per il legame al rispettivo recettore. GnRH agonisti e antagonisti possono essere utilizzati in combinazione dopo la criopreservazione del tessuto ovarico; in ogni caso, il loro impatto sulla gravidanza è sconosciuto. Per donne subfertili, la stimolazione ovarica per la fertilizzazione in vitro è possibile senza alcun rischio o ulteriori precauzioni rispetto alla popolazione generale. ${ }^{11}$

\section{Conclusioni}

Le alterazioni del sistema immunitario indotte dalla gravidanza possono influenzare il decorso della vasculite, con possibilità di alterato outcome materno e fetale. Sfortunatamente, non sono presenti dati estesi sulle gravidanze di pazienti affette da vasculite sistemica, a causa della bassa incidenza di queste patologie in donne in età fertile. Molte informazioni derivano unicamente da case reports e studi retrospettivi, mentre studi prospettici a lungo termine non sono ancora disponibili. Nonostante ciò, vengono suggerite alcune linee guida per il trattamento di pazienti affette da vasculite sistemica durante la gravidanza.

In particolare, si raccomanda adeguata contraccezione se la paziente è in trattamento con farmaci citotossici o presenta malattia in fase di attività. La gravidanza dovrebbe essere programmata quando la malattia è in remissione clinica, per ridurre il rischio delle complicanze materne ed aumentare le probabilità di un esito favorevole, con attento monitoraggio durante la gestazione e il periodo post-partum. Un flare di vasculite, più frequente in caso di malattia attiva al momento del concepimento, dovrebbe essere prontamente riconosciuto e trattato in maniera aggressiva, risultando più pericoloso per il feto rispetto all'uso dei farmaci attualmente a disposizione. Gravidanze complicate da un esordio di vasculite hanno una prognosi particolarmente severa, per cui è indicato un trattamento immediato e un'attenta sorveglianza clinica. La modalità del parto (vaginale o cesareo) dovrebbe essere valutata singolarmente, in accordo con lo stato di salute, l'attività di malattia e le eventuali complicanze. Oltre ai corticosteroidi e ai farmaci immunosoppressori noti, stanno emergendo nuove terapie per il trattamento delle vasculiti severe e/o refrattarie, con possibilità di miglioramento dell'outcome materno $\mathrm{e}$ fetale, anche se ulteriori dati sono necessari per definire in maniera chiara la loro sicurezza in gravidanza. Infine, alcuni tipi di vasculite, come ad esempio la malattia di Behçet, aumentano il rischio di eventi tromboembolici per cui, sebbene non vi sia una indicazione assoluta ad una terapia anti-aggregante e/o anticoagulante, il corretto approccio trombo-profilattico dovrebbe essere valutato per il singolo caso. ${ }^{12}$

Sebbene le vasculiti siano associate ad un incremento delle complicanze in gravidanza, un adeguato controllo di malattia, anche con l'utilizzo di farmaci immunosoppressori a basso rischio o piccole dosi di glucocorticoidi durante la gravidanza, potrebbe migliorare le probabilità di successo.

\section{Bibliografia}

1. Fredi M, Lazzaroni MG, Tani C, et al. Systemic vasculitis and pregnancy: A multicenter study on maternal and neonatal outcome of 65 prospectively followed pregnancies. Autoimmun rev 14 (2015); 686-691.

2. Jennette JC, Falk RJ, Bacon PA, et al. 2012 Revised International Chapel Hill Consensus Conference nomenclature of vasculitides. Arthritis Rheum 2013; 65:1-11.

3. Machen L, Clowse MEB. Vasculitis and pregnancy, Rheum Dis Clin N Am 43 (2017) 239-247.

4. Andreoli L, Gerardi MC, Fernandes M, et al. Disease activity assessment of rheumatic diseases during pregnancy: a comprehensive review of indices used in clinical studies. Autoimmun rev 18 (2019) 164-176.

5. Luqmani RA, Bacon PA, Moots RJ, et al. Birmingham vasculitis activity score (BVAS) in systemic necrotizing vasculitis. QJM 1994; 87 (11): 671-8.

6. Exley AR, Bacon PA, Luqmani RA, et al. Development and initial validation of the vasculitis damage index for the standardized clinical assessment of damage in the systemic vasculitides. Arthritis Rheum 1997;40(2):371-80.

7. Orgul G, Aktoz F, Beksac MS. Behcet's disease and pregnancy: what to expect? J Obstet Gynaecol 2018;38(2):185-8.

8. Raza SH, Sabghi R, Kuperman M, et al. Management of ANCA-Associated Vasculitis in Pregnancy. Case report and review of the literature. JCR 2018, Volume 00, Number 00.

9. $\mathrm{Xu} \mathrm{C}, \mathrm{Bao} \mathrm{S}$. Behçet disease and pregnancy - a case report and literature review. Am J Reprod Immunol 2017; 77; e12530.

10. Nguyen V, Wuebbolt D, Pagnoux C et al. Pregnancy out- 
comes in women with primary systemic vasculitis: a retrospective study. The Journal of Maternal-Fetal \& Neonatal Medicine, DOI: 10.1080/14767058.2019. 1671329.

11. Pagnoux C, Mahendira D, Laskin CA. Fertility and pregnancy in vasculitis. Best Practice \& Research Clinical Rheumatology 27 (2013) 79-94.

12. Gatto M, Iaccarino L, Canova MG et al. Pregnancy and vasculitis: a systematic review of the literature. Autoimmun rev 11 (2012) A447-A459.
13. Clowse MEB, Richeson RL, Pieper C et al. Pregnancy outcomes among patient with vasculitis. Arthritis Care Res 2013 august; 65 (8): 1370-1374.

14. Comarmond C, Mirault T, Biard L et al. Takayasu arteritis and pregnancy. Arthritis Rheum 2015; 67 (12):32623269.

15. Götestam Skorpen C, Hoeltzenbein M, Tincani A et al. The EULAR points to consider for use of antirheumatic drugs before pregnancy, and during pregnancy and lactation. Ann Rheum Dis 2016;75:795-810. 


\section{Sclerosi multipla}

Alessandra Protti, Emanuela Laura Susani, Lorenzo Saraceno, Maria Raffaella Marazzi, Elio Clemente Agostoni

Dipartimento di Neuroscienze, ASST Grande Ospedale Metropolitano Niguarda, Milano, Italia

\section{La donna con sclerosi multipla}

\section{Introduzione}

La sclerosi multipla (SM) è una malattia demielinizzante infiammatoria cronico-degenerativa del sistema nervoso centrale (SNC). La patogenesi non è ancora del tutto chiarita, ma si ritiene correlata ad un processo autoimmune, che si sviluppa in relazione a fattori predisponenti genetici ed ambientali. ${ }^{1-3} \mathrm{La}$ demielinizzazione ed il danno assonale a livello del SNC causano numerosi sintomi neurologici, caratterizzati variabilmente da problemi motori, sensitivi, visivi, sfinterici, cognitivi e sintomi 'nascosti' invalidanti quali fatica, spasticità, dolore, ansia e depressione.

Nel $40-74 \%$ delle pazienti sono presenti disturbi della sfera sessuale che possono essere spesso misconosciuti se non indagati proattivamente. ${ }^{4,5} \mathrm{La}$ disfunzione sessuale può essere primariamente correlata alla patologia (riduzione della libido, disturbi sensitivi vaginali e della lubrificazione), oppure secondaria ad altri problemi come la faticabilità e la debolezza muscolare, effetti collaterali dei farmaci sintomatici o aspetti psicosociali.

La SM colpisce più di 2,2 milioni di persone nel mondo, 750.000 in Europa, 122.000 in Italia con più di 3.400 nuovi casi all'anno (5-6 nuovi casi ogni 100.000 abitanti), con una prevalenza media di 198 casi/100.000 abitanti e con un rapporto donne/uomini più del doppio. Dati aggiornati al Barometro della Sclerosi Multipla 2019. ${ }^{6}$

La SM è stata un banco di prova della medicina di

Corrispondente: Alessandra Protti, SS Macroattività Ambulatoriali e Day Hospital Neurologico, Centro Sclerosi Multipla, S.C. Neurologia e Stroke Unit, Dipartimento Neuroscienze, ASST Grande Ospedale Metropolitano Niguarda, Milano, Italia. Tel.: +39.02.64442348.

E-mail: alessandra.protti@ospedaleniguarda.it

Articolo pubblicato secondo la Creative Commons Attribution NonCommercial 4.0 License (CC BY-NC 4.0).

${ }^{\circ}$ Copyright: the Author(s), 2021

Licensee PAGEPress, Italy

QUADERNI - Italian Journal of Medicine 2021; 9(4):e11 genere: i dati epidemiologici della maggiore frequenza nelle donne rispetto agli uomini con un rapporto fem$\mathrm{mina} / \mathrm{maschio}$ in progressivo aumento, il diverso decorso tra i due sessi e la modulazione dell'andamento della malattia durante la gravidanza hanno portato i ricercatori a speculare con un approccio bedside to bench. Le differenze di sesso e genere e gli aspetti sesso specifici quali la gravidanza e l'effetto degli ormoni sessuali sono uno spunto per indagare la patogenesi della malattia. In particolare, è stato molto studiato il ruolo degli ormoni sessuali, dei glucocorticoidi, della leptina, della prolattina ma anche di altri modulatori prodotti dall'unità feto-placentare e del fenomeno del microchimerismo. ${ }^{7-13}$

Durante la gravidanza il sistema immunitario è spinto ad adottare uno stato immunosoppressivo per proteggere il feto in sviluppo dall'attacco immune materno, questo stato immunitario è caratterizzato da uno shift da un fenotipo Th1 pro-infiammatorio ad uno Th2 antinfiammatorio. Altre modificazioni immunitarie in questo periodo includono: aumento delle cellule Treg, elevata espressione di citochine anti-infammatorie come IL-10, ridotta produzione di citochine proinfiammatorie come TNF- $\alpha$ e riduzione del recettore per le chemochine CXCR3. In questa immunoppressione sembrano giocare un ruolo importante gli estrogeni attraverso il recettore ER $\alpha{ }^{14}$ Anche il progesterone ed i glucocorticoidi, che aumentano in gravidanza, intervengono nel modellare il sistema immunitario materno.

La SM è dominata da uno stato pro-infiammatorio Th1, pertanto lo stato anti-infiammatorioTh2 indotto dagli ormoni durante la gravidanza è considerato un elemento chiave nella riduzione della attività di malattia durante il periodo gestazionale (con una maggiore riduzione del rischio nell'ultimo trimestre) e del possibile rebound nel postpartum con la rapida caduta degli ormoni. ${ }^{14}$

La SM è diagnosticata prevalentemente tra i 20 ed i 40 anni di età, nel pieno della progettualità di vita personale e lavorativa; fin dall'inizio la diagnosi cambia la vita e costringe la persona a ridefinirne l'organizzazione ed i progetti di breve e lungo periodo. Il decorso della patologia all'esordio è nell' $80-85 \%$ delle volte a 'ricadute e remissioni (RR)': i pazienti si tro- 
vano dunque a fronteggiare l'alternanza di diverse fasi di manifestazione dei sintomi. Nel 65\% dei casi delle forme RR si sviluppa una successiva progressione verso stadi sempre più gravi di disabilità (forme secondariamente progressive, SP). Nel 10-15\% il decorso è primariamente progressivo $(\mathrm{PP})$.

Nel corso degli anni si è molto ridotto l'intervallo di tempo tra esordio dei sintomi e la diagnosi. Pur in assenza di una cura definitiva, si è progressivamente consolidata l'evidenza che un trattamento precoce con i farmaci modificanti il decorso della malattia (DMTs, disease modifying therapies) ritarda la disabilità a lungo termine. Inoltre, con la crescente disponibilità di farmaci molto potenti nel controllare l'attività di malattia, sembrano ulteriormente aumentati i benefici correlati al trattamento precoce. ${ }^{15}$

È quindi incrementato nel mondo reale il numero di donne in età fertile esposte ai DMTs. I dati raccolti dai registri delle donne esposte costituiscono al momento l'unica fonte di informazioni sui rischi in quanto nei trials clinici registrativi sono state escluse le gravidanze. ${ }^{16}$

La possibilità di riproduzione e di formazione di una famiglia sono ritenute importanti per molte persone con SM con un impatto sulla qualità di vita. Una indagine conoscitiva sui giovani condotta da AISM-CENSIS nel 2005 e ripetuta successivamente nel 2018 ha rilevato una riduzione del divario sulla paura di diventare genitore tra giovani con SM e coetanei di controllo.

In uno studio sul benessere psicosociale delle persone con SM la maggioranza dei partecipanti considera la famiglia (avere una famiglia, avere o adottare bambini, avere nipoti, trovare il partner giusto) ed il benessere dei propri membri come elemento fondamentale. ${ }^{17}$

Già dagli studi di Confavreux del 1998 la gravidanza non è più controindicata nella $\mathrm{SM}$, ma ci sono ancora dati limitati e frammentari sugli esiti delle gravidanze nelle pazienti e sulla sicurezza per il feto esposto ai trattamenti materni. ${ }^{18}$

Si è resa evidente nel corso del tempo la necessità di ottenere dati epidemiologici e di sviluppare registri indipendenti su SM e gravidanza con raccolte prospettiche di informazioni su malattia, trattamenti durante la gestazione e allattamento e sullo stato di salute del neonato dalla nascita fino ai 12 anni. ${ }^{19,20}$

Dai registri delle gravidanze esposte emergono dati aggiornati sui rischi dei farmaci sulla cui base le autorità regolatorie formulano indicazioni formali. ${ }^{21}$

Un importante progetto in sviluppo in Italia è costituito del Registro Italiano Sclerosi Multipla. ${ }^{22}$

Le raccomandazioni nei documenti di consenso continuano a cambiare in base agli aggiornamenti della ricerca molto attiva in questo campo ed è quindi importante riferirsi a fonti multidisciplinari e aggiornate. ${ }^{23,24}$
Le conoscenze sulla gravidanza nelle donne con SM devono essere divulgate e condivise nel team multidisciplinare coinvolto (ginecologi, neonatologi, infermieri, ostetrici) ed al contempo implementate sulla base dell'esperienza clinica. ${ }^{25} \mathrm{E}$ fortemente da incoraggiare un counselling precoce su questi temi tra le persone con SM ed il personale sanitario.

\section{Pre-gravidanza}

\section{Pianificazione della gravidanza e counselling}

Il numero di donne con SM che ricerca una gravidanza è in aumento negli ultimi anni grazie alle maggiori conoscenze sull'andamento della patologia durante l'epoca gestazionale e la conseguente migliore gestione della malattia da parte dei neurologi, in collaborazione con ginecologi e ostetrici. Vista la possibilità di gravidanze inaspettate e la presenza di evidenze limitate sulla sicurezza di DMTs durante il periodo gestazionale, è opportuno impostare alle donne con SM in età fertile un counselling sulle tematiche inerenti alla gravidanza fin dal momento della diagnosi, in modo proattivo. La gravidanza, infatti, va pianificata e la scelta terapeutica deve essere guidata dal desiderio di maternità della donna, evitando possibilmente la prescrizione di terapie potenzialmente teratogene. Ritardare l'inizio della terapia per un progetto di gravidanza, pone la donna a rischio di ricadute e ad accumulo di disabilità ed è quindi sconsigliabile.

$\mathrm{Al}$ momento della pianificazione innanzitutto bisogna considerare il grado di attività della malattia e scegliere in modo indivualizzato il farmaco più adatto per controllare le ricadute.

Per le pazienti in età fertile con forme lievi di malattia (poche recidive, bassa disabilità, minimo carico lesionale alla RM), è preferibile optare per l'avvio di terapie moderatamente efficaci come glatiramer acetato e interferone beta, per le quali un'esposizione accidentale nel primo trimestre di gravidanza non sembrerebbe portare rischi per il feto. ${ }^{26,27}$

Attraverso la valutazione clinica e la risonanza magnetica (RM) si identificano le pazienti ad alta attività di malattia (frequenti ricadute in un breve periodo di tempo, parziale recupero dopo una ricaduta con accumulo precoce di disabilità, elevato carico lesionale alla RM, multiple lesioni captanti gadolinio alla RM, lesioni midollari), per le quali è raccomandato procrastinare la gravidanza fino a che non si è ottenuta una stabilità per almeno 6-12 mesi. ${ }^{28}$ In tal caso verranno avviate terapie più efficaci e verrà consigliata una adeguata contraccezione. Se la paziente fosse già in terapia con un farmaco altamente efficace, bisogna informarla del rischio correlato alla sua interruzione: la riduzione naturale delle ricadute durante la gravidanza, infatti, potrebbe non essere sufficiente a con- 
trollare l'attività di malattia e la sospensione di tali farmaci (natalizumab e fingolimod) potrebbe portare a fenomeni di rebound e disabilità a lungo termine. ${ }^{29,30}$

Nel caso in cui invece la paziente pianifichi la gravidanza quando è già in trattamento con farmaci potenzialmente teratogeni come fingolimod e teriflunomide, si raccomanda la sospensione del farmaco con tempi di wash out differenti a seconda dell'emivita, mantenendo la contraccezione, oppure la sostituzione della terapia immunomodulante con interferone beta o glatiramer acetato.

In generale, una donna che rimane incinta mentre sta assumendo una terapia per la SM deve contattare il prima possibile il proprio neurologo e non interrompere repentinamente la terapia di propria iniziativa.

Nel corso del counselling è opportuno rassicurare la donna su alcuni aspetti: i) avere la SM non comporta di per sé che la gravidanza sia ad alto rischio e pertanto la gestione ostetrica è da ritenersi equiparabile a quella della popolazione generale, eccezion fatta per le donne con significativa disabilità; ii) la SM non è una malattia genetica ma ad eziologia multifattoriale ed il rischio della prole di manifestare la malattia è del $2-3 \%$, e sale al $20-30 \%$ nel caso in cui entrambi i genitori ne siamo affetti; ${ }^{31}$ iii) il tasso di ricadute nell'anno gestazionale (nove mesi di gravidanza e tre di post-partum) è sovrapponibile a quello degli anni precedenti; $18,32,33$ iv) la gravidanza non aumenta il rischio di peggioramento della disabilità a lungo termine. ${ }^{32}$

È bene informare tuttavia la donna circa la possibilità di un peggioramento di alcuni sintomi neurologici durante la gravidanza come astenia, disequilibrio o disfunzione vescicale e la possibilità di avere ricadute.

Durante la pianificazione di una gravidanza è importante considerare anche la presenza di disturbi cognitivi, il setting familiare, le comorbidità con gli eventuali trattamenti associati, in special modo i disturbi dell'umore preesistenti e una disabilità fisica moderata-severa, poiché in tali casi sarà necessario un maggior supporto fisico, emotivo ed assistenziale.

Per limitare il rischio di ricadute è bene anticipare anche le tematiche relative all'allattamento e di conseguenza le tempistiche per la ripresa della terapia immunomodulante dopo il parto.

Vi sono poi indicazioni generali da ricordare alla paziente, come la supplementazione con acido folico per ridurre il rischio di difetti del tubo neurale nel nascituro, l'abolizione del fumo di sigaretta, una dieta equilibrata, l'attività fisica e la supplementazione di vitamina $\mathrm{D}$, considerato un possibile rischio aumentato di sviluppare la malattia in bambini nati da madri con SM e bassi livelli gestazionali di vitamina D. ${ }^{34}$

Qualora la paziente non desideri procreare è indicata l'assunzione di contraccettivi, la cui tipologia andrà scelta in collaborazione con il ginecologo. L'utilizzo di contraccettivi orali non influenza negativa- mente il decorso della malattia e non interferisce col metabolismo dei DMTs, ma i dati relativi ad altri metodi anticoncezionali così come evidenze inerenti al rischio di tromboelismo venoso (soprattutto per le donne con maggiore disabilità e immobilità) o altri effetti collaterali legati all'esposizione cronica sono ancora scarsi. ${ }^{35}$

\section{Fertilità e procreazione medicalmente assistita}

La fertilità in generale non sembra essere alterata nelle pazienti con SM più che nella popolazione generale, anche se sono state riportate nelle pazienti con SM disfunzioni sessuali associate a disturbi urinari e intestinali, alterazioni ormonali nei livelli di FSH e LH, iperprolattinemia e iperandrogenismo. ${ }^{36}$ L'utilizzo di tecniche di procreazione medicalmente assistita (PMA) è in aumento nelle donne con SM, come nella popolazione generale. Se una donna soffre di infertilità la PMA deve essere considerata con cautela. Nonostante gli studi siano ancora limitati, è stato osservato un aumentato rischio di recidive nei tre mesi successivi ad un ciclo di PMA senza successo. Una recente revisione sistematica ha confermato l'aumentato rischio di recidiva di SM dopo PMA sia che vengano utilizzati agonisti che antagonisti del GnRH. L'unico fattore che può ridurre il rischio di recidiva dopo PMA è mantenere il DMTs durante il percorso ginecologico ${ }^{37}$ Per confermare tali dati vi è la necessità di studi prospettici più completi. Una stretta cooperazione tra il centro di PMA e il neurologo è fondamentale per affrontare questo periodo a rischio per la malattia.

\section{Gravidanza}

Il neurologo curante deve essere informato appena si instaura la gravidanza, specialmente se la paziente sta assumendo delle terapie per la SM (sintomatiche o DMTs), per poter collaborare con ginecologi e ostetrici ed offrire un supporto appropriato.

Non vi è indicazione ad esami ostetrici addizionali, se non per motivi ginecologici.

È opportuno che la paziente esegua regolari controlli neurologici durante la gravidanza per monitorare eventuali nuovi sintomi o ricadute. La valutazione clinica può chiarire la natura di alcuni sintomi neurologici frequenti in gravidanza ma non correlati alla SM (lombosciatalgia, sindromi da intrappolamento, paralisi facciale). In caso di recidiva disabilitante si può effettuare un breve ciclo steroideo per via endovenosa. ${ }^{38}$

La RM non è controindicata in gravidanza, mentre l'utilizzo del mezzo di contrasto (mdc) a base di Gadolinio andrebbe evitato e riservato solo nei casi in cui è strettamente necessario, per i potenziali rischi sul feto. ${ }^{39}$ 


\section{Parto e opzioni anestesiologiche}

È ormai stabilito che la sclerosi multipla non influenza il decorso della gravidanza e non predispone ad un maggior rischio di complicanze ostetriche, aborti o malformazioni congenite. ${ }^{40}$ In genere il decorso della gravidanza in una paziente con SM non presenta differenze significative dalla popolazione generale, anche se in alcuni studi viene riportata una maggior frequenza di neonati con basso peso alla nascita, un'aumentata predisposizione ad infezioni urinarie e stipsi, una maggiore tendenza al parto assistito o al taglio cesareo soprattutto nelle pazienti con maggiore disabilità. ${ }^{11,42}$ D'altro canto la gravidanza non provoca effetti negativi sulla malattia, poiché non aumenta in generale il rischio di peggioramento della disabilità nel lungo termine, ma influisce sulla frequenza di recidive di malattia riducendone il rischio durante il periodo gestazionale, particolarmente nel terzo trimestre di gravidanza; viene invece riportato un significativo aumento di recidive di malattia nel primo anno dopo il parto e in particolare nel primo trimestre dopo il parto. ${ }^{36}$ La presenza di una recidiva correla con l'attività di malattia prima e durante la gravidanza e non correla con il tipo di parto (naturale non assistito o assistito, taglio cesareo) o con il tipo di anestesia usata (locoregionale o generale). ${ }^{43,44}$ Uno studio retrospettico che raccoglieva i dati di 389 donne provenienti dagli studi PRIMS e POPARTMUS ha confermato che l'utilizzo dell'analgesia loco-regionale (analgesia spinale e epidurale) per il controllo del dolore ostetrico non incide sulla frequenza delle recidive post-partum o sulla disabilità. Gli Autori suggerivano comunque la necessità di uno studio prospettico con migliore definizione delle procedure usate per l'analgesia, il tipo di anestetico e la sua concentrazione. ${ }^{45}$ In conclusione la scelta del tipo di parto o di analgesia nella donna con SM si basa, come per la donna senza SM, sulle indicazioni ostetriche e sull'esperienza dell'anestesista, tranne nel caso di grave disabilità in cui si deve tener conto dell'eventuale presenza di spasticità e fatica. La paziente deve essere attivamente coinvolta dal team multidisciplinare (ostetrico, neurologo, anestesista) nella decisione tra le varie opzioni di parto e di analgesia per esprimere un consenso informato.

\section{Post-gravidanza}

La fase del post partum è caratterizzata da un aumentato rischio di ricadute di cui i fattori determinanti sono il numero di recidive nell'anno precedente e durante la gravidanza. ${ }^{46} \mathrm{Per}$ ridurre tale probabilità, nelle donne maggiormente a rischio, è opportuno valutare la ripresa precoce della terapia immunomodulante. $\mathrm{La}$ stessa indicazione vale per quelle donne che presentano attività subclinica di malattia ad una RM effet- tuata entro tre mesi dal parto. Nessuno dei DMTs è raccomandato durante l'allattamento sia per quelli in cui l'escrezione nel latte è stata dimostrata sia se per quelli in cui non è nota poiché $\mathrm{i}$ rischi per il neonato non possono essere esclusi. Sarà necessario, pertanto, bilanciare il rapporto tra rischio di ricaduta per la madre e benefici legati all'allattamento per il neonato.

L'allattamento esclusivo sembrerebbe essere protettivo nei confronti dell'attività di malattia, vista l'amenorrea lattazionale e la soppressione ovarica, ma i dati della letteratura non sono conclusivi e sono necessari studi clinici più ampi. .7,48 $^{47}$

Negli ultimi anni la promozione dell'allattamento al seno, sostenuta dalle indicazioni dell'Organizzazione Mondiale della Sanità ed i benefici dimostrati per la donna e per il bambino nel breve e lungo termine, hanno modificato l'atteggiamento nei confronti di allattamento e utilizzo dei farmaci immunomodulanti, tenendo in considerazione la plausibilità biologica dell'escrezione di tali farmaci nel latte materno, del loro trasporto transluminale dall'intestino del bambino al suo flusso sanguigno ed i potenziali effetti sul neonato nel caso in cui una certa quota di farmaco raggiunga la circolazione neonatale. La possibilità di escrezione nel latte materno è più verosimile per molecole di piccole dimensioni (e.g. fingolimod, dimetilfumarato, teriflunomide), in particolare per quelle con basso legame alle proteine circolanti (e.g. dimetilfumarato); la possibilità di trasporto dall'intestino al flusso sanguigno del neonato è comune per gli agenti orali, mentre è più difficile per le immunoglobuline.

Sarà necessario quindi discutere caso per caso sulla base della storia di malattia, della terapia immunomodulante prima della gravidanza, dell'andamento in gravidanza e del desiderio della paziente di allattare, in tal caso è preferibile un allattamento esclusivo.

Se dovesse presentarsi una ricaduta di malattia in corso di allattamento sarebbe possibile effettuare un breve ciclo di terapia con metilprednisolone (attendere almeno 4 ore prima di allattare). ${ }^{49}$

Non esiste in ogni caso l'indicazione ad interrompere l'allattamento se è richiesta la somministrazione di un breve ciclo di steroide ev per una ricaduta nel post-partum.

In caso di necessità di effettuare la RM bisogna considerare che piccole quantità di gadolinio sono rintracciabili nel latte materno, e anche se la quantità è minima la sicurezza del neonato a tale esposizione non è nota, pertanto prudenzialmente si consiglia di tirare il latte e gettarlo nelle 24 ore successive alla somministrazione del mezzo di contrasto.

Alla madre che desidera allattare possono essere forniti consigli pratici quali: maggior coinvolgimento del partner e sostegno da parte di parenti e conoscenti per limitare lo stress fisico, conservazione del latte materno in freezer per i momenti di maggior astenia $\mathrm{e}$ 
per le notti, considerare eventuale difficoltà nel sostenere il bambino, utilizzare supporti comodi per la seduta. Un'attenzione particolare deve essere posta nelle donne che soffrivano di disturbo dell'umore prima dell'instaurarsi della gravidanza, per il rischio aumentato di depressione post-partum. ${ }^{50}$

\section{Messaggi chiave}

- Discussione proattiva sulle tematiche inerenti alla gravidanza in tutte le donne con SM in età fertile.

- Scelta del trattamento in base all'attività di malattia e al desiderio della donna di procreare.

- Pianificazione e gestione di gravidanza, parto e allattamento in collaborazione con ginecologi e ostetrici.

- Considerare il setting familiare e le comorbidità per garantire un supporto adeguato alla donna durante la gravidanza e il post-partum.

- Fondamentale aumentare le conoscenze sull'influenza delle terapie immunomodulanti su fertilità, gravidanza e allattamento attraverso la raccolta dati in registri e database internazionali.

\section{Farmaci e gravidanza}

\section{Trattamento della ricaduta}

La farmacoterapia delle riacutizzazioni si basa sul controllo dell'infiammazione acuta con i glucocorticoidi, in particolare metilprednisolone somministrato per via endovenosa (ev) al dosaggio di $1000 \mathrm{mg} / \mathrm{die}$ per 3-5 giorni. ${ }^{51}$ Nei pazienti con un attacco acuto non responsivo alla terapia steroidea ad alto dosaggio, è possibile considerare la plasmaferesi ${ }^{52}$ o l'infusione di immunoglobuline ev. ${ }^{53}$ Anche per le pazienti in stato di gravidanza che presentino una ricaduta acuta di malattia il trattamento elettivo consiste in un breve ciclo di metilprednisolone ad alte dosi. ${ }^{21,54}$ Tuttavia, poiché non è completamente escludibile, soprattutto nel primo trimestre, un potenziale rischio fetale (labioschisi, palatoschisi, ridotto peso alla nascita) il trattamento steroideo è usualmente riservato alle ricadute cliniche significative..$^{21,54}$ In caso di mancata risposta al trattamento steroideo può essere presa in considerazione la plasmaferesi. ${ }^{24,52}$ Grazie all'inattivazione placentare, la quantità attiva di prednisone, prednisolone e metilprednisolone in grado di raggiungere il feto risulta essere inferiore al 10\%. Al contrario i glucocorticoidi fluorurati (desametasone), superano la barriera placentare con un minimo metabolismo. ${ }^{54} \mathrm{Per}$ quanto concerne il trattamento corticosteroideo durante l'allattamento, la quantità di glucocorticoide riscontrabile nel latte è estremamente bassa, è comunque consigliato attendere ad allattare almeno 4 ore dall'infusione $\mathrm{o}$, per le donne meno avvezze al rischio, 12 ore. $^{49,55}$

\section{Trattamento con disease modifying therapies}

Nel 2020 i pazienti affetti da SM dispongono di numerosi trattamenti volti a garantire un controllo clinico e neuroradiologico dell'attività infiammatoria di malattia. Le strategie terapeutiche sono in continuo sviluppo (terapie di induzione e mantenimento $v s$ terapie immunomodulanti con potenziamento progressivo) e sempre più personalizzabili, sulla base delle caratteristiche del paziente e della malattia, all'esordio e durante la sua evoluzione. Nei pazienti con fattori clinici e neuroradiologici prognosticamente favorevoli alla diagnosi (basso tasso annuale di ricadute cliniche, buon recupero dopo l'attacco, basso carico lesionale alla $\mathrm{RM}$, in particolare a livello midollare, basso numero di lesioni captanti mdc) si può considerare l'utilizzo di DMTs di I linea. Questi sono farmaci che possiedono una discreta efficacia ed un basso profilo di effetti collaterali. Tra questi annoveriamo dalla fine degli anni ' 90 i farmaci iniettivi quali interferone- $\beta$ e glatiramer acetato. Il farmaco Interferone- $\beta$ ricombinante simula la proteina endogena che appartiene alla famiglia delle citochine ed è prodotta da leucociti, cellule endoteliali, epiteliali e fibroblasti; attivando la via JAK/STAT, porta alla regolazione della trascrizione di numerose centinaia di geni e alla produzione di citochine e chemochine con effetto immunomodulante..$^{56-58}$ Glatiramer acetato è una miscela di peptidi dotata di proprietà immunomodulanti e neuroprotettive. Sebbene il meccanismo d'azione di questo farmaco non sia ancora oggi completamente compreso, si ritiene tuttavia che, mimando la composizione strutturale della proteina basica della mielina, riduca la possibilità di induzione di una risposta immunitaria nei confronti della mielina centrale. Sembra inoltre essere in grado di promuovere uno shift fenotipico dei linfociti da Th1 a Th2.$^{59} \mathrm{Da}$ alcuni anni in Italia si sono aggiunte due terapie di I linea con modalità di somministrazione orale, teriflunomide e dimetilfumarato. Teriflunomide è un immunosoppressore selettivo che riduce l'attività dell'enzima mitocondriale diidroorotato deidrogenasi inibendo pertanto la sintesi delle pirimidine, necessaria per la proliferazione dei linfociti $\mathrm{T} .{ }^{60}$ Dimetilfumarato è invece caratterizzato da un'attività antinfiammatoria e citoprotettiva, grazie alla facilitazione della via del fattore di trascrizione Nrf2 conduce all'attivazione di una cascata di vie antiossidanti ed all'inibizione di risposte pro-infiammatorie. ${ }^{61}$

Se durante il monitoraggio clinico e neuroradiologico un paziente presenta segni di attività di malattia nonostante almeno un anno di trattamento con un farmaco di I linea, vi è indicazione a una modifica terapeutica verso farmaci di II linea, più efficaci, con meccanismi d'azione diversi. Tra questi, al momento, annoveriamo natalizumab, fingolimod, alemtuzumab, cladribina e ocrelizumab. Queste terapie 
possono anche essere indicate come primo trattamento per le forme di SM caratterizzate da un esordio clinico e/o neuroradiologico aggressivo. Natalizumab è un anticorpo monoclonale ricombinante legante l'integrina $\alpha 4 \beta 1$ (detta anche VLA-4), che impedisce l'adesione e la migrazione dei linfociti dal letto vascolare al tessuto cerebrale, sede dell'infiammazione. ${ }^{62}$ Fingolimod è un antagonista funzionale del recettore sfingosina 1-fosfato (S1P) espresso sui linfociti, la cui azione impedisce la fuoriuscita dei linfociti dagli organi linfoidi secondari, riducendo pertanto l'infiltrazione nel SNC. Studi sperimentali sembrano attribuire a questo farmaco anche un'azione neuroprotettiva mediante una interazione con i recettori S1P espressi da cellule del SNC. ${ }^{63}$ Alemtuzumab è un anticorpo monoclonale umanizzato anti-CD52 che conduce ad una deplezione prolungata dei linfociti $\mathrm{T}$ e $\mathrm{B}$ circolanti con un successivo progressivo ripopolamento con linfociti meno autoreattivi. ${ }^{64}$ Un altro trattamento immunodepletivo transitorio è costituito dalla cladribina, il cui metabolita attivo esercita un effetto apoptotico su linfociti T e B. ${ }^{65}$ Ocrelizumab è un anticorpo monoclonale umanizzato, dotato di effetto citotossico, in grado di legarsi selettivamente ai linfociti B CD20+. ${ }^{66}$ Altri farmaci ormai meno frequentemente utilizzati nella pratica clinica sono azatioprina, metotrexate, ciclofosfamide e mitoxantrone. In caso di pazienti con malattia altamente aggressiva è stata negli anni percorsa sperimentalmente la strada del trapianto autologo di cellule staminali in combinazione con chemioterapia ad alta dose. Sono in corso studi registrativi per vari altri principi attivi.

Nella scelta del trattamento in una donna in età fertile è da considerare anche la potenzialità di una gravidanza, desiderata o inaspettata, a tal scopo sono da privilegiare i farmaci con minor rischio teratogeno, il cui utilizzo in gravidanza può essere effettuato in modo personalizzato, bilanciando i rischi associati alla malattia della madre e/o il rischio embrio-fetale. $\mathrm{Al}$ momento sono controindicati in gravidanza e allattamento teriflunomide, fingolimod e cladribina. Le informazioni per ogni farmaco possono derivare da molteplici fonti, tra cui fondamentale è la scheda tecnica con il riassunto delle caratteristiche del prodotto (RCP) che nello specifico prevede il paragrafo 'fertilità, gravidanza e allattamento' ${ }^{67}$

Le RCP sono sottoposte a revisioni in base agli aggiornamenti che si rendono via via disponibili dalle segnalazioni e dalla raccolta dei dati. Sia le donne come utenti che i sanitari possono fare riferimento ad alcuni centri nazionali che forniscono delucidazioni in merito all'uso dei farmaci in gravidanza e allattamento.

In tutto il mondo viene riconosciuta la necessità di implementare le conoscenze sui rischi associati all'esposizione di DMTs in utero, attraverso lo sviluppo di registri di gravidanza idealmente con arruolamento prospettico per ogni principio attivo e la raccolta di

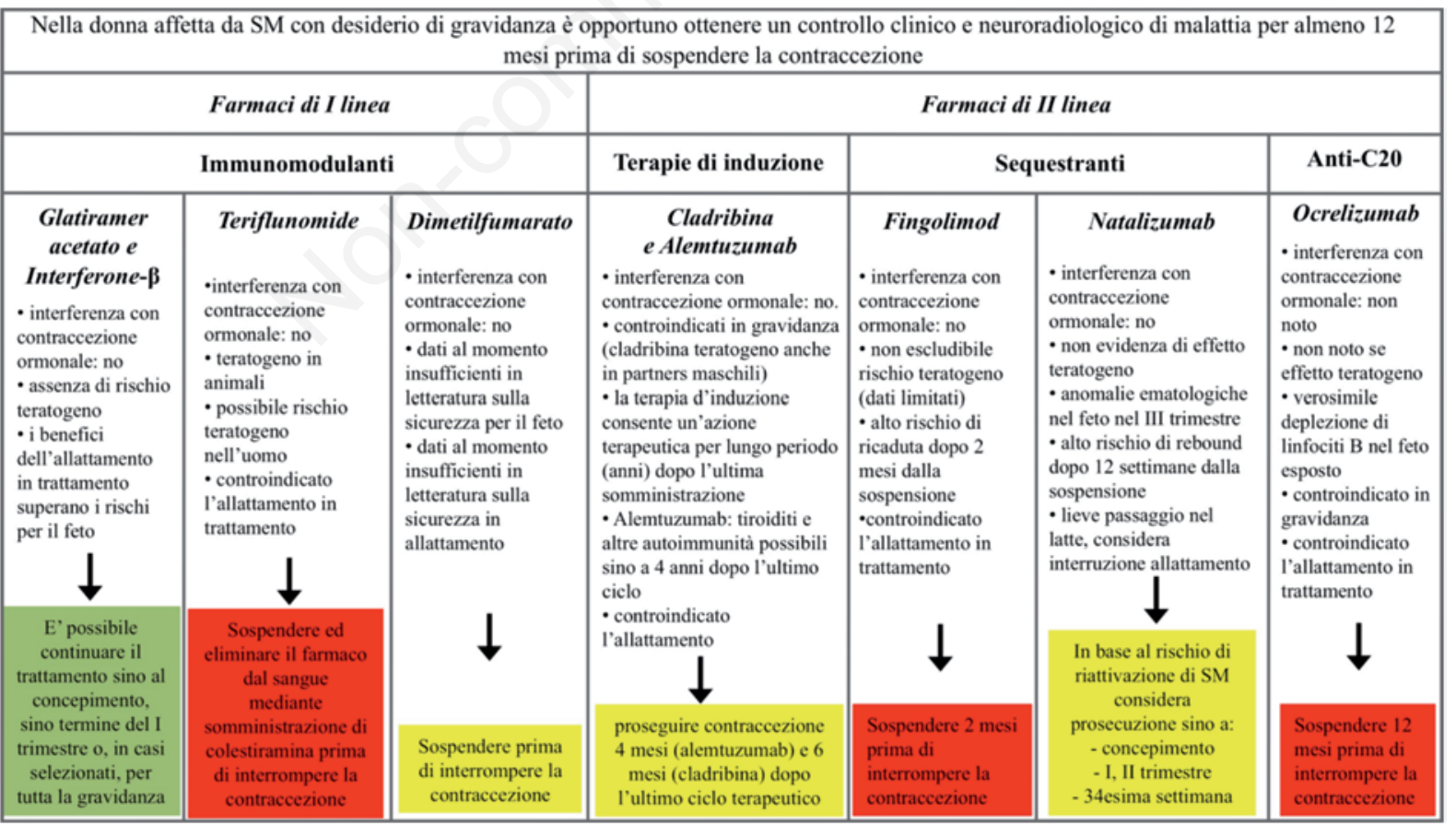

Figura 1. Potenziale interazione con la contraccezione, rischio teratogeno in gravidanza e compatibilità con allattamento per ciascun trattamento. La colorazione delle caselle illustra per ogni singolo farmaco un bilancio complessivo tra controllo della malattia e minimizzazione del rischio per il prodotto del concepimento. Verde: favorevole; giallo: intermedio; rosso: sfavorevole. 
informazioni sulle condizioni del prodotto del concepimento con un follow up del neonato.

La gestione della terapia della donna con SM in età fertile è sempre più complessa e in continua evoluzione. Da un lato l'accumulo di informazioni relative alla sicurezza dell'esposizione fetale ai DMTs nel mondo reale ha permesso alle autorità regolatorie di assumere un atteggiamento più rassicurante per alcuni farmaci (glatiramer acetato e interferone $\beta$ ), mentre sono stati formulati degli avvertimenti per altri (fingolimod). Risulta ad oggi ancora argomento di dibattito e studio la ricerca di strategie terapeutiche nelle pazienti ad alta attività di malattia per la cui la sospensione per un progetto di gravidanza di farmaci altamente efficaci può essere rischiosa per il rebound. Una possibilità si intravede con l'utilizzo di DMTs ad azione induttiva, in grado di prevenire l'attività di malattia negli anni successivi alla somministrazione.

È opportuno quindi che la gravidanza nella donna con SM sia affidata a un team multidisciplinare, che comprenda anche la figura del neonatologo per l'adeguata sorveglianza dei possibili effetti avversi sul neonato (ad esempio anomalie ematologiche con natalizumab ${ }^{68}$ ipotiroidismo con alemtuzumab $^{55}$ ).

La Figura 1 riassume le evidenze attuali su DMTs e contraccezione, rischio teratogeno in gravidanza e allattamento, raccolte dai registri sinora pubblicati, dai documenti di consenso internazionali ${ }^{21,24,33}$ e dalle schede tecniche dei farmaci.

La terapia della SM comporta anche l'utilizzo di farmaci sintomatici per il controllo della spasticità, dei disturbi vescicali, dei disturbi dell'umore, del dolore neuropatico ed altri che bisogna pertanto tenere in considerazione nella pianificazione e nella gestione clinica della gravidanza.

\section{Bibliografia}

1. Reich DS, Lucchinetti CF, Calabresi PA. Multiple Sclerosis. N Engl J Med. 2018; 378:169-80.

2. Dobson R, Giovannoni G. Multiple sclerosis - a review. Eur J Neurol. 2019 Jan; 26(1):27-40.

3. Waubant E, Lucas R, Mowry E, GravesJ, OlssonT, Alfredsson L et al. Environmental and genetic risk factors for MS: an integrated review. Annals of Clinical and Translational Neurology. 2019; vol 6 (9): 1905-22.

4. Ghezzi A. Sexual dysfunction in multiple sclerosis. Int MSJ. 1999; 5:44-53.

5. Bronner G, Elran E, Golomb J, Korczyn AD: Female sexuality in multiple sclerosis: the multidimensional nature of the problem and the intervention. Acta Neurol Scand. 2010; 121: 289-301.

6. Barometro della SM 2019- AISM a cura di Paolo Bandiera e Mario Alberto Battaglia.

7. Coyle PK Gender Issues. Neurolog Clin. 2005; 23: 39-60.

8. Deems N, Leuner B. Pregnancy, Postpartum and Parity: Resilience and Vulnerability in Brain Health and Dis- ease. Front Neuroendocrinol. 2020; Jan 24:100820. [Epub ahead of print]

9. Voskhul RR, Gold R. Sex-related factors in multiple sclerosis susceptibility and progression. Nat Rev Neurol. 2012; 8:255-263.

10. Houtchens MK, Bove R. A case for gender-based approach to multiple sclerosis therapeutics. Frontiers in Neuroendocrinology. 2018; 50:123-134.

11. Trojano M, Lucchese G, Graziano G, Taylor BV, Simpson $\mathrm{S}$, Lepore V et al. Geographical variations in sex ratio trends over time in multiple sclerosis. PLoS One. 2012; 7: e48078.

12. Maglione A, Rolla S, De Mercanti SF, Cutrupi S, Clerico M. The Adaptive Immune System in Multiple Sclerosis: An Estrogen-Mediated Point of View. Cells. 2019;8(10).

13. Snethen H, Jody Ye J, Kathleen M Gillespie KM, Neil J ScoldingNJ. Maternal micro-chimeric cells in the multiple sclerosis brain. Multiple Sclerosis and Related Disorders. 2020; 40:101925.

14. Ysrraelit MC, Correale J. Impact of sex hormones on immune function and multiple sclerosis development. Immunology. 2018; 156:9-22.

15. Comi G, Radaelli M, Soelberg Sørensen P. Evolving concepts in the treatment of relapsing multiple sclerosis. Lancet. 2017;389:1347-56.

16. Van der Graaf R, van der Zande ISE, den Ruijter HM, et al. Fair inclusion of pregnant women in clinical trials: an integrated scientific and ethical approach. Trials. 2018;19:78.

17. Delle Fave A, Bassi M, Allegri B, Cilia S, Falautano M, Goretti B et al. Beyond Disease: Happiness, Goals, and Meanings among Persons with Multiple Sclerosis and Their Caregivers. Front Psychol. 2017;8:2216.

18. Confavreux C, Hutchinson M, Hours MM, CortinovisTourniaire P, Moreau T. Rate of pregnancy-related relapse in multiple sclerosis: Pregnancy in Multiple Sclerosis Group. N Engl J Med. 1998; 339:285-291.

19. Alwan S, Chambers CD, Armenti VT, Sadovnick AD. The Need for a Disease-Specific Prospective Pregnancy Registry for Multiple Sclerosis. Multiple Sclerosis and Related Disorders (MSARD). 2015; 4:6-17.

20. Sadovnick AD, Carruthers R, Houtchens M, Schabas A, Smyth P. Canadian Multiple Sclerosis Pregnancy Study (CANPREG-MS): Rationale and Methodology. Can. J. Neurol. Sci. 2020;109-114.

21. Thöne J, Thiel S, Gold R, Hellwig K. Treatment of multiple sclerosis during pregnancy - safety considerations. Expert Opin Drug Saf. 2017;16:523-534.

22. Trojano M, Bergamaschi R, Amato MP, Comi G, Ghezzi $\mathrm{A}$, Lepore $\mathrm{V}$ et al. The Italian multiple sclerosis register. Neurol Sci 2019. Jan; 40:155-165. doi: 10.1007/s10072018-3610-0. Epub 2018 Nov 13.

23. Marrie RA, Montalban X. Disease-modifying therapy in multiple sclerosis: Two guidelines (almost) passing in the night. Multiple Sclerosis Journal. 2018; Vol. 24(5): 558-562.

24. Dobson, R, Dassan, P, Roberts, M, Giovannoni, G, Nelson-Piercy, C, Brex, PA. UK consensus on pregnancy in multiple sclerosis: association of British Neurologists' guidelines. Pract Neurol. 2019;19(2): 106-14.

25. Amato MP, Bertolotto A, Brunelli R, Cavalla P, Goretti B, Marrosu MG et al. Management of pregnancy-related issues in multiple sclerosis patients: the need for an in- 
terdisciplinary approach. Neurol Sci. 2017 Oct; 38(10):1849-1858.

26. Sandberg-Wollheim m, Neudorf O, Grinspan A et al. Pregnancy outcomes from the branded glatiramer acetato pregnacy database. Int J MS Care. 2018; 20: 9-14.

27. Thiel S, Langer-Gould A, Rockhoff $M$ et al. Interferonbeta exposure during first trimester is safe in women with multiple sclerosis - a prospective cohort study from the German Multiple Sclerosis and Pregnancy Registry. Mult Scler. 2016; 22: 801-809.

28.Vukusic S, Hutchinson M, Hours M et al. Pregnancy and multiple sclerosis (the PRIMS study): Clinical predictors of post-partum relapse. Brain. 2004; 127: 13531360.

29. Haghikia A, Langer-Gould A, Rellensmann G et al. Natalizumab use during the third trimester of pregnancy. JAMA Neurol. 2014; 71: 891-895.

30. Novi G,Ghezzi A, Pizzorno M et al. Dramatic rebounds of MS during pregnancy following fingolimod withdrawal. Neurol Neuroimmunol Neuroinflamm. 2017; 4: e377.

31. O’Gorman C, LIn R, Stankovich J et al. Modelling genetic susceptibility to multiple sclerosis with family data. Neuroepidemiology. 2013; 40:1-12.

32. Hughes S.E., Spelman T. Gray O.M. et al. Predictors and dynamic of postpartum relapses in women with multiple sclerosis. Mult Scler. 2014; 20: 739-746.

33. Langer-Gould A. Pregnancy and Family Planning. Continuum (Minneap Minn). 2019; 25: 773-792.

34. Munger K.L., Aivo J., Hongell K. et al. Vitamin D Status During Pregnancy and Risk of Multiple Sclerosis in Offspring of Women in the Finnish Maternity Cohort. JAMA Neurol. 2016; 73: 515-519.

35. Zapata L, Oduyebo T, Whiteman $\mathrm{mK}$ et al. Contraceptive use among women with multiple sclerosis: a systematic review. Contraception. 2016; 94: 612-620.

36. Amato MP, Portaccio E. Fertility, pregnancy and Childbirth in Patient with Multiple Sclerosis: Impact of Disease-Modifyng Drugs. CNS Drugs. 2015; 29: 207-20.

37. Bove R, Rankin K, Lin C, et al. Effect of assisted reproductive technology on multiple sclerosis relapses: case series and meta-analysis. Mult Scler. 2019; 1:1352458 519865118 .

38. Gotestam Skorpen C, Hoeltzenbein M, Tincani A et al. The EULAR points to consider for use of antirheumatic drugs before pregnany, and during pregnancy and lactation. Ann Rheum Dis. 2016; 75: 795-810.

39. Ray J., Vermeulen M.J., Bharatha A et al. Association between MRI Exposure During Pregnancy and Fetal and Childhood Outcomes. JAMA. 2016; 316: 952-61.

40. Coyle PK, OH J, Magyari M, et al. Management strategies for female patients of reproductive potential with multiple sclerosis: an evidence-based review. Mult Scler Relat Dis. 2019; 32: 54-63.

41. Van der Kop ML, Pearce MS, Dahgren L, et al. Neonatal and delivery outcomes in women with multiple sclerosis. Ann Neurol. 2011; 70(1): 41-50.

42. Hellwig K. Pregnancy in multiple sclerosis. Eur Neurol. 2014; 72: 39-42.

43. Houtchens MK, Edwards NC, Phillips AL. Relapses and disease-modifying drug treatment in pregnancy and live bith in US women with MS. Neurology. 2018; 91 : e1570-e78.
44. Pastò L, Portaccio E, Ghezzi A, et al. Epidural analgesia and cesarian delivery in multiple sclerosis post-partum relapses: the Italian cohort study. BMC Neurol. 2012; 12: 165 .

45. Lavie C, Rollot F, Durand-Dubief F et al. Neuraxial analgesia is not associated with an increased risk of postpartum relapses in MS. Mult Scler. 2019; 25 :591-600.

46. Portaccio E, Ghezzi A, Hakiki B et al. Postpartum relapses increase the risk of disability progression in multiple sclerosis: the role of disease modifying drugs. J Neurol Neurosurg Psychiatry. 2014; 85: 846-851.

47. Portaccio E, Ghezzi A, Hakiki B et al. Breastfeeding is not related to postpartum relapses in multiple sclerosis. Neurology. 2011; 77:145-150.

48. Hellwig K, Rockhoff M, Herbstritt S et al. Exclusive breastfeeding and the effect on postpartum multiple sclerosis relapses. JAMA Neurol. 2015; 72: 1132-1138.

49. Boz C, Terzi M, Karahan S Z et al. Safety of IV pulse methylprednisolone therapy during breastfeeding in patient with multiple sclerosis. Mult Scler. 2018; 24: 1205-1211.

50. Razaz N, Tremlett H, Marrie RA et al. Peripartum depression in parents with multiple sclerosis and psychiatric disorders in children. Mult Slcer. 2016; 22: 1830-40.

51. Burton JM, O’Connor PW, Hohhol M, Beyene K. Oral versus intravenous steroids for treatment of relapses in multiple sclerosis. Cochrane Database Syst Rev. 2012; 12:CD006921.

52. Cortese I, Chaudhry V, So YT, et al. Evidence-based guideline update: Plasmapheresis in neurologic disorders: report of the Therapeutics and Technology Assessment Subcommittee of the American Academy of Neurology. Neurology 2011; 76:294.

53. Elovaara I, Kuusisto H, Wu X et al. Intravenous immunoglobulins are a therapeutic option in the treatment of multiple sclerosis relapse. Clin Neuropharmacol 2011; 34:84-9.

54. Bove R, Alwan S, Friedman JM, et al. Management of multiple sclerosis during pregnancy and the reproductive years: a systematic review Obstet Gynecol. 2014; 124:1157-68.

55. Tivosic K and Lilyana Amezcua. Women's Health: Contemporary Management of MS in Pregnancy and PostPartum. Biomedicines. 2019; 7: 32.

56 .Taniguchi T, Takaoka A. The interferon-alpha/beta system in antiviral responses: a multimodal machinery of gene regulation by the IRF family of transcription factors. Curr Opin Immunol 2002; 14:111-116.

57. Sen GC, Lengyel P. The interferon system. A bird's eye view of its biochemistry. J Biol Chem 1992; 267 : 5017-20.

58. Kantor AB, Deng J, Waubant E, et al. Identification of short-term pharmacodynamic effects of interferon-beta1a in multiple sclerosis subjects with broad-based phenotypic profiling. J Neuroimmunol 2007; 188:103-16.

59. Aharoni R. The mechanism of action of glatiramer acetate in multiple sclerosis and beyond. Autoimmun Rev 2013; 12:543-553.

60. Vermersch P, Czlonkowska A, Grimaldi LM, et al. Teriflunomide versus subcutaneous interferon beta-1a in patients with relapsing multiple sclerosis: a randomised, controlled phase 3 trial. Mult Scler 2014; 20:705-16. 
61. Miller DH, Fox RJ, Phillips JT, et al. Effects of delayed-release dimethyl fumarate on MRI measures in the phase 3 CONFIRM study. Neurology. 2015; 84:1145-52.

62. Polman CH, O'Connor PW, Havrdova E, et al. A randomized, placebocontrolled trial of natalizumab for relapsing multiple sclerosis. N Engl J Med. 2006; 354:899-910.

63. Cohen JA and J Chun. Mechanisms of fingolimod's efficacy and adverse effects in multiple sclerosis. Ann Neurol 2011; 69:759-77.

64. Coles AJ, et al. Alemtuzumab for patients with relapsing multiple sclerosis after disease-modifying therapy: a randomised controlled phase 3 trial. Lancet 2012; 380: 1829-39.
65. Leist TP, Comi G, Cree BA et al. Effect of oral cladribine on time to conversion to clinically definite multiple sclerosis in patients with a first demyelinating event (ORACLE MS): a phase 3 randomised trial. Lancet Neurol. 2014; 13:257-67.

66. Montalban X, Hauser SL, Kappos L et al. Ocrelizumab versus Placebo in Primary Progressive Multiple Sclerosis. N Engl J Med. 2017; 376:209-220.

67. https://www.fda.gov/drugs/labeling-information-drugproducts/pregnancy-and-lactation-labeling-drugsfinal-rule

68. Triplett JD, Vijayan A, Rajanayagam S, Tuch P, Kermode AG. Pregnancy outcomes amongst multiple sclerosis females with third trimester natalizumab use. Mult Scler Relat Disord. 2020; 40: 101961. 


\title{
Malattie autoinfiammatorie ereditarie e gravidanza
}

\author{
Laura Obici \\ Centro per lo Studio e la Cura delle Amiloidosi Sistemiche, IRCCS Fondazione Policlinico San Matteo, Pavia, Italia
}

\section{Introduzione}

Le malattie autoinfiammatorie ereditarie sono patologie di interesse crescente in Medicina Interna e Reumatologia. Si tratta di disordini congeniti dell'immunità innata causati da mutazioni patologiche in proteine implicate nella risposta infiammatoria. ${ }^{1-3}$ Originariamente identificate con le febbri periodiche, oggi includono numerose altre condizioni, molto rare, prevalentemente caratterizzate da infiammazione articolare, ossea e cutanea, anche senza febbre. ${ }^{4}$

La febbre mediterranea familiare (FMF) è la più nota e frequente malattia autoinfiammatoria ereditaria e ha una prevalenza elevata soprattutto nel Mediterraneo sud-orientale. ${ }^{5}$ Esordisce nella maggior parte dei casi entro l'età di 20 anni ed è caratterizzata da episodi ricorrenti di febbre, sierosite che si manifesta tipicamente con dolore addominale e/o dolore toracico severo, artrite ed eritema simil-erisipela. Gli attacchi durano mediamente 3-5 giorni e hanno una frequenza molto variabile. La terapia di elezione è la colchicina, che induce un'ottima risposta in circa il $95 \%$ dei casi. Se non trattata, la principale complicanza della FMF è l'amiloidosi secondaria (amiloidosi AA) che colpisce soprattutto i reni, il tratto gastrointestinale e il cuore ma può coinvolgere anche il sistema riproduttivo. Episodi ricorrenti di flogosi a carico delle articolazioni, della cute e delle sierose, di durata e severità solitamente superiori rispetto alla FMF, dominano anche le altre febbri periodiche ereditarie, tra cui la TRAPS (acronimo di TNF-receptor associated periodic syndrome), le criopirinopatie (CAPS) e il deficit di mevalonato kinasi

Corrispondente: Laura Obici, Centro per lo Studio e la Cura delle Amiloidosi Sistemiche, IRCCS Fondazione Policlinico San Matteo, viale Golgi 19, 27100 Pavia, Italia.

Tel.: +39.0382.502983 - Fax: +39.0382502990

E-mail:1.obici@smatteo.pv.it

Articolo pubblicato secondo la Creative Commons Attribution NonCommercial 4.0 License (CC BY-NC 4.0).

${ }^{\circ}$ Copyright: the Author(s), 2021

Licensee PAGEPress, Italy

QUADERNI - Italian Journal of Medicine 2021; 9(4):e12
(MKD), noto anche come sindrome da Iper-IgD (Tabella 1). Anche questi pazienti, se non trattati, possono sviluppare amiloidosi renale in età adulta. ${ }^{6}$ Un'eccellente revisione di questi quadri è stata pubblicata nei Quaderni nel 2017.7

Negli ultimi dieci anni una più diffusa conoscenza, unita alla maggiore facilità di accesso ai test genetici ha migliorato sensibilmente il riconoscimento delle febbri periodiche ereditarie in età pediatrica, con una significativa riduzione del ritardo diagnostico. ${ }^{8}$ Parallelamente, la crescente disponibilità di nuove terapie, come gli inibitori di IL-1, ha rivoluzionato il trattamento di queste condizioni, consentendo un ottimo controllo delle manifestazioni flogistiche e una qualità di vita pressoché normale. ${ }^{9}$ È importante ricordare che la terapia deve essere effettuata continuativamente per prevenire gli attacchi e per evitare le complicanze di lungo termine, ${ }^{10}$ poiché sospensioni anche brevi possono causare una rapida riattivazione del quadro.

Un numero crescente di giovani affetti da malattie autoinfiammatorie si affaccia all'età riproduttiva, ponendo quindi importanti interrogativi in merito a fertilità e rischi correlati alla prosecuzione delle terapie durante la gestazione. ${ }^{11-12}$ Inoltre, il decorso della gravidanza può presentare alcune criticità. Ad esempio, la ricomparsa di dolore addominale severo richiede un'accurata diagnosi differenziale con complicanze gestazionali come aborto settico, contrazioni o distacco di placenta, per guidare gli interventi terapeutici ed evitare procedure non necessarie. ${ }^{13}$ Infine, l'eventuale insorgenza di amiloidosi può complicare il decorso della gestazione.

L'impatto delle malattie autoinfiammatorie su concepimento e gravidanza è stato indagato in modo sistematico pressoché esclusivamente nella FMF. D'altra parte, alla luce delle sostanziali analogie sul piano fisiopatologico e clinico, le indicazioni che derivano dagli studi nella FMF hanno rilevanza anche per le altre patologie autoinfiammatorie, che vengono qui discusse congiuntamente.

\section{Malattie autoinfiammatorie ereditarie e fertilità}

Numerose osservazioni, non tutte recenti, suggeriscono una possibile riduzione della fertilità nelle donne 
affette da FMF. ${ }^{11,14,15}$ Uno studio israeliano ha inoltre documentato una maggiore richiesta di trattamenti per infertilità da parte di donne con FMF rispetto alla popolazione generale. ${ }^{13}$ Uzunaslan e collaboratori hanno valutato la capacità riproduttiva nelle donne affette da malattia di Behçet includendo come gruppo di controllo anche 126 donne affette da FMF non in trattamento con colchicina. ${ }^{16}$ Non è emersa una riduzione della fertilità in associazione alla malattia di Behçet mentre le pazienti con FMF hanno presentato una significativa difficoltà nel concepimento (definita dal numero di donne che hanno concepito dopo oltre un anno di rapporti non protetti) e un maggiore ricorso alla tecniche di fecondazione in vitro. ${ }^{16}$ La presenza di aderenze peritoneali e fibrosi a carico delle salpingi in conseguenza dei ripetuti attacchi infiammatori peritoneali è stata inizialmente considerata una possibile causa di ridotta fertilità, soprattutto in epoca pre-colchicina. ${ }^{15}$ È stata anche suggerita la presenza di depositi ovarici di amiloide,${ }^{14} \mathrm{ma}$ nel complesso non vi sono sufficienti elementi a supporto di un interessamento clinicamente significativo delle ovaie in corso di amiloidosi. Alcuni autori hanno ipotizzato il potenziale contributo di una disfunzione ovarica, ${ }^{14,17}$ tuttavia uno studio recente ha escluso una significativa differenza funzionale sulla base della misurazione dell'ormone anti-mulleriano (AMH). ${ }^{18}$

Non vi sono evidenze che permettano di attribuire la ridotta fertilità alla terapia continuativa con colchicina. Al contrario, l'assunzione prolungata e regolare del farmaco favorisce il concepimento, ${ }^{19}$ coerentemente con l'ipotesi che il quadro flogistico cronico possa di per sé essere alla base della subfertilità osservata in queste condizioni.

Anche nei maschi non vi sono evidenze che la colchicina possa determinare una riduzione della capacità riproduttiva ${ }^{14,20-22}$ mentre l'interessamento testicolare da amiloidosi, oggi per fortuna osservato sempre più raramente, può contribuire sensibilmente all'insorgenza di azoospermia e infertilità. ${ }^{23}$ Una recente osservazione suggerisce la potenziale reversibilità del danno testicolare, se trattato precocemente. ${ }^{12}$ Due pazienti affetti da CAPS e amiloidosi AA con oligospermia severa hanno infatti concepito dopo avere ottenuto un ottimo controllo della flogosi e del danno renale in corso di trattamento con inibitori di IL-1. La rivalutazione dei depositi di amiloide mediante scintigrafia anti-SAP ha parallelamente mostrato una significativa riduzione dei depositi di amiloide in sede testicolare, confermando il ruolo chiave del controllo completo e adeguato della flogosi. ${ }^{12}$ Dal punto di vista pratico, è importante discutere i possibili effetti negativi di una flogosi non adeguatamente controllata sulla capacità riproduttiva. Coerentemente, deve essere menzionata chiaramente ai soggetti in età fertile che iniziano una terapia specifica e che fino a quel momento non sono riusciti a concepire, la possibilità che il miglior controllo infiammatorio possa associarsi ad una recuperata capacità riproduttiva, al fine di evitare gravidanze non pianificate.

\section{Malattie autoinfiammatorie ereditarie e gestazione}

Nel corso della gravidanza alcune donne affette da malattie autoinfiammatorie sperimentano un periodo di benessere completo, talvolta mai vissuto in precedenza. In altri casi invece gli attacchi possono divenire più frequenti o non essere differenti per intensità e durata da quelli insorti prima della gravidanza. ${ }^{14,24}$ Oltre all'impatto sulla qualità di vita, l'insorgenza di episodi infiammatori nel corso della gestazione è un fattore di

Tabella 1. Basi genetiche e principali manifestazioni cliniche delle febbri periodiche ereditarie.

\begin{tabular}{|c|c|c|c|c|}
\hline & Gene & Ereditarietà & Manifestazioni cliniche & Terapia \\
\hline Febbre mediterranea familiare & $M E F V$ & Autosomica recessiva & $\begin{array}{l}\text { Episodi febbrili ricorrenti, sierositi } \\
\text { (peritonite, pleurite) artralgia o artrite } \\
\text { monoarticolare, rash simil-erisipela. } \\
\text { La durata degli attacchi è mediamente } \\
\text { 3-5 giorni }\end{array}$ & $\begin{array}{l}\text { Colchicina; nei pazienti } \\
\text { refrattari o intolleranti } \\
\text { alla colchicina: } \\
\text { canakinumab, anakinra }\end{array}$ \\
\hline $\begin{array}{l}\text { TRAPS (TNF receptor-associated } \\
\text { periodic syndrome) }\end{array}$ & TNFRSF $1 A$ & Autosomica dominante & $\begin{array}{l}\text { Episodi febbrili associati a sierosite, } \\
\text { mialgia, poliartralgie, congiuntivite, } \\
\text { edema periorbitale. Gli attacchi } \\
\text { durano solitamente oltre } 10-15 \text { giorni }\end{array}$ & $\begin{array}{l}\text { Canakinumab, anakinra, } \\
\text { corticosteroidi }\end{array}$ \\
\hline $\begin{array}{l}\text { Deficit di mevalonato } \\
\text { kinasi-Sindrome da Iper-IgD }\end{array}$ & $M V K$ & Autosomica recessiva & $\begin{array}{l}\text { Episodi febbrili associati a nausea, } \\
\text { vomito, diarrea, linfoadenomegalie } \\
\text { laterocervicali, artralgia, rash. } \\
\text { Gli episodi in media durano 7-10 giorni }\end{array}$ & $\begin{array}{l}\text { Canakinumab, anakinra, } \\
\text { corticosteroidi }\end{array}$ \\
\hline Criopirinopatie & $N L R P 3$ & Autosomica dominante & $\begin{array}{l}\text { Episodi febbrili talvolta scatenati } \\
\text { dall'esposizione al freddo, rash } \\
\text { orticarioide, congiuntivite, sordità } \\
\text { neurosensoriale, cefalea }\end{array}$ & $\begin{array}{l}\text { Canakinumab, anakinra, } \\
\text { corticosteroidi }\end{array}$ \\
\hline
\end{tabular}


rischio, perché la flogosi peritoneale può determinare contrazioni premature e provocare un aborto spontaneo o favorire il parto pretermine. ${ }^{11,19}$ Uno studio retrospettivo turco ha riportato una maggiore frequenza di aborti ricorrenti nelle donne con FMF. L'incidenza è risultata superiore nelle pazienti non in trattamento con colchicina rispetto a quelle stabilmente in terapia. ${ }^{25}$ Ofir et al. hanno inoltre dimostrato che la FMF è un fattore di rischio indipendente per l'insorgenza di parto pretermine. ${ }^{13}$ Questa osservazione è coerente con la maggiore frequenza di rottura prematura delle membrane osservata da Yasar et al. ${ }^{25}$ Non vi sono invece elementi che suggeriscano un rischio maggiore di diabete gestazionale, preeclampsia, ritardo di crescita intrauterino (IUGR), polidramnio o oligoidramnio nelle gestanti affette da FMF. ${ }^{13,25}$

Nonostante la maggiore frequenza di parti pretermine, l'outcome perinatale non differisce da quello della popolazione generale. ${ }^{13}$ In particolare non sono state osservate differenze nella frequenza di bassi punteggi Apgar, distress fetale, emorragie post-parto, distacco di placenta, placenta previa, malformazioni o mortalità perinatale.

Un approccio multidisciplinare alla gravidanza è importante nella gestione di eventuali episodi di dolore addominale acuto, che possono rappresentare recrudescenze della malattia di base o dipendere da una complicanza della gestazione. Un'accurata diagnosi differenziale è fondamentale per guidare provvedimenti tempestivi e specifici e per evitare procedure non necessarie o potenzialmente dannose. Infine, poiché il parto, come evento stressante, si associa spesso alla recrudescenza delle manifestazioni infiammatorie, è utile considerare un transitorio incremento della terapia nella fase perinatale o il suo reinserimento, se precedentemente sospesa, nelle settimane precedenti, per garantire un post-parto sereno.

Più complessa e delicata è la gestione della gravidanza quando è già presente un danno renale da amiloidosi. Vi sono alcune osservazioni che indicano un maggiore rischio di complicanze gestazionali e soprattutto di deterioramento della funzione renale materna. ${ }^{11,26}$ Livneh et al. hanno osservato una significativa progressione del danno renale in 7 gravidanze su 29 decorse in presenza di amiloidosi renale. ${ }^{26} \mathrm{Il}$ rischio di progressione è maggiore nelle pazienti con creatininemia $>1,5 \mathrm{mg} / \mathrm{dL}$ e proteinuria $>2 \mathrm{~g} / 24$ ore, similmente a quanto osservato in altre patologie renali. Anche in una serie più recente è stata segnalata una maggiore frequenza di preeclampsia, IUGR e parto pretermine. Un aumento della proteinuria accompagna la comparsa di IUGR.${ }^{27}$ Nell'insieme, il potenziale rischio renale deve essere apertamente discusso con le pazienti affette da amiloidosi che desiderano intraprendere una gravidanza. Parimenti è importante uno stretto monitoraggio associato a un controllo ottimale della flogosi, con target di siero amiloide A (SAA) inferiore a $6,4 \mathrm{mg} / \mathrm{L} .{ }^{10} \mathrm{Se}$ un approccio multidisciplinare alla gravidanza nel corso di una malattia autoinfiammatoria è certamente un valore aggiunto, il coordinamento tra ginecologo, nefrologo e un esperto della malattia di base appare indispensabile nelle pazienti con amiloidosi renale, per implementare i controlli e valutare interventi terapeutici specifici.

\section{La terapia delle malattie autoinfiammatorie in gravidanza e durante l'allattamento}

\section{Colchicina}

Nonostante la colchicina sia in grado di attraversare la barriera placentare e sia classificata come farmaco potenzialmente teratogeno sulla base del meccanismo d'azione e di studi animali, vi è oggi unanime consenso sull'opportunità di proseguire la terapia nelle pazienti affette da FMF durante la gestazione. Come si è detto, la colchicina previene gli attacchi infiammatori e riduce il rischio di aborto spontaneo e di parto pretermine. ${ }^{28}$

Diversi studi indicano che l'assunzione di colchicina in gravidanza non si associa a un maggiore rischio di anomalie citogenetiche o malformazioni fetali. ${ }^{13,28-30}$ Una recente meta-analisi ha valutato la sicurezza del trattamento in gravidanza e, pur in assenza di studi randomizzati, ha confermato l'assenza di una significativa incidenza di aborto e malformazioni. ${ }^{31}$ Coerentemente, le recenti raccomandazioni EULAR sottolineano l'importanza di un adeguato controllo della flogosi legata alla malattia di base per prevenire danni al feto e consigliano la prosecuzione della colchicina in gravidanza al dosaggio di $1 \mathrm{mg}$ al giorno. ${ }^{32}$

L'esecuzione di un'amniocentesi o di una villocentesi è stata raccomandata alle gestanti in terapia con colchicina fino ad anni recenti. Tuttavia, alla luce delle evidenze attuali che escludono una maggiore insorgenza di anomalie citogenetiche, oggi non si ritiene più giustificato esporre il feto al potenziale rischio di queste procedure. . $^{28,30}$

È in ogni caso sempre fondamentale discutere adeguatamente i vantaggi e i potenziali rischi della terapia con la coppia e con il referente ginecologo prima dell'inizio della gravidanza, in modo da poter pianificare le scelte e condividere le decisioni.

Anche nei pazienti con FMF di sesso maschile l'assunzione di colchicina prima del concepimento non è correlata a un rischio più elevato di malformazioni fetali o di interruzione precoce di gravidanza. ${ }^{33}$ Non vi sono pertanto controindicazioni alla sua prosecuzione ma anche in questo caso è importante condividere la scelta con il paziente e la partner.

La prosecuzione della terapia con colchicina è at- 
tualmente raccomandata anche durante l'allattamento sia dall' American Academy of Pediatrics sia dalla task force EULAR. ${ }^{31,32}$ La quantità di farmaco ingerita dal neonato è inferiore a un decimo della dose terapeutica (per kg) utilizzata nell'adulto e non vi sono evidenze di rischi per la crescita del bambino. ${ }^{34}$

\section{Inibitori di interleuchina-1}

Gli inibitori di interleuchina-1 (IL-1) anakinra e canakinumab hanno rivoluzionato negli ultimi anni l'approccio terapeutico delle malattie autoinfiammatorie ereditarie e delle febbri periodiche in particolare, garantendo finalmente anche ai pazienti affetti da CAPS, TRAPS e MKD un ottimo controllo delle manifestazioni flogistiche e una qualità di vita pressoché normale. Canakinumab e anakinra sono inoltre estremamente efficaci nei pazienti con FMF refrattari o intolleranti alla colchicina. ${ }^{35-37}$ I dati sulla sicurezza di questi farmaci in gravidanza e durante l'allattamento sono tuttavia ancora molto limitati e i produttori ne raccomandano la sospensione prima del concepimento. D'altra parte, per la maggior parte dei pazienti che beneficiano di queste terapie fin dall'infanzia è difficile immaginare una prolungata interruzione del trattamento ai fini della procreazione, sia per la rapida recidiva del quadro infiammatorio sistemico sia per l'assenza di valide alternative terapeutiche. Inoltre, la riattivazione della malattia infiammatoria di base potrebbe di per sé, come discusso in precedenza, comportare un maggiore rischio di subfertilità o di interruzione precoce della gravidanza.

Nell'insieme è consigliabile affrontare gli aspetti connessi al concepimento e alla gravidanza con discreto anticipo, in modo da offrire ai pazienti e ai partners un tempo sufficiente per valutare le opzioni, pianificare le scelte più opportune e coinvolgere il ginecologo di fiducia.

Vi sono dati recenti che suggeriscono un buon profilo di sicurezza di anakinra e canakinumab rispetto al concepimento e alla gestazione. Un recente studio multicentrico retrospettivo ha descritto il decorso e l'outcome di 43 gravidanze esposte inibitori di IL-1, di cui 29 in corso di anakinra e 14 in canakinumab. ${ }^{12}$ In 11 di questi casi l'esposizione al trattamento è stata paterna. I dati mostrano che sia anakinra sia canakinumab sono ben tollerati in gravidanza, con un valido controllo della malattia infiammatoria nella maggior parte dei casi e senza insorgenza di eventi infettivi nella madre e nel bambino. È stata osservata una singola malformazione fetale, consistente in agenesia renale sinistra e neuroipofisi ectopica con deficit di GH in un bimbo nato da una paziente affetta da malattia di Still dell'adulto. La paziente, già precedentemente esposta a terapia con azatioprina e steroidi ad alte dosi, aveva iniziato anakinra alla nona settimana di gestazione per lo scarso controllo della malattia infiammatoria. Questa osserva- zione è importante perché si tratta del secondo caso di agenesia renale in una gravidanza esposta ad anakinra. ${ }^{38}$ Sebbene non vi siano dati che correlino il pathway di IL-1 alla nefrourogenesi, la possibilità che il trattamento possa associarsi a un aumentato rischio di anomalie del tratto renale non può essere esclusa e deve essere pertanto adeguatamente discussa.

Anche se non ci sono elementi per un confronto diretto tra anakinra e canakinumab in gravidanza, alla luce della maggiore esperienza clinica finora raccolta, della breve emivita del farmaco e del ruolo fisiologico dell'antagonista del recettore di IL-1, alcuni centri raccomandano l'impiego di anakinra nelle donne che si accingono a intraprendere una gravidanza. ${ }^{12}$

\section{Conclusioni}

L'impatto delle malattie autoinfiammatorie ereditarie sul sistema riproduttivo femminile e maschile è certamente significativo, anche se finora è stato indagato soprattutto nella febbre mediterranea familiare. Nelle pazienti e nei pazienti con FMF il beneficio della colchicina prima del concepimento, durante la gravidanza e nel corso dell'allattamento è ormai un dato acquisito e consente di programmare la nascita di un figlio in serenità.

Gli inibitori di IL-1 hanno straordinariamente migliorato la prognosi e la qualità di vita di chi è affetto da TRAPS, CAPS e MKD. Grazie anche a una diagnosi sempre più precoce, questi pazienti possono oggi affrontare la vita riproduttiva in benessere e senza complicanze renali. È tuttavia difficile in molti casi sospendere o sostituire queste terapie, per cui è importante affrontare il tema del concepimento e della gravidanza con adeguato anticipo, per garantire una scelta informata e consapevole, minimizzando i rischi per il nascituro e salvaguardando la sicurezza materna. I ginecologi avranno un ruolo crescente nella gestione delle malattie auto infiammatorie ed è quindi fondamentale che siano sempre più coinvolti nell'approccio multidisciplinare a queste patologie.

\section{Bibliografia}

1. Lucherini OM, Rigante D, Sota J, et al. Updated overview of molecular pathways involved in the most common monogenic autoinflammatory diseases. Clin Exp Rheumatol 2018;36(suppl 110):S3-S9.

2. Schnappauf O, Aksentijevich I. Current and future advances in genetic testing in systemic autoinflammatory diseases. Rheumatology 2019;58:vi44-vi55.

3. Ben-Chetrit E, Gattorno M, Gul A, et al. Consensus proposal for taxonomy and definition of the autoinflammatory diseases (AIDs): a Delphi study. Ann Rheum Dis 2018;77:1558-1565.

4. Manthiram K, Zhou Q, Aksentijevich I, Kastner DL. The 
monogenic autoinflammatory diseases define new pathways in human innate immunity and inflammation. Nat Immunol 2017;18:832-42.

5. Ozen S. Update on the epidemiology and disease outcome of Familial Mediterranean fever. Best Pract Res Clin Immunol 2018;32:254-60.

6. Gattorno M, Hofer M, Federici S, et al. Classification criteria for autoinflammatory recurrent fevers. Ann Rheum Dis 2019; 78:1025-32.

7. Gattorno M, Brucato A. Le malattie autoinfiammatorie. Quaderni - Ital J Med 2017;5:161-71.

8. Toplak N, Frenkel J, Ozen S, et al. An international registry on autoinflammatory diseases: the Eurofever experience. Ann Rheum Dis 2012;71:1177-82.

9. Koné-Paut I, Lachmann HJ, Kuemmerle-Deschner JB, et al. Sustained remission of symptoms and improved health-related quality of life in patients with cryopyrin-associated periodic syndrome treated with canakinumab: results of a double-blind placebo-controlled randomized withdrawal study. Arthritis Res Ther 2011;13:R202.

10. Obici L, Merlini G. AA amyloidosis: basic knowledge, unmet needs and future treatments. Swiss Med Wkly 2012; 142:w13580. doi: 10.4414/smw.2012.13580.

11. Yanmaz MN, Ozcan AJ, Savan K. The impact of familial Mediterranean fever on reproductive system. Clin Rheumatol 2014;33:1385-88.

12. Youngstein $\mathrm{T}$, Hoffmann $\mathrm{P}$, Gul A, et al. International multi-centre study of pregnancy outcomes with interleukin-1 inhibitors. Rheumatology 2017;56:2102-8.

13. Ofir D, Levy A, Wiznitzer A, et al. Familial Mediterranean fever during pregnancy: an independent risk factor for preterm delivery. Eur J Obstet Gynecol Reprod Biol 2008;141:115-18.

14. Ben-Chetrit E, Levy M. Reproductive system in familial Mediterranean fever: an overview. Ann Rheum Dis 2003;62:916-19.

15. Ehrenfeld M, Brzezinski A, Levy M, Eliakim M. Fertility and obstetric history in patients with familial Mediterranean fever on long-term colchicine therapy. $\mathrm{Br}$ J Obstet Gynaecol 1987;94:1186-91.

16. Uzunaslan, Saygin C, Hatemi G, et al. No appreciable decrease in fertility in Behçet syndrome. Rheumatology 2014;53:828-833.

17. Zayed A, Nabil H, State O, Badawy A. Subfertility in women with familial Mediterranean fever. J Obstet Gynaecol Res 2012;38:1240-44.

18. Sahin A, Karakus S, Durmaz Y, et al. Evaluation of ovarian reserve with anti-Mullerian hormone in Familial Mediterranean fever. Int J Rheumatol 2015; 2015:380354.

19. Dotters-Katz S, Kuller J, Price T. The impact of Familial Mediterranean fever on women's health. Obstet Gynecol Surv 2012;67:357-64.

20. Bremner WJ, Paulsen CA. Colchicine and testicular function in man. N Engl J Med 1976;294:1384-1385.

21. Levy M, Yaffe C. Testicular function in patients with familial Mediterranean fever on long-term colchicine treatment. Fertil Steril 1978;29:667-668.
22. Ben-Chetrit E, Backenroth R, Haimov-Kochman R, Pizov G. Azoospermia in familial Mediterranean fever patients: the role of colchicine and amyloidosis. Ann Rheum Dis 57:259-60.

23. Haimov-Kochman R, Prus D, Ben-Chetrit E. Azoospermia due to testicular amyloidosis in a patient with Familial Mediterranean fever. Hum Reprod 2001;16: 1218-20.

24. Bodur H, Yurdakul FG, Cay, HF, et al. Familial Mediterranean fever: assessment of clinical manifestations, pregnancy, genetic mutational analyses and disease severity in a national cohort. Rheum Int 2020;40:29-40.

25. Yasar O, Iskender C, Kaymak O, et al. Retrospective evaluation of pregnancy outcomes in women with familial Mediterranean fever. J Matern Fetal Neonatal Med 2014;27:733-36.

26. Livneh A, Cabili S, Zemer D, et al. Effect of pregnancy on renal function in amyloidosis of familial Mediterranean fever. J Rheumatol 1993;20:1519-23.

27. Turgal M, Selcuk I, Ozyuncu O. Pregnancy outcome of five patients with renal amyloidosis reagarding familial Mediterranean fever. Ren Fail 2014;36:306-8

28. Ben-Chetrit E, Ben-Chetrit A, Berkun Y, Ben-Chetrit E. Pregnancy outcomes in women with familial Mediterranean fever receiving colchicine: is amniocentesis justified? Arthritis Care Res 2010; 62:143-8.

29. Rabinovitch O, Zemer D, Kukia E, et al. Colchicine treatment in conception and pregnancy: two hundred thirty-one pregnancies in patients with familial Mediterranean fever. Am J Reprod Immunol 1992;28:245-6.

30. Diav-Citrin O, Shechtman S, Schwartz V, et al. Pregnancy outcome after in utero exposure to colchicine. Am J Obstet Gynecol 2010;203:144.e1-6.

31. Indraratna PL, Virk S, Gurram D and Day RO. Use of colchicine in pregnancy: a systematic review and metaanalysis. Rheumatology 2018;57:382-87.

32. Gotestam SC, Hoeltzenbein M, Tincani A, et al. The EULAR points to consider for use of antirheumatic drugs before pregnancy and lactation. Ann Rheum Dis 2016;75:795-810.

33. Ben-Chetrit E, Berkun Y, Ben-Chetrit E, Ben-Chetrit A. The outcome of pregnancy in the wives of men with familial Medierranean fever treated with colchicine. Semin Arthritis Rheum 2004;34:549-52.

34. Ben-Chetrit E, Scherrmann JM and Levy M. Colchicine in breast milk of patients with Familial Mediterranean Fever. Arthritis Rheum 1996;7:1213-17.

35. Gattorno M, Pelagatti MA, Meini A, et al. Persistent efficacy of anakinra in patients with tumor necrosis factor receptor-associated periodic syndrome. Arthritis Rheum 2008; 58:1516-20.

36. Lachmann HJ, Kone-Paut I, Kuemmerle-Deschner JB, et al. Use of canakinumab in the cryopyrin-associated periodic syndrome. New Engl J Med 2009;360:2416-25.

37. De Benedetti F, Gattorno M, Anton J et al. Canakinumab for the treatment of autoinflammatory recurrent fever syndromes. New Engl J Med 2018;378:1908-19.

38. Chang Z, Spong CY, Jesus AA, et al. Anakinra use in pregnancy in patients with cryopyrin-associated periodic syndromes. Arthritis Rheum 2014;66:3227-32. 


\title{
Pericardite in gravidanza
}

\author{
Elena Barbagelata, ${ }^{1}$ Imma Ambrosino, ${ }^{2}$ Elena Bernero, ${ }^{1}$ Antonio Brucato ${ }^{3}$ \\ ${ }^{1}$ Dipartimento di Medicina Interna, Ospedale di Lavagna, ASL 4 Chiavarese, Lavagna (GE); ${ }^{2}$ ASL Bari DSS $13 ;{ }^{3}$ Ospedale \\ Fatebenefratelli, Dipartimento di scienze biomediche e cliniche 'L. Sacco', Università degli Studi di Milano, Milano, Italia
}

\section{Introduzione}

La patologia pericardica infiammatoria si compone: della pericardite, a sua volta distinguibile in acuta, ricorrente (comparsa di un secondo episodio acuto, dopo un periodo libero di almeno 4-6 settimane rispetto a un ben documentato primo episodio), incessante (di durata compresa tra 4-6 settimane e 3 mesi) e cronica (di durata superiore a 3 mesi), del versamento pericardico, del tamponamento cardiaco e della pericardite costrittiva.

Secondo le linee guida della European Society of Cardiology (ESC) le pericarditi sono definite come patologie infiammatorie a carico del pericardio con o senza versamento pericardico, caratterizzate dalla presenza di due tra i seguenti criteri: dolore toracico, alterazioni ECG, versamento pericardico, sfregamenti pericardici. ${ }^{1}$

Durante la gestazione il coinvolgimento del pericardio è raro e le donne gravide non sembrano mostrare alcuna predisposizione particolare a sviluppare malattia pericardica.

La forma più comune di interessamento pericardico in gravidanza è l'idropericardio, ovvero un versamento lieve-moderato che si riscontra in circa il $40 \%$ delle gestanti nel terzo trimestre. ${ }^{2}$ Tale versamento è di solito asintomatico, clinicamente non significativo con assenza di alterazioni all'ECG e che va incontro a risoluzione spontanea entro 1-2 mesi dal parto. Solitamente si tratta di un riscontro occasionale, che non soddisfa i criteri diagnostici di pericardite acuta secondo le linee guida e che in questo setting di pazienti non richiede alcun trattamento farmacologico.

Corrispondente: Elena Barbagelata, Ospedale di Lavagna, via don Bobbio, ASL 4 Chiavarese, Lavagna (GE), Italia. E-mail: elena.barbagelata@asl4.liguria.it

Articolo pubblicato secondo la Creative Commons Attribution NonCommercial 4.0 License (CC BY-NC 4.0).

${ }^{\circ}$ Copyright: the Author(s), 2021

Licensee PAGEPress, Italy

QUADERNI - Italian Journal of Medicine 2021; 9(4):e13
In alcuni casi soltanto sono stati documentati una pressione arteriosa lievemente elevata e/o alterazioni aspecifiche del tratto ST-T.

La pericardite acuta è la seconda forma più comune di interessamento pericardico in gravidanza e necessita di solito di trattamento. ${ }^{3}$ In USA e in Europa la pericardite ha nell' $85 \%$ dei casi un'eziologia idiopatica. Va ricordato che, a causa dell'incremento del volume ematico che si verifica fisiologicamente in gravidanza, l'espressione clinica del tamponamento cardiaco in gravidanza risulta attenuata.

Altre cause sono meno comuni: la tubercolosi è da tenere in considerazione nei paesi in via di sviluppo, dove spesso si associa all'infezione da HIV, e nelle immigrate; rare sono le pericarditi neoplastiche e il tumore della mammella, spesso in fase avanzata, è la neoplasia più frequente in gravidanza..$^{4,5}$

La scelta accurata della terapia farmacologica rappresenta senza dubbio un nodo cruciale nella gestione delle pericarditi acute e ricorrenti in gravidanza, ma le evidenze disponibili in letteratura sono limitate e attualmente la gestione si basa principalmente su piccole case series e sull'opinione degli esperti, ${ }^{6}$ situazione peraltro comune a tutte le condizioni rare in corso di gravidanza.

\section{Eziologia}

Non sono attualmente stati identificati fattori eziologici significativamente e specificamente correlati alla pericardite in stato di gravidanza.

Si pongono pertanto i medesimi cardini diagnostici della popolazione femminile di pari età a partire dalla raccolta anamnestica che, alla luce dei principali ruoli eziologici, sarà volta a identificare eventuali fattori predisponenti quali: i) esposizione a infezioni virali (comunemente enterovirus, herpesvirus, adenovirus, parvovirus B19), batteriche (soprattutto M. tubercolosis nelle popolazioni dei paesi in via di sviluppo), fungine e parassitarie; ii) presenza di malattie autoimmuni o autoinfiammatorie quali lupus eritematoso sistemico, sclerosi sistemica, sindrome di Sjögren, artrite reumatoide, vasculiti, sarcoidosi, malattie infiammatorie croniche intestinali, Morbo di Still o febbre me- 
diterranea familiare; iii) presenza di neoplasia; iv) presenza di alterazioni metaboliche quali uremia, distiroidismo; v) fatti traumatici a carico del torace; vi) assunzione di farmaci che possono indurre sindrome lupus-like o immunosoppressori quali ciclosporina e anti TNF; vii) presenza di patologie concomitanti quali amiloidosi, ipertensione polmonare, dissecazione aortica, scompenso cardiaco.

Come nella popolazione generale, anche in gravidanza non viene per lo più identificata alcuna eziologia specifica, anche se una malattia autoimmune sistemica (in particolare il LES) va sospettata soprattutto in presenza di cospicuo versamento o di tamponamento cardiaco come manifestazione clinica di esordio. ${ }^{4}$

La più comune classificazione divide le pericarditi in cause infettive e non infettive (Tabella 1).

\section{Patogenesi}

La patogenesi della pericardite idiopatica non è ad oggi conosciuta, ma sono stati ipotizzati meccanismi autoimmuni o auto infiammatori.

A supporto dell'ipotesi autoimmune ci sono il frequente riscontro nelle pazienti di autoanticorpi antinucleo (ANA), anti-heart (AHA) e anti-discointercalato, ${ }^{7}$ la presenza di citochine (IFN$\gamma$, IL-8, IL-6) nel liquido pericardico e la prevalenza, nelle pazienti con pericardite idiopatica ricorrente degli HLA DQB1* 0202*02, $\mathrm{CW}^{*} 07$ e, con minor frequenza, DQB $1 * 0302 .{ }^{8}$

Inoltre, il meccanismo che sostiene le recidive della pericardite idiopatica, almeno per quanto riguarda il sottotipo caratterizzato da forte componente infiammatoria (con febbre, PCR molto elevata, interessamento sistemico e spesso coinvolgimento pleuropolmonare), è probabilmente spesso di natura autoinfiammatoria con un ruolo portante di IL-1.

\section{Sintomatologia e diagnosi}

In gravidanza il dolore trafittivo rappresenta il sintomo più tipico, frequentemente è presente febbre. Il versamento pericardico può dare segno di sé con dispnea e ortopnea, soprattutto se la raccolta fluida si è

Tabella 1. Classificazione delle pericarditi.

\begin{tabular}{ll}
\hline Cause infettive & Cause non infettive \\
\hline Virali & Autoimmuni \\
\hline Batteriche & Neoplastiche \\
\hline Fungine & Metaboliche \\
\hline Parassitarie & Traumatiche e iatrogene cause infettive
\end{tabular}

formata velocemente. Occasionalmente possono manifestarsi sintomi dovuti alla compressione delle strutture adiacenti quali nausea, disfagia, singhiozzo per sollecitazione di diaframma, esofago e nervo frenico rispettivamente.

La diagnosi di pericardite acuta si basa sulla presenza di almeno due tra i seguenti criteri: ${ }^{1}$

- Dolore toracico acuto: tipicamente trafittivo, di tipo pleuritico (85-90\% dei casi). Spesso trova beneficio dalla posizione seduta col tronco flesso, può essere aggravato dall'inspirazione profonda $\mathrm{o}$ dalla tosse.

- Sfregamenti pericardici all'auscultazione, raschianti o graffianti $(<33 \%$ dei casi). Spesso irradiati al margine sternale inferiore destro e sinistro.

- Alterazioni ECG tipiche (60\% dei casi). Depressione del tratto PR e sopraslivellamento a concavità superiore del tratto ST di nuovo riscontro. Evidenti in fase acuta a causa della flogosi subepicardica. In poche settimane le alterazioni ECG tendono a scomparire senza lasciare esiti.

- Versamento pericardico (60\% dei casi), normalmente il sacco pericardico ospita $10-50 \mathrm{~mL}$ di liquido, ogni processo patologico a carico della sierosa può alterarne la produzione e/o l'assorbimento determinando raccolte di maggiore entità.

Può essere utile classificare il versamento pericardico sulla base di caratteristiche quali: i) modalità di comparsa: acuta, sub acuta o cronica ( $>3$ mesi); ii) entità: scarso $(<10 \mathrm{~mm})$, moderato $(10-20 \mathrm{~mm})$, abbondante $(>20 \mathrm{~mm})$; iii) distribuzione: circonferenziale o localizzata; iv) composizione: trasudatizio (per ridotto riassorbimento del liquido pericardico generalmente secondario all'aumento della pressione venosa) o essudatizio (da aumentata produzione).

Obiettivamente la paziente, oltre ai già citati reperti auscultatori cardiaci, potrà manifestare i segni dell'eventuale patologia concomitante. Fondamentale resta la valutazione dei parametri vitali (pressione arteriosa e frequenza cardiaca). Nei casi complicati in tamponamento cardiaco potranno rendersi evidenti aumenti della pressione venosa giugulare, polso paradosso e riduzione dell'intensità dei toni cardiaci. ${ }^{3}$

Agli esami ematochimici è frequente l'alterazione degli indici di flogosi e della conta leucocitaria. Nei casi di concomitante interessamento del miocardio può essere presente rialzo degli indici di miocardionecrosi.

Secondo le linee guida ESC 2015 per la diagnosi di pericardite gli esami strumentali di primo livello fortemente raccomandati nei pazienti con sospetto di malattia sono ECG, ecocardiografia transtoracica e radiografia del torace (I-C). ${ }^{1}$

Per quanto riguarda l'elettrocardiogramma sono già state citate le alterazioni tipiche della pericardite acuta. Occorre tenere presente che durante la gravi- 
danza possono essere presenti altre anomalie: il cuore, infatti, viene lievemente dislocato verso sinistra, e ciò determina una parafisiologica deviazione assiale sinistra di circa 15-20 gradi. Sono comuni, inoltre, transitorie alterazioni del segmento ST e dell'onda T, presenza di onda Q e inversione dell'onda $\mathrm{T}$ in $\mathrm{V} 1, \mathrm{~V} 2$ e, occasionalmente, V3. ${ }^{9}$

Capitolo controverso riguarda l'esecuzione di esami radiologici quali rx del torace, esame che, oltre a essere meno sensibile nel rilevare alterazioni della silhouette cardiaca, espone il feto a radiazioni potenzialmente nocive. È noto che l'effetto delle radiazioni sul feto dipende dalla dose delle stesse e dall'età gestazionale, inoltre il rischio teratogeno si riduce superando le 12 settimane di gestazione, momento nel quale la principale organogenesi è avvenuta. Nel caso in cui l'esame sia necessario è stato stabilito che la dose di radiazioni alle quali il feto può essere esposto deve rimanere inferiore a $50 \mathrm{mGy}$, dosaggio entro il quale non ci sono evidenze di aumentato rischio di malformazioni congenite, disfunzioni intellettive, alterazioni della crescita o aborto.

L'rx del torace espone il feto a $<0,01 \mathrm{mGy}$ e la madre a $0,1 \mathrm{mGy} .^{10}$

L'ecocardiografia transtoracica può confermare la diagnosi identificando e quantificando un versamento pericardico anche di modesta entità e delinearne alcune caratteristiche quali volume, localizzazione, presenza di materiale sospeso. L'indagine ecografica consente, inoltre, di valutare la presenza di eventuali complicanze (disfunzione ventricolare, tamponamento cardiaco, pericardite costrittiva, ecc.). Durante la gravidanza l'ecocardiografia transtoracica rappresenta lo strumento d'indagine preferibile grazie all'assenza di esposizione a radiazioni, la facilità nell'esecuzione e la ripetibilità all'occorrenza.

Relativamente sicura è anche l'esecuzione dell'esame per via transesofagea.

Tra gli esami di secondo livello la TC rappresenta un'indagine complementare, utile per evidenziare ulteriori reperti e in grado di fornire informazioni sia di tipo quantitativo che qualitativa sulla falda di versamento, permettendo quindi di distinguere raccolte di tipo trasudatizio, essudatizio o sieroematico già sulla base dell'imaging. Inoltre, la TC permette di valutare eventuali patologie toraciche concomitanti quali neoplasie solide, linfomi, lesioni tubercolari o altre alterazioni del parenchima polmonare, del mediastino e dei suoi linfonodi partecipando così alla diagnosi differenziale. Tale esame risulta indispensabile prima di qualsiasi iniziativa chirurgica.

L'indagine TC però, esponendo il feto a dosi più elevate di radiazioni $(0,3 \mathrm{mGy})$, viene preferibilmente evitata nel percorso diagnostico della donna in gravidanza. $^{11}$

La RMN cardiaca è un altro esame di secondo li- vello che permette di valutare sia il pericardio sia il miocardio. I parametri che vengono valutati in RMN sono lo spessore del pericardio in T1 (normalmente $<4 \mathrm{~mm}$ ), l'edema in T2 STIR (che può essere meno riconoscibile in presenza di versamento) e la presenza di versamento.

L'esecuzione della RMN cardiaca dovrebbe essere riservata ai casi nei quali gli altri strumenti diagnostici non sono stati sufficientemente efficienti nel fornire informazioni utili al percorso diagnostico-terapeutico della donna. Nonostante il numero limitato di dati attualmente disponibili la metodica, senza l'utilizzo di mezzo di contrasto Gadolinio, sembrerebbe essere sicura, soprattutto dopo le 12 settimane di gestazione. ${ }^{12}$

\section{Terapia}

Nelle più recenti linee guida europee sulla gestione delle malattie cardiovascolari durante la gravidanza non vengono menzionate le pericarditi, ${ }^{9}$ pertanto la scelta della terapia farmacologica, che risulta essere un nodo cruciale nella gestione di tali patologie, si basa soltanto su alcuni case reports e piccole case series e sull'opinione degli esperti. Il recente studio condotto da Brucato e coll. ${ }^{3}$ ha delineato l'approccio alla paziente con pericardite durante la gravidanza e l'allattamento analizzando 21 gravidanze in 14 donne affette da pericardite idiopatica recidivante, utilizzando un protocollo adottato fin dal 2011 sulla base dell'esperienza generale maturata dal suo gruppo nelle donne con malattie reumatiche autoimmuni.

Risulta essere fondamentale la pianificazione familiare della gravidanza nelle donne in età fertile con storia di pericardite. Innanzitutto, la gravidanza dovrebbe essere programmata in una fase di quiescenza della pericardite e la paziente dovrebbe essere seguita da un team multidisciplinare con esperienza in tale ambito. Inoltre, è opportuno pianificare, prima della gravidanza, l'aggiustamento della terapia per il controllo delle recidive di pericardite. In particolare, bisognerebbe discutere con la paziente l'uso della colchicina, così come l'utilizzo di farmaci antinfiammatori non steroidei (FANS) e acido acetilsalicilico ad alte dosi (se necessari, da sospendere alla 20-25 settimana di gestazione) ed eventualmente di prednisone a basse dosi.

Per quanto riguarda l'aggiustamento delle diverse terapie raccomandate per il trattamento delle pericarditi acute e recidivanti, Brucato e coll. ${ }^{3}$ suggeriscono di utilizzare i farmaci raccomandati a seconda dell'epoca gestazionale della paziente. In particolare, in caso di età gestazionale $<20$ settimane la paziente può essere trattata con tutti i farmaci (acido acetilsalicilico, FANS, paracetamolo, prednisone e colchicina) previsti dalle linee guida ESC e solitamente utilizzati per la gestione delle pericarditi acute e ricorrenti (Tabella 2). 


\section{Farmaci anti-infiammatori non steroidei e acido acetilsalicilico ad alte dosi}

I FANS rappresentano la terapia di prima scelta nella gestione delle pericarditi acute e ricorrenti ${ }^{1,10-13}$ e l'utilizzo dei FANS più vecchi e convenzionali quali per es. ibuprofene o indometacina, non si associa ad un aumento del rischio di malformazione congenita ${ }^{14}$ Se invece l'età gestazionale risulta essere $>20$ settimane si consiglia di interrompere l'utilizzo di acido acetilsalicilico ad alte dosi e FANS che, bloccando le ciclossigenasi, inibiscono la produzione di prostaglandine, mediatori essenziali nel parto, con conseguente aumento del tempo di travaglio. Inoltre, il blocco della sintesi di prostaglandine può indurre chiusura precoce del dotto del Botallo e danno della funzione renale fetale. ${ }^{6}$ Se necessario, la paziente può essere trattata con paracetamolo, colchicina e/o corticosteroidi a basse dosi (2,5-5 mg). Può essere, inoltre, proseguito il trattamento con acido acetilsalicilico a basse dosi $(\leq 100$ $\mathrm{mg} / \mathrm{die}$ ) che, pur non possedendo un effetto antinfiammatorio significativo, permette di ridurre il rischio di preeclampsia nelle donne a rischio (Tabella 3). L'acido acetilsalicilico, nel post-partum e durante l'allattamento, andrebbe preferibilmente evitato per il rischio, pur remoto, d'insorgenza della sindrome di Reye. ${ }^{14}$

Durante l'allattamento è possibile l'utilizzo dei FANS tradizionali (Tabella 4).

\section{Corticosteroidi}

I corticosteroidi short-acting maggiormente utilizzati sono prednisone, prednisolone e metilprednisolone. Tali steroidi sono inattivati quasi completamente da enzimi placentari (a differenza dei corticosteroidi fluoru- rati quali desametazone e betametasone), e quindi sono sicuri per il feto. Essi però dovrebbero essere sempre usati alla dose più bassa possibile (es. $5 \mathrm{mg} / \mathrm{die}$ ) e spesso in combinazione con acido acetilsalicilico o FANS. Il loro utilizzo a basse dosi non è associato ad un aumentato rischio di anomalie congenite ${ }^{14,15}$ ed è ben tollerato dalla madre e dal feto. Dosi più alte di prednisone, maggiori di $10 \mathrm{mg} / \mathrm{die}$, si associano a maggior rischio di effetti collaterali quali ipertensione e diabete gestazionale, osteoporosi e soprattutto prematurità dovuta a rotture pretermine delle membrane (PROM). Ovviamente più è basso il dosaggio di corticosteroide, maggiore è il rischio di recidive che, tuttavia, possono essere facilmente gestite con aumenti temporanei e limitati della dose e associando altri farmaci. A causa dell'aumentato rischio di osteoporosi le pazienti in terapia corticosteroidea dovrebbero assumere vitamina $\mathrm{D}(800$ $\mathrm{UI} /$ die) e calcio (1500 mg/die) durante la gravidanza.

\section{Colchicina}

L'utilizzo di colchicina in gravidanza è ampiamente documentato in letteratura nelle donne con febbre mediterranea familiare (FMF) ${ }^{16-18}$ e malattia di Behçet. ${ }^{19}$ I dati clinici hanno dimostrato che le preoccupazioni rispetto al suo effetto antimitotico sono infondate; la colchicina, infatti, non aumenta l'incidenza di aborto o malformazioni fetali, così come non sono state evidenziate differenze significative nel peso alla nascita o nell'età gestazionale. Contestualmente la colchicina è divenuta lo standard of care durante la gravidanza e l'allattamento nelle donne con FMF. Anche il position paper dell'EULAR (Società Europea di Reumatologia) sull'utilizzo dei farmaci in gra-

Tabella 2. Farmaci in età gestazionale $<20$ settimane.

\begin{tabular}{ll}
\hline Acido acetilsalicilico & $\begin{array}{l}\text { Dosaggio iniziale: } 500-1000 \mathrm{mg} \text { ogni 6-8 } \mathrm{h} \text { (range } 1,5-4 \mathrm{~g} / \mathrm{die}) \\
\text { Ridurre la dose di } 250-500 \mathrm{mg} \text { ogni } 1-2 \mathrm{settimane}\end{array}$ \\
\hline $\begin{array}{l}\text { FANS, es. } \\
\text { Ibuprofene } \\
\text { Indometacina }\end{array}$ & $\begin{array}{l}600 \mathrm{mg} \text { ogni } 8 \mathrm{~h}(\text { range } 1200-2400 \mathrm{mg} / \mathrm{die}) \\
25 \mathrm{mg} \text { ogni } 8 \mathrm{~h}(\text { range } 50-150 \mathrm{mg} / \mathrm{die})\end{array}$ \\
\hline Colchicina & $\begin{array}{l}\text { In associazione alla terapia antinfiammatoria senza dose di carico e a dosi aggiustate per il peso corporeo: } \\
0.5 \mathrm{mg} \text { bid nei pazienti con peso }>70 \mathrm{~kg}, \text { o } 0,5 \mathrm{mg} \text { in monodose, se peso }<70 \mathrm{~kg}\end{array}$ \\
\hline Prednisone & A basse dosi $(2,5-7,5 \mathrm{mg})$, in caso di parziale risposta all'aspirina/FANS e alla colchicina \\
\hline Paracetamolo & Possibile alternativa \\
\hline
\end{tabular}

Tabella 3. Farmaci in età gestazionale $>\mathbf{2 0}$ settimane.

\begin{tabular}{ll}
\hline Acido acetilsalicilico & Dose $\leq 100 \mathrm{mg} /$ die \\
\hline FANS & Sospendere \\
\hline Colchicina & Possibile alternativa \\
\hline Corticosteroidi (prednisone) & A basse dosi $(2,5-5 \mathrm{mg})$ \\
\hline Paracetamolo & Possibile alternativa \\
\hline
\end{tabular}

Tabella 4. Farmaci nel post-partum e durante l'allattamento.

\begin{tabular}{ll}
\hline Acido acetilsalicilico & Da evitare \\
\hline FANS & Possibile alternativa \\
\hline Colchicina & Possibile alternativa \\
\hline Corticosteroidi (prednisone) & A basse dosi (2,5-5 mg) \\
\hline Paracetamolo & Possibile alternativa \\
\hline
\end{tabular}


vidanza include la colchicina tra i farmaci compatibili sia con la gravidanza che con 1'allattamento. ${ }^{20}$ Nella case series di Brucato e coll. la colchicina è stata utilizzata in sicurezza in 2 donne. $^{3}$

Si può pertanto affermare che l'utilizzo della colchicina può essere proseguito in sicurezza fino alla conferma della gravidanza, anche nelle pazienti con pericardite. Nei periodi successivi il suo uso deve essere discusso con la paziente, in particolare in quei casi in cui il trattamento è essenziale per mantenere un controllo ottimale della malattia. La letteratura non ha evidenziato eventi avversi nei neonati allattati al seno da madri con FMF o altre patologie reumatiche in terapia con colchicina e, di conseguenza, molti Autori considerano l'uso della colchicina sicuro anche durante l'allattamento. ${ }^{3,21}$

\section{Altre terapie in gravidanza}

In casi refrattari possono essere considerate anche le gamma globuline ad alte dosi endovena (IVIG).

\section{Bibliografia}

1. Adler Y, Charron P, Imazio M, et al. 2015 ESC Guidelines for the diagnosis and management of pericardial diseases: The Task Force for the Diagnosis and Management of Pericardial Diseases of the European Society of Cardiology endorsed by: the European Association for Cardio-Thoracic Surgery (EACTS). Eur Heart J. 2015; 36:2921-64.

2. Spodick DH. Pericardial disorders during pregnancy. In: The Pericardium: A Comprehensive Textbook. Dekker, NY, USA, 89-92. 1997

3. Brucato A, Pluymaekers N, Tombetti E, et al. Management of idiopathic recurrent pericarditis during pregnancy. Int J Cardiol. 2019 May1;282:60-65

4. Imazio M. Pericardial involvement in systemic inflammatory diseases. Heart 2011; 97(22), 1882-1892.

5. Khabele D, Chasen S. Cardiac tamponade as an unusual presentation of advanced breast cancer in pregnancy. J. Reprod. Med. 44(11), 989-991 (1999).

6. Imazio M, Brucato A, Rampello S, et al. Management of pericardial diseases during pregnancy. Journal of cardiovascular medicine. Hagerstown, Md 2010; 11:557-62.

7. Caforio AL, Brucato A, Doria A, et al. Anti-heart and anti-intercalated diskautoantibodies: evidence for autoimmunity in idiopathic recurrent acute pericarditis. Heart 2010; 96:779-84.
8. Lazaros G, Karavidas A, Spyropoulou M et al. The role of the immunogenetic background in the development and recurrence of acute idiopathic pericarditis. Cardiology 2011;118:55e62.

9. ESC guidelines on the management of cardiovascular diseases during pregnancy: the Task Force on the Management of Cardiovascular Diseases during Pregnancy of the European Society of Cardiology (ESC), Eur Heart J 2011, 32, 3147-3197 V. Regitz-Zagrosek, C. Blomstrom Lundqvist, C. Borghi, et al.

10. Guidelines for diagnostic imaging during pregnancy $\mathrm{Ob}-$ stet Gynecol 2004;104:647-651. ACOG Committee Opinion.

11. Maggiolini S, De Carlini CC, Ferri LA et al. The role of early contrast-enhanced chest computed tomography in the aetiological diagnosis of patients presenting with cardiac tamponade or large pericardial effusion. Eur Heart J Cardiovasc Imaging. 2016;17:421-8.

12. De Wilde JP, Rivers AW, Price DL. A review of the current use of magnetic resonance imaging in pregnancy and safety implications for the fetus. Prog Biophys Mol Biol 2005;87:335-353.

13. Imazio M, Spodick D.H., Brucato A, et al. Controversialissues in the management of pericardial diseases. Circulation 121 (2010) 916-928.

14. M. Ostensen, L. Andreoli, A. Brucato, et al., State of the art: reproduction and pregnancy in rheumatic diseases, Autoimmun. Rev. 14 (2015) 376-386.

15. L. Park-Wyllie, P. Mazzotta, A. Pastuszak, et al., Birth defects after maternal exposure to corticosteroids: prospective cohort study and meta-analysis of epidemiological studies. Teratology 62 (2000) 385-392.

16. E. Ben-Chetrit, M. Levy, Reproductive system in familial Mediterranean fever: an overview, Ann. Rheum. Dis. 62 (2003) 916-919.

17. O. Diav-Citrin, S. Shechtman, V. Schwartz, et al., Pregnancy outcome after in utero exposure to colchicine, Am. J. Obstet. Gynecol. 203 (2010) 144 (e1-6).

18. P.L.Indraratna, S. Virk, D. Gurram, R.O. Day, Use of colchicine in pregnancy: a systematic review and metaanalysis. Rheumatology (Oxf. Engl.) 57 (2018) 382-387.

19. N. Noel, B. Wechsler, J. Nizard, et al. Behcet's disease and pregnancy, Arthritis Rheum. 65 (2013) 2450-2456.

20. C. Gotestam Skorpen, M. Hoeltzenbein, A. Tincani, et al., The EULAR points to consider for use of antirheumatic drugs before pregnancy, and during pregnancy and lactation, Ann. Rheum. Dis. 75 (2016) 795-810.

21. T. Herscovici, P. Merlob, B. Stahl, et al, Colchicine use during breastfeeding, Breastfeed. Med. Off. J. Acad. Breastfeed. Med. 10 (2015) 92-95. 


\title{
Fisiologia del rene in gravidanza
}

\author{
Tiziana Ciarambino, ${ }^{1}$ Francesca Saladini, ${ }^{2}$ Dario Manfellotto ${ }^{3}$ \\ ${ }^{1}$ Dipartimento di Medicina Interna, Ospedale Marcianise, Asl Caserta; ${ }^{2}$ UO Cardiologia, PO Cittadella (PD), Azienda ULSS6 \\ Euganea; ${ }^{3}$ Dipartimento di Medicina Interna, Ospedale Fatebenefratelli Isola Tiberina, Roma, Italia
}

\section{Introduzione}

Durante la gravidanza si manifestano profondi cambiamenti sia strutturali che funzionali nel sistema cardiovascolare della donna, dovuti all'effetto degli ormoni sessuali (quali relaxina, progesterone, estrogeni, 17 beta-estradiolo, estriolo, deidroepiandrosterone, e testosterone) prodotti dall'unità feto-placentare. Tali ormoni stimolano la sintesi endoteliale di ossido nitrico (NO) e della prostaclinica endogena, con effetto vasodilatatore, mentre inibiscono l'attività dell'endotelina 1 , vasocostrittrice, con effetto finale di vasodilatazione che, a sua volta stimola l'attività del sistema renina-angiotensina-aldosterone (RAAS) e inibisce la produzione di ormone natriuretico, determinando ritenzione idro-salina, anemia da diluzione e ridotta viscosità ematica. ${ }^{1}$ Le modifiche emodinamiche che interessano la donna durante la gestazione sono riassunte in Tabella $1 .{ }^{1}$ Tali modifiche emodinamiche comportano delle ricadute anche sull'apparato renale e delle vie escretrici, sia in termini di modifiche anatomiche sia come funzione emodinamica renale., ${ }^{2,3}$ Tali modifiche sono evidenti già dalle prime settimane dal concepimento, in risposta all'aumento di volume ematico e come risposta agli ormoni circolanti e rientrano entro le 4-6 settimane dal parto. ${ }^{4}$ In condizioni fisiologiche i principali cambiamenti che si verificano possono essere raggruppati in modifiche anatomiche a carico del rene, alterazioni della emodinamica glomerulare, della funzione tubulare e del bilancio idroelettrolitico, come riassunto in Tabella $2 .{ }^{4}$ Altro elemento che contribuisce a modulare il flusso glomerulare renale è l'effetto

Corrispondente: Tiziana Ciarambino, Dirigente Medico Medicina Interna, Ospedale di Marcianise, Marcianise (CE), Italia. E-mail: tiziana.ciarambino@gmail.com

Articolo pubblicato secondo la Creative Commons Attribution NonCommercial 4.0 License (CC BY-NC 4.0).

${ }^{\circ}$ Copyright: the Author(s), 2021

Licensee PAGEPress, Italy

QUADERNI - Italian Journal of Medicine 2021; 9(4):e14 di compressione che l'utero, nelle fasi avanzate della gravidanza esercita sulla vena cava inferiore quando la donna decombe in posizione supina, comportando una riduzione della gittata cardiaca, del flusso plasmatico renale e di conseguenza della velocità di filtrazione glomerulare. ${ }^{5}$ Tale dato però trova riscontro solo in alcuni autori. ${ }^{5}$ Altri studi non hanno dimostrato alcuna correlazione tra la posizione assunta dalla gestante e le variazioni emodinamiche renali., ${ }^{6,7}$ La compressione uterina a carico degli organi materni determina inoltre l'interessamento del rene destro dovuta al fenomeno di destro-rotazione dell'utero da parte del colon sigma. Tale modifica dei rapporti anatomici può determinare idro-ureteronefrosi con ritenzione urinaria. ${ }^{8}$ Questa può complicarsi con stasi urinaria (circa 200-300 mL), batteriuria ed aumentato rischio di pielonefrite i cui sintomi caratteristici sono disuria, nicturia, pollachiuria, urgenza ed incontinenza da stress. ${ }^{9}$ In Tabella 3 riportiamo in dettaglio le alterazioni idro-elettrolitiche che incorrono durante la gravidanza: ${ }^{10}$

- calo dell'osmolalità plasmatica fino a valori di 270 mosmol $/ \mathrm{Kg}$ associata a una riduzione dei livelli di sodiemia di 4-5 meq/L. ${ }^{11}$

- riduzione della sodiemia, correlata all'aumentata produzione di gonadotropina corionica (hCG). ${ }^{12}$ Tuttavia, un'eccessiva riduzione della sodiemia $(<130 \mathrm{meq} / \mathrm{L})$ deve sempre far sospettare una possibile sindrome da inappropriata secrezione di ADH (SIADH). Dal lato opposto un'ipernatremia in gravidanza, soprattutto se associata a poliuria, richiede un approfondimento per un possibile diabete insipido.

- glicosuria, presente fino al 50\% delle gravidanze, dovuta prevalentemente al ridotto riassorbimento del glucosio a livello del tubulo prossimale. ${ }^{13,14}$

- alcalosi respiratoria cronica per stimolo diretto dei centri respiratori da parte del progesterone, cui consegue una caduta della $\mathrm{pCO}_{2}$ a 27-32 $\mathrm{mmHg}$, un incremento del consumo di ossigeno del $20-33 \%$ ed una riduzione dei bicarbonati a $22 \mathrm{mmol} / \mathrm{L} .{ }^{3}$

- ipouricemia secondaria ad aumento del GFR con un nadir di 2,0-4,0 mg/dL (119-238 microl/L) fino alla 22-24 settimana di gravidanza. ${ }^{15}$ 
- riduzione dell'anion gap fino a valori pari 8,5 $\mathrm{mg} / \mathrm{dL}$.

- riduzione dei livelli di albumina. ${ }^{16}$

- riduzione del riassorbimento di aminoacidi e di beta-microglobuline con conseguente glicosuria e aminoaciduria in assenza di iperglicemia o di malattie renali in gravidanza. ${ }^{17}$

\section{Insufficienza renale cronica e gravidanza}

L'insufficienza renale cronica interessa circa il $6 \%$ delle donne in età fertile ${ }^{18}$ e si associa fino a $3 \%$ delle gravidanze nei paesi sviluppati. Tale prevalenza sembra destinata a crescere a causa del progressivo invecchiamento dell'età materna al concepimento e dell'aumen- tare dell'obesità nelle gestanti. ${ }^{19-22}$ La malattia in sé non preclude il concepimento, tuttavia la presenza di malattia renale cronica in corso di gravidanza può impattare sull'out-come della gestante e del feto, favorendo la pre-eclampsia, il ritardo di crescita fetale, il parto pretermine, la necessità di parto cesareo, l'accelerazione della progressione della perdita di funzione renale. ${ }^{19}$

In previsione della gravidanza è opportuno per la donna con insufficienza renale cronica, eseguire counselling per renderla edotta sulle possibili complicanze che potrebbero insorgere durante la gestazione. Inoltre, è necessario stabilizzare la malattia renale con i minimi dosaggi farmacologici necessari, ottimizzare il controllo pressorio $(<140 / 90 \mathrm{mmHg})$, i livelli glicemici in caso di concomitante diabete, il rischio di esposizione

Tabella 1. Cambiamenti emodinamici in gravidanza. ${ }^{1}$

\begin{tabular}{ll}
\hline Incremento & Volume ematico \\
& - Gittata sistolica \\
& - Contrattilità miocardica con sviluppo graduale di lieve ipertrofia ventricolare \\
\hline Riduzione & - Resistenze vascolari periferiche \\
& - Pressione arteriosa sistemica \\
& Ematocrito \\
\hline
\end{tabular}

Tabella 2. Adattamenti anatomici, funzionali e metabolici a carico del rene in corso di gravidanza fisiologica. ${ }^{4}$

\begin{tabular}{ll}
\hline Anatomia & - Aumento della dimensione renale $(1 \mathrm{~cm})$ \\
\hline Emodinamica glomerulare & - Dilatazione del sistema collettore \\
& - Aumedilatazione \\
\hline Funzione tubulare & - Alterato riassorbimento delle proteine del glucosio, degli aminoacidi e acido urinario \\
\hline Bilancio idroelettrolitico & - Aumento del sodio totale fino a $900-1000 \mathrm{mEq}$ \\
& - Aumento del potassio totale fino a $320 \mathrm{mEq}$ \\
& - Riduzione de set-point per lo stimolo della sete e rilascio di ADH \\
& Espansione del volume plasmatico
\end{tabular}

Tabella 3. Alterazioni idro-elettrolitiche che incorrono durante la gravidanza. ${ }^{10}$

\begin{tabular}{|c|c|c|c|}
\hline Test & Itrimestre & $\begin{array}{l}\text { Range normale } \\
\text { IItrimestre }\end{array}$ & IIItrimestre \\
\hline Sodio $(\mathrm{mEq} / \mathrm{L})$ & $135-139$ & $131,8-136,2$ & $134.6-137,4$ \\
\hline Potassio (mEq/L) & $3,6-5,0$ & $3,3-5,0$ & $3,3-5,1$ \\
\hline Cloro (mEq/L) & $101-105$ & $97-109$ & $97-109$ \\
\hline BUN (mg/dL) & $7-12$ & $3-13$ & $3-11$ \\
\hline Creatinina (mg/dL) & $0,4-0,7$ & $0.4-0.8$ & $0,4-0,9$ \\
\hline Calcio (mg/dL) & $8,8-10,6$ & $8,2-9,0$ & $8,2-9,7$ \\
\hline Magnesio (mg/dL) & $1,6-2,2$ & $1,5-2,2$ & $1,5-2,2$ \\
\hline Fosfato (mg/dL) & $3,1-4,6$ & $2,5-4,9$ & $3,1-6,3$ \\
\hline Ac. urico (mg/dL) & $2,0-4,2$ & $2,4-4,9$ & $3,1-6,3$ \\
\hline Albumina (mg/dL) & $3,1-5,1$ & $2,6-4,5$ & $2,3-4,2$ \\
\hline Proteinuria 24 h (mg) & $19-141$ & $47-186$ & $46-185$ \\
\hline
\end{tabular}


a farmaci teratogeni ed è necessario programmare un'eventuale terapia di supporto nell'eventualità di iperemesi gravidica. È inoltre fondamentale programmare la sospensione/sostituzione di farmaci bloccanti il RAAS e in caso di insufficienza renale cronica stadio 4-5 è necessario informare la donna della possibilità di dover incorrere alla procedura dialitica. ${ }^{19}$ Durante la gravidanza è necessario valutare la funzione renale della gestante attraverso il dosaggio della creatinina sierica, in quanto la stima del GFR non è attendibile durante la gravidanza. È noto, infatti, che durante la gestazione vi sono delle modifiche nell'emodinamica renale ${ }^{4}$ con incremento della GFR fino al $50 \%$ e secondaria riduzione dei valori di creatinina. ${ }^{23}$ Nella gestante va eseguito inoltre un periodico controllo dei valori di proteinuria. Infatti, anche questo parametro presenta un fisiologico incremento durante la gravidanza dovuto agli adattamenti che avvengono nella gravida quali: aumento del flusso plasmatico renale, maggiore porosità della membrana glomerulare basale, alterato riassorbimento tubulare. ${ }^{19}$ Dati della letteratura definiscono come valore normale della proteinuria delle $24 \mathrm{~h}$, un valore fino a $259,4 \mathrm{mg}$, mentre risulta patologico un valore $>300 \mathrm{mg}^{24,25}$ Tali indici si riferiscono a gravidanza fisiologiche, mentre mancano valori di riferimento per gravide affette da insufficienza renale cronica. Il riscontro di proteinuria patologica nelle fasi precoci della gravidanza è un fattore prognostico di outcome sfavorevole materno-fetale, con rischio di parto pretermine, pre-eclampsia, basso peso alla nascita. ${ }^{22,26}$ L'utilizzo del dipstick urinario può essere un valido supporto per diagnosticare la presenza di proteine nelle urine, tra cui primariamente l'albumina. ${ }^{19}$ La correlazione tra la positività al dipstick e la quantità di proteine nelle urine è la seguente:

- negativo (proteine assenti);

- $\operatorname{tracce}(15-30 \mathrm{mg} / \mathrm{dL})$;

- $1+(30 \mathrm{mg} / \mathrm{dL})$

- $2+(100 \mathrm{mg} / \mathrm{dL})$

- $3+(300 \mathrm{mg} / \mathrm{dL})$

- $4+(1000 \mathrm{mg} / \mathrm{dL}) .^{27}$

Il dipstick urinario può dare falsi positivi in caso di macroematuria, $\mathrm{pH}$ urinario alcalino, uso di detergenti e disinfettanti, uso di mezzo di contrasto, disidratazione, esercizio fisico, infezioni, urine concentrate e/o alcaline (con peso specifico $\geq 1030$ ). Può dare invece falsi negativi in caso di urine diluite (peso specifico $<1010$ ), di $\mathrm{pH}$ urinario acido, proteinuria non albuminica. ${ }^{19}$

Altri indici utili per quantificare le proteine nelle urine sono: il dosaggio del rapporto proteine:creatinina urinaria oppure il rapporto albumina:creatinina urinaria,${ }^{19}$ mentre la raccolta delle 24 ore non è strettamente necessaria ed è una metodica che fa perdere una notevole quantità di tempo e può essere soggetta ad errori nella raccolta. ${ }^{28}$
Per quanto riguarda la classificazione del rapporto proteine:creatinina urinaria, in letteratura vengono riportati i seguenti cut off:

- $<0,15 \mathrm{mg}$ proteine $/ \mathrm{mg}$ creatinina = normale;

- $\geq 0,3 \mathrm{mg}$ proteine/mg creatinina dopo 20 settimane di gestazione $=$ pre-eclampsia;

- $\geq 0,7 \mathrm{mg}$ proteine $/ \mathrm{mg}$ creatinina $=$ proteinuria significativa. ${ }^{29-31}$

Per quanto riguarda il rapporto albumina:creatinina urinaria viene indicato un cut-off di 20-60 mg albumina/mg creatinina. Valori alterati di questi due parametri identificano rapidamente le gravidanze a rischio di eventi avversi. ${ }^{32}$ È necessario ricordare che nel $15 \%$ delle gravidanze è possibile osservare un incremento del rapporto proteine:creatinina urinaria in assenza di ipertensione arteriosa e di patologie renali. In tal caso si parla di proteinuria isolata. ${ }^{33}$

Per quanto riguarda invece la proteinuria delle 24 ore, la maggior parte delle linee guida ostetriche indicano come proteinuria significativa un'escrezione di proteine urinarie $\geq 300 \mathrm{mg} / 24$ ore, valore doppio rispetto al limite superiore di normalità in soggetti sani. ${ }^{25,34}$ Durante la gravidanza di una donna affetta da insufficienza renale cronica, è necessario raccomandare lo screening per la ricerca di trisomia fetale e in caso di esposizione a farmaci teratogeni è necessario indirizzarla ad uno specialista di medicina fetale, ed è consigliabile un controllo ecografico nel terzo trimestre per la valutazione della crescita fetale. In caso di assunzione da parte della madre di prednisolone e/o inibitori di calcineurina è necessario eseguire uno screening per il diabete mellito. Per ridurre il rischio di pre-eclampsia è indicato suggerire alle donne l'assunzione di bassa dose di aspirina (75-150 mg) e un controllo pressorio ottimale con valori pressori $\leq 135 / 85 \mathrm{mmHg}$. I farmaci indicati per il controllo pressorio nella gravida nefropatica sono: labetalolo, nifedipina e metildopa, mentre i farmaci bloccanti il sistema renina-angiotensina-aldosterone e diuretici sono sconsigliati. ${ }^{19}$ Se si dovesse ritenere necessario potrebbe essere consentita una bassa dose di diuretico, in particolare un diuretico dell'ansa, con stretto monitoraggio dell'emodinamica della madre e del bilancio idroelettrolitico.

Si parla di pre-eclampsia superimposta in presenza di:

- donne con insufficienza renale cronica senza proteinuria, che sviluppano ipertensione (pressione arteriosa $(\mathrm{PA})>140 \mathrm{e} / \mathrm{o} 90 \mathrm{mmHg}$ ) e proteinuria (rapporto proteine:creatinina urinaria $>30$ $\mathrm{mg} / \mathrm{mmol}$ o rapporto albumina:creatinina urinaria $>8 \mathrm{mg} / \mathrm{mmol}$ );

- donne con insufficienza renale cronica e proteinuria che sviluppano ipertensione arteriosa $(\mathrm{PA}>140$ e/o $90 \mathrm{mmHg}$ ) o insufficienza d'organo materna dopo la $20^{\mathrm{a}}$ settimana di gestazione; 
- donne con ipertensione preesistente e proteinuria che sviluppano disfunzione d'organo dopo la $20^{\wedge}$ settimana di gestazione. ${ }^{19}$

Vanno inoltre considerati situazioni ad alto rischio di pre-eclampsia superimposta la presenza di un'ipertensione arteriosa cronica e proteinuria con rialzo acuto dei valori pressori (PA sistolica $>160$ e/o diastolica $>110 \mathrm{mmHg}$ ) oppure un incremento dei valori di proteinuria (raddoppiato rispetto ai valori di inizio gestazione). Pertanto, possono essere utili il dosaggio di alcuni fattori angiogenetici (come $\mathrm{PlGF} \pm$ sFlt-1) per identificare le donne a rischio di sviluppare una preeclampsia superimposta. ${ }^{19,33}$

Gli indicatori materno-fetali per la diagnosi di preeclampsia sono riportati in Tabella $4 .{ }^{31,35}$

Inoltre, nelle donne con insufficienza renale cronica e proteinuria nel range di sindrome nefrosica (rapporto proteine:creatinina urinaria $>300 \mathrm{mg} / \mathrm{mmol}$ o rapporto albumina:creatinina urinaria $>250$ $\mathrm{mg} / \mathrm{mmol}$ ) va suggerita la profilassi per il tromboembolismo venoso con eparina a basso peso molecolare fatte salve controindicazioni specifiche legate ad alto rischio di sanguinamento.$^{19}$ In caso di insufficienza renale cronica e proteinuria non nefrosica va consigliata la profilassi se sono presenti altri fattori addizionali di rischio pro-trombotico. ${ }^{19}$

Per la donna gravida con insufficienza renale cronica è inoltre indicata la terapia marziale in caso di anemia e può essere somministrata anche eritropoietina, laddove indicato. In caso di ipovitaminosi $\mathrm{D}$ vi è indicazione alla supplementazione, mentre vanno sospesi calciomimetici e chelanti del fosfato. Inoltre, laddove la diagnosi possa modificare il decorso della gravidanza vi è indicazione a biopsia renale entro il primo trimestre o nella fase precoce del secondo trimestre. ${ }^{19}$

Il monitoraggio ginecologico e ostetrico indicato nella gravida con insufficienza renale cronica è il seguente:

- nel I trimestre controlli ogni mese;

- nel II trimestre ogni due settimane;

- nel III trimestre ogni settimana.
Ad ogni controllo è indicato il monitoraggio di:

- pressione arteriosa;

- creatinina sierica, bicarbonato, elettroliti sierici;

- glicemia basale;

- emocromo con formula;

- funzione epatica;

- esame urine del mattino;

- livelli di tacrolimus o ciclosporina nelle donne che assumono immunosoppressori;

- valutazione nutrizionale.

Per quanto riguarda il monitoraggio ostetrico è consigliabile eseguire: ${ }^{36}$

- nel I trimestre: ecografia addome;

- nel II trimestre: valutazione della sindrome Down;

- tra la 18 e 20 settimana: ecografia strutturale;

- alla 22 settimana: eco-color-Doppler per valutare il flusso placentare.

\section{Insufficienza renale acuta in gravidanza}

L'incidenza dell'insufficienza renale acuta (AKI) mostra un trend in riduzione nei paesi sviluppati, legato a una maggiore conoscenza e ad un migliore trattamento di alcune condizioni come la setticemia peripartum ${ }^{38} \mathrm{O}$ la sindrome uremico-emolitica atipica. ${ }^{39}$ L'AKI è una condizione drammatica in gravidanza e la causa più comune risulta essere la pre-eclampsia. Inoltre, l'AKI è la condizione clinica principale di ricorso alla dialisi nei paesi poco sviluppati e in quelli in via di sviluppo ${ }^{40-42} \mathrm{e}$ che, sebben non comune, si associa ad un elevato rischio di morbidità materna e fetale. ${ }^{43}$ Altre casistiche riportano invece un incremento della sua incidenza passando da 1,66 casi/10.000 casi nel 2003-2004, verso 2,68 casi/10.000 parti nel 2009-2010, ${ }^{33}$ riconducendo questo fenomeno all'aumentato uso di tecniche di riproduzione assistita, all'incremento del numero di donne in gravidanza in età sempre più avanzata, all'obesità e all'aumento dei disordini ipertensivi in gravidanza.

Diverse sono le definizioni diagnostiche di AKI riportate in letteratura: dai criteri RIFLE (risk, injury, failure, loss of kidney function, and end-stage kidney

Tabella 4. Criteri diagnostici per pre-eclampsia. ${ }^{2}$

\begin{tabular}{|c|c|c|}
\hline PAS & $>140 \mathrm{mmHg}$ & \\
\hline o & o & \\
\hline PAD & $\begin{array}{l}>90 \mathrm{mmHg} \text { in almeno } \\
\text { normotesa cui si asso }\end{array}$ & $\begin{array}{l}\text { asioni dalla } 20 \text { settimana di gestazione in donna precedentemente al parto } \\
\text { no } 1 \text { o più dei seguenti criteri: }\end{array}$ \\
\hline & - Proteinuria & $0,3 \mathrm{gr}$ in $24 \mathrm{~h}$ o dipstick urinario (random) $>2+$ \\
\hline & - Conta piastrinica & $<100.000 \mathrm{~mm}^{3}$ \\
\hline & - Creatinina sierica & $1,1 \mathrm{mg} / \mathrm{dL}(97,2 \mathrm{microl} / \mathrm{L})$ o valori di creatinina sierica raddoppiati in assenza di malattie renali \\
\hline & - Transaminasemia & Superiore a due volte il limite massimo \\
\hline & - Edema polmonare & Segni e sintomi (dispnea, edema refrattario) \\
\hline & - Sintomi cerebrali o & Nuova comparsa di cefalea non responsiva ad analgesici, visione offuscata, scotomi \\
\hline
\end{tabular}


disease), ai criteri AKIN (acute kidney injury network), ma la più frequente definizione è quella di AKI (acute Kidney Injury), basata sui livelli di creatinina sierica e sulla necessità di terapia dialitica. ${ }^{44,45} \mathrm{Anche} \mathrm{la} \mathrm{presenza}$ di una proteinuria delle 24 ore $>300 \mathrm{mg}$ è un altro elemento diagnostico importante. La biopsia renale è indicata in quelle situazioni in cui la diagnosi può cambiare il trattamento della donna in gravidanza, ma è tuttavia controindicata nell'ultimo trimestre in quanto il rischio di complicanze supera il beneficio di una diagnosi in una fase di gestazione così avanzata. ${ }^{46}$

L'AKI è una perdita ex abrupto della funzione renale, cui consegue ritenzione di urea, alterazioni elettrolitiche e del volume extracellulare.

Le cause più frequenti ${ }^{47}$ di AKI nel primo trimestre sono:

- aborto settico;

- iperemesi gravidica.

Mentre nel II e III trimestre le cause più frequenti sono:

- pre-eclampsia;

- sindrome HELLP (emolisi, elevazione enzimi epatici, piastrinopenia);

- porpora trombotica trombocitopenica/sindrome uremico-emolitica;

- insufficienza epatica acuta;

- nefrite lupica/sindrome da anticorpi antifosfolipidi. La gestione di questa condizione clinica prevede la preservazione della funzione renale piuttosto che un trattamento sostitutivo, la diagnosi e la cura della patologia sottostante. Le misure di supporto includono trattamento pressorio, mantenimento del bilancio idrico, controllo equilibrio acido-base e degli elettroliti sierici, evitare l'utilizzo di sostanze nefrotossiche. In caso di ipovolemia è necessario ripristinare i fluidi al fine di mantenere una adeguata perfusione renale e uterina. ${ }^{47}$ Le indicazioni all'inizio della dialisi sono le stesse indicate per la popolazione generale. La modalità con cui avviare il trattamento sostitutivo dipendono dalle condizioni cliniche della gestante, in particolare la emodialisi intermittente è la modalità più frequentemente utilizzata, mentre si predilige l'emodialisi continuativa nelle gravide con instabilità emodinamica. La dialisi peritoneale non ha controindicazione assoluta e potrebbe avere il vantaggio della mobilizzazione di una ridotta quantità di liquidi con minori fluttuazioni emodinamiche in particolare per il feto, tuttavia, ha lo svantaggio di poter rimuovere solo modesti volumi di liquidi per l'ingombro dato dall'utero, ed è gravata dal rischio di peritoniti, rottura precoce delle membrane e di emorragia post-partum. ${ }^{47}$

Andiamo di seguito ad analizzare le cause più frequenti di AKI:

\section{Microangiopatie trombotiche}

Sono condizioni cliniche caratterizzate da trombosi microvascolare che determina insufficienza d'organo. Costituiscono un'emergenza medica nella donna in gravidanza e le cause più comuni sono: pre-eclampsia/emolisi, rialzo di transaminasi con piastrinopenia (HELLP syndrome), porpora trombotica trombocitopenica, e sindrome uremico-emolitica gravidica. ${ }^{47}$

\section{Sindrome emolitico uremica e la porpora trombotica trombocitopenica}

La sindrome emolitico uremica (HUS) e la porpora trombotica trombocitopenica (TTP) sono entrambe caratterizzate dalla presenza di microtrombi di fibrina o di piastrine in molti organi, soprattutto rene e cervello. ${ }^{48}$ La HUS è frequente nell'immediato postpartum, la TTP è più comune nel II-III trimestre.

La HUS è caratterizzata da:

- anemia emolitica microangiopatica;

- trombocitopenia;

- ridotta funzione renale.

Le donne in gravidanza che presentano HUS sono caratterizzate da elevato rischio fetale e da pre-eclampsia. Inoltre, circa il $76 \%$ di queste donne va incontro a dialisi. La diagnosi di HUS e TTP è riportata in Tabella 5. Nel sospetto di HUS o di TTP, in attesa di ricevere il valore dell'attività del fattore di Von Willebrand (ADAMTS13), è fondamentale somministrare plasma exchange. In particolare, se il valore dell'ADAMTS13 è $<10 \%$, l'HUS è associata alla TTP. Se invece l'attività dell'ADAMTS13 è normale, ma è comunque presente il sospetto per l'HUS, è indicato il trattamento con eculizumab, un anticorpo monoclonale che inibisce l'attivazione del complemento. ${ }^{35}$

\section{Insufficienza epatica acuta}

L'insufficienza epatica acuta è associata all'AKI nel $60 \%$ dei casi. ${ }^{49}$ Si palesa nel III trimestre con segni

Tabella 5. Criteri diagnostici: Anemia emolitica microangiopatica e porpora trombotica trombocitopenica. ${ }^{35}$

\begin{tabular}{ll}
\hline Anemia emolitica micronagiopatica & Porpora trombotica trombocitopenica \\
\hline - Anemia emolitica & $\bullet$ Anemia emolitica severa \\
\hline - Trombocitopenia & $\bullet$ Trombocitopenia severa \\
\hline - Preeclampsia & $\bullet$ Bilirubina indiretta aumentata \\
\hline - Sindrome HEELP & $\bullet$ Ipertentransaminasemia \\
\hline
\end{tabular}


clinici di pre-eclampsia, ipoglicemia, ipofibrinogenemia, anormalità della funzione epatica, iperbilirubinemia e prolungamento del $\mathrm{PTT}^{50}$ ed in genere si risolve entro 1-2 settimane dal parto. Dal punto di vista clinico la diagnosi può essere sospettata per la comparsa di inappetenza, ipoglicemia, nausea e vomito nel III trimestre. La terapia prevede il trattamento della coagulazione intravasale disseminata ed il parto anticipato.

\section{Pre-eclampisa/emolisi/rialzo delle transaminasi e piastrinopenia}

L'AKI complica il 7-15\% delle gravide con HELLP syndrome. La sindrome HELLP va in diagnosi differenziale con la pre-eclampsia ed è un compito difficile a carico del clinico discernere tra le due forme in quanto la patogenesi delle due forme è comune. Si ha un incremento del volume placentare che non è supportato da un'adeguata vascolarizzazione con conseguente ischemia e disfunzione endoteliale, attivazione piastrinica, rilascio di fattori vasocostrittori, ed alterazione del rilassamento vascolare. In una percentuale di donne in gravidanza, che varia dal 8.5 al $18 \%$, con preeclampsia si sono riscontrate sindrome anticorpi antifosfolipidi/lupus eritematoso sistemico o alterazioni nelle proteine del complemento. ${ }^{47}$

\section{Insufficienza renale acuta associate a infezioni}

La donna gravida è soggetta a un maggior rischio di infezioni per via delle modifiche anatomiche che il tratto genito-urinario subisce in corso di gravidanza, per l'elevato numero di esami strumentali e procedure a cui viene sottoposta durante la gravidanza e per il rischio di complicanze ostetriche come rottura di membrane, aborto settico, morte intrauterina. ${ }^{47}$ Spesso la diagnosi risulta tardiva in quanto molti dei segni clinici della sepsi, quali tachicardia, tachipnea e ipotensione possono essere attribuiti a dolore o perdita ematica. ${ }^{51} \mathrm{~L}$ 'infezione può interessare direttamente il rene oppure il rene può essere coinvolto in corso di shock settico con insufficienza multiorgano. ${ }^{47}$ Le infezioni possono suddividersi in ante-partum, a carico prevalentemente del tratto urinario con l'Escherichia coli come germe più frequentemente isolato, e che possono complicarsi fino a quadri di pielonefriti. ${ }^{52} \mathrm{Vi}$ sono poi le forme puerperali, generalmente polimicrobiche e favorite da condizioni quali rottura delle membrane, bassa condizione socioeconomica, pregresse infezioni da streptococchi del gruppo B. ${ }^{53}$ Infine, vi sono le infezioni post-abortive generalmente a carico dell'endometrio, causate da interventi con scarse condizioni igieniche o ritenzione di prodotti di concepimento. ${ }^{54}$

Il trattamento prevede la stabilizzazione materna, colture ematiche e dell'endometrio, antibiotici intravenosi ad ampio spettro ed eventuale intervento chirurgico urgente per svuotamento del contenuto uterino. ${ }^{54}$

\section{Uropatia ostruttiva}

La presenza di idronefrosi bilaterale dovuta alla presenza di calcolosi renale bilaterale, l'utero gravido in particolare in presenza di gravidanze multiple, polidramnios e fibrosi possono determinare insufficienza renale acuta. ${ }^{55} \mathrm{Il}$ trattamento è diretto alla causa sottostante, ad esempio in presenza di calcolosi sarà necessario un intervento chirurgico come una ureteroscopia, il posizionamento di stent ureterali o il confezionamento di una nefrostomia. ${ }^{56} \mathrm{Le}$ forme che insorgono nel post-partum generalmente sono associate a parti cesarei d'urgenza con prolungato tempo d'intervento ed analgesia post-operatoria che richiede la cateterizzazione vescicale. ${ }^{57} \mathrm{La}$ lesione iatrogena della vescica o degli ureteri in corso di parto cesare è una causa non comune e richiede il trattamento chirurgico riparativo. ${ }^{57}$

\section{Necrosi renale corticale}

È un'importante causa di AKI associata a distacco di placenta ed emorragia massiva. Rappresenta circa $1 ' 1-2 \%$ di tutte le cause di AKI. ${ }^{35}$ Si palesa con oliguria, anuria, macroematuria, dolore lombare ed ipotensione arteriosa.$^{58} \mathrm{La}$ diagnosi può essere confermata dall'ecografia e dalla TAC addome. Non esiste una terapia specifica. Purtroppo, nel $20-40 \%$ dei pazienti è necessaria la dialisi. ${ }^{59}$

\section{Nefropatia ad immunoglobuline A}

È spesso diagnosticata al II-III trimestre di gravidanza. Recenti studi dimostrano che nelle donne con nefropatia da IgA la gravidanza non aumenta il rischio di eventi avversi. Spesso le donne con nefropatia IgA nelle forme lievi e stabili non ricevono terapia immunosoppressiva. ${ }^{59}$

\section{Nefropatia diabetica}

È caratterizzata da un decorso lento e progressivo con graduale comparsa di ipertensione arteriosa, albuminuria e perdita del GFR. È presente nel $6 \%$ delle donne in gravidanza con diabete mellito tipo 1 . In particolare, le donne con diabete tipo 1 (circa 2/3) presentano un rischio aumentato per lo sviluppo di pre-eclampsia, complicanze come le malformazioni congenite, la macrosomia, il parto pretermine e la mortalità perinatale. Pertanto, almeno sei mesi prima del concepimento, è necessario uno stretto monitoraggio glicemico che può contribuire a migliorarne l'outcome. Studi in letteratura raccomanda valori target di $\mathrm{HbA} 1 \mathrm{c}<6,5 \%$ evitando le ipoglicemie, soprattutto nelle gestanti alla 29-30 settimana. ${ }^{60}$ L'insulina è la terapia di elezione. ${ }^{61,62}$

\section{Nefrite lupica}

Le donne con nefrite lupica possono considerare di programmare una gravidanza in presenza di malat- 
tia stabile da almeno 6 mesi e in presenza di un filtrato glomerulare $>50 \mathrm{~mL} / \mathrm{min} .{ }^{63} \mathrm{Va}$ considerato che le donne con lupus e nefrite lupica presentano un alto rischio di parto pretermine e precoce insorgenza di preeclampsia, mentre la mortalità è pari a circa $1 \%$. L'insorgenza di forme extrarenali di lupus è più comune nel II-III trimestre, mentre le forme renali si palesano soprattutto nel post-partum. In particolare, l'attività immunologica (come bassi livelli di C3 ed anticorpi antiDNA) rappresentano i migliori predittori di coinvolgimento renale. Bassi livelli di $\mathrm{C} 4$ ed alti livelli di anti-C1q sono associati alle forme precoci di lupus che si palesano nel I-II trimestre di gravidanza. Predittori di outcome avverso sono rappresentati dalla presenza di anticorpi specifici (lupus anticoagulant, ed antiRo). ${ }^{64}$ La presenza di insufficienza renale va trattata con farmaci quali idroclorochina, azatioprina o prednisone.$^{65}$ In caso di necessità di sospensione di immunosoppressori può essere introdotta l'idroclorochina che è ben tollerata e consente di stabilizzare la malattia. La ciclofosamide e il micofenolato non vanno utilizzati negli ultimi 3 mesi prima del concepimento, mentre gli agenti biologici vanno sospesi almeno 4 mesi prima del concepimento. La Tabella 6 riassume i principali effetti avversi dei farmaci immunosoppressori. ${ }^{63}$ La pressione arteriosa va tenuta sotto controllo con farmaci diversi dai bloccanti del RAAS che hanno un effetto teratogeno nel primo trimestre, possono invece essere utilizzati labetalolo o nifedipina. ${ }^{66,67} \mathrm{Vi}$ è indicazione all'utilizzo di acido acetil salicilico per ridurre il rischio di pre-eclampsia in corso di gravidanza, ${ }^{68}$ mentre la presenza di anticorpi anti fosfolipidi (che complica fino a un quarto delle gravidanze e si associa a pre-eclampsia e mortalità fetale), o di fattori di rischio addizionali pro-trombotici (come pregressi eventi trombotici o almeno 3 gravidanze con aborto spontaneo) suggeriscono un trattamento di profilassi con eparina a basso peso molecolare o eparina non frazionata. Un eventuale trattamento con warfarin va discontinuato.$^{69}$ Anche le donne con associata sindrome nefrosica sono soggette a rischio aumentato di eventi trombotici e sono candidate a terapia anticoagulante. ${ }^{63}$

Tabella 6. Effetti avversi dei farmaci immunosoppressori in gravidanza. ${ }^{6}$

\begin{tabular}{ll}
\hline Farmaci & Effetti avversi \\
\hline Idrossiclorochina & - Rischio di teratogenità non noto \\
\hline Glucocorticoidi & - Diabete gestazionale \\
\hline Azatioprina & Rottura prematura membrane \\
\hline Ciclosporina & Rischio di teratogenità non noto \\
\hline Tacrolimus & Aumentato rischio di colestasi \\
\hline
\end{tabular}

\section{Dialisi}

La frequenza delle donne in gravidanza con insufficienza renale cronica $(\mathrm{CKD})$ pre-dialitica è compresa tra lo 0,3 ed il 2,2\% l'anno. ${ }^{70} \mathrm{~L}$ 'indicazione ad iniziare la dialisi nella donna gravida si ha quando le concentrazioni di urea nella donna superano $17-20 \mathrm{mmol} / \mathrm{L}$, e il rischio di parto pretermine compensa quello dell'inizio dialisi. Oltre ai valori dell'azotemia vanno tenuti in considerazione altri parametri come l'andamento della gravidanza e della funzione renale, bilancio idrico, parametri biochimici, l'andamento pressorio ed eventuali sintomi uremici, oltre a parametri di benessere fetale quali il profilo di crescita ed il polidramnios. ${ }^{19,71}$ Laddove la donna sia già sottoposta a dialisi prima del concepimento è utile indicarle la possibilità di posticipare la gravidanza fino a dopo il trapianto. Coloro che sono stabilizzate con la dialisi peritoneale dovrebbero essere seguite con l'emodialisi, ${ }^{19}$ eccetto che nei casi di difficoltà nel reperire accessi vascolari, problemi logistici nell'accedere all'emodialisi e una buona funzionalità renale residua. ${ }^{72,73}$ In alcuni casi le due procedure dialitiche possono essere combinate insieme. Il target di azotemia da raggiungere con l'emodialisi è rappresentato da valori di azotemia $<12,5 \mathrm{mmol} / \mathrm{L} .{ }^{19} \mathrm{Il}$ valore di ultrafiltrazione va attestato a $300 \mathrm{~g} / \mathrm{settimana}$ nel secondo trimestre e 300-500 g/settimana nel terzo trimestre, ${ }^{74}$ con l'obiettivo di raggiungere una pressione post dialitica $<140 / 90 \mathrm{mmHg} .{ }^{75}$ Gli esperti suggeriscono una dieta senza restrizioni, ricca in proteine $(1,5-1,8 \mathrm{~g} / \mathrm{kg}) \cdot{ }^{75} \mathrm{Gli}$ elettroliti in particolare magnesio e calcio-fostato dovrebbero essere controllati ogni 12 settimane. ${ }^{75}$ Può essere necessario incrementare le concentrazioni di magnesio, calcio e potassio nel dializzato, così come la supplementazione di acido folico pre-concepimento e nel primo trimestre. ${ }^{75}$ Una durata maggiore della dialisi è associata a una maggiore fertilità $(48 \pm 5$ ore/settimana con 32 gravidanze su 1000 donne/anno vs 20 ore/settimana con 5 gravidanze/1000 donne/anno $)^{76,77}$ e a un miglior outcome fetale $\left(37-56 \mathrm{~h} / \mathrm{settimana}\right.$ con $85 \%$ di nati vivi, alla $38^{\mathrm{a}}$ settimana di gestazione con $2600 \mathrm{~g}$ peso alla nascita, vs 20 ore/settimana con $48 \%$ di natalità, $28^{\mathrm{a}}$ settimana di gestazione, $1800 \mathrm{~g}$ di peso alla nascita). ${ }^{71}$

\section{Gravidanza e trapianto di rene}

Secondo dati della letteratura la gravidanza ha un esito positivo nelle donne che hanno subito trapianto di rene ${ }^{78}$ sebbene il rischio di sviluppare pre-eclampsia sia più elevato rispetto alla popolazione generale ${ }^{79} \mathrm{e}$ rimanga elevato indipendentemente dai valori di GFR di base. ${ }^{80}$ Va inoltre tenuto in considerazione che il tasso di fertilità nella donna trapiantata è ridotto ${ }^{81} \mathrm{e}$ 
che la gravidanza ha un rischio più elevato di complicarsi con ipertensione, pre-eclampsia, parto pretermine, basso peso alla nascita, taglio cesareo e mortalità fetale ${ }^{80-82}$ Fattori che contribuiscono a un possibile outcome sfavorevole della gravidanza sono i farmaci che le donne trapiantate hanno necessità di assumere e in particolare gli immunosoppressori. Per quanto riguarda l'impatto che la gravidanza produce sulla funzione renale in donne trapiantate, $i$ dati in letteratura sono contrastanti in quanto alcuni studi a lungo termine non trovano sostanziali differenze nelle donne trapiantate che hanno avuto o meno una gravidanza, ${ }^{83}$ mentre altri autori riportano un incremento stabile della creatinina sierica dopo il parto. ${ }^{84}$

La Società Americana dei Trapiantati dà indicazione ad intraprendere una gravidanza solo in condizioni di stabilità clinica della malattia ${ }^{85,86}$ indicando $i$ seguenti parametri di stabilità clinica:

- stabilità della funzione del graft (creatinina sierica $<1,5 \mathrm{mg} / \mathrm{dL}$ );

- assenza di rigetto da almeno un anno;

- assenza di infezioni acute;

- dosaggio stabile di immunosoppressori.

Altro dato da tenere in considerazione nella donna sottoposta a trapianto che intraprende una gravidanza è la terapia farmacologica assunta che comprende immunosoppressori, antivirali e antiipertensivi. Tali farmaci, infatti, sono fondamentali per la salute della madre, ma possono risultare nocivi alla crescita fetale. ${ }^{78}$ Per quanto riguarda gli immunosoppressori risulta un compito assai difficile mantenere stabile il loro livello ematico durante la gravidanza in quanto l'aumento del volume ematico, della velocità di filtrazione glomerulare e il metabolismo placentare possono richiedere aggiustamento dei dosaggi. ${ }^{87}$ Tra gli immunosoppressori risultano sicuri in gravidanza: tacrolimus, ciclosporina, azatioprina, corticosteroidi e l'idroclorochina. La sicurezza dei corticosteroidi in gravidanza deriva dal fatto che la dose presente nel sangue materno viene metabolizzata a livello placentare e il feto non viene esposto agli effetti collaterali del farmaco. ${ }^{87}$ Sono segnalati però dei casi d'insufficienza surrenalica nei nuovi nati in donne che in gravidanza erano sottoposte ad elevati dosaggi di corticosteroidi. ${ }^{78}$ Farmaci che vanno sospesi, in quanto responsabili di malformazioni fetali, sono rappresentati da ciclofosfamide, $i$ derivati del micofenolato e il rituximab, mentre non si hanno dati certi sulla sicurezza di sirolimus e everolimus. ${ }^{78}$ Tra gli antivirali sono consentiti i seguenti farmaci: aciclovir, valacilovir, lamivudina, tenofovir, isoniazide, nistatina (topica); risultano invece tossici: ganciclovir, vangalciclovir, cotrimoxazolo, chinolone. Tra gli antiipertensivi in gravidanza possono essere utilizzati: labetalolo, calcio-antagonisti, metildopa, idralazina, furosemide, mentre i bloccanti del RAS e il minoxidil sono controindicati. ${ }^{78}$

\section{Bibliografia}

1. Bianca I, Geraci G, Gulizia MM, Egidy-Assenza G, Barone C, Campisi M, Alaimo A, Adorisio R, Comoglio F, Favilli S, Agnoletti G, Carmina MG, Chessa M, Sarubbi B, Mongiovì M, Russo MG, Bianca S, Canzone G, Bonvici M, Viora E, Poli M. Documento di consenso ANMCO/SICP/SIGO: Gravidanza e cardiopatie congenite. G Ital Cardiol 2016;17(9):687-755.

2. Conrad KP, Gaber LW, Lindheimer MD. The kidney in normal pregnancy and preeclampsia. In Chesley's hypertensive disorders in pregnancy, 4th ed Taylor RN, Roberts JM, Cunningham fg, Academic Press, Amsterdam 2014.

3. Maternal physiology. In Williams Obstetrics 24th ed Cunningham GF, Leveno KJ, Bloom SL McGraw-Hill Education 2014, 63.

4. Odutayo A, Hladunewich M. Obstetric nephrology: renal hemodynamic and metabolic physiology in normal pregnancy. Clin JASN 2012:7, 2073.

5. Chesley LC, Sloan DM: The effect of posture on renal function in late pregnancy. Am J Obstet Gynecol 89: 754-759, 1964.

6. Sims EA, Krantz KE: Serial studies of renal function during pregnancyand the puerperium in normal women. J Clin Invest 37:1764-1774, 1958.

7. Dunlop W: Investigations into the influence of posture on renal plasma flow and glomerular filtration rate during late pregnancy. Br J Obstet Gynaecol 83: 17-23, 1976.

8. Rasmussen PE, Nielsen FR. Hydronephrosis during pregnancy, a literature survey, Eur J Obstet Gynecol Reprod Biol 1988, 27:249.

9. Nel JT, Diedericks A, Joubert G. A prospective clinical and urodynamic study of bladder funzction during and after pregnancy. Int Urogynecol J Pelvico Floor Dysfunc 2001, 12:21.

10. Abbassi Ghanavati M, Greer LG. Reference table of normal laboratory values in uncomplicated pregnancies. McGraw Hill $201023^{\circ}$ ed.

11. Lindheimer MD, Barron WM, Davison JM, Osmoregulation of thirst and vasopressin release in pregnancy, Am J Physiol 1989:257,F159.

12. Davison JM, Shiells EA, Philipps PR. Serial evaluation of vasopression relase and thirst in human pregnancy. Role of human chorionic gonadotrophin in the osmoregulatory changes of gestation. J Clin Invest 1988, 81.798.

13. Alto WA. No need for glycosuria/proteinuria screen in pregnant women. J Fam Pract 2005, 54:798.

14. Davison JM, Hiytten FE. The effect of pregnancy on the renal handling of glucose, Br J Obstet Gyneìaecol 1975:82.374.

15. Lind T, Godfrey KA, Otun H. Changes in serum urica acid concentrations during normal pregnancy. $\mathrm{Br} \mathrm{J} \mathrm{Ob-}$ stet Gynaecol 1984:91, 128.

16. Akbari A, Wilkes P, Lindheimer M. Reference intervals for anion gap and strong ion difference in pregnancy, a pilot study. Hypertens Pregnancy 2007, 26.111.

17. Coolen JC, Verhaeghe J. Physiology and clinical value of glycosuria after a glucose challenge during pregnancy Eur J Obst Gynecol Reprod Biol 2010, 150:132.

18. Webster P, Lightstone L, McKay DB, Josephson MA. 
Pregnancy in chronic kidney disease and kidney transplantation. Kidney Int. 2017 May;91(5):1047-1056.

19. Wiles K, Chappell L, Clark K, Elman L, Hall M, Lightstone L, Mohamed G, Mukherjee D, Nelson-Piercy C, Webster P, Whybrow R, Bramham K. Clinical practice guideline on pregnancy and renal disease. BMC Nephrology (2019) 20:401.

20. Jone DC, Hayslett JP. Outocme of pregnancy in women with moderate or severe renal insufficiency NEJM 1996:335-226.

21. Gonzales SML, Kattah A, Grande PJ. Renal disorders in pregnancy. Am JKD 2018.

22. Zhang JJ, Ma XXM Hao L. A systematic review and meta-analysis of outcomes of pregnancy in CKD and CKD outcomes in pregnancy. Clin JASN 2015:10-1964.

23. Davison JM, Dunlop W. Renal hemodynamics and tubular function normal human pregnancy. Kidney Int. 1980;18:152-61.

24. Moran P, Baylis PH, Lindheimer MD. Glomerulari ultrafiltration in normal and preeclamptic pregnancy. JASN 2003, 14:648.

25. Highby K, Suiter CR, Phelps JY, et al. Normal values of urinary albumin and total protein excretion during pregnancy. Am J Obstet Gynecol. 1994;171:984-9.

26. Piccoli GB, Cabiddu G, Attini R, et al. Risk of Adverse Pregnancy Outcomes in Women with CKD. J Am Soc Nephrol. 2015;26:2011-22.

27. Jin Ju Song Kyu-Beck Lee Young Youl Hyun Hyang Kim. Trace Albumin in the Urine Dipstick Test is Associated with Coronary Artery Calcification in Korean Adults . Nephron 2018.

28. Waugh JJ, Bell SC, Kilby MD, et al. Optimal bedside urinalysis for the detection of proteinuria in hypertensive pregnancy: a study of diagnostic accuracy. BJOG. 2005;112:412-7.

29. Henderson JT, Thompson JH, Burda BU. Preeclampsia screening. Evidence reports and systematic review for the US Preventive Services Task Force. JAMA 2017, 317-1668.

30. Eknovan O, Hpstetter T, Bkris GI. Proteinuria and other markers of CKD. A position statement of the national kidney foundation and the national institute of diabetess and digestive and kidney disease. Am Jkd 2003, 42-617.

31. ACOG Practice Bulletin N. 202. Gestational hypertension and preeclampsia. Obstet Gynecol 2019,133.

32. Cade TJ, De Crespigny PC, Nguven T. Shpuld the spot albumin-to creatinine ratio replaces the spot proteinto-creatinine ratio as the primary screening tool for proteinuria in pregnancy. Pregnancy hypertens 2015,6-298.

33. Suarez ML Gonzalez, Kattah A, Grande JP, Renal Disorders in Pregnancy: Core curriculum 2019.

34. Brown MA, Lindheimer MD, de Swiet M, Van Assche A, Moutquin JM: The classification and diagnosis of the hypertensive disorders of pregnancy: Statement from the International Society for the Study of Hypertension in Pregnancy (ISSHP). Hypertens Pregnancy 20: IX-XIV, 2001.

35. Fakhouri F, Vercel C, Fremeaux-Bachi v. Obstetric nephrology. AKI and thrombotic microangiopathies in pregnacy. Clin JASN 2012, 7:2100.

36. Piccoli, Giorgina Barbara et al. 'Pregnancy and chronic kidney disease: a challenge in all CKD stages.' Clinical journal of the American Society of Nephrology : CJASN vol. 5,5 (2010): 844-55.

37. Stratta P, Besso L, Canavese C, Grill A, Todros T, Benedetto C, Hollo S, Segoloni GP. Is pregnancy-related acute renal failure a disappearing clinical entity? Ren Fail. 1996;18(4):575-84.

38. Fakhouri F, Deltombe C. Pregnancy-related acute kidney injury in high income countries: still a critical issue. J Nephrol. 2017;30(6):767-71.

39. Jim B, Garovic VD. Acute kidney injury in pregnancy. Semin Nephrol. 2017;37(4):378-85.

40. Stratta P, Canavese C, Dogliani M, Todros T, Gagliardi L, Vercellone A. Pregnancy-related acute renal failure. Clin Nephrol. 1989;32:14-20.

41. Prakash J, Niwas SS, Parekh A, Pandey LK, Sharatchandra L, Arora P, Mahapatra AK. Acute kidney injury in late pregnancy in developing countries. Ren Fail. 2010;32:309-313.

42. Hildebrand AM, Liu K, Shariff SZ, Ray JG, Sontrop JM, Clark WF, Hladunewich MA, Garg AX. Characteristics and outcomes of AKI treated with Dialysis during pregnancy and the postpartum period. J Am Soc Nephrol. 2015; 26(12):3085-91.

43. Bellomo R, Ronco C, Kellum JA, et al. Acute renal failure - definition, outcome measures, animal models, fluid therapy and information technology needs: the Second International Consensus Conference of the Acute Dialysis Quality Initiative (ADQI) Group. Crit Care 2004; 8:R204-R212.

44. Mehta RL, Kellum JA, Shah SV, et al. Acute Kidney Injury Network: report of an initiative to improve outcomes in acute kidney injury. Crit Care 2007; 11:R31.

45. Piccoli GB, Daidola G, Attini R, et al. Kidney biopsy in pregnancy: evidence for counselling? A systematic narrative review. BJOG Int $\mathrm{J}$ Obstet Gynaecol2013; 120:412-427.

46. Vijayan M, Avendano M, Chinchilla KA, Jim B. Acute kidney injury in pregnancy. Curr Opin Crit Care. 2019 Dec;25(6):580-590)

47. George JN. Clinical practice. Thrombotic thrombocytopenic purpura, NEJM 2006, 354-1927.

48. Grunfeld JP, Pertuiset N. Acute renal failure in pregnancy:1987 AmJKD 1987, 9-359.

49. Usta IM, Barton JR, Amon EA. Acute fatty liver of pregnacy: an experience in the diagnosis and management of fourteen cases. Am J Obstet Gynecol 1994:171-1342.

50. Burlinson CEG, Sirounis D, Walley KR. Sepsis in pregnancy and the puerperium. Int J Obstet Anesth 2018; 36:96-107.

51. Cunningham FG, Lucas MJ, Hankins GD. Pulmonary injury complicating antepartum pyelonephritis. Am J Obstet Gynecol 1987; 156:797-807.

52. Mackeen AD, Packard RE, Ota E, et al. Antibiotic regimens for postpartum endometritis. Cochrane Database Syst Rev 2015; CD001067.

53. Eschenbach DA. Treating spontaneous and induced septic abortions. Obstet Gynecol 2015; 125:1042-1048.

54. Jena M, Mitch WE. Rapidly reversible acute renal failure from ureteral obstruction in pregnancy. Am J Kidney Dis 1996; 28:457-460.

55. Semins MJ, Matlaga BR. Kidney stones during pregnancy. Nat Rev Urol 2014; 11:163-168.

56. Rajasekar D, Hall M. Urinary tract injuries during ob- 
stetric intervention. Br J Obstet Gynaecol 1997; 104:731-734.

57. Black RM. Vascular disease of the kidney. Pathophysiology of renal disease McGraw-Hill 1987, 349.

58. Matlin RA, Gary NE. Acute cortical necrosis. Case report and review of the literature. Am J Med 1974, 56:110.

59. Chee Kay Cheung, Jonathan Barratt. Pregnancy in IgA Nephropathy: An Effect on Renal Outcome? Am J Nephrol 2019;49:212-213.

60. Yong SL, Ng BK, Mohd Yassin MAJ, Syed Zakaria SZ, Mohamed Ismail NA. Impact of late pregnancy haemoglobin $\mathrm{A}_{1 \mathrm{c}}$ at 29-30 weeks' gestation on adverse pregnancy outcomes among women with pre-existing diabetes: a retrospective analysis. J Obstet Gynaecol. 2018 May;38(4):461-465.

61. Silver B, Ramaiya K, Andrew SB, Fredrick O, Bajaj S, Kalra S, Charlotte BM, Claudine K, Makhoba A. EADSG Guidelines: Insulin Therapy in Diabetes. Diabetes Ther. 2018 Apr;9(2):449-492.

63. Bertsias GK, Tektonidou M, Amoura Z, et al; European League Against Rheumatism and European Renal Association-European Dialysis and Transplant Association. Joint European League Against Rheumatism and European Renal Association-European Dialysis and Transplant Association (EULAR/ERA-EDTA) recommendations for the management of adult and paediatric lupus nephritis. Ann Rheum Dis. 2012 Nov;71(11):1771-82.

64. Aisha Lateef and Michelle Petri. Managing lupus patients during pregnancy. Best Pract Res Clin Rheumatol. 2013 June ; 27(3).

65. The Canadian Hydroxychloroquine Study Group. A randomized study of the effect of withdrawing hydroxychloroquine sulfate in systemic lupus erythematosus. N Engl J Med 1991;324:150-4.

66. Clowse ME, Magder LS, Witter F, et al. Early risk factors for pregnancy loss in lupus. Obstet Gynecol 2006;107:293-9.

67. Kwok LW, Tam LS, Zhu T, et al. Predictors of maternal and fetal outcomes in pregnancies of patients with systemic lupus erythematosus. Lupus 2011;20:829-36.

68. Imbasciati E, Tincani A, Gregorini G, et al. Pregnancy in women with pre-existing lupus nephritis: predictors of fetal and maternal outcome. Nephrol Dial Transplant 2009;24:519-25.

69. Ruiz-Irastorza G, Cuadrado MJ, Ruiz-Arruza I, et al. Evidence-based recommendations for the prevention and long-term management of thrombosis in antiphospholipid antibody-positive patients: report of a task force at the 13th International Congress on antiphospholipid antibodies. Lupus 2011;20:206-18.

70. Hous S. Pregnancy in CKD and ESRD. AmJKD 1999, 33-235.

71. Hladunewich MA, Hou S, Odutayo A, et al. Intensive he- modialysis associates with improved pregnancy outcomes: a Canadian and United States cohort comparison. J Am Soc Nephrol. 2014;25:1103-9.

72. Ross LE, Swift PA, Newbold SM, et al. An Alternative Approach to Delivering Intensive Dialysis in Pregnancy. Perit Dial Int. 2016;36:575-7.

73. Malin GL, Wallace S, Hall M, et al. Peritoneal dialysis throughout pregnancy with successful outcome: A case report. Obstet Med. 2018;11:98-100.

74. Cabiddu G, Castellino S, Gernone G, et al. Best practices on pregnancy on dialysis: the Italian Study Group on Kidney and Pregnancy. J Nephrology. 2015;28:279-88.

75. Hladunewich M, Schatell D. Intensive dialysis and pregnancy. Haemodial Int. 2016;20:339-48.

76. Okundaye I, Abrinko P, Hou S. Registry of pregnancy in dialysis patients. Am J Kidney Dis. 1998;31:766-73.

77. Barua M, Hladunewich M, Keunen J, et al. Successful pregnancies on nocturnal home hemodialysis. Clin J Am Soc Nephrol. 2008;3:392-6.

78. Webster P, Lightstone L, McKay DB, Josephson MA. Pregnancy in chronic kidney disease and kidney transplantation. Kidney Int. 2017 May;91(5):1047-1056.

79. Bramham K, Nelson-Piercy C, Gao H et al. Pregnancy in renal transplant recipients: a UK national cohort study. Clin. J. Am. Soc. Nephrol. 2013;8:290-298.

80. Deshpande NA, James NT, Kucirka LM et al. Pregnancy outcomes in kidney transplant recipients: a systematic review and meta-analysis. Am. J. Transplant 2011;11: 2388-2404.

81. Gill JS, Zalunardo N, Rose C et al. The pregnancy rate and live birth rate in kidney transplant recipients. Am. J. Transplant 2009;9:1541-1549.

82. Coscia LA, Constantinescu S, Moritz MJ et al. Report from the National Transplantation Pregnancy Registry (NTPR): outcomes of pregnancy after transplantation. Clin. Transpl. 2010:65-85.-20.

83. Levidiotis V, Chang S, McDonald S. Pregnancy and maternal outcomes among kidney transplant recipients. J. Am. Soc. Nephrol. 2009;20:2433-2440.

84. Sibanda N, Briggs JD, Davison JM et al. Pregnancy after organ transplantation: a report from the UK Transplant pregnancy registry. Transplantation 2007;83:1301-1307.

85. McKay DB, Josephson MA, Armenti VT et al. Reproduction and transplantation: report on the AST Consensus Conference on Reproductive Issues and Transplantation. Am. J. Transplant 2005;5:1592-1599.

86. Deshpande NA, Coscia LA, Gomez-Lobo V et al. Pregnancy after solid organ transplantation: a guide for obstetric management. Rev. Obstet. Gynecol. 2013;6:116-125.

87. McKay DB, Josephson MA. Pregnancy in recipients of solid organs - effects on mother and child. N. Engl. J. Med. 2006;354:1281-1293. 


\title{
Terapia con farmaci antireumatici in corso di gravidanza e allattamento
}

\author{
Maria Chiara Gerardi, Daniele Lini, Laura Andreoli \\ Unità Operativa di Reumatologia e Immunologia Clinica, ASST-Spedali Civili, Brescia; Dipartimento di Scienze Cliniche e \\ Sperimentali, Università degli Studi di Brescia, Italia
}

\section{Introduzione}

La valutazione del rapporto rischio/beneficio di un farmaco in gravidanza e durante l'allattamento è complicata da rilevanti problemi metodologici ed etici che rendono difficoltoso individuare i composti sicuri e quelli pericolosi. Nel corso degli anni sono stati pubblicati numerosi studi sulla possibile associazione tra l'assunzione di farmaci in gravidanza ed effetti teratogeni, ma l'impossibilità di includere le pazienti in gravidanza nei trial clinici per evidenti ragioni etiche non ha consentito di raccogliere informazioni dirimenti. I dati sulla sicurezza dei farmaci in gravidanza si basa su sperimentazioni animali, studi osservazionali o coorti selezionate di donne, in particolare gravidanze non programmate e dunque accidentalmente esposte al farmaco. In assenza di studi controllati, l'associazione tra complicanze materno-fetali ed esposizione farmacologica in gravidanza non è valutabile, così come non lo è correlazione con la possibile insorgenza di patologie nelle fasi successive dello sviluppo. ${ }^{1}$

Nella gestione della gravidanza e dell'allattamento nelle donne con malattie reumatiche è necessario tenere in considerazione una serie di principi generali (Figura 1). Il presupposto fondamentale per ottenere il miglior esito gestazionale possibile è la pianificazione della gravidanza in un periodo di remissione stabile della malattia, grazie all'utilizzo di farmaci considerati sicuri, tenendo però presente che circa un terzo delle gravidanze non sono programmate per cui

Corrispondente: Laura Andreoli, Unità Operativa di Reumatologia e Immunologia Clinica, ASST-Spedali Civili; Dipartimento di Scienze Cliniche e Sperimentali, Università degli studi di Brescia, piazzale Spedali Civili 1, 25123 Brescia, Italia. Tel.: +39.030.39954557; +39.030.3995488.

Fax: +39.030.399508.

E-mail: laura.andreoli@unibs.it

Articolo pubblicato secondo la Creative Commons Attribution NonCommercial 4.0 License (CC BY-NC 4.0).

${ }^{\circ}$ Copyright: the Author(s), 2021

Licensee PAGEPress, Italy

QUADERNI - Italian Journal of Medicine 2021; 9(4):e15 diventa importante anche sapere come gestire gravidanze che si verificano in donne in terapia con farmaci teratogeni ${ }^{2}$. A questo proposito, va segnalata l'importanza di discutere una adeguata contraccezione con le pazienti in terapia con farmaci teratogeni.

Il trattamento delle pazienti con malattie reumatiche in gravidanza e durante l'allattamento ha come obiettivo quello di controllare l'attività di malattia materna con farmaci sicuri per il feto. ${ }^{2}$ È altresì importante valutare da una parte il rischio della terapia farmacologica per il feto in rapporto al rischio che la malattia materna non trattata per nove mesi possa danneggiare la salute materna e indirettamente quella-fetale. ${ }^{2}$

Infine, tutte le scelte terapeutiche andrebbero valutate e discusse nell'ambito di un'equipe multidisciplinare formata da reumatologo, ginecologo/ostetrico e neonatologo, accompagnando e coinvolgendo nel processo decisionale la paziente. Infatti, un punto di non secondaria importanza è costituito dalla adesione alla prescrizione medica. Vanno esplicitamente affrontate le preoccupazioni che la donna generalmente nutre rispetto alla salute fetale e che possono determinare una mancata $\mathrm{o}$ insufficiente assunzione del farmaco prescritto. ${ }^{2}$

La Società Britannica di Reumatologia (BSR), la Società Europea di Reumatologia (European League Against Rheumatism - EULAR) e la Società Americana di Reumatologia (ACR) hanno elaborato negli ultimi anni delle raccomandazioni sull'utilizzo dei farmaci anti-reumatici (Disease Modifying Antirheumatic Drugs - DMARDs) in corso di gravidanza e allattamento. ${ }^{3-5}$ In questa revisione narrativa della letteratura riassumeremo le attuali conoscenze sui DMARDs in gravidanza e in allattamento (Tabelle 1 e 2). Nella prima parte affronteremo i DMARDs di sintesi (sDMARDs) distinguendo tra sDMARDs convenzionali (csDMARDs) e quelli rivolti contro le small molecules (tsDMARDs). Nelle sezioni successive, invece, parleremo dei DMARDs biologici (bDMARDs), che si suddividono in originator (boDMARDs) e in biosimilari (bsDMARDs). ${ }^{6}$

\section{Farmaci anti-infiammatori non steroidei}

I farmaci anti-infiammatori non steroidei (FANS) sono frequentemente utilizzati nei pazienti affetti da ar- 
triti croniche in quanto permettono un controllo rapido della sintomatologia, ma non esercitano alcuna azione documentata sulla progressione della malattia. I dati disponibili dimostrano che l'esposizione a FANS nel primo e nel secondo trimestre non aumenta il rischio di anomalie congenite, di prematurità o di aborto spontaneo nei nati esposti e non sono state altresì rilevate influenze sul peso alla nascita. Dopo la $20^{\circ}$ settimana di gestazione, i FANS possono compromettere la funzionalità renale fetale (con conseguente oligoidramnios), inoltre possono causare una chiusura prematura del dotto di Botallo (con conseguente ipertensione polmonare nel neonato). ${ }^{7}$ Inoltre, poiché influenzano negativamente il travaglio, i FANS dovrebbero essere sospesi prima della $32^{\circ}$ settimana di gestazione. I dati sulla sicurezza degli inibitori della cicloossigenasi-2 (COX-2) sono scarsi e pertanto si consiglia di passare ai FANS tradizionali durante la gravidanza. ${ }^{8,9}$ Per quanto concerne l'allattamento, i FANS sono utilizzati da molte donne nel periodo post-partum. I FANS non selettivi sono considerati compatibili con l'allattamento. Tra i FANS COX-2 selettivi, l'unico per il quale è disponibile sufficiente documentazione e pertanto consigliato è il celecoxib. Gli altri COX-2 selettivi andrebbero evitati durante l'allattamento. ${ }^{4}$

\section{Glucocorticoidi}

I glucocorticoidi (GC) sono ampiamente impiegati per controllare nella fase acuta l'attività di malattia in corso di gravidanza. Dato il potenziale rischio di palatoschisi, è consigliato ridurre al minimo la dose di GC assunta nel primo trimestre di gravidanza. ${ }^{10}$ Tra i GC, bisogna distinguere quelli che non attraversano la placenta, come il prednisone (PDN) e il metilprednisolone, e i GC fluorurati, desametasone e betametasone, che attraversano la placenta in concentrazioni più elevate $\mathrm{e}$, pertanto, il loro utilizzo dovrebbe essere limitato solamente per favorire la maturazione polmonare fetale. ${ }^{9} \mathrm{Il}$ PDN sembra essere un farmaco relativamente sicuro per la madre e per il feto a dosaggi medio-bassi, mentre l'utilizzo a dosaggi elevati è associato a ritardo di crescita intrauterina (IUGR), parto pretermine e rottura prematura delle membrane (PROM). ${ }^{10,11}$

\section{Synthetic disease-modifying antirheumatic drugs}

\section{Conventional synthetic disease-modifying antirheumatic drugs}

\section{Clorochina}

Le attuali evidenze scientifiche non mostrano un aumentato rischio di malformazioni fetali in caso di esposizione alla clorochina durante la gravidanza e, inoltre, risulta compatibile con l'allattamento.,

\section{Idrossiclorochina}

L'idrossiclorochina (HCQ) attraversa la placenta ma l'assunzione in gravidanza non aumenta il rischio di malformazioni fetali e studi a lungo termine sui nati esposti non rilevano nessun tipo di anomalia. ${ }^{8}$

La sospensione di questo farmaco in pazienti affetti da lupus eritematoso sistemico (LES) al momento del concepimento espone la paziente ad un maggior rischio di riacutizzazione di malattia in gravidanza e alle conseguenze che questo porta anche sul benessere fetale. ${ }^{12}$ È stato recentemente dimostrato che nelle pazienti con LES l'HCQ riduce il rischio di pre-eclampsia. ${ }^{13}$ Inoltre,

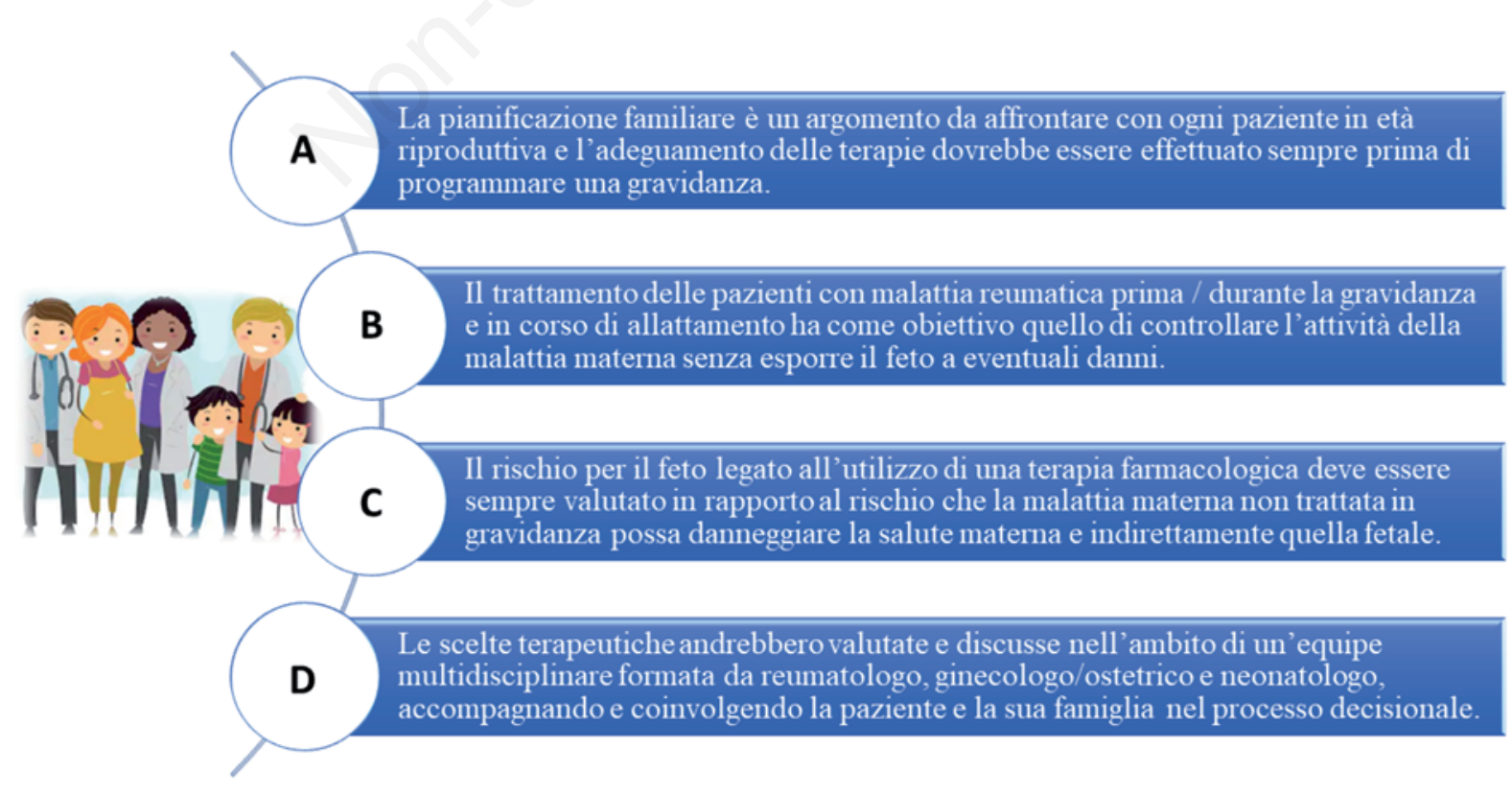

Figura 1. Principi generali della terapia delle malattie reumatiche in corso di gravidanza e allattamento. 
l'effetto benefico dell'HCQ è stato suggerito anche nelle pazienti affette da sindrome da anticorpi antifosfolipidi (APS), sebbene i dati non siano ancora sufficienti per raccomandarne l'utilizzo di routine in queste pazienti. ${ }^{12}$

L'HCQ sembrerebbe ridurre la probabilità di sviluppo del blocco cardiaco congenito nei feti esposti ad anticorpi anti Ro/SSA materni in donne che hanno avuto un precedente neonato con blocco cardiaco congenito e il rischio di sviluppare lupus cutaneo neonatale in utero. ${ }^{14,15} \mathrm{Il}$ farmaco può essere rilevato nel latte materno in minime quantità e pertanto l'allattamento al seno è considerato compatibile. ${ }^{4}$

Per queste ragioni, l'HCQ risulta l'antimalarico di scelta nelle donne affette da malattia reumatica che necessitino di trattamento continuo e stessero pianificano una gravidanza. Le pazienti con LES che non stessero assumendo HCQ andrebbero avviate al farmaco in fase di counselling preconcezionale.

\section{Mepacrina}

Le attuali evidenze risultano insufficienti in gravidanza e non esistono dati riguardanti l'uso in allattamento, per cui l'utilizzo di mepacrina dovrebbe essere evitato. ${ }^{4}$

\section{Metotrexato}

Il metotrexato (MTX), farmaco antimetabolita, è il csDMARD di scelta per la terapia delle artriti croniche ed è somministrato al 50-70\% dei pazienti con questa patologia. Tuttavia, il MTX è un noto agente teratogeno e pro-abortivo. Se assunto in gravidanza può provocare l'embriofetopatia da aminopterina/ MTX, una sindrome caratterizzata da deficit della crescita, dismorfismi facciali, difetti del tubo neurale, del cranio e degli arti. ${ }^{15}$ Considerando che il MTX si distribuisce ampiamente nei tessuti e può persistervi a

Tabella 1. Compatibilità di utilizzo in gravidanza di farmaci indicati nelle malattie reumatiche.

\begin{tabular}{|c|c|c|c|}
\hline \multicolumn{4}{|c|}{ GRAVIDANZA } \\
\hline $\begin{array}{l}\text { SOSPENDERE } \\
\text { PRIMA DEL } \\
\text { CONCEPIMENTO }\end{array}$ & $\begin{array}{l}\text { SOSPENDERE } \\
\text { AL TEST } \\
\text { DI GRAVIDANZA } \\
\text { POSITIVO }\end{array}$ & $\begin{array}{l}\text { COMPATIBILI } \\
\text { CON LA } \\
\text { GRAVIDANZA }\end{array}$ & $\begin{array}{l}\text { TERAPIA } \\
\text { AGGIUNTIVA }\end{array}$ \\
\hline $\begin{array}{l}\text { - } \text { Metotressato }^{\text {a }} \\
(3 \text { mesi prima }) \\
\text { - Micofenolato mofetile } \\
\text { (6 settimane prima) } \\
\text { - Ciclofosfamide } \\
\text { ( } 6 \text { mesi prima) }\end{array}$ & - Inibitori COX2 selettivi & $\begin{array}{l}\text { - FANS } \\
\left.\text { (non utilizzare oltre la } 32^{\circ} \mathrm{SG}\right)\end{array}$ & $\begin{array}{l}\text { - Acido folico } \\
\text { (preferibilmente } \\
\text { dal preconcezionale) }\end{array}$ \\
\hline $\begin{array}{l}\text { - } \text { Leflunomide }^{\mathrm{b}} \\
\text { - } \text { Tofacitinib }^{\mathrm{b}} \\
\text { - } \text { Apremilast }^{\mathrm{b}} \\
\text { - } \text { Baricitinib }^{\mathrm{b}}\end{array}$ & $\begin{array}{l}\text { - Warfarin/Acenocumarolo } \\
\left(<6^{\circ} \mathrm{SG}\right)\end{array}$ & $\begin{array}{l}\text { - Prednisone } \\
\text { - Metilprednisolone }\end{array}$ & $\begin{array}{l}\text { - Calcio } \\
\text { - Vitamina D }\end{array}$ \\
\hline \multirow[t]{2}{*}{$\begin{array}{l}\text { - Abatacept } \\
\text { - Tocilizumab } \\
\text { - Rituximab } \\
\text { - } \text { Belimumab }^{\mathrm{c}} \\
\text { - Ustekinumab } \\
\text { - Secukinumab }\end{array}$} & • Mepacrina & $\begin{array}{l}\text { - Idrossiclorochina } \\
\text { - Clorochina } \\
\text { - Sulfasalazina } \\
(<2 g r / d i e)^{a} \\
\text { - Azatioprina } \\
(<2 \mathrm{mg} / \mathrm{kg} / \mathrm{die}) \\
\text { - Ciclosporina } \\
\text { - Tacrolimus } \\
\text { - Colchicina }\end{array}$ & $\begin{array}{l}- \pm \text { ASA } \\
\text { a basso dosaggio } \\
\text { (preconcezionale o } \\
\text { introdurre entro la } \\
16^{\circ} \mathrm{SG} \text { ) }\end{array}$ \\
\hline & & 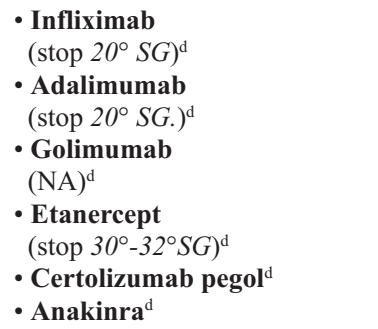 & $\begin{array}{l}\cdot \pm \mathbf{E P B M} \\
\text { profilattica/terapeutica }^{\mathrm{f}}\end{array}$ \\
\hline
\end{tabular}

- Immunoglobuline endovena

${ }^{a}$ Importante supplementazione con acido folico $5 \mathrm{mg} /$ die. ${ }^{b}$ Documentazione limitata sull'uso sicuro in gravidanza e deve essere dunque sostituito prima del concepimento con altri farmaci. 'In considerazione della limitata documentazione sull'utilizzo in gravidanza, le schede tecniche di questi farmaci raccomandano di sospendere la terapia prima del concepimento. Tuttavia, in caso di esposizione a farmaco in gravidanza non programmata, è possibile rassicurare le pazienti spiegando quanto riportato al punto d. ${ }^{\mathrm{L}} \mathrm{La}$ struttura molecolare di molti di questi farmaci (anticorpi monoclonali) suggerisce che il loro passaggio transplacentare può essere praticamente assente fino al secondo trimestre a causa dell'immaturità della placenta. In teoria, l'assunzione di questi farmaci durante il primo trimestre non dovrebbe causare effetti sul feto. Il loro uso può essere valutato con la paziente se non c'è altra opzione terapeutica.

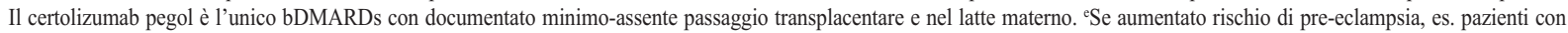
nefrite lupica o positive per anticorpi anti-fosfolipidi. ${ }^{\mathrm{N}}$ Nella sindrome da anticorpi anti-fosfolipidi in base alle manifestazioni cliniche o al profilo di rischio. 
lungo, se ne consiglia la sospensione almeno 3 mesi prima del concepimento assicurando una supplementazione quotidiana di acido folico $(5 \mathrm{mg} /$ die $)$ dalla sospensione della terapia per tutta la durata della gravidanza. In caso di gravidanza accidentale durante l'assunzione di MTX, il farmaco deve essere interrotto immediatamente proseguendo la supplementazione con acido folico e monitorando attentamente il rischio fetale. Inoltre, poiché piccole quantità si possono ritrovare nel latte materno, se ne sconsiglia l'assunzione durante l'allattamento ${ }^{3,4}$.

\section{Leflunomide}

La leflunomide (LEF) è un altro csDMARD impiegato nel trattamento dell'artriti croniche. Sebbene in studi su animali la LEF sia risultata teratogena, studi più recenti sull'uomo non hanno documentato un aumento del rischio di malformazioni congenite in seguito all'esposizione a LEF nel primo trimestre quando è seguito dal wash-out con colestiramina. ${ }^{17-19}$ Tuttavia, a causa della scarsità di dati disponibili, si raccomanda di evitarne l'assunzione in gravidanza e in allattamento.,

\section{Sulfasalazina}

Diversi studi hanno dimostrato che la sulfasalazina (SSZ), altro csDMARD, se assunta alla dose $\leq$ ai $2 \mathrm{gr} / \mathrm{die}$ non determina rischi per il feto. ${ }^{8}$ Recenti studi sperimentali, inoltre, hanno suggerito un'azione antinfiammatoria e antiossidante della SSZ sulle cellule placentali ed endoteliali che potrebbe avere un ruolo nel prevenire la pre-eclampsia. ${ }^{20,21}$ Poiché la SSZ influenza il riassorbimento di folati, è consigliabile una supplementazione con acido folico $(5 \mathrm{mg} / \mathrm{die})$. Basse concentrazioni di SSZ sono state ritrovate nel latte materno, mentre sono state rilevate concentrazioni maggiori (30-60\%) del suo metabolita, la sulfapiridina. Tuttavia, l'allattamento al seno è considerato sicuro nei neonati nati a termine, ${ }^{4} \mathrm{ma}$ controindicato in neonati con ittero, deficit di G6P-deidrogenasi e nei nati prematuri. ${ }^{4}$

\section{Micofenolato mofetile}

L'esposizione al micofenolato mofetile (MMF) durante la gravidanza è associata alla presenza di un'elevata incidenza di malformazioni fetali, in particolare a livello di orecchio esterno e medio ${ }^{22}$ motivo per cui è raccomandata la sospensione del farmaco almeno 6 settimane prima del concepimento. ${ }^{4,23,24}$ Non sono disponibili dati circa la sicurezza di utilizzo di MMF in allattamento, pertanto andrebbe sconsigliato. ${ }^{3,4}$

\section{Azatioprina}

L'azatioprina (AZA) è un csDMARD utilizzato per anni nelle gravidanze in donne post-trapianto e attualmente utilizzato nel trattamento delle connettiviti e vasculiti. Le evidenze accumulate negli anni non mostrano un aumentato rischio di malformazioni congenite. Come sottolineato dalle raccomandazioni EULAR e da quelle della BSR, l'AZA può essere utilizzata in gravidanza a dosi $\leq$ ai $2 \mathrm{mg} / \mathrm{kg} /$ die ed è compatibile con l'allattamento. ${ }^{3,4}$

\section{Ciclosporina A}

Le evidenze disponibili dimostrano che l'assunzione di ciclosporina $\mathrm{A}$ (CysA) in gravidanza non aumenta il rischio di malformazioni congenite. Pertanto, la CysA può essere proseguita durante tutta la gravidanza alla minima dose efficace. Inoltre, è compatibile con l'allattamento. , $^{3,4}$

Tabella 2. Compatibilità di utilizzo in allattamento di farmaci indicati nelle malattie reumatiche.

\begin{tabular}{|c|c|c|}
\hline \multicolumn{3}{|c|}{ ALLATTAMENTO } \\
\hline COMPATIBILI & DATI INSUFFICIENTI & CONTROINDICATI \\
\hline $\begin{array}{l}\text { - FANS } \\
\text { - Celecoxib } \\
\text { - Prednisone } \\
\text { - Metilprednisone } \\
\text { - Idrossiclorochina } \\
\text { - Clorochina } \\
\text { - Sulfasalazina } \\
\text { - Azatioprina } \\
\text { - Ciclosporina } \\
\text { - Tacrolimus } \\
\text { - Colchicina } \\
\text { - Infliximab } \\
\text { - Adalimumab } \\
\text { - Golimumab } \\
\text { - Etanercept } \\
\text { - Certolizumab pegol } \\
\text { - Anakinra }\end{array}$ & $\begin{array}{l}\text { - Abatacept* } \\
\text { - Tocilizumab* } \\
\text { - Rituximab* } \\
\text { - Belimumab* } \\
\text { - Ustekinumab* } \\
\text { - Secukinumab* } \\
\text { - Inibitori COX2 selettivi (ad eccezione di Celecoxib) } \\
\text { - Mepacrina }\end{array}$ & $\begin{array}{l}\text { - Metotressato } \\
\text { - Micofenolato mofetile } \\
\text { - Ciclofosfamide } \\
\text { - Leflunomide }\end{array}$ \\
\hline
\end{tabular}




\section{Ciclofosfamide}

La Ciclofosfamide è un csDMARD gonadotossico e teratogeno per cui dovrebbe essere sospeso prima del concepimento e non utilizzata durante la gravidanza, specialmente nel primo trimestre l'utilizzo di ciclofosfamide potrebbe essere considerato nel terzo trimestre nel caso di condizioni materne life-threatening che non possano essere gestite con altri farmaci. A causa dei pochi dati disponibili si consiglia di evitarne l'uso durante l'allattamento. ${ }^{3,4}$

\section{Targeted synthetic disease-modifying antirheumatic drugs}

Negli ultimi decenni l'armamentario terapeutico reumatologico si è arricchito di una nuova classe di farmaci definita small molecules o targeted synthetic diseasemodifying antirheumatic drugs (tsDMARDs). Si tratta di farmaci di basso peso molecolare con una azione selettiva su una proteina coinvolta nella patogenesi della malattia, chiamato target molecolare.

\section{Apremilast}

Apremilast è un inibitore a basso peso molecolare della fosfodiesterasi 4 (PDE4), che agisce a livello intracellulare modulando una rete di mediatori pro-infiammatori e antinfiammatori, somministrato per via orale. Il suo utilizzo è indicato nel trattamento della psoriasi moderato-severa e dell'artrite psoriasica attiva. In studi animali sui topi e nelle scimmie apremilast, a dosi superiori alla dose massima attualmente raccomandata per uso umano, ha provocato perdita embriofetale nei topi e nelle scimmie, riduzione del peso del feto e ritardo dell'ossificazione nei topi. Tali effetti non sono stati osservati quando l'esposizione negli animali è stata pari a 1,3 volte l'esposizione clinica. Apremilast è stato rilevato nel latte delle femmine di topo nel periodo di lattazione. Non è noto se apremilast/metaboliti siano escreti nel latte materno. Pertanto, apremilast andrebbe sospeso prima del concepimento e non utilizzato durante la gravidanza e l'allattamento. ${ }^{25}$

\section{Baricitinib}

Baricitinib è è un inibitore selettivo e reversibile di Janus chinasi (JAK)1 e JAK2 indicato per il trattamento dell'artrite reumatoide (AR). Il suo utilizzo è controindicato in gravidanza, dal momento che i dati pre-clinici sugli animali hanno mostrato un ridotto sviluppo fetale e la presenza di malformazioni. ${ }^{26}$ Non sono disponibili dati sull'uso di baricitinib nelle donne in gravidanza e in corso di allattamento, motivo per cui il farmaco andrebbe sospeso prima dell'eventuale concepimento.

\section{Tofacitinib}

Tofacitinib è un selettivo inibitore selettivo delle JAK 1-3 utilizzato per il trattamento dell'AR e dell'ar- trite psoriasica (AP). I dati preclinici su animali hanno mostrato un effetto teratogeno a dosaggi superiori a quelli utilizzati nell'uomo. ${ }^{27} \mathrm{Negli}$ studi di registrazione del farmaco in pazienti con AR, psoriasi e rettocolite ulcerosa (RU), l'esposizione non intenzionale durante il concepimento e/o la gravidanza non sembra aumentare il rischio di complicanze fetali rispetto alla popolazione generale. ${ }^{28,29}$ Tuttavia, a causa dei pochi dati disponibili, si consiglia la sospensione prima del concepimento e se ne sconsiglia l'utilizzo in corso di gravidanza e allattamento. I tempi precisi su quando interrompere questo farmaco e gli altri tsDMARDs prima del concepimento non sono chiari, ma date le loro brevi emivite (3-12 ore) $)^{30-32}$ interrompere tali farmaci 1 mese prima del concepimento dovrebbe essere sufficiente.

\section{Biological disease-modifying antirheumatic drugs}

\section{Biological originator disease-modifying antirheumatic drugs}

L'introduzione dei farmaci biological originator disease-modifying antirheumatic drugs (boDMARDs) circa 20 anni fa ha rivoluzionato il decorso di molte malattie reumatiche permettendo di ottenere una remissione stabile nel tempo di queste malattie. La maggior parte dei dati di sicurezza oggi disponibili riguardano i boDMARDs anti-TNF $\alpha$. Ma sebbene abbiano strutture molecolari diverse e agiscano su molecole diverse, la struttura molecolare di molti di questi farmaci (anticorpi monoclonali) suggerisce che il loro passaggio attraverso la placenta possa essere virtualmente assente fino al secondo trimestre a causa della immaturità della placenta. In linea teorica, ricevere questi farmaci durante il primo trimestre non dovrebbe determinare effetti sul feto, come confermato dai dati sulle gravidanze esposte nei trial registrativi.

\section{boDMARDs -anti-TNFa}

Trattasi di cinque farmaci utilizzati nel trattamento delle artriti croniche.

L'infliximab (IFX) è un anticorpo monoclonale chimerico $\operatorname{IgG}_{1}$, composto da strutture polipeptidiche di origine murina (circa $25 \%$ ) a livello dei domini variabili delle due regioni Fab, deputate al riconoscimento e al legame del TNF, e per la restante parte (domini costanti delle regioni Fab e regione Fc) da strutture polipeptidiche di origine umana (circa $75 \%$ ). Infliximab si lega con alta affinità sia alla forma solubile che a quella transmembrana del TNF $\alpha$, ma non alla linfotossina $\alpha$ $(\mathrm{TNF} \beta))^{33,34} \mathrm{Il}$ farmaco è stato approvato nel 1998, somministrato come infusione endovenosa ed è indicato nel trattamento di AR, Spondiloartriti (SpA), psoriasi, AP, morbo di Crohn e RU. ${ }^{35}$

L'adalimumab (ADA) è un anticorpo monoclonale umano ricombinante diretto contro il $\mathrm{TNF} \alpha$, indicato 
per il trattamento di AR, AP, psoriasi, artrite idiopatica giovanile (AIG) e SpA associate alle malattie infiammatorie croniche intestinali (IBD). Etanercept (ETA) è una proteina di fusione costituita da un dimero della porzione extracellulare del recettore p75 per il TNF $\alpha$ associato al frammento $\mathrm{Fc}$ di una $\mathrm{IgG}_{1}$ umana. Il meccanismo d'azione dell'ETA consiste in una inibizione competitiva del legame del TNF al recettore superficiale TNF-R1, che previene le risposte cellulari mediate dal TNF rendendo il TNF biologicamente inattivo. È stato approvato nel 1998 e può essere impiegato per il trattamento dell'AR AIG poliarticolare, AP, SA grave e psoriasi a placche. ${ }^{35,36}$

Il golimumab (GOL) ha la caratteristica di essere un anticorpo monoclonale umano appartenente alla classe delle $\mathrm{IgG}_{1}$. Possiede una regione Fc completa e ha la capacità di legare il TNF in maniera bivalente, con formazione di complessi antigene-anticorpo multimerici, dove molecole diverse di TNF possono essere legate dalla stessa molecola di anticorpo monoclonale anti-TNF. GOL è stato approvato nel 2009 ed è indicato per il trattamento di AR, AP in fase attiva e progressiva, singolarmente $\mathrm{o}$ in associazione con MTX, SpA grave in fase attiva, AIG e RU. ${ }^{37}$

Certolizumab pegol (CTZ) differisce in quanto è un frammento Fab' di un anticorpo ricombinante umanizzato diretto contro il TNF $\alpha$ espresso in Escherichia Coli e coniugato con polietilenglicole. CTZ è stato approvato nel 2009, viene somministrato mediante iniezione sottocutanea ed è indicato nel trattamento di AR attiva da moderata a grave, SpA, AP e morbo di Crohn. ${ }^{36}$

Le attuali raccomandazioni $i^{3,4}$ suggeriscono di continuare il trattamento con anti-TNF $\alpha$ durante la gravidanza poichè l'interruzione di questi farmaci al concepimento aumenta il rischio di riacutizzazioni di malattia $^{38}$ e complicanze gravidiche. ${ }^{39}$

Poiché il trasporto attivo attraverso la placenta delle immunoglobuline $\operatorname{IgG}$ diventa significativo dopo la $16^{\circ}$ settimana di gestazione, i boDMARDs anti-TNF $\alpha$ che sono anticorpi monoclonali IgG verranno trasferiti al feto dopo tale periodo. È stato dimostrato che la concentrazione degli anticorpi monoclonali è più elevata nel neonato rispetto alla madre, come previsto per qualsiasi IgG. Pertanto, si raccomanda di interrompere i boDMARDs antiTNF $\alpha$ (con tempi diversi in base alla loro struttura) nel secondo trimestre - inizio terzo trimestre al fine di ridurre al minimo l'esposizione al farmaco ed evitare che il neonato sia immunosoppresso a causa del farmaco ricevuto dal madre ${ }^{3,4}$. Tra i boDMARDs anti$\mathrm{TNF} \alpha$, il $\mathrm{CTZ}$ però manca del frammento $\mathrm{Fc}$ necessario per il passaggio transplacentare. Sulla base di questa peculiarità, lo studio CRIB ha dimostrato che nel sangue dei neonati le cui madri hanno ricevuto il farmaco fino al parto sono state rilevate minime quantità di farmaco e questi bambini non hanno avuto particolari eventi avversi nei primi due mesi di vita. ${ }^{40}$ Lo studio CRADLE invece ha mostrato l'assenza del farmaco nel latte ma- terno e l'assenza di eventi avversi nei bambini allattati al seno mentre le loro madri stavano assumendo CTZ. ${ }^{41}$

L'esposizione a farmaci immunosoppressori, in particolare ai boDMARD, durante l'ultima parte della gravidanza ci pone di fronte al problema del possibile rischio di infezioni e della gestione delle vaccinazioni nel neonato, con un sistema immunitario ancora immaturo. I dati provenienti da grandi database amministrativi statunitensi hanno mostrato che i bambini esposti durante il terzo trimestre a farmaci anti-TNF $\alpha$ non avevano un aumentato rischio di infezioni severe durante il primo anno di vita. ${ }^{42}$ L'unica preoccupazione per le vaccinazioni riguarda i vaccini vivi: si raccomanda di evitare queste vaccinazioni nei primi 6 mesi di vita dei neonati nati da madri trattate con boDMARDs nella seconda parte della gravidanza. ${ }^{43}$ Questa raccomandazione può essere modulata in base al tipo di farmaco assunto e alla sua emivita e all'epoca gestazionale di sospensione del farmaco stesso; il livello di esposizione del neonato va discusso con la paziente con la quale va valutato il rapporto rischio-beneficio di sottoporre il neonato a vaccinazione a virus vivo.

\section{boDMARDs - non anti-TNFa}

Dati limitati sono disponibili sulla sicurezza di utilizzo in gravidanza degli altri boDMARDs con meccanismo d'azione non anti-TNF $\alpha$ [rituximab, tocilizumab, abatacept, anakinra, belimumab, ustekinumab, secukinumab]. Sebbene i pochi dati non sembrino rilevare un pericolo per il feto se assunti prima del concepimento o nel primo trimestre, se ne consiglia l'interruzione alcuni mesi prima del concepimento ${ }^{4}$. Tuttavia, la sospensione pre-concepimento rischia di lasciare la paziente scoperta da terapia per diversi mesi in attesa dell'avvio della gravidanza, con rischio di riacutizzazione di malattia. Pertanto, sembra essere ragionevole proporre la sospensione del farmaco al test di gravidanza positivo. Nel caso in cui l'attività di malattia materna dovesse essere non controllata e non vi fossero altre opzioni terapeutiche, l'assunzione in corso di gravidanza può essere discussa con la paziente, considerando gli aspetti già descritti per i farmaci anti-TNF $\alpha$. Anche i dati sulla loro sicurezza in corso di allattamento sono scarsi. Tuttavia, bisogna ricordare che questi farmaci sono molecole proteiche di grosse dimensioni e dunque dotate di scarse possibilità di passaggio nel latte materno. E qualora fosse presente nel latte materno, il farmaco verrebbe degradato nell'apparato digerente del neonato con impossibilità di assorbimento. Pertanto, va discussa la possibilità di allattare in corso di terapia con la singola paziente. ${ }^{35-43}$

\section{Biosimilar disease-modifying antirheumatic drugs}

Negli ultimi anni sono stati sviluppati farmaci biosimilar disease-modifying antirheumatic drugs (bsDMARDs) biosimilari dei boDMARDs infliximab, etanercept e adalimumab ma non sono disponibili dati 
di sicurezza in gravidanza e in allattamento. Ciò implica che nelle donne con desiderio di gravidanza o in gravidanza dovrebbero essere preferiti i boDMARDs rispetto ai bsDMARDs.

\section{Profilassi con acido acetilsalicilico ed eparina}

Sebbene l'acido acetilsalicilico (ASA) e l'eparina non siano DMARDs, è necessario menzionare questi farmaci come profilassi e terapia per le malattie reumatiche in corso di gravidanza e allattamento. La terapia nelle pazienti con sindrome da anticorpi antifosfolipidi (APS), primaria o associata ad altre patologie autoimmuni (LES), nelle donne positive per anticorpi antifosfolipidi (aPL) verrà esaminata dettagliatamente nel capitolo dedicato di questo volume (capitolo Sindrome da anticorpi antifosfolipidi e gravidanza). Nelle pazienti ad alto rischio di pre-eclampsia, come quelle con nefrite lupica o con fattori di rischio ostetrici generali (positività per aPL, pregressa pre-eclampsia, diabete pregravidico, gravidanza plurima, ipertensione preesistente la gravidanza, patologia renale preesistente la gravidanza o proteinuria asintomatica) $)^{44}$ è raccomandabile introdurre l'ASA a basso dosaggio (100 mg/die), preferibilmente assunta dal periodo preconcezionale o cominciata non più tardi della $16^{\circ}$ settimana di gestazione..$^{45}$

Nelle altre patologie con noto impegno vascolare (es. sclerosi sistemica, vasculiti) o con aumentato rischio trombotico (M. di Beçhet), sebbene non esistano dati a riguardo, andrà valutata una terapia con ASA a basso dosaggio e/o eparina (a dosaggio profilattico o terapeutico) in base all'anamnesi positiva/negativa per eventi trombotici. ${ }^{46}$

Considerato l'aumentato rischio di tromboembolismo venoso nel puerperio, tutte le pazienti ad aumentato rischio trombotico (positività per $\mathrm{aPL}$, rischio trombotico legato alla patologia reumatica o altri fattori di rischio generali) andranno profilassate con eparina a dosaggio profilattico per almeno sei settimane successive al parto.

\section{Conclusioni}

Le attuali evidenze scientifiche presentate in questa revisione ci mostrano che, nonostante i già citati limiti metodologici, oggi è possibile un trattamento farmacologico efficace delle malattie reumatiche con farmaci sicuri per il feto (Tabelle 1 e 2).

La maggior parte dei farmaci csDMARDs e boDMARDs - anti-TNF $\alpha$ possono essere utilizzati sia in gravidanza che in allattamento. Alcuni farmaci csDMARDs (MTX, MMF, ciclosfomide) sono teratogeni e quindi vanno sospesi prima del concepimento con un diverso periodo di wash out ( 6 settimane per il MMF, 3 mesi per il MTX e 6 mesi per la ciclofosfamide). Particolare attenzione merita l'HCQ che ha mostrato effetti benefici in gravidanza nelle pazienti con LES, ${ }^{12}$ APS ${ }^{12}$ e nelle donne positive per gli anticorpi Anti-Ro/SSA. ${ }^{14,15}$ Questo farmaco non dovrà essere sospeso se già in corso $\mathrm{o}$ andrà introdotto in caso di desiderio di gravidanza.

Alcuni DMARDs, soprattutto boDMARDs, sono attualmente sconsigliati non perché dannosi per il feto ma per mancanza di sufficiente documentazione. Nell'attesa di acquisire informazioni circa la sicurezza di utilizzo di un farmaco, è preferibile sconsigliarne l'uso. $\mathrm{Nel}$ caso in cui un certo farmaco sia l'unica opzione proponibile, con la paziente deve essere valutato e condiviso il rapporto rischio-beneficio. La paziente deve essere informata da parte del medico di ciò che si sa e non si sa riguardo all'utilizzo di un certo farmaco in gravidanza e allattamento, in modo tale che possa operare una scelta consapevole. E tenendo bene in mente che una malattia materna attiva e non controllata può essere dannosa per il nascituro, verosimilmente molto di più della esposizione al farmaco.

\section{Bibliografia}

1. Vinet E, Chakravarty EF, Clowse MEB. Power in numbers. Rheumatology (Oxford). 2018; 57: v40-71.

2. Østensen M. Preconception Counseling. Rheum Dis Clin North Am. 2017; 43: 189-199.

3. Flint J, Panchal S, Hurrell A, et al. BSR and BHPR guideline on prescribing drugs in pregnancy and breastfeeding-Part I: standard and biologic disease modifying anti-rheumatic drugs and corticosteroids. Rheumatology (Oxford). 2016; 55: 1693-7.

4. Götestam Skorpen C, Hoeltzenbein M, Tincani A, et al. The EULAR points to consider for use of antirheumatic drugs before pregnancy, and during pregnancy and lactation. Ann Rheum Dis. 2016; 75: 795-810.

5. Sammaritano LR, Bermas BL, Chakravarty EE, et al. American College of Rheumatology Guideline for the Management of Reproductive Health in Rheumatic and Musculoskeletal Diseases. Arthritis Care Res. 2020; 72 : 461-488.

5. Smolen JS, Landewé R, Breedveld FC et al. EULAR recommendations for the management of rheumatoid arthritis with synthetic and biological disease-modifying antirheumatic drugs: 2013 update. Ann Rheum Dis. 2014; 73: 492-509.

6. Østensen M, Förger F. Management of RA medications in pregnant patients. Nature reviews Rheumatology. 2009; 5: 382-90.

7. Østensen M, Khamashta M, Lockshin M et al. Anti-inflammatory and immunosuppressive drugs and reproduction. Arthritis Res Ther. 2006; 8: 209.

8. Dathe K, Padberg S, Hultzsch S et al. Exposure to cox2 inhibitors (coxibs) during the first trimester and pregnancy outcome: a prospective observational cohort study, 2017 European Journal of Clinical Pharmacology, 2018; 74: 489-95.

9. Bermas BL. Non-steroidal anti-inflammatory drugs, glucocorticoids and disease modifying anti-rheumatic drugs for the management of rheumatoid arthritis before and during pregnancy. Curr Opin Rheumatol. 2014; 26: 334-40. 
10. Palmsten K, Bandoli G, Vazquez-Benitez G, et al. Oral corticosteroid use during pregnancy and risk of preterm birth. Rheumatology (Oxford). 2019. doi: 10.1093/rheumatology/kez405 [Epub ahead of print].

11. Sciascia S, Hunt BJ, Talavera-Garcia E, et al. The impact of hydroxychloroquine treatment on pregnancy outcome in women with antiphospholipid antibodies. Am J Obstet Gynecol. 2016; 214: 273.e1-273.e8.

12. Seo MR, Chae J, Kim YM, et al. Hydroxychloroquine treatment during pregnancy in lupus patients is associated with lower risk of preeclampsia. Lupus. 2019; 28 : 722-730.

13. Izmirly PM, Costedoat-Chalumeau N, Pisoni CN, et al. Maternal use of hydroxychloroquine is associated with a reduced risk of recurrent anti-SSA/Ro-antibody-associated cardiac manifestations of neonatal lupus. Circulation 2012; 126: 76-82.

14. Barsalou J, Costedoat-Chalumeau N, Berhanu A, et al. Effect of hydroxychloroquine exposure on the development of 15. Ann Rheum Dis. 2018; 77: 1742-9.

15. https://www.pfizermedicalinformation.ca/en$\mathrm{ca} /$ methotrexate/warnings-and-precautions.

16. Bérard A, Zhao JP, Shui I, et al. Leflunomide use during pregnancy and the risk of adverse pregnancy outcomes. Ann Rheum Dis. 2018; 77: 500-9.

17. Cassina M, Johnson DL, Robinson LK, et al. Pregnancy outcome in women exposed to leflunomide before or during pregnancy. Arthritis Rheum. 2012; 64: 2085-94.

18. Chambers CD, Johnson DL, Robinson LK, et al. Birth outcomes in women who have taken leflunomide during pregnancy. Arthritis Rheum. 2010; 62: 1494-503.

19. Brownfoot FC, Hannan NJ, Cannon P, et al. Sulfasalazine reduces placental secretion of antiangiogenic factors, up-regulates the secretion of placental growth factor and rescues endothelial dysfunction. EBioMedicine. 2019; 41: 636-48

20. Hastie R, Brownfoot FC, Cannon P, et al. Sulfasalazine decreases soluble fms-like tyrosine kinase-1 secretion potentially via inhibition of upstream placental epidermal growth factor receptor signalling. Placenta. 2019; 87: 53-7.

21. Kearsley-Fleet L, Závada J, Hetland ML et al. The EULAR Study Group for Registers and Observational Drug Studies: comparability of the patient case mix in the European biologic disease modifying anti-rheumatic drug registers. Rheumatol Oxf Engl. 2015; 54; 1074-9.

22. Pergola PE, Kancharla A, Riley DJ. Kidney transplantation during the first trimester of pregnancy: immunosuppression with mycophenolate mofetil, tacrolimus and prednisone. Transplantation. 2001; 71; 994-7.

23. De Jong PH, Dolhain RJ. Fertility, Pregnancy, and 24. Rheum Dis Clin North Am. 2017; 43: 227-37.

24. Gerosa M, Argolini LM, Artusi C, et al. The use of biologics and small molecules in pregnant patients with rheumatic diseases. Expert Rev Clin Pharmacol. 2018; 11: 987-98.

25. https://farmaci.agenziafarmaco.gov.it/aifa/servlet/PdfDownloadServlet?pdfFileName=footer_001230_04526 $0 \_$FI.pdf\&retry $=0 \&$ sys $=\mathrm{m} 0 \mathrm{~b} 113$

26. Pfizer Inc. Xeljanz prescribing information. 2014. http://labeling. pfizer.com/ShowLabeling. aspx?id=959.

27. Clowse ME, Feldman SR, Isaacs JD, et al. Pregnancy Outcomes in the Tofacitinib Safety Databases for
Rheumatoid Arthritis and Psoriasis. Drug Saf. 2016; 39 : 755-62.

28. Mahadevan U, Dubinsky MC, Su C, Lawendy N, et al. Outcomes of Pregnancies With Maternal/Paternal Exposure in the Tofacitinib Safety Databases for Ulcerative Colitis. Inflamm Bowel Dis. 2018; 24: 2494-500.

29. Keating GM. Apremilast: a review in psoriasis and psoriatic arthritis. Drugs 2017; 77: 459-72.

30. Dhillon S. Tofacitinib: a review in rheumatoid arthritis. Drugs 2017; 77: 1987-2001.

31. Al-Salama ZT, Scott LJ. Baricitinib: a review in rheumatoid arthritis. Drugs 2018; 78: 761-72.

32. Taylor PC. Pharmacology of TNF blockade in rheumatoid arthritis and other chronic inflammatory diseases. Curr Opin Pharmacol. 2010; 10: 308-15.

33. Thalayasingam N, Isaacs JD. Anti-TNF therapy. Best Pract Res Clin Rheumatol. 2011; 25: 549-67.

34. Østensen M. The use of biologics in pregnant patients with rheumatic disease, Expert Review of Clinical Pharmacology. 2017; 10; 661-9.

35. Etanercept - Enbrel® - EMEA Scientific Discussion, 2004.

36. https://farmaci.agenziafarmaco.gov.it/aifa/servlet/PdfDownloadServlet?pdfFileName=footer_000720_03954 1_RCP.pdf\&sys $=$ m0b113

37. van den Brandt S, Zbinden A, Baeten D, et al. Risk factors for flare and treatment of disease flares during pregnancy in rheumatoid arthritis and axial spondyloarthritis patients. Arthritis Res Ther. 2017; 19: 64.

38. Zbinden A, van den Brandt S, Østensen M, et al. Risk for adverse pregnancy outcome in axial spondyloarthritis and rheumatoid arthritis: disease activity matters. Rheumatology (Oxford). 2018. doi: 10.1093/rheumatology/key053 [Epub ahead of print].

39. Mariette X, Förger F, Abraham B, et al. Lack of placental transfer of certolizumab pegol during pregnancy: results from CRIB, a prospective, postmarketing, pharmacokinetic study. Ann Rheum Dis. 2018; 77: 228-33.

40. Clowse ME, Förger F, Hwang C et al. Minimal to no transfer of certolizumab pegol into breast milk: results from CRADLE, a prospective, postmarketing, multicentre, pharmacokinetic study. Ann. Rheum. Dis. 2017; 76: 1890-96.

41. Vinet É, De Moura C, Pineau CA, et al. Infections in Rheumatoid Arthritis Offspring Exposed to Tumor Necrosis Factor Inhibitors: A Cohort Study. Arthritis Rheumatol. 2018; 70: 1565-71.

42. Milne F, Redman C, Walker J, et al. The pre-eclampsia community guideline (PRECOG): how to screen for and detect onset of pre-eclampsia in the community. BMJ 2005; 330: 576-80.

43. Milne F, Redman C, Walker J, et al. The pre-eclampsia community ASA guideline (PRECOG): how to screen for and detect onset of pre-eclampsia in the community. BMJ 2005; 330: 576-80.

44. Andreoli L, Bertsias GK, Agmon-Levin N, et al. EULAR recommendations for women's health and the management of family planning, assisted reproduction, pregnancy and menopause in patients with systemic lupus erythematosus and/or antiphospholipid syndrome. Ann Rheum Dis. 2017; 76: 476-85.

45. Machen, L, Clowse MEB. Vasculitis and Pregnancy. Rheumatic Disease Clinics of North America, 2017; 43 : 239-47. 


\title{
Il ruolo delle analisi di laboratorio nella gravidanza delle donne con malattie immunoreumatologiche
}

\author{
Francesca Bartoli, ${ }^{1}$ Cecilia Beatrice Chighizola ${ }^{2}$ \\ ${ }^{1}$ UO Allergologia e Immunologia Clinica, Ospedale Carlo Poma, ASST Mantova, Mantova; ${ }^{2}$ Laboratorio Sperimentale di Ricerche \\ ImmunoReumatologiche, IRCCS Istituto Auxologico Italiano, Cusano Milanino (MI), Italia
}

\section{Introduzione}

Le donne in gravidanza sono sottoposte ad esami di laboratorio a cadenza regolare, al fine di identificare precocemente alterazioni che potrebbero inficiare la salute materno-fetale. La valutazione dagli esami di laboratorio in donne gravide non può prescindere dalla consapevolezza delle variazioni che tali tests subiscono nel corso della gravidanza. Infatti, numerosi sono i cambiamenti fisiologici che, al fine di soddisfare le esigenze materne e fetali, si verificano fin dal concepimento fino alla gestazione tardiva. Tale adattamento fisiologico si riflette in cambiamenti significativi nei valori dei test di laboratorio. La corretta interpretazione degli esami di laboratorio in corso di gravidanza riveste una particolare rilevanza nelle donne affette da malattie reumatologiche, in cui numerose cause possono essere responsabili di alterazioni dei valori di laboratorio: non solo le complicanze gestazionali spesso osservate in gravidanze fisiologiche, ma anche le manifestazioni di malattia o gli effetti collaterali di farmaci. È importante ricordare che le modificazioni fisiologiche in gravidanza possono da un lato mascherare un flare di malattia; dall'altro lato una malattia in attività, seppur lieve, può inficiare le condizioni cliniche sia materne sia fetali, risultando in un aumento del rischio di complicanze ostetriche. La valutazione dell'attività di malattia nel corso della ge-

Corrispondente: Cecilia Beatrice Chighizola, Laboratorio Sperimentale di Ricerche ImmunoReumatologiche, IRCCS Istituto Auxologico Italiano, via Zucchi 18, 20095 Cusano Milanino (MI), Italia.

Tel.: +39.02.619112554 - Fax: +39.02.619113033.

E-mail: c.chighizola@auxologico.it

Articolo pubblicato secondo la Creative Commons Attribution NonCommercial 4.0 License (CC BY-NC 4.0).

${ }^{\circ}$ Copyright: the Author(s), 2021

Licensee PAGEPress, Italy

QUADERNI - Italian Journal of Medicine 2021; 9(4):e16 stazione va contestualizzata in base alla patologia di base: proteina $\mathrm{C}$ reattiva, livelli di complemento, titolo degli anti-dsDNA sono tra gli strumenti disponibili al clinico, che vanno ad implementare esami di routine quali emocromo, funzionalità epatica e renale, esame urine e glicemia. Il profilo autoanticorpale (in particolare anticorpi anti-fosfolipidi, anti-Ro ed anticorpi anti-tiroide) è da valutare in epoca pre-concezionale, in modo da stratificare il rischio di complicanze ostetriche ed impostare un attento monitoraggio delle stesse.

Questo capitolo fornisce gli strumenti utili per interpretare correttamente le principali analisi di laboratorio nelle pazienti con malattie reumatologiche in corso di gravidanza.

\section{Background}

Nel corso della gestazione, le donne sono sottoposte ad esami di laboratorio a cadenza regolare, al fine di identificare precocemente alterazioni che potrebbero inficiare la salute materno-fetale: anemia sideropenica, diabete gestazionale, ipertensione gestazionale, infezioni delle vie urinarie (IVU), per citare le evenienze più frequenti. È quindi consueta pratica clinica il controllo di esami di routine quali emocromo, funzionalità epatica e renale, esame urine e glicemia. Numerosi agenti infettivi possono arrecare un danno al nascituro, e pertanto è opportuno monitorare nel corso della gravidanza i marcatori sierologici. Ad esempio, donne con negatività del toxotest e del rubeotest sono sottoposte a controllo mensile della sierologia, per identificare tempestivamente una potenzialmente pericolosa infezione da Toxoplasma gondii, rubella virus e citomegalovirus. È invece sufficiente controllare in un'unica occasione, ad inizio gravidanza, la sierologia per il virus dell'epatite B e C, il virus dell'immunodeficienza umana (HIV) ed il Treponema pallidum, agente eziologico della sifilide. Analogamente, dopo l'accertamento dello stato di gravidanza, è corretto richiedere la tipizzazione del 
gruppo sanguigno con il fattore $\mathrm{Rh}$ ed il test di Coombs indiretto, che permette di rilevare anticorpi circolanti diretti contro l'antigene D del sistema Rhesus (Figura 1A). In caso di madre con Rh negativo e padre con Rh positivo, il feto può sviluppare la malattia emolitica del neonato (MEN); il test di Coombs indiretto è ripetuto mensilmente per tutta la durata della gravidanza così da evidenziare tempestivamente l'alloimmunizzazione eritrocitaria materna. ${ }^{1}$

Nel valutare gli esami di laboratorio in donne gravide, è necessario essere consapevoli delle variazioni che tali tests subiscono nel corso della gravidanza. Infatti, numerosi sono i cambiamenti fisiologici che si verificano durante la gravidanza, al fine di soddisfare le esigenze materne e fetali. ${ }^{1}$ Tale adattamento fisiologico inizia subito dopo il concepimento e continua fino alla gestazione tardiva, riflettendosi in cambiamenti significativi nei valori dei test di laboratorio che pertanto possono discostarsi dall'usuale range di riferimento.

Le donne affette da malattie reumatologiche possono sviluppare non solo le più comuni complicanze gestazionali già citate, ma anche manifestazioni cliniche dovute alla patologia autoimmune sistemica. Va inoltre ricordato che spesso le donne con diagnosi in ambito reumatologico sono sottoposte a terapie farmacologiche, che possono rendersi responsabili di effetti collaterali. Queste pazienti necessitano pertanto di un attento monitoraggio, che comprenda non solo i già citati esami

\section{A}
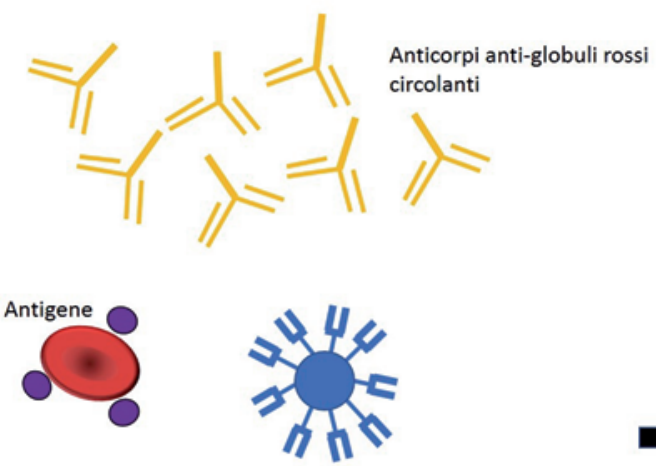

Reagente polispecifico anti-lgG
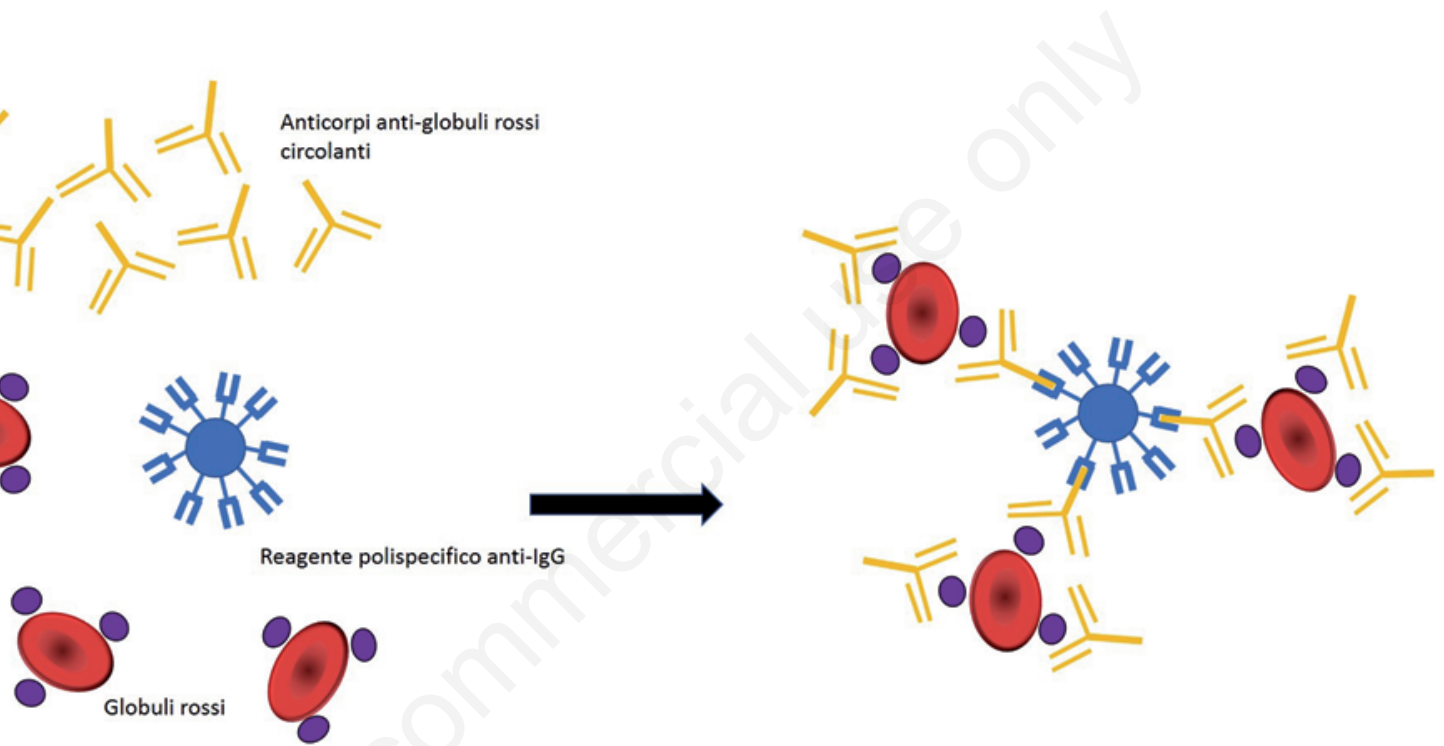

B
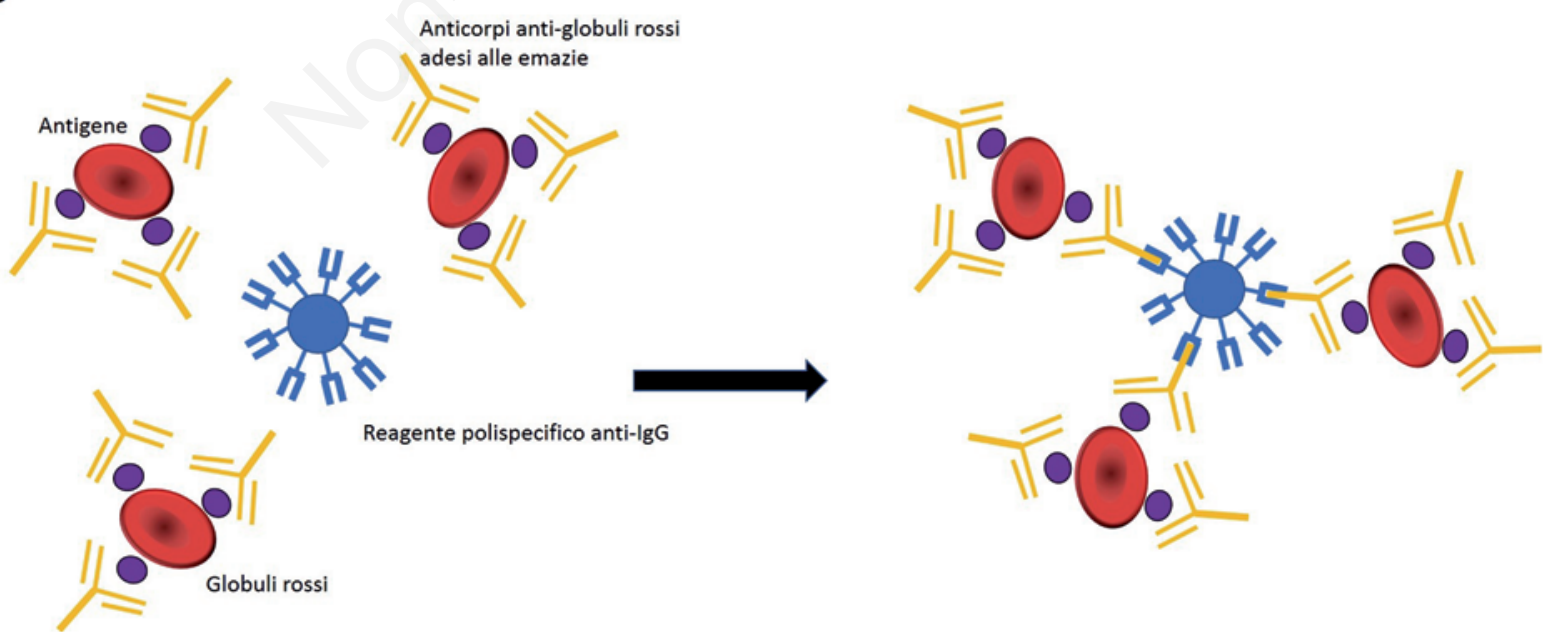

Figura 1. Test di Coombs. (A) Test di Coombs indiretto: globuli rossi sono incubati con il siero del paziente. Si aggiunge quindi il siero di Coombs. (B) Test di Coombs diretto: globuli rossi isolati dal sangue del paziente sono incubati con un reagente polispecifico anti-IgG umane (siero di Coombs). Il siero di Coombs è in grado di legare gli anticorpi adesi alla membrana dei globuli rossi. Questo legame determina l'agglutinazione dei globuli rossi con la formazione di un precipitato visibile nella provetta. 
di laboratorio previsti per le gravidanze fisiologiche ma anche accertamenti specifici per la patologia di base (ad esempio, profilo autoanticorpale, indici di flogosi, fattori del complemento; Tabella 1).

Questo capitolo fornisce gli strumenti utili per interpretare correttamente le principali analisi di laboratorio nelle pazienti con malattie reumatologiche in corso di gravidanza.

\section{Esame emocromocitometrico}

Durante la gravidanza fisiologica, alcuni parametri emocromocitometrici, quali l'emoglobina $(\mathrm{Hb})$ e le piastrine, tendono a diminuire mentre altri, come i globuli bianchi, aumentano. ${ }^{2}$

L'anemia è il problema ematologico più comune in corso di gravidanza: secondo le raccomandazioni stilate dall'Organizzazione Mondiale della Sanità nel 1968, si definiscono come anemia nella donna in stato di gravidanza valori di $\mathrm{Hb}$ inferiori a $11 \mathrm{~g} / \mathrm{L} .{ }^{3} \mathrm{~L}$ 'Hb si riduce gradualmente a partire dal I trimestre, raggiungendo valori minimi nel II trimestre, per poi incrementare nel corso del III trimestre. Tale andamento è verosimilmente da attribuire all'emodiluizione secondaria ad un aumento del volume plasmatico circolante. Queste fisiologiche modifiche emodinamiche sono secondarie all'assetto ormonale che viene ad instaurarsi in corso di gravidanza: il progesterone e gli estrogeni secreti dalla placenta causano un rilascio di renina a livello renale; quest'ultima stimola l'asse renina-angiotensina-aldosterone, portando alla ritenzione di sodio ed all'aumento del volume plasmatico. Il volume del plasma inizia ad incrementare già dopo 6 settimane di gestazione, e l'aumento può eccedere di oltre il 50\% le condizioni preconcezionali. Tali cambiamenti sono necessari per soddisfare le esigenze del letto vascolare placentare e fetale, oltre che per proteggere la madre dalle perdite di sangue che si verificano al momento del parto. In corso di gravidanza si osserva anche un aumento del numero di globuli rossi totali, per un aumento della produzione materna di eritropoietina; tuttavia, questo fenomeno avviene in misura minore rispetto all'incremento del volume plasmatico, il che si traduce in una riduzione sia dei valori di $\mathrm{Hb}$ sia dell'ematocrito. Come anticipato, nel III trimestre si assiste alla risalita di entrambi i parametri per aumento della produzione di peptide natriuretico atriale a fronte di un'ascesa del volume plasmatico a ritmo più lento. Inoltre, va ricordato che il declino dell' $\mathrm{Hb}$ durante la gravidanza può essere dovuto ad una maggiore domanda di ferro, sia per l' $\mathrm{Hb}$ materna sia per le esigenze di crescita fetale, spesso inadeguatamente soddisfatta dall'assunzione dietetica. È importante prevenire e trattare adeguatamente la carenza marziale in donne gravide, data la correlazione dell'anemia sideropenica con basso peso alla nascita, parto pre-termine e mortalità peri-natale. La ferritina rimane il test più accurato per valutare l'entità del deficit marziale anche nel corso della gestazione. In donne gravide non anemiche, un valore di ferritina inferiore a $15 \mathrm{ng} / \mathrm{mL}$ è considerato suggestivo di carenza marziale; alcuni autori ritengono più appropriato definire il deficit di ferro al di sotto dei $40 \mathrm{ng} / \mathrm{mL}$.

$\mathrm{La}$ trombocitopenia gestazionale è per frequenza il secondo problema ematologico osservato in gravidanze fisiologiche; ${ }^{2}$ il calo delle piastrine può essere ascritto sia all'attivazione sia all'aumentata clearance durante la gestazione. Sebbene si assista nei mesi ad

Tabella 1. Monitoraggio con esami di laboratorio delle gravidanze in donne con patologie reumatologiche.

\begin{tabular}{ll}
\hline Frequenza & Esami di laboratorio \\
\hline Prima del concepimento & Emocromo \\
& Funzionalità epatica \\
& Funzionalità renale con esame urine \\
& Funzionalità tiroidea \\
& Anticorpi anti-tiroide \\
& Anticorpi anti-fosfolipidi \\
& ANA \\
& ENA \\
& Ferritina \\
\hline Al concepimento & Sierologia HIV, HBV, HCV, sifilide, CMV, toxotest*, rubeotest* \\
\hline Mensilmente & \\
& Emocromo \\
& Funzionalità epatica \\
& Funzionalità renale con esame urine \\
& Funzionalità tiroidea \\
In base alla patologia di base, mensilmente & Glicemia \\
\hline & PCR \\
& Complemento \\
& Anti-dsDNA \\
& Proteinuria 24 ore \\
\hline
\end{tabular}

*Da ripetersi mensilmente se sierologia negativa; ${ }^{\circ}$ da ripetersi più spesso in caso di necessità clinica. 
una riduzione graduale della conta piastrinica, generalmente la trombocitopenia gestazionale non richiede alcun trattamento specifico e si corregge spontaneamente dopo il parto. Una piastrinopenia severa (definita come conta piastrinica inferiore a $50.000 \mathrm{~mm}^{3} \mathrm{o}$ associata a sanguinamento) o una piastrinopenia instauratasi acutamente sono da considerarsi patologiche e necessitano di adeguato trattamento.

La leucocitosi è dovuta ad un'aumentata risposta infiammatoria durante la gravidanza, secondaria all'instaurarsi di una tolleranza immunitaria selettiva e all'immunomodulazione del feto. ${ }^{2}$ L'aumento del numero dei globuli bianchi è principalmente causato da un aumento della conta dei granulociti neutrofili circolanti, da ascriversi alla ridistribuzione dei globuli bianchi all'interno dei vasi ed alla ridotta apoptosi di tali cellule. L'aumento delle forme immature circolanti (circa il 20\% delle donne nel II e III trimestre presenta mielociti e metamielocociti circolanti) riflette un'adeguata risposta midollare alla spinta eritropoietica che si instaura durante la gravidanza.

In corso di LES, frequente è l'interessamento ematologico. La manifestazione più comune è l'anemia emolitica autoimmune, dovuta alla produzione di anticorpi diretti contro i globuli rossi in grado di determinarne la lisi o l'aumentata clearance splenica. Tale condizione deve essere sospettata in occasione di anemizzazione acuta, soprattutto quando associata all'aumento dei livelli sierici di LDH e della bilirubina indiretta e presenza di urobilinogeno urinario, e trattata tempestivamente per evitare danni gravi alla madre e al feto. La ricerca di questi anticorpi avviene tramite l'esecuzione del test di Coombs diretto (Figura 1B). Il fisiologico aumento dei globuli bianchi negli ultimi mesi di gravidanza potrebbe mascherare una leucopenia secondaria ad un flare di malattia in corso di LES; pertanto, la linfopenia, e non la leucopenia, risulta essere l'indicatore maggiormente sensibile dell'attività di LES in gravidanza. ${ }^{4}$

La trombocitopenia è tra le più frequenti manifestazioni 'non criterio' della sindrome da anticorpi antifosfolipidi (APS) e le pazienti che ne sono affette presentano in corso di gravidanza una conta piastrinica significativamente ridotta rispetto a donne sane. È interessante notare che, secondo uno studio recente, la conta piastrinica sembra avere un valore predittivo per lo sviluppo di preeclampsia in pazienti gravide affette da APS. ${ }^{5}$

\section{Indici di flogosi}

Gli indici di flogosi abitualmente utilizzati nella pratica clinica reumatologica comprendono la velocità di eritrosedimentazione (VES), la proteina $\mathrm{C}$ reattiva (PCR) e la calprotectina fecale. È noto come la VES aumenti in corso di gravidanza fisiologica (soprattutto nel II e III trimestre), verosimilmente per effetto dell'aumento del fibrinogeno circolante e dello stato di anemia che frequentemente si instaura. Pertanto le sue alterazioni sono prive di significato anche in pazienti con patologie immunoreumatologiche. ${ }^{6}$ Risulta quindi più utile il dosaggio della PCR; ${ }^{7}$ la maggior parte degli autori afferma, infatti, che la PCR rimanga invariata in corso di gravidanze fisiologiche. Tuttavia, il valore di PCR può risultare quadruplicato nell'immediato postpartum dopo un normale parto vaginale ${ }^{8}$ e raggiungere valori ancor più elevati in seguito a parto cesareo. ${ }^{9}$ Pertanto, ad eccezione del peripartum, la PCR mantiene la sua attendibilità in gravidanza, essendo quindi molto utile nel monitoraggio delle patologie reumatiche caratterizzate da elevata flogosi sistemica in fase attiva (ad esempio, vasculiti e malattie autoinfiammatorie). I livelli di calprotectina fecale rimangono invariati in corso di gravidanza nelle pazienti sane. Un incremento di calprotectina, invece, correla con l'attività di malattia nelle donne gravide affette da malattia infiammatoria cronica intestinale, ${ }^{10}$ in maniera decisamente più specifica e sensibile rispetto alla PCR.

\section{Funzionalità renale}

Nel primo trimestre di gravidanza, il flusso plasmatico renale e la filtrazione glomerulare aumentano di circa il $60 \%$ rispetto ai valori pre-concepimento, di conseguenza si assiste ad una riduzione del $25 \%$ dei valori di creatinina sierica ed urea. Nel III trimestre, invece, il flusso plasmatico renale tende a ridursi e i valori di creatinina a stabilizzarsi su valori pari a quelli preconcezionali. È importante quindi riconoscere che valori normali di creatinina, cioè nei limiti di normalità per sesso ed età al di fuori di una gravidanza, possono rappresentare una condizione di insufficienza renale in corso di gravidanza. Analogamente, bisogna aspettarsi un peggioramento della creatinina nel II e III trimestre in quelle donne che intraprendono una gravidanza con funzione renale alterata al basale. Tale peggioramento generalmente tende a rientrare nel post-partum, spesso assestandosi su valori superiori rispetto al basale. ${ }^{11}$ Durante la gravidanza, in particolare dopo la XX settimana gestazionale, si assiste inoltre ad un aumento dell'albuminuria e della proteinuria, comunemente attribuite all'aumento del filtrato glomerulare, anche se con una cinetica non parallela. ${ }^{11} \mathrm{Il}$ dosaggio delle proteine urinarie dovrebbe, quando possibile, essere eseguito sulle urine delle 24 ore; in alternativa il calcolo del rapporto tra proteine e creatinina urinarie su urine spot sembra essere una buona stima della proteinuria giornaliera, senza essere influenzato dall'ora del giorno in cui viene eseguito. ${ }^{12}$ Le donne che intraprendono una gravidanza con un certo grado di proteinuria, qualunque essa sia, corrono il rischio di incorrere in un incremento significativo 
della proteinuria, rendendo la diagnosi di una eventuale preeclampsia sovrapposta estremamente difficile. ${ }^{13}$ L'esame urine in corso di gravidanza mostra spesso ematuria microscopica, più comunemente segno di IVU. È stato suggerito che il riscontro di ematuria all'esame urine possa essere predittivo dello sviluppo di preeclampsia ed ipertensione gestazionale, ma non sono ancora disponibili dati conclusivi.

Da un lato, l'instaurarsi di una gravidanza può modificare l'evoluzione di una nefropatia cronica preesistente, dall'altro un pre-esistente danno renale cronico o l'insorgenza di una nefropatia acuta possono avere ripercussioni sull'evoluzione di una gravidanza. Alcune delle patologie immunoreumatologiche, prima tra tutte il LES ma anche l'amiloidosi secondaria ad artrite idiopatica giovanile (AIG) sistemica o sindrome autoinfiammatoria, sono spesso caratterizzate da interessamento renale di vario grado che può esordire o peggiorare in corso di gravidanza. Non bisogna inoltre dimenticare come alcuni dei farmaci abitualmente utilizzati nella pratica clinica reumatologica (ad esempio, farmaci anti-infiammatori non steroidei e ciclosporina A) possano influenzare la funzionalità renale, soprattutto quando l'utilizzo è cronico e protratto nel tempo.

Una nefrite lupica attiva al momento del concepimento è associata ad un outcome gravidico peggiore, ${ }^{14}$ la gravidanza va pertanto pianificata in donne con nefrite non attiva da almeno 6 mesi, un rapporto proteine-creatinina nelle urine inferiore a 50 $\mathrm{mg} / \mathrm{mmol}$ e funzionalità renale e pressione sanguigna nei limiti di norma. ${ }^{15}$

Un'anamnesi positiva per nefrite lupica o un flare renale di LES in gravidanza rappresentano fattori di rischio per preeclampsia e sindrome HELLP (dall'inglese hemolysisis, elevated liver enzyme levels and low platelet count). Va ricordato come spesso la diagnosi differenziale tra l'impegno renale da lupus e la preeclampsia rappresenti una sfida per il clinico, sebbene nel primo caso l'ipertensione ed una proteinuria di nuova insorgenza o in aumento si associno ad un consumo del complemento, aumento del titolo di anticorpi anti-DNA a doppio filamento ed ematuria con cilindruria (anti-dsDNA, Tabella 2). ${ }^{16}$

Data la complessità delle variabili da considerare e i possibili rischi per la madre e il nascituro, è necessario che le pazienti con LES caratterizzato da coinvolgimento renale intraprendano un personalizzato counselling preconcezionale e, in caso di gravidanza, vengano seguite da un'equipe multidisciplinare che includa ostetrico, nefrologo e reumatologo.

\section{Funzionalità epatica}

Nel corso della gravidanza fisiologica, la funzionalità epatica, così come l'aspetto istologico epatico, non risulta sostanzialmente modificata. Tuttavia, è possibile osservare variazioni della concentrazione sierica di alcune delle principali proteine prodotte dal fegato e modificazioni di alcuni dei principali test di funzionalità epatica. Durante la gravidanza, infatti, è stato descritto un aumento della concentrazione sierica della fosfatasi alcalina, dovuto alla produzione dell'enzima placentare e nel III trimestre anche dell'enzima osseo. ${ }^{17} \mathrm{Si}$ riduce invece la concentrazione della gamma glutamil transferasi $(\gamma \mathrm{GT})$. La concentrazione delle transaminasi sieriche (AST e ALT) è sostanzialmente invariata; la bilirubina totale e le sue frazioni sono immodificate e tendono ad una lieve riduzione nel terzo trimestre di gestazione. Il tracciato elettroforetico tende a modificarsi: le proteine totali e l'albumina sierica sono sensibilmente ridotte. A tale proposito, è stato ipotizzato un aumentato catabolismo dell'albumina per permettere il passaggio al feto di aminoacidi. ${ }^{18}$ Aumentano invece $\beta 2$-globuline e $\gamma$-globuline, mentre si riduce il rapporto albumina/globuline. ${ }^{19}$ Il colesterolo e i trigliceridi aumentano progressivamente fino al termine di gravidanza.

Un'importante causa di elevazione acuta delle transaminasi in gravidanza è rappresentata dalla sindrome HELLP, ${ }^{20}$ una severa complicanza che è associata alla positività per gli anticorpi anti-fosfolipidi (aPL). In corso di HELLP, gli esami di laboratorio mostrano emolisi, piastrinopenia severa e rialzo marcato delle transaminasi. Può comparire un danno multiorgano ed innescarsi una coagulazione intravascolare disseminata. In caso di ipertransaminasemia gravidica, la diagnosi differenziale dovrebbe contemplare sia la porpora trombotica trombocitopenica che la sindrome HELLP; a questo proposito, un rapporto LDH/AST maggiore di 22 può essere utile per distinguere le due condizioni. ${ }^{21,22}$ Un'ipoalbuminemia in gravidanza potrebbe essere secondaria ad un coinvolgimento renale in corso di LES se associata a proteinuria; nel classico quadro di preeclampsia, coesistono ipertensione arteriosa ed edemi discrasici. Un aumento acuto della ALP

Tabella 2. Diagnosi differenziale tra preeclampsia e nefrite lupica.

\begin{tabular}{lll}
\hline Caratteristiche comuni & Preeclampsia & Nefrite lupica \\
\hline Ipertensione arteriosa & Incremento transaminasi & Titolo anti-dsDNA in aumento \\
Proteinuria & Incremento acido urico & Riduzione livelli di C3 e C4 \\
Trombocitopenia & & Eritrociti o cilindri all'esame urine \\
Insufficienza renale &
\end{tabular}


può, infine, indicare un danno o un infarto placentare ${ }^{23}$ elevati livelli di ALP sono stati riscontrati anche in corso di APS in assenza di complicanze ostetriche. ${ }^{24}$

\section{Coagulazione}

$\mathrm{Al}$ fine di prevenire sanguinamenti durante la gestazione e nel post-partum, la bilancia dello stato emostatico in gravidanza risulta inclinata verso una condizione di ipercoagulabilità: ${ }^{25}$ si osserva infatti l'aumento di fattori procoagulanti, la riduzione di fattori anticoagulanti e una ridotta fibrinolisi; il fibrinogeno e i fattori VII, VIII, IX e X della coagulazione risultano aumentati mentre la protrombina e l'antitrombina III sono sostanzialmente stabili. Tale stato pro-trombotico è all'apice nel peri-partum: donne di età superiore ai 35 anni hanno un rischio 1,28 volte maggiore di sviluppare una trombosi; donne con una anamnesi positiva per eventi vascolari hanno una seconda trombosi nel $10,9 \%$ dei casi. ${ }^{25}$ Tali dati vanno adeguatamente considerati nella gestione clinica nel peri-partum di donne con patologie reumatologiche, in particolare se positive per aPL.

\section{Funzione tiroidea}

Numerose modificazioni fisiologiche della funzione tiroidea si verificano in corso di gravidanza: i) riduzione dei valori circolanti di ormone tireostimolante (TSH) nel primo trimestre per effetto dell'incremento della $\gamma$-HCG, dotata di azione TSH-mimetica e pertanto stimolante la funzione tiroidea ed inibente, per la controregolazione da parte degli ormoni tiroidei, la funzione ipofisaria con diminuita secrezione di TSH; ii) aumento della produzione epatica della globulina legante la tiroxina (TBG), come diretta conseguenza dell'incremento della concentrazione estrogenica, con conseguente incremento degli ormoni totali e riduzione delle frazioni libere; tale aumento inizia entro le prime settimane e raggiunge il valore massimo intorno al IV$\mathrm{V}$ mese di gravidanza. Questi cambiamenti suggeriscono come la gravidanza rappresenti una condizione di stress per la tiroide, in grado di slatentizzare un ipotiroidismo subclinico. Nelle donne in trattamento sostitutivo con tiroxina prima del concepimento, la gravidanza rende necessario un aumento della dose di 1-tiroxina di circa il $30 \%$

Tra le patologie tiroidee l'autoimmunità rappresenta il fattore eziologico più importante (morbo di Graves nelle forme ipertiroidee e tiroidite di Hashimoto nell'ipotiroidismo). Le malattie reumatologiche autoimmuni (in particolare le connettiviti sistemiche) sono frequentemente associate a disordini tiroidei autoimmuni, soprattutto nelle donne in età fertile. ${ }^{26} \mathrm{En}$ trambe le condizioni possano essere responsabili di complicanze gravidiche (aborto, ritardo di crescita intrauterina e parto pretermine). È stato proposto che la positività per anticorpi anti-tiroide possa aumentare il rischio di eventi avversi in donne con malattie reumatiche. ${ }^{27}$ Pertanto, è necessario valutare l'autoimmunità tiroidea (anticorpi diretti contro la tireoperossidasi [TPO], la tireoglobulina [TG] ed il recettore del TSH [TSHr]) regolarmente nelle donne in gravidanza con malattia immunoreumatologica.

\section{Controllo glicemico}

La gravidanza è caratterizzata da un complesso rimaneggiamento endocrino-metabolico finalizzato a garantire il necessario apporto di nutrienti al feto ed a preparare adeguatamente l'organismo materno al parto ed alla lattazione. Le principali modificazioni metaboliche che si osservano in gravidanza si possono riassumere in una riduzione della sensibilità insulinica, un modesto aumento delle glicemie, soprattutto postprandiali, ed una alterazione dei livelli circolanti di acidi grassi liberi, dei trigliceridi, del colesterolo e dei fosfolipidi. L'insulinoresistenza, che compare soprattutto nella seconda metà della gestazione, fa della gravidanza una condizione diabetogena; tuttavia, il diabete gestazionale compare solo in concomitanza di fattori predisponenti di natura genetica e/o ambientale. L'espletamento del parto è spesso seguito dalla normalizzazione della tolleranza glucidica. Il diabete gestazionale interessa il 3-10\% delle donne ${ }^{28}$ e si associa ad un aumentato rischio di morbilità del feto e del neonato; questa percentuale tende ovviamente ad aumentare nelle pazienti con malattie immunoreumatologiche. Consolidati dati della letteratura confermano come non siano le malattie reumatologiche di per sé ad aumentare il rischio di diabete gestazionale, ma soprattutto l'uso di corticosteroidi in corso di gravidanza, ${ }^{29,30}$ con un rischio peraltro proporzionale alla dose giornaliera assunta. In donne in terapia cronica con steroidi, è opportuno monitorare attentamente la glicemia; è possibile anticipare la minicurva da carico di glucosio, abitualmente prescritta tra la XXIV e la XXVIII settimana gestazionale.

\section{Complemento}

Il sistema del complemento è composto da più di 50 proteine e normalmente opera ad un livello di attivazione a basso regime; la cascata del complemento può essere amplificata seguendo 3 noti percorsi di attivazione (Figura 2).

Numerosi sono i riarrangiamenti del sistema immunitario, sia innato sia adattativo, che si verificano in gravidanza, al fine di garantire la tolleranza verso il prodotto del concepimento e difendere madre e feto da 
eventuali agenti esterni; questi adattamenti riguardano anche il sistema del complemento. ${ }^{31}$

Inoltre, dati recenti indicano l'importanza del sistema del complemento nell'orchestrare una normale placentazione ed il decorso regolare della gravidanza. ${ }^{32}$

I livelli sierici dei fattori del complemento in gravidanza tendono ad aumentare lievemente, soprattutto nel corso del III trimestre. Nel 2010 Derzsy e colleghi hanno valutato le modifiche del sistema del complemento in donne non gravide e donne sane in gravidanza, dosando i livelli circolanti di complemento e dei suoi prodotti di attivazione $(\mathrm{C} 4 \mathrm{~d}, \mathrm{C} 3 \mathrm{a}, \mathrm{sC} 5 \mathrm{~b}-9)$ e regolazione (fattore $\mathrm{H}$ ). ${ }^{33}$ In gravidanze normali, a 36-37 settimane di gestazione, le concentrazioni di C4d, C3a, sC5b-9, $\mathrm{C} 3, \mathrm{C} 9$ e fattore $\mathrm{H}$ erano maggiori nelle donne non gravide, mentre il $\mathrm{C} 1$ inibitore risultava più basso; l'aumento nel rapporto $\mathrm{C} 4 \mathrm{~d} / \mathrm{C} 4$, del rapporto $\mathrm{C} 3 \mathrm{a} / \mathrm{C} 3$ e del sC5b-9 confermava un aumento dell'attivazione del complemento tramite la via classica o lectinica in corso di gravidanza normale, senza significative alterazioni della via alterna.

I componenti del complemento sono principalmente sintetizzati dal fegato, ma essi possono anche essere sintetizzati localmente in numerosi tessuti, compresa la placenta. A livello placentare il sangue materno incontra il tessuto fetale semiallogenico (sinciziotrofoblasto): in tale sede, è evidente un'importante produzione di fattori regolatori/inibitori del sistema complementare con un gradiente inversamente proporzionale alla vicinanza con il sangue materno (sinciziotrofoblasto e citotrofoblasto extravilloso si caratterizzano per maggior sintesi di CD46, CD55 e CD59, necessitando questi tessuti di maggior protezione dall'attivazione del complemento materno). ${ }^{34}$ Nonostante la presenza di regolatori del complemento nella placenta, un certo grado di attivazione complementare si verifica a livello placentare anche in gravidanze fisiologiche. ${ }^{35,36}$

Il dosaggio del complemento in corso di gravidanza riveste un ruolo importante in donne affette da LES. I flares di malattia in corso di lupus generalmente si caratterizzano per riduzione dei livelli di $\mathrm{C} 3$ e C4. ${ }^{37}$ Questo dato, durante la gravidanza, può essere utile per una corretta diagnosi differenziale con la preeclampsia grave, caratterizzata da un'importante attivazione complementare con aumento dei prodotti di clivaggio del complemento ma solo modesto consumo di $\mathrm{C} 3$ e $\mathrm{C} 4$ (elevato rapporto di $\mathrm{C} 3 \mathrm{a} / \mathrm{C} 3$ e $\mathrm{C} 4 \mathrm{~d} / \mathrm{C} 4$ ). ${ }^{33}$ Le pazienti lupiche possono però presentare ridotti livelli di $\mathrm{C} 3 \mathrm{e}$ $\mathrm{C} 4$ rispetto a soggetti sani anche al di fuori di una riacutizzazione; è fondamentale, perciò, monitorare le fluttuazioni dei valori complementari mediante frequenti determinazioni per tutta la durata della gravidanza.

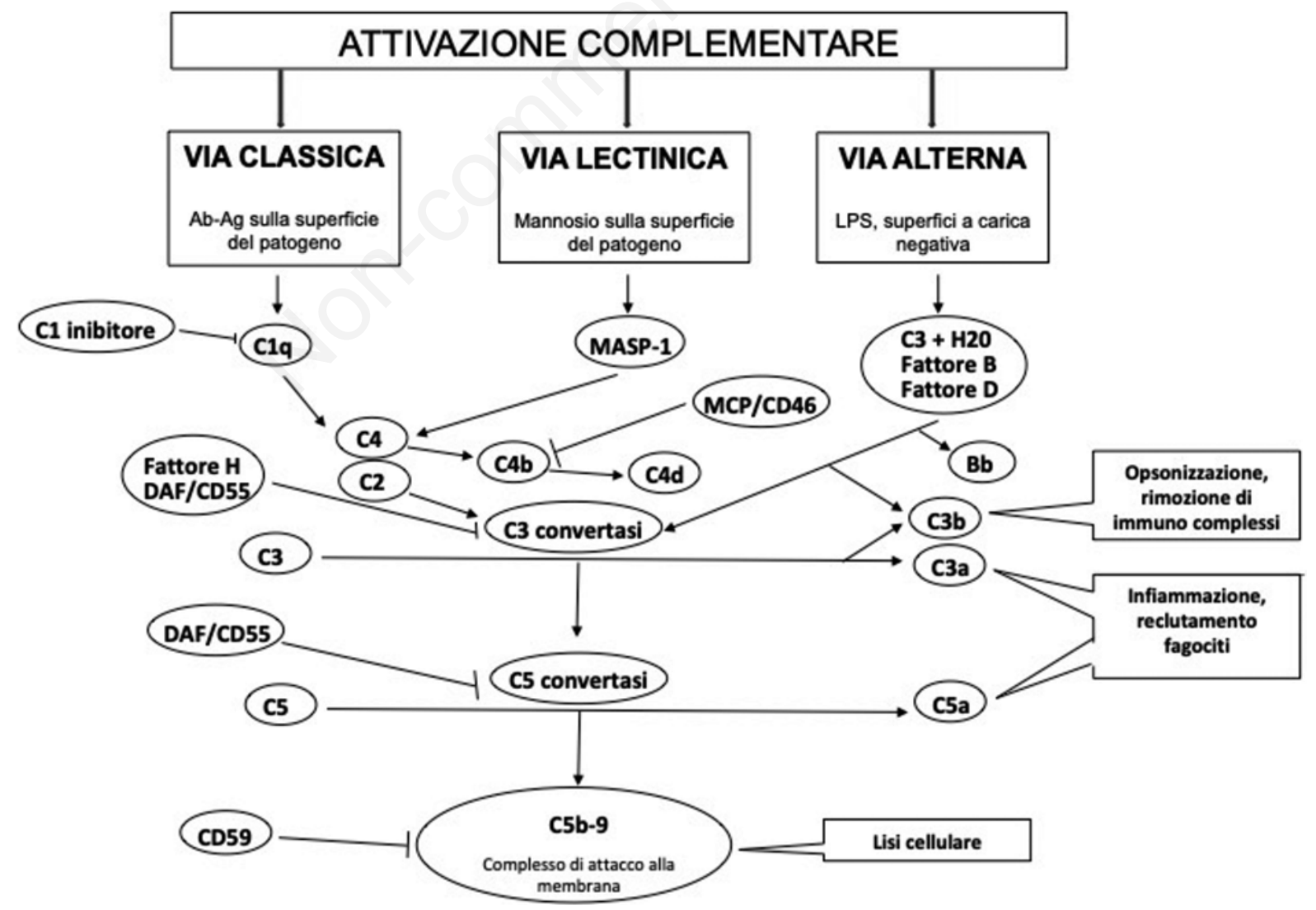

Figura 2. Cascata del complemento. 
Più dibattuto il significato del monitoraggio dei livelli di complemento in pazienti gravide affette da APS. Donne gravide con positività per aPL presentano livelli ridotti di $\mathrm{C} 3$ e C4, seppur in assenza di una chiara associazione con le complicanze ostetriche. Più recentemente, si è osservato un aumento dei prodotti di attivazione $\mathrm{Bb}$ e $\mathrm{C} 5 \mathrm{~b}-\mathrm{C} 9$, suggerendo l'attivazione della via alterna. L'analisi istologica di placenta da donne aPL-positive ha dimostrato in due studi il deposito di C4d ed, in misura minore, di C3d. Del resto, il potenziale ruolo del complemento come marcatore nelle gravidanze in donne con APS è suggerito dall'importante ruolo patogenetico che l'attivazione del complemento svolge in questa patologia, come evidenziato nei modelli animali: topi gravidi deficienti per $\mathrm{C} 3, \mathrm{C} 5$, o per il recettore del C5a sono resistenti all'aborto indotto dal trattamento con aPL. ${ }^{38}$

\section{Autoanticorpi}

La ricerca degli autoanticorpi riveste un ruolo rilevante in reumatologia. La maggior parte degli autoanticorpi presenta un significato diagnostico e prognostico (ad esempio, fattore reumatoide [FR], anticorpi antipeptidi ciclici citrullinati [ACPA], anticorpi anti-nucleo [ANA]). Variazioni del titolo autoanticorpale eventualmente evidenziabili in corso di gravidanza non sono risultate correlate né all'attività di malattia né al rischio di eventi avversi materno-fetali, pertanto non è consigliabile il monitoraggio in paziente gravide che abbiano già ricevuto una diagnosi di patologia reumatologica.

La determinazione quantitativa del titolo degli antidsDNA tramite metodiche immunometriche è strumento estremamente utile nel monitoraggio clinico di pazienti affetti da LES; un incremento del titolo anticorpale è risultato predittivo dello sviluppo di interessamento renale.$^{39}$ Analogamente, il titolo degli anticorpi anti-dsDNA nelle pazienti lupiche in corso di gravidanza merita attenzione clinica. ${ }^{40}$ Infatti, un incremento del titolo degli anti-dsDNA nel secondo trimestre di gravidanza, soprattutto se l'aumento si registra in più determinazioni consecutive $\mathrm{o}$ in presenza di bassi livelli di complemento, è stato associato ad un più alto tasso di perdita fetale e di parto pretermine, indipendentemente dall'attività di malattia clinicamente evidente. ${ }^{41}$ Pertanto, ipocomplementemia ed incremento del titolo degli anti-dsDNA sono in grado di predire l'outcome gravidico ed è fondamentale che vengano ripetuti mensilmente in queste pazienti. ${ }^{42}$

Nelle pazienti con APS, la stratificazione del rischio di ulteriori complicanze gravidiche si basa, sebbene non esclusivamente, sul profilo autoanticorpale: triplice positività, positività per l'anticoagulante lupico (LA), un titolo anticorpale medio-alto e la presenza di isotipo IgG definiscono un profilo ad alto rischio. ${ }^{43}$ Il PROMISSE, uno studio osservazionale prospettico multicentrico su donne gravide con diagnosi di LES o APS, ha dimostrato che, sebbene il titolo anticorpale degli aPL tenda a ridursi leggermente nel corso della gravidanza, questa modificazione sia del tutto priva di significato clinico. ${ }^{44}$ Analogamente, è evenienza rara che aPL negativi nel I trimestre si positivizzino nei mesi successivi, suggerendo la sostanziale inutilità di dosaggi seriati degli aPL nel corso della gravidanza. In considerazione dell'alta prevalenza di aPL in pazienti con patologie reumatologiche, è opportuno testare questi anticorpi in tutte le donne in epoca preconcezionale. Inoltre, le donne affette da malattie reumatologiche, in particolare con diagnosi di LES, sindrome di Sjögren o altre connettiviti, devono essere sottoposte alla ricerca di anticorpi diretti contro gli antigeni nucleari estraibili (ENA), al fine di rilevare una reattività contro gli antigeni Ro/SS-A e $\mathrm{La} / \mathrm{SS}-\mathrm{B} .{ }^{45}$ A partire dalla XVI settimana di gestazione, il sinciziotrofoblasto esprime il recettore per la porzione Fc degli anticorpi, permettendo il passaggio transplacentare degli anticorpi materni. Il trasferimento degli anti-Ro al feto può risultare in una serie di complicanze, di cui la più temibile è il blocco cardiaco congenito. Gli anticorpi materni possono legare tramite un meccanismo di cross-reattività epitopi espressi su canali ionici cardiaci fetali, inducendo un sovraccarico intracellulare di calcio, dunque l'apoptosi. ${ }^{46}$ Questo danno cellulare è in grado di determinare un blocco atrioventricolare (BAV) di I grado, il quale -in base a fattori di infiammazione locale e suscettibilità fetale- può risolversi o peggiorare sino all'irreversibile BAV di III grado. È stato stimato che una donna con anti-Ro abbia un rischio di un feto con blocco cardiaco congenito pari all' $1-2 \%$, una percentuale che sale a circa il $20 \%$ se la madre presenta anamnesi positiva per un figlio con blocco cardiaco congenito. ${ }^{47,48}$ Sebbene si tratti un'evenienza molto rara, è fondamentale che medico e paziente siano a conoscenza di questo rischio al fine di poter impostare un'adeguata sorveglianza con ecocardiografia fetale in corso di gravidanza. Questa forma di autoimmunizzazione passiva più frequentemente causa il lupus neonatale: il rischio nei figli di una madre con anti-Ro è di circa il $25 \%$ alla prima gravidanza. Il lupus neonatale può caratterizzarsi per una o più tra le seguenti manifestazioni: rash cutaneo, trombocitopenia ed alterazione degli enzimi epatici. ${ }^{45}$ Tali manifestazioni cliniche sono transitorie, regredendo dopo i canonici 46 mesi necessari perché il neonato smaltisca gli anticorpi materni acquisiti.

\section{Conclusioni}

Gli esami di laboratorio rivestono una notevole importanza nel monitoraggio della gravidanza in donne affette da patologie reumatologiche. Il profilo autoanticorpale, in particolare aPL, anti-Ro ed anticorpi antitiroide, andrebbe valutato in epoca pre-concezionale 
in tutte le pazienti, in modo da stratificare il rischio di complicanze ostetriche ed impostare un corretto monitoraggio delle stesse. La valutazione dell'attività di malattia nel corso della gestazione va contestualizzata in base alla patologia di base: PCR, livelli di complemento, titolo degli anti-dsDNA sono tra gli strumenti disponibili al clinico. La corretta interpretazione degli esami di laboratorio in corso di gravidanza riveste una particolare rilevanza nelle donne affette da malattie reumatologiche: le modificazioni fisiologiche in gravidanza possono mascherare un flare di malattia; dall'altro lato una malattia in attività, seppur lieve, può inficiare le condizioni cliniche sia materne sia fetali, risultando in un aumento del rischio di complicanze ostetriche. In donne con patologie reumatologiche, le alterazioni dei valori di laboratorio richiedono un'attenta diagnosi differenziale, che prenda in considerazione non solo le complicanze gestazionali descritte spesso anche in gravidanze fisiologiche, ma soprattutto le manifestazioni di malattia o gli effetti collaterali di farmaci. Appare dunque chiara la complessità del compito che spetta ai clinici deputati a seguire le gravidanze in donne con patologie reumatologiche, complessità che rende altamente necessario l'approccio multi-disciplinare.

\section{Bibliografia}

1. Teasdale S, Morton A. Changes in biochemical tests in pregnancy and their clinical significance. Obstet Med 2018;11:160-170.

2. Li A, Yang S, Zhang J, Qiao R. Establishment of reference intervals for complete blood count parameters during normal pregnancy in Beijing. J Clin Lab Anal 2017;31(6).

3. WHO. Nutritional anaemias. In: WHO Technical Report Series. No 405; Geneve, 1968.

4. Ruiz-Irastorza G, Khamashta MA. Evaluation of systemic lupus erythematosus activity during pregnancy. Lupus 2004;13:679-682.

5. Mayer-Pickel K, Stern C, Eberhard K, Let al. Changes of platelet count throughout pregnancy in women with antiphospholipid syndrome. J Reprod Immunol 2019;136:102612.

6. van den Broe NR, Letsky EA. Pregnancy and the erythrocyte sedimentation rate. Br J Obstet Gynaecol 2001;108:1164-1167.

7. Haram K, Augensen K, Elsayed S. Serum protein pattern in normal pregnancy with special reference to acutephase reactants. Br J Obstet Gynaecol 1983;90:139-145.

8. Romem Y, Artal R. C-reactive protein in pregnancy and in the postpartum period. Am J Obstet Gynecol 1985;151:380-383.

9. Kaapa P, Koistinen E. Maternal and neonatal C-reactive protein after interventions during delivery. Acta Obstet Gynecol Scand 1993;72:543-546.

10. Julsgaard M, Hvas CL, Gearry RB, et al. Fecal Calprotectin is not affected by pregnancy: clinical implications for the management of pregnant patients with inflam- matory bowel disease. Inflamm Bowel Dis 2017;23: 1240-1246.

11. Cheung KL, Lafayette RA. Renal physiology of pregnancy. Adv Chronic Kidney Dis 2013;20:209-214.

12. Hossain N, Khan N, Shah N, et al. Spot urine proteincreatinine ratio and 24-h urine protein excretion: Diagnostic accuracy in women with pre-eclampsia. Pregnancy Hypertens 2014;4:87-90.

13. Lindheimer MD, Kanter D. Interpreting abnormal proteinuria in pregnancy: the need for a more pathophysiological approach. Obstet Gynecol 2010;115:365-375.

14. Attia DH, Mokbel A, Haggag HM, et al. Pregnancy outcome in women with active and inactive lupus nephritis: A prospective cohort study. Lupus 2019;28:806-817.

15. Bertsias GK, Tektonidou M, Amoura Z, et al. Joint European League Against Rheumatism and European Renal Association- European Dialysis and Transplant Association (EULAR/ERA-EDTA) recommendations for the management of adult and paediatric lupus nephritis. Ann Rheum Dis 2012;71(11):1771-1782.

16. Lightstone L, Hladunewich MA. Lupus Nephritis and Pregnancy: concerns and management. Semin Nephrol 2017;37:347-353.

17. Viglione V. FR, Melani B., Carignani L., Melani A. Patologia epatica in gravidanza. In. Risveglio Ostetrico 2004, volume I.

18. Klajnbard A, Szecsi PB, Colov NP, et al. Laboratory reference intervals during pregnancy, delivery and the early postpartum period. Clin Chem Lab Med 2010;48:237-248.

19. Carter J. Liver function in normal pregnancy. Aust N Z J Obstet Gynaecol 1990;30:296-302.

20. Le Thi Thuong D, Tieulie N, Costedoat N, et al. The HELLP syndrome in the antiphospholipid syndrome: retrospective study of 16 cases in 15 women. Ann Rheum Dis 2005;64:273-278.

21. Keiser SD, Boyd KW, Rehberg JF, et al. A high LDH to AST ratio helps to differentiate pregnancy-associated thrombotic thrombocytopenic purpura (TTP) from HELLP syndrome. J Matern Fetal Neonatal Med 2012;25:1059-1063.

22. Ranganath L, Taylor W, John L, et al. Biochemical diagnosis of placental infarction/damage: acutely rising alkaline phosphatase. Ann Clin Biochem 2008;45:335338.

23. Gong JM, Shen Y, He YX. Reference intervals of routine coagulation assays during the pregnancy and puerperium period. J Clin Lab Anal 2016;30:912-917.

24. Delluc C, Costedoat-Chalumeau N, Saadoun D, et al. Elevation of alkaline phosphatase in a pregnant patient with antiphospholipid syndrome: HELLP syndrome or not? Rheumatology (Oxford) 2008;47:554-555.

25. Battinelli EM, Marshall A, Connors JM. The role of thrombophilia in pregnancy. Thrombosis 2013;2013:516420.

26. Tagoe CE. Rheumatic symptoms in autoimmune thyroiditis. Curr Rheumatol Rep 2015;17:5.

27. Beneventi F, Locatelli E, Caporali R, et al. Connective tissue diseases and autoimmune thyroid disorders in the first trimester of pregnancy. J Reprod Immunol 2016;114:32-37.

28. King H. Epidemiology of glucose intolerance and gestational diabetes in women of childbearing age. Diabetes Care 1998;21:9-13. 
29. Zbinden A, van den Brandt S, Ostensen M, et al. Risk for adverse pregnancy outcome in axial spondyloarthritis and rheumatoid arthritis: disease activity matters. Rheumatology (Oxford) 2018; doi:10.1093/rheumatology/key053.

30. Dong Y, Dai Z, Wang Z, et al. Risk of gestational diabetes mellitus in systemic lupus erythematosus pregnancy: a systematic review and meta-analysis. BMC Pregnancy Childbirth 2019;19:179.

31. Regal JF, Gilbert JS, Burwick RM. The complement system and adverse pregnancy outcomes. Mol Immunol 2015;67:56-70.

32. Kolev M, Le Friec G, Kemper C. Complement-tapping into new sites and effector systems. Nat Rev Immunol 2014:14:811-820.

33. Derzsy Z, Prohaszka Z, Rigo J, et al. Activation of the complement system in normal pregnancy and preeclampsia. Mol Immunol 2010;47:1500-1506.

34. Buurma A, Cohen D, Veraar K, et al. Preeclampsia is characterized by placental complement dysregulation. Hypertension 2012;60:1332-1337.

35. Bulla R, Bossi F, Agostinis C, et al. Complement production by trophoblast cells at the feto-maternal interface. J Reprod Immunol 2009;82:119-125.

36. Lokki AI, Heikkinen-Eloranta J, Jarva H, et al. Complement activation and regulation in preeclamptic placenta. Front Immunol 2014;5:312.

37. Birmingham DJ, Irshaid F, Nagaraja HN, et al. The complex nature of serum $\mathrm{C} 3$ and $\mathrm{C} 4$ as biomarkers of lupus renal flare. Lupus 2010;19:1272-1280.

38. Tedesco F, Borghi MO, Gerosa M, et al. Pathogenic Role of complement in antiphospholipid Syndrome and therapeutic implications. Front Immunol 2018;9:1388.

39. Pisetsky DS. Anti-DNA antibodies-quintessential bio- markers of SLE. Nat Rev Rheumatol 2016;12:102-10

40. Clowse ME, Magder LS, Petri M. The clinical utility of measuring complement and anti-dsDNA antibodies during pregnancy in patients with systemic lupus erythematosus. J Rheumatol 2011;38:1012-1016.

41. Tincani A, Nalli C, Khizroeva J, et al. Autoimmune diseases and pregnancy. Best Pract Res Clin Endocrinol Metab 2019:101322.

42. Jara LJ, Medina G, Cruz-Dominguez P, et al. Risk factors of systemic lupus erythematosus flares during pregnancy. Immunol Res 2014;60:184-192.

43. Andreoli L, Bertsias GK, Agmon-Levin N, et al. EULAR recommendations for women's health and the management of family planning, assisted reproduction, pregnancy and menopause in patients with systemic lupus erythematosus and/or antiphospholipid syndrome. Ann Rheum Dis 2017;76:476-485.

44. Yelnik CM, Porter TF, Branch DW, et al. Changes in antiphospholipid antibody titers during pregnancy: effects on pregnancy outcomes. Arthritis Rheumatol 2016;68: 1964-1969.

45. Brucato A, Cimaz R, Stramba-Badiale M. Neonatal lupus. Clin Rev Allergy Immunol 2002;23:279-299.

46. Ambrosi A, Sonesson SE, Wahren-Herlenius M. Molecular mechanisms of congenital heart block. Exp Cell Res 2014;325:2-9.

47. Cimaz R, Spence DL, Hornberger L, et al. Incidence and spectrum of neonatal lupus erythematosus: a prospective study of infants born to mothers with anti-Ro autoantibodies. J Pediatr 2003;142:678-683.

48. Clowse MEB, Eudy AM, Kiernan E, et al. The prevention, screening and treatment of congenital heart block from neonatal lupus: a survey of provider practices. Rheumatology (Oxford) 2018;57:9-17. 


\title{
Gravidanza e malattie autoimmuni: il bambino
}

\author{
Micol Romano, ${ }^{1}$ Rolando Cimaz ${ }^{1,2}$ \\ ${ }^{1}$ ASST-Pini-CTO, Milano; ${ }^{2}$ Dipartimento di Scienze Cliniche e di Comunità, Università degli Studi di Milano, Italia
}

\section{Introduzione}

Le patologie autoimmuni non sono malattie ereditarie in senso stretto, ovvero non vi è una trasmissione diretta madre-figlio. I dati pubblicati in letteratura hanno suggerito invece un'aggregazione familiare. Ulteriori studi sono necessari al fine di comprendere il contributo relativo di fattori genetici, dell'esposizione ambientale, nonché dell'esposizione in utero a processi infiammatori e agli autoanticorpi materni.

Gli anticorpi anti-Ro e anti-La sono in grado di attraversare la placenta tra la $16 \mathrm{ma}$ e la $28 \mathrm{ma}$ settimana di gestazione e possono determinare una rara sindrome nel bambino chiamata lupus neonatale. Il lupus neonatale è diverso dal lupus eritematoso sistemico (LES). Il sintomo più comune è l'eritema cutaneo, visibile pochi giorni o settimane dopo la nascita, in particolare dopo l'esposizione al sole, e transitorio (di solito scompare entro 4-6 mesi). Molto raramente (1$2 \%)$ si verifica un tipo particolare di anomalia della frequenza cardiaca nota come blocco cardiaco congenito. Poiché tale complicanza è identificabile precocemente e curabile prima della nascita, il battito cardiaco fetale andrebbe monitorato circa una volta ogni 7/15 giorni, tra la $16 \mathrm{ma}$ e la $28 \mathrm{ma}$ settimana di gravidanza. La prognosi delle mamme è buona ma il $50-60 \%$ dei bambini richiede l'impianto di un pacemaker già durante l'infanzia.

Le pazienti affette da LES presentano un aumentato rischio di parto pretermine, bassa età gestazionale e basso peso alla nascita. Tuttavia, oggigiorno, le possibili complicanze correlate a tali condizioni, possono essere trattate con relativa facilità.

L'allattamento al seno non è sconsigliato per le pa-

Corrispondente: Micol Romano, ASST-Pini-CTO, Piazza Cardinal Ferrari 1, Presidio Ospedaliero Gaetano Pini, 20122 Milano, Italia.

E-mail: micol.dr.romano@gmail.com

Articolo pubblicato secondo la Creative Commons Attribution NonCommercial 4.0 License (CC BY-NC 4.0).

${ }^{\circ}$ Copyright: the Author(s), 2021

Licensee PAGEPress, Italy

QUADERNI - Italian Journal of Medicine 2021; 9(4):e17 zienti con patologie autoimmuni ma l'utilizzo, in accordo con i dati della letteratura, di farmaci anti-reumatici, in questa fase deve essere comunicato al curante.

Il counselling delle donne con malattie reumatologiche in gravidanza è di fondamentale importanza per un buon outcome.

\section{Il rischio di contrarre la malattia materna}

La trasmissione delle malattie autoimmune non rispetta un codice mendeliano, ovvero non si trasmette in senso stretto, vale a dire una trasmissione diretta tra madre e figlio. Si eredita invece una generica predisposizione a sviluppare una patologia autoimmune.

Molti studi hanno suggerito un'aggregazione familiare per il lupus eritematoso sistemico (LES) e per l'artrite reumatoide (AR), come per altre malattie autoimmuni quali il diabete di tipo I. Dati preliminari dalla coorte OSLER hanno messo in evidenza che $\mathrm{i}$ bambini nati da madri affette da LES presentano un rischio doppio di sviluppare patologie autoimmuni non reumatologiche (inclusi il diabete di tipo I e malattie infiammatorie croniche intestinali) rispetto alla popolazione generale. Tuttavia, l'effetto stimato per le patologie reumatologiche non è stato significativo. ${ }^{1}$

In un vasto studio olandese $\mathrm{e}^{2}$ che ha visto coinvolti 13.566 bambini nati da genitori affetti da AR, Rom AL e colleghi, hanno valutato la prole di madri affette da AR e la prole di madri non affette da AR. Tra i bambini nati da mamme con $\mathrm{AR}$ si è osservata una più alta morbilità per 8 su 11 gruppi di malattie classificate in accordo con l'International Classification of Disease. Simili risultati sono stati riscontrati in 6330 bambini nati da padri con AR. Di interesse, gli autori hanno anche dimostrato un incremento del rischio di sviluppare patologie autoimmuni reumatologiche o non reumatologiche: un rischio di tre volte maggiore per l'artrite idiopatica giovanile (AIG), un rischio del $40 \%$ per il diabete di tipo I, un rischio del 30\% per l'asma. Inoltre, gli autori riscontravano un rischio maggiore di malattie infettive, disordini mentali e del comportamento nella prole di madri con AR. È stata osservata poi, una più frequente associazione con lo sviluppo di malattie autoimmuni per i bambini nati da madri con AR rispetto ai bambini nati da padri con AR. 
Nuovi studi, condotti in età adulta, potrebbero mostrare un rischio maggiore con l'avanzare dell'età.

Questi dati devono essere presi in considerazione nel counselling delle madri affette. Di certo, ulteriori ricerche sono necessarie al fine di comprendere il contributo relativo di fattori genetici, dell'esposizione ambientale, nonché dell'esposizione in utero a processi infiammatori e agli autoanticorpi materni.

\section{Il rischio di sviluppare il lupus neonatale}

Alcune donne affette da patologie immunoreumatologiche come LES, la sindrome di Sjögren, e le connettiviti indifferenziate, possono presentare nel sangue particolari autoanticorpi. Tali anticorpi, in grado di determinare alcuni quadri patologici nel bambino, sono gli anti-Ro/SSA, anti-La/SSB (che fanno parte degli ENA). ${ }^{3}$ Gli anticorpi antinucleo (ANA) e gli anticorpi antifosfolipidi, anch'essi spesso presenti nelle malattie autoimmuni, non provocano invece quasi mai problemi al bambino. Gli anti-Ro (90\%) e gli anti-La (50$70 \%$ ) sono in grado di attraversare la placenta tra la $16 \mathrm{ma}$ e la $28 \mathrm{ma}$ settimana di gestazione e possono determinare una rara sindrome nel bambino chiamata Lupus Neonatale.

Va comunque precisato che tali anticorpi sono presenti in circa un terzo delle pazienti con LES, ma molte madri con questi anticorpi non partoriscono bambini con lupus neonatale e inoltre, il lupus neonatale potrebbe essere riscontrato nella prole di madri non affette da LES.

Il lupus neonatale non ha nulla a che vedere con il LES. Il sintomo più comune è l'eritema cutaneo, simile a quello che si osserva nel LES (da qui il nome 'lupus'), visibile pochi giorni o settimane dopo la nascita, in particolare dopo l'esposizione al sole. Si tratta di un'eruzione cutanea del tutto transitoria che di solito scompare entro i 4-6 mesi (suggerendo un meccanismo diretto anticorpo-mediato) e che non lascia esiti cicatriziali. Talvolta possono persistere ipopigmentazione o teleangectasie fino ai 2 anni di vita.

Gli esami di laboratorio possono risultare alterati. Sono infatti descritte alterazioni della funzionalità epatica con o senza ittero e alterazioni dell'emocromo (anemia, leucopenia, piastrinopenia) che di solito tendono a risolversi nel corso di alcune settimane senza alcun trattamento., ${ }^{4,5}$

Molto raramente si verifica un tipo speciale di anomalia della frequenza cardiaca nota come blocco cardiaco congenito. Il blocco cardiaco congenito compare generalmente tra la $16 \mathrm{ma}$ e la $28 \mathrm{ma}$ settimana ed è una complicanza molto rara: si stima che il rischio di blocco cardiaco congenito nelle donne portatrici di anticorpi anti-SSA/Ro è dell' $1-2 \% .{ }^{6}$ Va comunque detto che il $10-20 \%$ dei blocchi cardiaci congeniti è in realtà negativo per anticorpi anti-SSA/Ro. ${ }^{7}$ Il primo segno clinico di blocco cardiaco (blocco atrio-ventricolare completo) è la bradicardia fetale. Si ipotizza che alla base di tale fenomeno vi sia un processo di infiammazione e successiva fibrosi del sistema di conduzione mediato dagli anticorpi. ${ }^{8-10}$ Il blocco cardiaco è identificabile precocemente e curabile prima della nascita. Per tale motivo è necessario che donne affette da LES o da altre malattie autoimmuni con anticorpi anti-Ro e/o anti-La si sottopongano a frequenti valutazioni ginecologiche ed ecografiche allo scopo di identificare precocemente l'eventuale comparsa del blocco atrio-ventricolare. Il battito cardiaco fetale andrebbe monitorato circa una volta ogni $7 / 15$ giorni, tra la 16 ma e la 28 ma settimana di gravidanza. Il trattamento consiste nel somministrare alla mamma cortisone (betametasone o desametasone) in grado di attraversare la placenta, ma non sempre questa terapia risulta efficace. ${ }^{11,12}$ L'idrossiclorochina, sembra ridurre il rischio di sviluppo del blocco cardiaco congenito. ${ }^{13}$ La prognosi delle mamme dei bambini nati con blocco cardiaco congenito è buona; molte restano asintomatiche o oligosintomatiche. Solo la metà delle donne asintomatiche possono sviluppare sintomi di una patologia reumatica, più di frequente le artralgie, la xeroftalmia, ma solo pochi casi sviluppano una nefrite lupica. Il blocco cardiaco congenito completo è una patologia severa che può raggiungere una mortalità del $30 \%$, di solito in utero o nelle prime settimane di vita. ${ }^{14}$ Tuttavia, la maggior parte dei bambini nati con blocco cardiaco che sopravvive a questo periodo, ha un buon outcome, nonostante il 50-60\% richieda l'impianto di un pacemaker già durante l'infanzia. È stata descritta, nonostante l'impianto precoce di pacemaker, un'incidenza di cardiomiopatia dilatativa ad insorgenza tardiva del $10 \%$ con evoluzione a insufficienza cardiaca congestizia. ${ }^{15,16}$

Lo sviluppo neuropsicologico dei bambini con blocco congenito è normale. ${ }^{17}$

Non c'è correlazione tra la severità della malattia materna e l'insorgenza di lupus neonatale. Dopo i 6-9 mesi di vita gli anticorpi della madre scompaiono completamente dal sangue del bambino, e se non è presente blocco cardiaco non persistono reliquati di alcun tipo.

\section{Messaggi chiave}

- Gli anticorpi anti-Ro e anti-La sono in grado di attraversare la placenta e possono determinare una rara sindrome nel bambino chiamata lupus neonatale.

- Il lupus neonatale è diverso dal LES.

- Il sintomo più comune è l'eritema cutaneo, visibile pochi giorni o settimane dopo la nascita, che scompare entro 4-6 mesi.

- Nell'1-2\% dei casi si verifica un tipo particolare di anomalia della frequenza cardiaca nota come blocco cardiaco congenito. Poiché tale complicanza è identificabile precocemente e curabile 
prima della nascita, il battito cardiaco fetale andrebbe monitorato circa una volta ogni 7/15 giorni, tra la $16 \mathrm{ma}$ e la $28 \mathrm{ma}$ settimana di gravidanza.

- La prognosi delle mamme è buona ma il 50-60\% dei bambini richiede l'impianto di un pacemaker già durante l'infanzia.

\section{Il rischio di prematurità, iposviluppo fetale, basso peso alla nascita}

Buona parte delle donne lupiche partorisce in anticipo rispetto al termine. Infatti, il 30\% delle nascite avviene prima della $37 \mathrm{ma}$ settimana. Il rischio di prematurità è stato anche osservato in altre malattie autoimmuni come AR, AIG e la sclerodermia. Pertanto, è di fondamentale importanza, in pazienti affette da patologie reumatiche, la consulenza pregravidica e uno stretto monitoraggio durante la gravidanza ${ }^{18}$ (Figura 1).

In una systematic review e meta-analisi, ${ }^{19}$ gli autori riscontravano un significativo aumento (2,98 volte) del rischio di parto pretermine in pazienti con LES in fase attiva rispetto alle pazienti con LES quiescente verosimilmente perché l'infiammazione può influire sul sistema endocrino materno (cortisolo e prostaglandine) e l'immunità umorale sulla nascita prematura. Anche l'incremento della posologia steroidea necessario per contrastare l'attività di malattia può essere associato al parto pretermine.

Per quanto invece concerne l'iposviluppo fetale, in uno studio Mintz e collaboratori hanno osservato che, nel $23 \%$ delle gravidanze che aveva superato la $30 \mathrm{ma}$ settimana di gestazione, i nati presentavano un ritardo di crescita. ${ }^{20}$ Altri lavori riportano una percentuale di iposviluppo fetale tra il $12 \%$ e $32 \%{ }^{21}$

Inoltre, i bambini nati da mamme affette da patologie reumatologiche possono presentare un basso peso alla nascita. ${ }^{22}$

Grazie alle moderne tecniche assistenziali dei reparti neonatologici odierni, le complicanze quali insufficienza respiratoria o ittero possono tuttavia essere trattate con relativa facilità. Dopo le 30 settimane di età gestazionale generalmente non si riscontrano problematiche di rilievo, e non è più sorprendente vedere oggi crescere bene bambini nati con un peso di $1500 \mathrm{~g}$.

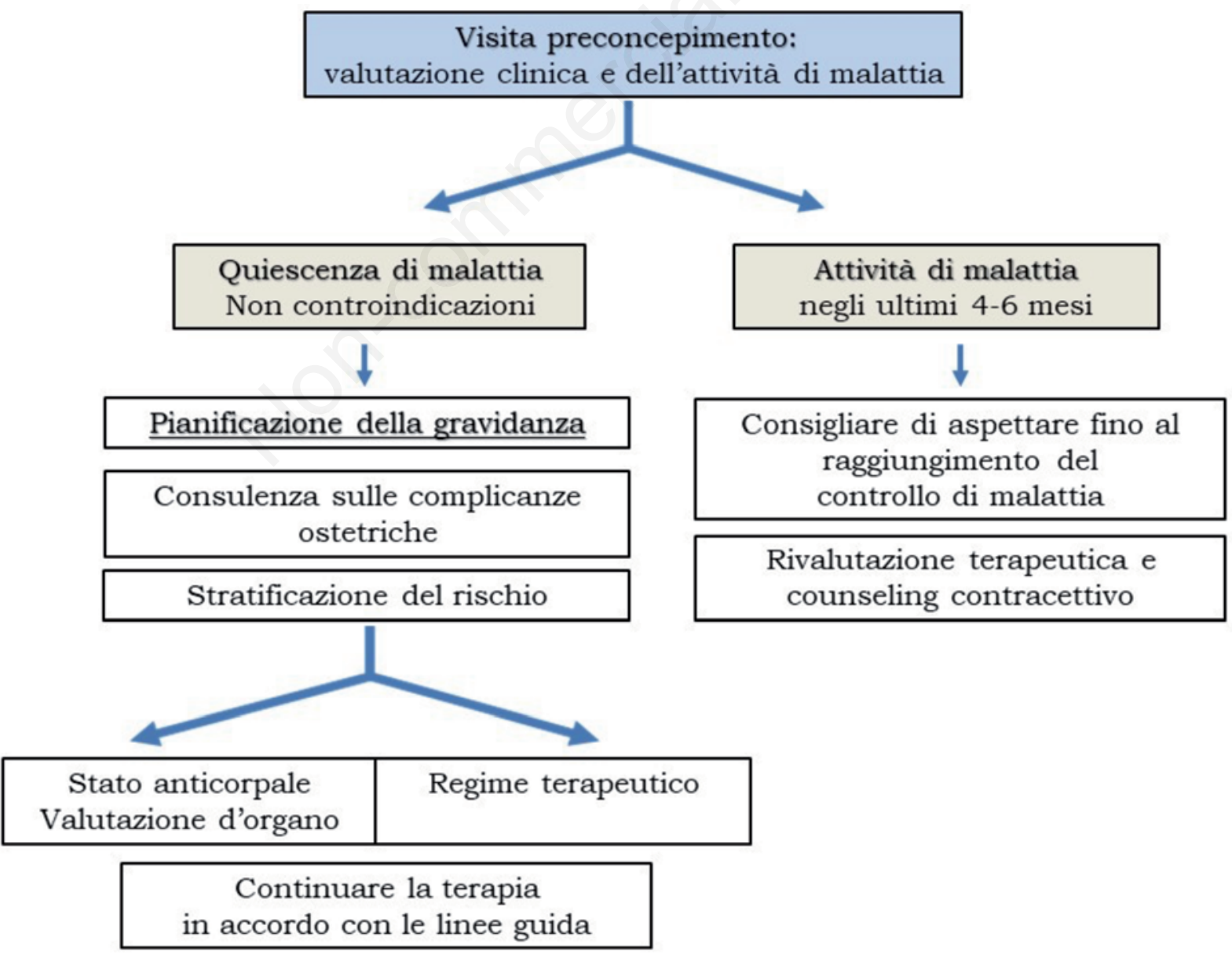

Figura 1. Management gravidico e pregravidico. 


\section{Messaggi chiave}

- Le pazienti affette fa LES presentano un aumentato rischio di parto pretermine, bassa età gestazionale e basso peso alla nascita.

- Tuttavia, con le moderne tecniche assistenziali, le possibili complicanze correlate a tali condizioni, possono essere trattate con relativa facilità.

\section{L'allattamento}

I benefici dell'allattamento materno per la madre e per il bambino sono ben noti. Essi includono il rafforzamento del legame della mamma con il proprio bambino, la riduzione del rischio di malattie metaboliche nella madre e nel bimbo, ${ }^{23}$ la riduzione del rischio cardiovascolare e la diversificazione del microbioma infantile. ${ }^{24,25}$

Inoltre, il latte materno fornisce una ricca fonte nutrizionale per il neonato e un assortimento di molecole immuno-attive protettive contro infezioni in grado anche di modulare la risposta immunitaria mucosale. ${ }^{26}$

L'allattamento è associato ad un complesso meccanismo di feedback che coinvolge l'ipofisi e che porta al rilascio di prolattina che da ultimo stimola la produzione di latte. La prolattina sembra aumentare l'espressione di TNF $\alpha$ nei monociti periferici CD14 delle pazienti affette da $\mathrm{AR}^{27}$ e dal punto di vista clinico, alcuni autori hanno riscontrato un incremento del rischio di flare durante la fase dell'allattamento. ${ }^{28}$ In contrasto altri studi sembrano suggerire una riduzione del rischio di sviluppare AR con l'allattamento al seno. ${ }^{29}$ Altri studi condotti in pazienti affette da LES sembrano indicare che elevate concentrazioni di prolattina possano essere correlate ad una possibile recidiva di malattia. ${ }^{30}$

Tuttavia, l'allattamento materno è insostituibile per il neonato e non ci sono dati certi e univoci per sconsigliare l'allattamento al seno, qualora la madre lo tolleri dal punto di vista fisico.

L'unica limitazione è rappresentata dalla tipologia di farmaci assunti dalla neomamma per controllare la malattia, dal momento che alcuni possono ritrovarsi nel latte materno.

Durante l'allattamento, i farmaci vengono trasferiti al latte materno prevalentemente per diffusione passiva da una zona ad alta concentrazione ad una a bassa concentrazione. Solo pochi farmaci vengono trasportati attivamente nel latte materno. Il picco di concentrazione dei medicinali nel latte materno si raggiunge entro 1-2 ore dall'ingestione. ${ }^{31}$ Alcuni fattori possono aumentare la concentrazione del farmaco nel latte materno, tra cui lo scarso legame proteico, il basso peso molecolare, una maggiore solubilità lipidica.

La biodisponibilità orale del farmaco nel neonato è bassa, tuttavia data l'immaturità del metabolismo epatico, l'emivita di alcuni farmaci può essere più lunga causando un accumulo del medicinale. ${ }^{32}$

Di solito l'assunzione di cortisone non è una controindicazione dal momento che solo una piccola percentuale del farmaco passa nel latte materno. L'assunzione di altri farmaci deve essere comunicata al proprio medico curante, che potrà rassicurare $o$ meno la paziente sulla sicurezza del medicinale in fase di allattamento.

Nella Tabella 1 sono riassunti i principali dati sui trattamenti anti-reumatici in corso di allattamento. ${ }^{31}$

\section{Messaggi chiave}

- L'allattamento al seno non è sconsigliato per le pazienti con patologie autoimmuni e fornisce notevoli benefici per la mamma e per il bambino.

- Fortunatamente, molti, ma non tutti i farmaci antireumatici possono essere continuati durante l'allattamento.

\section{Conclusioni}

In conclusione, possiamo riassumere i punti fondamentali dell'articolo, come segue:

i) Fattori genetici, l'esposizione in utero a citochine, agli anticorpi materni e a farmaci volti al controllo di malattia possono influenzare l'outcome della gravidanza di madri affette da malattie autoimmuni.

ii) I pochi dati pubblicati in letteratura suggeriscono che i bambini nati da madri con patologie reumatiche possono presentare verosimilmente un rischio aumentato di sviluppare malattie autoimmuni. Tuttavia, poiché il rischio assoluto è di lieve entità, le donne affette da malattie autoimmuni non dovrebbero essere scoraggiate ad avere bambini.

iii) L'allattamento al seno è incoraggiato in tutte le pazienti.

iv) Il counselling delle donne con malattie reumatologiche in gravidanza è di fondamentale importanza per un buon outcome.

v) È consigliato un approccio multidisciplinare nella gestione di queste pazienti. In particolare, un team composto dal reumatologo, dal ginecologo, dal neonatologo e da altri specialisti coinvolti nel management della gravidanza, rappresenta il supporto medico ottimale.

\section{Bibliografia}

1. Couture J, Bernatsky S, Scott S, Pineau CA, Vinet E. Brief Report: Risk of Childhood Rheumatic and Nonrheumatic Autoimmune Diseases in Children Born to Women With Systemic Lupus Erythematosus. Arthritis Rheumatol. 2018;70(11):1796-800.

2. Rom AL, Wu CS, Olsen J, et al. Parental rheumatoid 
Tabella 1. Terapie anti-reumatiche durante l'allattamento

\begin{tabular}{|c|c|c|}
\hline Farmaco & Sicurezza in corso di allattamento & Note \\
\hline FANS & Compatibili & Preferire FANS con breve emivita \\
\hline Aspirina & Compatibile & Evitare dosi superiori ai $100 \mathrm{mg} / \mathrm{die}$ \\
\hline Prednisone, Prednisolone & Compatibile & $\begin{array}{l}\text { Per dosi superiori a } 20 \mathrm{mg} \text { evitare l'allattamento nelle } 4 \mathrm{~h} \\
\text { successive all'assunzione }\end{array}$ \\
\hline Colchicina & Compatibile & \\
\hline Idrossiclorochina, Clorochina & Compatibile & Dati di follow up a lungo termine non dimostrano danni retinici \\
\hline Sulfasalazina & Compatibile & Riportati casi di diarrea; evitare in neonati prematuri \\
\hline Azatioprina & Compatibile & \\
\hline Ciclosporina & Compatibile & $\begin{array}{l}\text { Monitoraggio dei valori di creatinina e dei livelli ematici del } \\
\text { farmaco nel bambino }\end{array}$ \\
\hline Tacrolimus & Compatibile & - \\
\hline Metotrexate & Potenzialmente ad elevato rischio & - \\
\hline Micofenolato mofetile & Sconosciuto & Evitare \\
\hline Ciclofosfamide & Alto rischio & Ipotetico rischio di immunosoppressione e cancerogenesi \\
\hline Leflunomide & Probabilmente elevato rischio & - \\
\hline Etanercept & Compatibile & - \\
\hline Adalimumab & Compatibile & 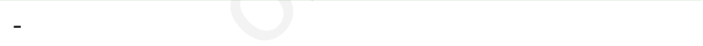 \\
\hline Infliximab & Compatibile & 81 \\
\hline Certolizumab pegol & Compatibile & 0 \\
\hline Golimumab & - & $\begin{array}{l}\text { L'elevato peso molecolare rende improbabile il trasferimento } \\
\text { nel latte materno }\end{array}$ \\
\hline Anakinra & Compatibile & - \\
\hline Abatacept & - & $\begin{array}{l}\text { L'elevato peso molecolare rende improbabile il trasferimento } \\
\text { nel latte materno }\end{array}$ \\
\hline Tocilizumab & - & $\begin{array}{l}\text { L'elevato peso molecolare rende improbabile il trasferimento } \\
\text { nel latte materno }\end{array}$ \\
\hline Rituximab & - & $\begin{array}{l}\text { L'elevato peso molecolare rende improbabile il trasferimento } \\
\text { nel latte materno }\end{array}$ \\
\hline Belimumab & - & $\begin{array}{l}\text { L'elevato peso molecolare rende improbabile il trasferimento } \\
\text { nel latte materno }\end{array}$ \\
\hline Secukinumab & - & $\begin{array}{l}\text { L'elevato peso molecolare rende improbabile il trasferimento } \\
\text { nel latte materno }\end{array}$ \\
\hline Tofacitinib & Evitare & $\begin{array}{l}\text { Il basso peso molecolare rende probabile il trasferimento nel } \\
\text { latte materno }\end{array}$ \\
\hline IVIG & Compatibile & \\
\hline
\end{tabular}

Modificato e adattato da Bermas et al., 2017,31 con permesso.

arthritis and long-term child morbidity: a nationwide cohort study. Ann Rheum Dis. 2016;75:1831-1837.

3. Brucato A, Cimaz R, Caporali R, Ramoni V, Buyon J. Pregnancy outcomes in patients with autoimmune diseases and anti-Ro/SSA antibodies. Clin Rev Allergy Immunol. 2011;40(1):27-41.

4. Cimaz R, Spence DL, Hornberger L, Silverman ED. Incidence and spectrum of neonatal lupus erythematosus: a prospective study of infants born to mothers with antiRo autoantibodies. The Journal of pediatrics. 2003;142(6): 678-83.

5. Laxer RM, Roberts EA, Gross KR, Britton JR, Cutz E, Dimmick J, et al. Liver disease in neonatal lupus erythematosus. The Journal of pediatrics. 1990;116(2): 238-42.
6. Brucato A, Frassi M, Franceschini F, Cimaz R, Faden $\mathrm{D}$, Pisoni MP, et al. Risk of congenital complete heart block in newborns of mothers with anti-Ro/SSA antibodies detected by counterimmunoelectrophoresis: a prospective study of 100 women. Arthritis Rheum. 2001;44(8):1832-5.

7. Brucato A, Grava C, Bortolati M, Ikeda K, Milanesi O, Cimaz R, et al. Congenital heart block not associated with anti-Ro/La antibodies: comparison with antiRo/La-positive cases. The Journal of rheumatology. 2009;36(8):1744-8.

8. Clancy RM, Askanase AD, Kapur RP, Chiopelas E, Azar N, Miranda-Carus ME, et al. Transdifferentiation of cardiac fibroblasts, a fetal factor in anti-SSA/Ro-SSB/La antibody-mediated congenital heart block. Journal of 
immunology (Baltimore, Md : 1950). 2002;169(4): 2156-63.

9. Ho SY, Esscher E, Anderson RH, Michaelsson M. Anatomy of congenital complete heart block and relation to maternal anti-Ro antibodies. The American journal of cardiology. 1986;58(3):291-4.

10. Carter JB, Blieden LC, Edwards JE. Congenital heart block. Anatomic correlations and review of the literature. Archives of pathology. 1974;97(1):51-7.

11. Saleeb S, Copel J, Friedman D, Buyon JP. Comparison of treatment with fluorinated glucocorticoids to the natural history of autoantibody-associated congenital heart block: retrospective review of the research registry for neonatal lupus. Arthritis Rheum. 1999;42(11):2335-45.

12. Theander E, Brucato A, Gudmundsson S, Salomonsson S, Wahren-Herlenius M, Manthorpe R. Primary Sjogren's syndrome - treatment of fetal incomplete atrioventricular block with dexamethasone. The Journal of rheumatology. 2001;28(2):373-6.

13. Izmirly PM, Costedoat-Chalumeau N, Pisoni CN, Khamashta MA, Kim MY, Saxena A, et al. Maternal use of hydroxychloroquine is associated with a reduced risk of recurrent anti-SSA/Ro-antibody-associated cardiac manifestations of neonatal lupus. Circulation. 2012;126(1):76-82.

14. Brucato A, Gasparini M, Vignati G, Riccobono S, De Juli E, Quinzanini M, et al. Isolated congenital complete heart block: longterm outcome of children and immunogenetic study. The Journal of rheumatology. 1995;22(3):541-3.

15. Eronen M, Siren MK, Ekblad H, Tikanoja T, Julkunen H, Paavilainen T. Short- and long-term outcome of children with congenital complete heart block diagnosed in utero or as a newborn. Pediatrics. 2000;106(1 Pt 1):86-91.

16. Moak JP, Barron KS, Hougen TJ, Wiles HB, Balaji S, Sreeram N, et al. Congenital heart block: development of late-onset cardiomyopathy, a previously underappreciated sequela. Journal of the American College of Cardiology. 2001;37(1):238-42.

17. Brucato A, Astori MG, Cimaz R, Villa P, Li Destri M, Chimini L, et al. Normal neuropsychological development in children with congenital complete heart block who may or may not be exposed to high-dose dexamethasone in utero. Ann Rheum Dis. 2006;65(11):1422-6.

18. Do SC, Druzin ML. Systemic lupus erythematosus in pregnancy: high risk, high reward. Current opinion in obstetrics \& gynecology. 2019;31(2):120-6.

19. Wei S, Lai K, Yang Z, Zeng K. Systemic lupus erythematosus and risk of preterm birth: a systematic review and meta-analysis of observational studies. Lupus. 2017;26(6):563-71.
20. Mintz G, Niz J, Gutierrez G, Garcia-Alonso A, Karchmer S. Prospective study of pregnancy in systemic lupus erythematosus. Results of a multidisciplinary approach. The Journal of rheumatology. 1986;13(4):732-9.

21. Oviasu E, Hicks J, Cameron JS. The outcome of pregnancy in women with lupus nephritis. Lupus. 1991;1(1):19-25.

22. Strouse J, Donovan BM, Fatima M, Fernandez-Ruiz R, Baer RJ, Nidey N, et al. Impact of autoimmune rheumatic diseases on birth outcomes: a population-based study. RMD open. 2019;5(1):e000878.

23. Armstrong J, Reilly JJ. Breastfeeding and lowering the risk of childhood obesity. Lancet (London, England). 2002;359(9322):2003-4.

24. Ladomenou F, Moschandreas J, Kafatos A, Tselentis Y, Galanakis E. Protective effect of exclusive breastfeeding against infections during infancy: a prospective study. Archives of disease in childhood. 2010;95(12): 1004-8.

25. Horta BL, Loret de Mola C, Victora CG. Long-term consequences of breastfeeding on cholesterol, obesity, systolic blood pressure and type 2 diabetes: a systematic review and meta-analysis. Acta paediatrica (Oslo, Norway : 1992). 2015;104(467):30-7.

26. Hanson LA, Ahlstedt S, Andersson B, Carlsson B, Fallstrom SP, Mellander L, et al. Protective factors in milk and the development of the immune system. Pediatrics. 1985;75(1 Pt 2):172-6.

27. Tang C, Li Y, Lin X, Ye J, Li W, He Z, et al. Prolactin increases tumor necrosis factor alpha expression in peripheral CD14 monocytes of patients with rheumatoid arthritis. Cellular immunology. 2014;290(1):164-8.

28. Barrett JH, Brennan P, Fiddler M, Silman A. Breastfeeding and postpartum relapse in women with rheumatoid and inflammatory arthritis. Arthritis Rheum. 2000;43(5):1010-5.

29. Karlson EW, Mandl LA, Hankinson SE, Grodstein F. Do breast-feeding and other reproductive factors influence future risk of rheumatoid arthritis? Results from the Nurses' Health Study. Arthritis Rheum. 2004;50(11): 3458-67.

30. Walker SE, McMurray RW, Houri JM, Allen SH, Keisler D, Sharp GC, et al. Effects of prolactin in stimulating disease activity in systemic lupus erythematosus. Ann N Y Acad Sci. 1998;840:762-72.

31. Bermas BL. Lactation and Management of Postpartum Disease. Rheumatic diseases clinics of North America. 2017;43(2):249-62.

32. Neville MC. Anatomy and physiology of lactation. Pediatr Clin North Am. 2001;48(1):13-34. 


\section{Fecondazione medicalmente assistita nelle malattie autoimmuni sistemiche}

Simona Truglia, Silvia Mancuso, Fabrizio Conti

Dipartimento di Scienze Cliniche Internistiche, Anestesiologiche e Cardiovascolari, Università La Sapienza, Roma, Italia

\section{Introduzione}

Le malattie autoimmuni sistemiche (MAS) che includono le diverse connettiviti quali il lupus eritematoso sistemico (LES), la sindrome da anticorpi antifosfolipidi (APS), la sclerosi sistemica (SS), la sindrome di Sjögren (SdS), la connettivite mista, le miopatie infiammatorie idiopatiche e l'artrite reumatoide (AR), si presentano spesso nelle donne in età fertile per cui, il potenziale impatto di queste malattie sulla funzione riproduttiva rappresenta una delle maggiori preoccupazioni delle pazienti.

Nella popolazione generale è stato stimato che il $12-15 \%$ delle coppie in età riproduttiva soffre di infertilità, non sorprende quindi che una percentuale così elevata possa includere anche pazienti con malattie autoimmuni sistemiche.

Le MAS non sono considerate una chiara causa di infertilità femminile ma, i problemi di fertilità in queste donne non sono rari, con un tempo alla prima gravidanza aumentato rispetto alla popolazione generale. ${ }^{1-3}$ Sebbene in queste pazienti, nella maggior parte dei casi, la ridotta fertilità sia dovuta a una funzione riproduttiva anormale correlata alla malattia o indotta da farmaci, vi sono casi in cui il ritardo nella pianificazione della gravidanza, a causa della malattia attiva, o il timore di complicanze ostetriche associate alla malattia stessa, determinano un mancato concepimento per esaurimento della riserva ovarica. ${ }^{4}$

L'associazione delle malattie autoimmuni sistemi-

Corrispondente: Simona Truglia, Dipartimento di Scienze Cliniche Internistiche, Anestesiologiche e Cardiovascolari, Università La Sapienza, Roma, Italia.

Tel.: +39.06.49974631.

E-mail: dott.trugliasimona@gmail.com

Articolo pubblicato secondo la Creative Commons Attribution NonCommercial 4.0 License (CC BY-NC 4.0).

${ }^{\circ}$ Copyright: the Author(s), 2021

Licensee PAGEPress, Italy

QUADERNI - Italian Journal of Medicine 2021; 9(4):e18 che con l'endometriosi, la celiachia e le tireopatie autoimmuni, cause ben note di infertilità e/o subfertilità, devono essere prese in considerazione quando si riscontrano problemi di concepimento nelle pazienti affette da MAS.

\section{Fattori potenzialmente coinvolti nell'infertilità in pazienti affette da malattie autoimmuni sistemiche}

Numerosi fattori possono svolgere un ruolo nel ridurre il potenziale riproduttivo nelle pazienti con MAS (Tabella 1):

- l'infiammazione cronica compromette il corretto funzionamento dell'asse ipotalamo-ipofisi-ovaio (HPO), causando un anormale rilascio di gonadotropina $(\mathrm{GnRH})$ e di ormoni gonadotropi. ${ }^{5}$

- La diatesi autoimmune delle pazienti può essere responsabile della generazione di anticorpi antiovarici che mediano il danno del tessuto ovarico e la ridotta riserva ovarica (DOR) attraverso l'induzione dell'ooforite autoimmune. ${ }^{6}$

- Le riacutizzazioni di malattia si associano ad alti livelli sierici di prolattina che incidono sull'ovulazione e sulla fecondabilità. ${ }^{7}$

- La maggior parte dei farmaci antireumatici non interferisce con la fertilità; tuttavia, la ciclofosfamide potrebbe favorire l'insufficienza ovarica prematura. ${ }^{8,9}$ I farmaci antinfiammatori non steroidei possono causare infertilità temporanea e i glucocorticoidi sono associati a un tempo alla prima gravidanza aumentato in alcune malattie reumatiche. ${ }^{10}$

- Anche fattori psico-sociali svolgono un ruolo in questo scenario. Le MAS possono, infatti, avere un impatto sulle relazioni personali e sul desiderio della donna di procreare; ${ }^{11}$ in particolare, alcune pazienti sono preoccupate per l'ipotetico rischio di trasmissione della loro malattia al nascituro. ${ }^{12}$ Oltre agli impedimenti fisici all'attività sessuale direttamente associati alla malattia come l'astenia, il dolore muscoloscheletrico, la rigidità articolare o il coinvolgimento diretto del tratto genitale, la diagnosi può avere un impatto negativo sulla fiducia 
in sé stesse e sul benessere mentale con conseguente diminuzione della frequenza dei rapporti sessuali e infine sulla riduzione della fertilità. ${ }^{13,14}$

La presenza dei comuni autoanticorpi legati alle MAS non sembra influire sulla fertilità. Tuttavia, la prevalenza di anticorpi anti-nucleo (ANA) è più elevata nelle donne con funzione riproduttiva alterata rispetto ai controlli fertili. ${ }^{15}$ Inoltre, nel contesto della fecondazione in vitro (IVF), la positività per gli ANA è stata associata a una ridotta percentuale di impianto di embrioni ${ }^{16}$ e di gravidanza. ${ }^{17}$ Per quanto riguarda gli anticorpi anti-fosfolipidi (aPL), due studi hanno riportato una riduzione della riserva ovarica, come indicato da livelli più bassi di ormone anti-Mülleriano (AMH) in oltre il 50\% delle pazienti con aPL rispetto ai controlli sieronegativi di pari età. ${ }^{18,19}$ Inoltre, alcune evidenze suggeriscono un ruolo degli aPL nell'alterata decidualizzazione uterina, ${ }^{20}$ portando al fallimento dell'impianto. Tuttavia, in una recente revisione della letteratura, gli autori hanno concluso che non è ancora chiaro se la più alta frequenza di aPL registrata tra le donne sterili sia alla base di un'associazione clinicamente significativa. ${ }^{21}$

Al fine di garantire un outcome materno e fetale ottimale, prima di programmare la gravidanza in pazienti con MAS è indicato eseguire un counselling multidisciplinare, con il ginecologo-ostetrico e il reumatologo, allo scopo di valutare specificatamente il singolo caso e informare la donna sul timing ideale per programmare una gravidanza e sull'importanza di ottimizzare in tal senso la terapia. ${ }^{22,23}$

Nelle malattie autoimmuni sistemiche, la malattia ben controllata al momento del concepimento si associa, infatti, a un migliore outcome gravidico sia per la madre che per il neonato. ${ }^{24-26} \mathrm{Ne}$ consegue che prima del concepimento è fondamentale una valutazione puntuale dell'attività della malattia, considerando il tipo di coinvolgimento d'organo, la frequenza e la gravità delle riacutizzazioni di malattia e la presenza di anticorpi che potrebbero influire sull'esito negativo della gravidanza (come gli aPL e/o anticorpi anti$\mathrm{SSA} / \mathrm{SSB}){ }^{23}$ Nelle pazienti con malattia attiva biso- gnerebbe rimandare la gravidanza fino alla remissione o al raggiungimento di una malattia stabile per almeno 6-12 mesi. ${ }^{23}$ Nelle pazienti con LES e AR, un'accurata pianificazione della gravidanza riduce il tasso di riacutizzazione di malattia con conseguente miglior outcome gravidico..$^{27,28}$ Durante il counselling è importante valutare eventuali condizioni potenzialmente responsabili dell'infertilità femminile al fine di identificare le pazienti candidate a specifici trattamenti per la fertilità.

I fattori di rischio che possono influenzare negativamente la gravidanza, tra cui il diabete gestazionale, la disfunzione tiroidea e l'ipertensione arteriosa, devono essere considerati, poiché nelle donne sottoposte a fecondazione in vitro (IVF) alcune di queste condizioni, possono riacutizzarsi o insorgere in seguito all'induzione dell'ovulazione. ${ }^{29}$ È importante sottolineare che l'adeguatezza dei regimi terapeutici e la loro compatibilità con la gravidanza dovrebbero essere discussi prima del concepimento, in base ai potenziali effetti teratogeni dei farmaci antireumatici e al rischio di riacutizzazioni della malattia in caso di sospensione del trattamento durante la gravidanza.

\section{Conservazione della fertilità nelle malattie autoimmuni sistemiche}

Sebbene il counselling sul potenziale di fertilità e l'opzione di preservazione della fertilità (FP) siano fondamentali per le pazienti con MAS sembra che non vengano ancora affrontati correttamente in queste pazienti. La preservazione della fertilità dovrebbe essere raccomandata principalmente in: i) pazienti che necessitano di trattamenti con effetti gonadotossici noti o potenziali (principalmente ciclofosfamide in entrambi i sessi); ii) pazienti in cui sono attesi ritardi significativi nel concepimento a causa della malattia attiva o alla paura di complicazioni della gravidanza associate alla malattia che possono provocare esaurimento della riserva ovarica correlato all'età.

Come in tutte le popolazioni femminili a rischio di perdita di fertilità, dovrebbero essere prese in consi-

Tabella 1. Cause di infertilità nelle donne affette da malattie autoimmuni sistemiche.

\section{Fattori legati alla malattia}

- Disfunzione dell'asse ipotalamo-ipofisi dovuta all'infiammazione

- Ooforite autoimmuneIperprolattinemia associata alle riacutizzazioni di malattia

- Ritardi nella pianificazione del concepimento (es. malattia attiva, timore di complicanze correlate alla malattia, ecc.)

- Diminuzione della frequenza dei rapporti sessuali sia per impedimenti fisici legati alla malattia (secchezza vaginale, rigidità articolare, affaticamento, dolore muscoloscheletrico, ecc.) che fattori psico-sociali (ridotta autostima, alterato benessere mentale, alterata immagine corporea, ecc.)

- Disturbi affettivi (depressione, perdita della libido, ecc.)

Farmaci utilizzati per il trattamento della malattia

- FANS: sindrome LUF, problemi di impianto legato all'alterata permeabilità vascolare endometriale

- Glucocorticoidi: disfunzione dell'asse ipotalamo ipofisi, soppressione del rilascio di LH e FSH, apoptosi delle cellule ovariche

- Ciclofosfamide: amenorrea, insufficienza ovarica precoce

FANS, farmaci anti-infiammatori non steroidei; LUF, sindrome del follicolo luteinizzato; LH, ormone luteinizzante; FSH, ormone follicolo-stimolante. 
derazione le seguenti opzioni per la preservazione della fertilità:

- agonisti ormonali che rilasciano gonadotropina $(G n R H-a)$. È stato segnalato che l'uso di GnRH-a riduce l'incidenza di insufficienza ovarica prematura (POF) nelle pazienti con LES e in altre pazienti con MAS sottoposte a terapie gonadotossiche senza determinare riacutizzazione della malattia. ${ }^{30,31}$ Tuttavia, sulla base di studi più ampi condotti sulle pazienti affette da patologie oncologiche, l'efficacia di GnRH-a come strategia per la preservazione della fertilità è ancora ampiamente dibattuta. ${ }^{32}$ Pertanto, alle pazienti con MAS sottoposte a trattamenti gonadotossici dovrebbero essere offerte, oltre agli GnRH-a, anche altre strategie per la preservazione della fertilità.

- Congelamento di ovociti o embrioni. La vetrificazione di ovociti per la crioconservazione è il metodo attualmente più efficace per la $\mathrm{FP}$ e non è più considerata una tecnica sperimentale. ${ }^{33}$ Pertanto, questa opzione dovrebbe essere presa in considerazione in tutte le pazienti in età fertile che sono a rischio di riduzione del loro potenziale riproduttivo. Poiché i tassi di gravidanza per le tecniche di crioconservazione di ovociti sono proporzionali al numero di ovociti, in tali tecniche si utilizza la stimolazione ovarica controllata (COS) con gonadotropine (GN) per ottenere un recupero ottimale di ovociti.

- Congelamento del tessuto ovarico per autotrapianto. Comprende la raccolta e la crioconservazione del tessuto ovarico in laparoscopia (OTCP), una strategia che non richiede alcuna precedente stimolazione ovarica. Le due principali indicazioni alla OTCP, piuttosto che di congelamento di ovociti, sono la presenza di vincoli temporali relativi a un bisogno imminente di trattamento gonadotossico o - soprattutto - la necessità di FP in una paziente in età prepuberale. Nonostante sia ancora considerato sperimentale, l'efficacia dell'OTCP è ampiamente descritta $^{34}$ e la tecnica pone poche preoccupazioni in termini di sicurezza, specialmente se non eseguita in pazienti con patologie oncologiche in cui esiste un rischio di metastasi ovariche occulte. Poiché non è richiesta alcuna stimolazione ovarica controllata, le uniche preoccupazioni per la sicurezza dell'OTCP nelle pazienti con MAS sono i rischi anestesiologici e chirurgici. Ad oggi, tuttavia, non sono state segnalate complicanze a seguito dei pochi casi di OTCP nei pazienti con MAS. ${ }^{35,36}$

\section{Tecniche di procreazione medicalmente assistita nelle malattie autoimmuni sistemiche}

Le coppie sterili generalmente iniziano il percorso diagnostico ed eventuali trattamenti per l'infertilità dopo 12 mesi di tentativi falliti nel concepire natural- mente. Nelle pazienti con MAS potrebbe essere indicato anticipare la diagnosi di infertilità e i trattamenti specifici ad un periodo di 6 mesi di tentativi naturali falliti. Questa strategia potrebbe abbreviare il tempo alla prima gravidanza - con un beneficio rilevante soprattutto in quei casi in cui la stabilità della malattia è ottenuta difficilmente o in cui i regimi terapeutici devono essere modificati a causa degli effetti teratogeni e dell'incompatibilità con la gravidanza. Non ci sono prove che $\mathrm{i}$ tassi di successo della fertilità o il numero di cicli di fecondazione in vitro tra le donne con MAS che si sottopongono a trattamenti per l'infertilità differiscano dalla popolazione generale, tuttavia studi hanno suggerito esiti peggiori se la malattia è attiva in gravidanza.

Per quanto riguarda la popolazione sterile generale, sono disponibili i seguenti trattamenti:

- induzione dell'ovulazione (OI), rapporti mirati e l'inseminazione intrauterina (IUI). L'induzione dell'ovulazione e i rapporti mirati/IUI possono essere eseguiti sia su ciclo naturale che dopo somministrazione di clomifene citrato (CC), inibitore dell'aromatasi (AI) o gonadotropine a basso dosaggio (GN).

- Altre tecniche di procreazione medicalmente assistita (PMA): fecondazione in vitro/Iniezione di spermatozoi intra-citoplasmatici e il trasferimento di embrioni (IVF/ICSI-ET).

Queste tecniche prevedono la stimolazione ovarica, il recupero degli ovociti, la fecondazione in vitro e il trasferimento dell'embrione fecondato nell'utero. La stimolazione ovarica controllata viene raggiunta attraverso uno dei numerosi protocolli che utilizzano agonisti o antagonisti dell'ormone di rilascio della gonadotropina e che porta alla maturazione di due o più follicoli ovarici. La somministrazione di gonadotropina corionica umana ( $\mathrm{hCG}$ ) innesca l'ovulazione. Il recupero degli ovociti viene effettuato mediante aspirazione follicolare transvaginale eco-guidata circa 36 ore dopo la somministrazione di hCG. Gli ovociti recuperati vengono uniti agli spermatozoi (isolati dal liquido seminale); in alternativa, per i pazienti con grave infertilità maschile, vengono eseguite micromanipolazione e iniezione intracitoplasmatica di spermatozoi (ICSI). Gli ovociti fertilizzati vengono quindi esaminati dopo 17-24 ore per confermare l'avvenuta scissione embrionale e il trasferimento dell'embrione nell'utero avviene quando raggiunge lo stadio di blastocisti. I livelli di estrogeni sierici, le dimensioni delle ovaie e il numero di follicoli sono monitorati durante la stimolazione ovarica; mentre i livelli di estradiolo e progesterone sono rispettivamente 6 e 3 volte più alti dei normali livelli fisiologici durante la stimolazione, i livelli totali di estradiolo a termine sono 100 volte $i$ valori normali.

Le tecniche di crioconservazione consentono di 
congelare embrioni soprannumerari ed eseguire i successivi trasferimenti di embrioni (FET) congelati e scongelati con probabilità simili - se non aumentate di gravidanza rispetto all'ET fresco. ${ }^{37} \mathrm{La}$ disponibilità di tecniche di crioconservazione ben funzionanti ha portato alla strategia di frammentazione del ciclo di FIVET/ ICSI-ET, ovvero di non eseguire ET subito dopo il ciclo di stimolazione e crioconservare elettivamente tutti gli embrioni. La possibilità di eseguire l'ET in assenza di un aumento dei livelli ormonali indotta dalla stimolazione ovarica elimina il rischio di sindrome da iperstimolazione ovarica. ${ }^{37}$ In letteratura non è stato descritto un aumento del rischio chirurgico correlato alla procedura di recupero degli ovociti nei pazienti con MAS rispetto alla popolazione infertile generale.

- Test genetici preimpianto. Il test genetico preimpianto (PGT) è una tecnologia per analisi genetiche eseguite su una biopsia dell'embrione durante i trattamenti con tecnologia di riproduzione assistita. Il test per i disturbi monogenici (PGT-M) è clinicamente fattibile in famiglie affette da disturbi ereditari, per impedire la trasmissione verificando se gli embrioni preimpianto portino o meno la mutazione nota ma possono anche essere utilizzati per rilevare riarrangiamenti strutturali cromosomici (PGT-SR) in coppie portatrici di una traslocazione cromosomica bilanciata nota. Al di fuori di queste indicazioni specifiche, PGT può essere altrimenti utilizzato per valutare l'aneuploidia dell'embrione (PGT-A). Per quanto riguarda le malattie autoimmuni, non è stato segnalato né un aumento del rischio di aneuploidia dell'embrione né una mutazione specifica che causa MAS - nonostante la forte associazione osservata tra i loci della regione HLA e l'autoimmunità. Pertanto, attualmente la PGT non è raccomandata nelle pazienti con MAS in assenza di altri fattori di rischio genetici - e in particolare in coloro che sono preoccupati del rischio ipotetico di trasmissione fetale della loro malattia.

\section{Rischi associati ai trattamenti utilizzati per l'infertilità nelle pazienti affette da malattie autoimmuni sistemiche}

\section{Rischio di esacerbazione della malattia autoimmune sistemica}

In letteratura sono disponibili i dati sulla sicurezza dei trattamenti della fertilità in corso di malattia autoimmune sistemica, in termini di sviluppo/progressione della malattia, soprattutto per il LES e l'APS. Le procedure di PMA nelle donne con malattie autoimmuni sistemiche sembrano avere un'efficacia simile alla popolazione generale, con un tasso di successo in termini di gravidanze indotte di circa il 20-30\%. Le complicanze materne sono state riportate in casi di donne in cui la diagnosi di LES non era ancora documentata al momento dei trattamenti di infertilita ${ }^{38} \mathrm{o}$ che non avessero ricevuto terapia per la malattia reumatica e/o la profilassi antitrombotica. ${ }^{39} \mathrm{Al}$ contrario, in pazienti con LES trattate adeguatamente, sono stati osservati esiti favorevoli e tassi di esacerbazioni della malattia comparabili a quelli descritti in donne non gravide e non stimolate ${ }^{40}$ Recenti studi multicentrici suggeriscono che l'incidenza di complicanze sia virtualmente assente se la paziente segue scrupolosamente le indicazioni terapeutiche in corso di stimolazione ovarica e di gravidanza. ${ }^{41}$ Queste osservazioni evidenziano la sicurezza dei trattamenti di infertilità nelle pazienti affette da MAS con una malattia ben controllata o in remissione che abbiano ricevuto un'adeguata consulenza sull'importanza dell'aderenza alla terapia antireumatica per prevenire le esacerbazioni della malattia.

\section{Trombosi}

I livelli di estradiolo - con gli effetti procoagulanti noti - aumentano durante OI e COS, potenzialmente superando da 2 a 10 volte i livelli del periodo mestruale ${ }^{42} \mathrm{~A}$ loro volta, i livelli ormonali raggiunti durante la gravidanza sono fino a dieci volte superiori a quelli ottenuti con farmaci correlati alla fertilità. ${ }^{43}$ Pertanto, esiste un rischio di trombosi durante i trattamenti per l'infertilità, anche se è inferiore a quello osservato durante la gravidanza. Mentre mancano dati per le pazienti con altre MAS, il rischio di trombosi correlata a $\mathrm{OI} / \mathrm{COS}$ è noto per essere aumentato nelle pazienti con LES, specialmente se con concomitante positività per $\mathrm{aPL}$ - e ancora di più nelle pazienti con APS in cui sono state riportate trombosi arteriosa cerebrale e cardiaca. ${ }^{44-47}$ Queste osservazioni suggeriscono l'indicazione alla terapia antitrombotica profilattica nelle donne con LES e APS sottoposte a trattamenti di infertilità. A seconda del rischio individuale, potranno essere consigliati aspirina a basso dosaggio e/o eparina a dosaggio profilattico/ anticoagulante come durante la gravidanza. ${ }^{23}$ In tutti i casi, il trattamento con eparina deve essere interrotto 12-24 ore prima della procedura di recupero degli ovociti e reintrodotto 6-12 ore dopo se non si siano verificati sanguinamenti. L'aspirina a basso dosaggio deve essere interrotta 5-7 giorni prima del recupero degli ovociti. A tal proposito, nel 2016, si è espressa anche l'EULAR pubblicando raccomandazioni, secondo le quali, nelle pazienti con aPL/APS, si dovrebbero usare i farmaci (LDA, LMWH/UFH) al dosaggio (profilattico/terapeutico) che si userebbe nella stesse in gravidanza in base al rischio stimato.

\section{Sindrome da iperstimolazione ovarica}

La sindrome da iperstimolazione ovarica (OHSS), una complicanza dell'induzione dell'ovulazione, è po- 
tenzialmente pericolosa per la vita delle pazienti e si verifica quando la stimolazione con estrogeni è incontrollata; può provocare aumento eccessivo delle dimensioni delle ovaie e maggiore permeabilità vascolare. Questo può causare ascite, versamento pleurico, emoconcentrazione, ridotta perfusione renale, coagulazione intravascolare disseminata, sindrome da distress respiratorio dell'adulto e trombosi, con un tasso di mortalità tra $1 / 45.000$ e $1 / 500.000 .{ }^{48}$ Le pazienti con MAS non sembrano avere un rischio più elevato di OHSS rispetto alla popolazione generale di pazienti infertili, ${ }^{39}$ ma presentano un rischio più elevato di complicanze correlate all'OHSS, anche severe. ${ }^{44-46}$ La prevenzione dell'OHSS è obbligatoria nelle pazienti con MAS. Poiché l'OHSS è principalmente causata dalla somministrazione di hCG esogeno, utilizzato per l'induzione dell'ovulazione, potrebbe essere prevenuta con la frammentazione del ciclo IVF/ICSI-ET grazie all'utilizzo della crioconservazione degli embrioni e utilizzando gli antagonisti del GnRH al posto dell'hCG per l'induzione dell'ovulazione.

Nella letteratura scientifica è riportato, inoltre, un caso di polmonite da aspirazione grave con conseguente insufficienza respiratoria e disfunzione multiorgano in una paziente affetta da connettivite mista, ipertensione polmonare e APS secondaria sottoposta a COS con gonadotropine per un trattamento urgente di preservazione della fertilità. ${ }^{49}$ È importante sottolineare che la paziente è stata sottoposta a trattamento COS nonostante fosse in una fase attiva della malattia. Infine, è stato descritto un caso di polimiosite e vasculite insorto 5 giorni dopo la somministrazione di GnRH utilizzato per l'induzione dell'ovulazione in una paziente sterile senza precedenti patologie autoimmuni. ${ }^{50}$

\section{Sicurezza dei farmaci per la fertilità nelle malattie autoimmuni sistemiche}

\section{Gonadotropine}

Le gonadotropine - purificate o ricombinanti - vengono utilizzate per ottenere COS per IUI o IVF/ICSI. Per quanto concerne eventuali effetti avversi, in letteratura sono riportati due casi di LES che si sono presentati rispettivamente dopo 8 e 10 cicli di COS ed attribuiti agli alti livelli di estradiolo (E2) dovuti al trattamento. ${ }^{38}$ Tuttavia, la ripetizione di più cicli di COS potrebbe essere ingiustificata sia nella popolazione generale che in quella a rischio più elevato come pazienti con MAS. In generale, bisognerebbe preferite le strategie volte a ottimizzare i risultati cumulativi di un singolo COS. Poiché le 'stimolazioni lievi' con basse dosi di GN si associano a livelli di picco di E2 inferiori ma anche a risultati peggiori in termini di produzione ovocitaria rispetto alla COS standard, ${ }^{51}$ per ottimizzare gli effetti di un singolo COS, il trattamento con gonadotropine nei pazienti con MAS dovrebbe utilizzare dosi standard.

\section{Gonadotropina corionica umana}

La hCG purificata o ricombinante è comunemente usata per favorire la maturazione follicolare finale al termine di OI o COS. Tuttavia, l'hCG esogena utilizzata per l'induzione dell'ovulazione è la causa principale di OHSS. Pertanto, la somministrazione di hCG dovrebbe preferibilmente essere evitata nelle pazienti ad alto rischio di OHSS o di complicanze trombotiche correlate all'OHSS, come le pazienti con MAS.

\section{Agonisti del GnRH}

Oltre alla conservazione della fertilità, GnRH-a ha due indicazioni principali nel contesto dei trattamenti dell'infertilità, vale a dire la controregolazione ipofisaria durante la COS in protocolli 'lunghi' e l'induzione dell'ovulazione follicolare alla fine di OI, IUI o COS - in alternativa all'hCG. ${ }^{52}$ Studi sulla somministrazione dei GnRH-a per altre indicazioni e in i pazienti con patologie reumatiche non hanno riportato esacerbazioni di LES o connettivite mista. ${ }^{43,53}$ A causa dei possibili effetti avversi della somministrazione dell'hCG in pazienti con MAS, è consigliabile l'utilizzo dei GnRH-a per l'induzione dell'ovulazione.

\section{Antagonisti del GnRH}

Gli antagonisti del GnRH possono essere utilizzati per la desensibilizzazione ipofisaria durante il ciclo di stimolazione ovarica in protocolli 'brevi' e si associano a picchi sierici più bassi di estradiolo rispetto ai regimi che utilizzano GnRH-a con un'incidenza notevolmente ridotta di OHSS. ${ }^{54}$ Finora nessuno studio ha affrontato la sicurezza dell'utilizzo dell' antagonista del GnRH in protocolli COS nelle pazienti con MAS, ma è stato suggerito un effetto antinfiammatorio degli antagonisti del GnRH nei pazienti affetti da artrite reumatoide. ${ }^{55}$

\section{Anti-estrogeni}

Clomifene citrato (CC) somministrato per cinque giorni - tipicamente utilizzato nei protocolli OI/IUI non sembra associarsi ad un aumento dei tassi di complicanze nelle pazienti con MAS, ad eccezione di un caso descritto di trombocitopenia e lesioni cutanee in una paziente con LES e aPL dopo il sesto ciclo con $\mathrm{CC}^{56} \mathrm{e}$ un altro caso di insorgenza di LES dopo 6 cicli di trattamento. ${ }^{38}$ Sulla base di questi risultati, la ripetizione di diversi cicli di CC potrebbe essere sconsigliata nelle pazienti con MAS.

Inibitori dell'aromatasi (AI). Il letrozolo assunto per cinque giorni viene utilizzato per l'induzione dell'ovulazione, principalmente nelle pazienti con sindrome dell'ovaio policistico. ${ }^{57}$ Mancano dati sull'uso dell'IA per 
l'induzione dell'ovulazione in pazienti con MAS. Sulla base di studi su donne che assumono AI per carcinoma mammario, alcuni autori hanno ipotizzato che l'IA possa interrompere l'equilibrio tra i linfociti Th1/Th2 e favorire l'insorgenza dell'artrite reumatoide ${ }^{58}$ e della sclerosi sistemica. ${ }^{59}$ Tuttavia, sembra improbabile che una somministrazione dell'IA di breve durata, come necessario per l'induzione dell'ovulazione, possa determinare gli stessi problemi di sicurezza della terapia prolungata utilizzata nel carcinoma mammario. Nel contesto dei trattamenti per la fertilità, il letrozolo viene utilizzato per abbattere i livelli di E2 nelle pazienti con carcinoma mammario sensibile agli ormoni sottoposte a COS, al fine di migliorare la sicurezza della procedura. Questa strategia potrebbe essere utile anche nelle pazienti con MAS sottoposte a COS, in cui vi siano preoccupazioni simili sull'aumento dei livelli di E2. Comunque, questa opzione non è mai stata riportata nelle pazienti con MAS.

\section{Estrogeni}

I cicli integrati con estrogeni sono usati come alternativa al ciclo naturale per i tentativi di FET, per una più facile sincronizzazione della procedura ET o a causa di cicli anovulatori irregolari delle pazienti. Nelle pazienti con MAS a rischio di complicanze mediate dagli estrogeni, ove possibile, la FET deve essere programmata preferenzialmente in un ciclo naturale, senza integrazione di estrogeni. Quando la somministrazione esogena non può essere evitata, è stato proposto l'uso di estrogeni naturali che sembrano più sicuri, ${ }^{60}$ poiché sono meno procoagulanti degli estrogeni sintetici. Inoltre, dovrebbe essere preferita una via di somministrazione non orale per evitare l'effetto di primo passaggio.

\section{Progestinici}

Diversi trattamenti con progestinici sono utilizzati per il supporto della fase luteale nei trattamenti per l'infertilità. I progestinici sono stati utilizzati senza complicanze anche per la fase luteale e il supporto della gravidanza nelle pazienti con MAS. . $^{61,62}$ Pertanto, anche se la necessità di integrare il progesterone deve essere attentamente valutata rispetto al rischio di trombosi, la terapia con progesterone non è controindicata nelle pazienti con MAS. La terapia antitrombotica concomitante deve essere prescritta come indicato in gravidanza in pazienti a rischio significativo di complicanze tromboemboliche (come ad es. pazienti con APS), in base al rischio individuale. ${ }^{23}$

\section{Conclusioni}

Le procedure di PMA risultano sicure per le donne con malattie autoimmuni sistemiche se le pazienti sono in remissione stabile di malattia e se ricevono un trattamento adeguato. Inoltre, in presenza di trombofilia congenita o acquisita (es. aPL positività), è necessario intraprendere un trattamento profilattico al fine di prevenire il rischio trombotico dovuto alla stimolazione ormonale utilizzata durante le procedure. Le donne con malattie autoimmuni sistemiche mostrano un tasso di successo delle procedure di PMA paragonabile a quello della popolazione generale e le complicanze delle successive gravidanze di queste pazienti sono in linea con quelle osservate nelle gravidanze spontanee.

\section{Bibliografia}

1. Ostensen M, Brucato A, Carp H, et al. Pregnancy and reproduction in autoimmune rheumatic diseases. Rheumatology (Oxford). 2011;50:657-64.

2. Brouwer J, Hazes JM, Laven JS, et al. Fertility in women with rheumatoid arthritis: influence of disease activity and medication. Ann Rheum Dis. 2015;74: 1836-41.

3. Jawaheer D, Zhu JL, Nohr EA, et al. Time to pregnancy among women with rheumatoid arthritis. Arthritis Rheum. 2011;63:1517-21.

4. Vanni VS, De Lorenzo R, Privitera L, et al. Safety of fertility treatments in women with systemic autoimmune diseases (SADs). Expert opinion on drug safety, (justaccepted). 2019;18:841-52

5. Harbuz MS, Chover-Gonzalez AJ, Jessop DS. Hypothalamo-pituitary-adrenal axis and chronic immune activation. Ann N Y Acad Sci.2003;992:99-106.

6. Ebrahimi M, Akbari Asbagh F. The role of autoimmunity in premature ovarian failure. Iran J Reprod Med. 2015;13:461-72

7. Borba VV, Zandman-Goddard G, Shoenfeld Y. Prolactin and Autoimmunity. Front Immunol. 2018;9:73.

8. Oktem O, Oktay K. A novel ovarian xenografting model to characterize the impact of chemotherapy agents on human primordial follicle reserve. Cancer Res. 2007;67:10159-62.

9. Appenzeller S, Blatyta PF, Costallat LT. Ovarian failure in SLE patients using pulse cyclophosphamide: comparison of different regimes. Rheumatol Int. 2008;28:567-71.

10. Khizroeva J, Nalli C, Bitsadze V, et al. Infertility in women with systemic autoimmune diseases. Best Pract Res Clin Endocrinol Metab. 2019;2:101369.

11. Ntali S, Damjanov N, Drakakis P, et al. Women's health and fertility, family planning and pregnancy in immunemediated rheumatic diseases: a report from a south-eastern European Expert Meeting. Clin Exp Rheumatol. 2014;32:959-68.

12. Katz PP. Childbearing decisions and family size among women with rheumatoid arthritis. Arthritis Rheum. 2006;55:217-23.

13. Ostensen M. New insights into sexual functioning and fertility in rheumatic diseases. Best Pract Res Clin Rheumatol. 2004;18:219-32.

14. Helland Y, Kjeken I, Steen E, et al. Rheumatic diseases and sexuality: disease impact and self-management strategies. Arthritis Care Res (Hoboken). 2011;63:743-50. 
15. Simopoulou M, Sfakianoudis K, Maziotis E, et al The Impact of Autoantibodies on IVF Treatment and Outcome: A Systematic Review. Int J Mol Sci. 2019;19:20.

16. Kikuchi K, Shibahara H, Hirano Y, et al. Antinuclear antibody reduces the pregnancy rate in the first IVF-ET treatment cycle but not the cumulative pregnancy rate without specific medication. Am J Reprod Immunol. 2003;50:363-7.

17. Ying Y, Zhong YP, Zhou CQ, et al. Antinuclear antibodies predicts a poor IVF-ET outcome: impaired egg and embryo development and reduced pregnancy rate. Immunol Invest. 2012;41:458-68.

18. Vega M, Barad DH, Yu Y, et al. Anti-mullerian hormone levels decline with the presence of antiphospholipid antibodies. Am J Reprod Immunol. 2016;76:333-7.

19. Yamakami LY, Serafini PC, de Araujo DB, et al. Ovarian reserve in women with primary antiphospholipid syndrome. Lupus. 2014;23:862-7.

20. Chighizola CB, Pregnolato F, Raschi E, et al. Antiphospholipid anti- bodies and infertility: a gene expression study in decidual stromal cells. Isr Med Assoc J. 2016;18:146-9.

21. Chighizola CB, de Jesus GR, Branch DW. The hidden world of anti-phospholipid antibodies and female infertility: A literature appraisal. Autoimmun Rev. 2016;15:493-0.

22. Ostensen M. Preconception Counseling. Rheum Dis Clin North Am. 2017;43:189-99

23. Andreoli L, Bertsias GK, Agmon-Levin N, et al. EULAR recommendations for women's health and the management of family planning, assisted reproduction, pregnancy and menopause in patients with systemic lupus erythematosus and/or antiphospholipid syndrome. Ann Rheum Dis. 2017;76:476-85.

24. Ostensen M, Andreoli L, Brucato A, et al. State of the art: reproduction and pregnancy in rheumatic diseases. Autoimmun Rev. 2015;14:376-86.

25. Ostensen M, Cetin I. Autoimmune connective tissue diseases. Best Pract Res Clin Obstet Gynaecol. 2015;29: 658-70.

26. Birru Talabi M, Clowse MEB, Schwarz EB, et al. Perspectives of adult rheumatologists regarding family planning counseling and cure: a qualitative study. Arthritis Care Res. 2019;15

27. Bermas BL, Sammaritano LR. Fertility and pregnancy in rheumatoid arthritis and systemic lupus erythematosus. Fertil Res Pract. 2015;1:13.

28. Peart E, Clowse ME. Systemic lupus erythematosus and pregnancy outcomes: an update and review of the literature. Curr Opin Rheumatol. 2014;26:118-23.

29. Sullivan-Pyke CS, Senapati S, Mainigi MA, et al. In Vitro fertilization and adverse obstetric and perinatal outcomes. Semin Perinatol. 2017;41:345-53.

30. Manger K, Wildt L, Kalden JR, et al. Prevention of gonadal toxicity and preservation of gonadal function and fertility in young women with systemic lupus erythematosus treated by cyclophosphamide: the PREGOStudy. Autoimmun Rev. 2006;5:269-72.

31. Koga T, Umeda M, Endo Y, et al. Effect of a gonadotropinreleasing hormone analog for ovarian function preservation after intravenous cyclophosphamide therapy in systemic lupus erythematosus patients: a retrospective inception cohort study. Int J Rheum Dis. 2018;21:1287-92.
32. Lambertini M, Horicks F, Del Mastro L, et al. Ovarian protection with gonadotropin-releasing hormone agonists during chemotherapy in cancer patients: from biological evidence to clinical application. Cancer Treat Rev. 2019;72:65-77.

33. Elizur SE, Chian RC, Pineau CA, et al. Fertility preservation treatment for young women with autoimmune diseases facing treatment with gonadotoxic agents. Rheumatology (Oxford). 2008;47:1506-9.

34. Ott J, Nouri K, Stögbauer L, et al. Ovarian tissue cryopreservation for non-malignant indications. Arch Gynecol Obstet. 2010;281:735-9.

35. Henes M, Henes JC, Neunhoeffer E, et al. Fertility preservation methods in young women with systemic lupus erythematosus prior to cytotoxic therapy: experiences from the FertiPROTEKT network. Lupus. 2012;21:953-8.

36. Ragab A, Barakat R, Ragheb M, et al. Subfertility treatment in women with systemic lupus erythematosus. J Obstet Gynaecol. 2012;32:569-71.

37. Roque M, Valle M, Kostolias A, et al. Freeze-all cycle in reproductive medicine: current perspectives. JBRA Assist Reprod. 2017;21:49-3.

38. Ben-Chetrit A, Ben-Chetrit E. Systemic lupus erythematosus induced by ovulation induction treatment. Arthritis Rheum. 1994;37:1614-7.

39. Orquevaux P, Masseau A, Le Guern V, et al. In vitro fertilization in 37 women with systemic lupus erythematosus or antiphospholipid syndrome: a series of 97 procedures. J Rheumatol. 2017;44:613-8.

40. Guballa N, Sammaritano L, Schwartzman S, et al. Ovulation induc- tion and in vitro fertilization in systemic lupus erythematosus and antiphospholipid syndrome. Arthritis Rheum. 2000;43:550-6.

41. Reggia R, Andreoli L, Sebbar H, et al. An observational multicentre study on the efficacy and safety of assisted reproductive technologies in women with rheumatic diseases. Rheumatology Advances in Practice, 2019,22:3 rkz005.

42. Levine AB, Lockshin MD. Assisted reproductive technology in SLE and APS. Lupus. 2014;23:1239-41.

43. Blumenfeld Z, Shapiro D, Shteinberg M, et al. Preservation of fertility and ovarian function and minimizing gonadotoxicity in young women with systemic lupus erythematosus treated by chemotherapy. Lupus. 2000;9:401-5.

44. Andrejevic S, Bonaci-Nikolic B, Bukilica M, et al. Intracardiac throm- bosis and fever possibly triggered by ovulation induction in a patient with antiphospholipid antibodies. Scand J Rheumatol. 2002;31:249-51.

45. Koo EJ, Rha JH, Lee BI, et al. A case of cerebral infarct in combined antiphospholipid antibody and ovarian hyperstimulation syndrome. $\mathrm{J}$ Korean Med Sci. 2002;17:574-6.

46. Giner V, Oltra MR, Esteban MJ, et al. Catastrophic antiphospholipid syndrome related to severe ovarian hyperstimulation. Clin Rheumatol. 2007;26:991-3.

47. Girolami A, Scandellari R, Tezza F, et al. Arterial thrombosis in young women after ovarian stimulation: case report and review of the literature. J Thromb Thrombolysis. 2007;24:169-74.

48. Costa M, Colia D. Treating infertility in autoimmune patients. Rheumatology (Oxford). 2008;47:38-41. 
49. Sioulas VD, Gracia CR. Ovarian stimulation and embryo banking for fertility preservation in a woman with severe mixed connective tissue disease: is it safe? J Assist Reprod Genet. 2012;29:271-5.

50. Lazúrová I, Angelovicová J, Petríková J, et al. A case of polymyositis and vasculitis induced by ovulation induction therapy with gonadotropin-releasing hormone. Clin Rheumatol. 2010;29:1327-30.

51. Orvieto R, Vanni VS, Gleicher N. The myths surrounding mild stimula- tion in vitro fertilization (IVF). Reprod Biol Endocrinol. 2017;15:48.

52. Youssef MA, Van der Veen F, Al-Inany HG, et al. Gonadotropin- releasing hormone agonist versus HCG for oocyte triggering in antagonist-assisted reproductive technology. Cochrane Database Syst Rev. 2014;10: CD008046.

53. Blumenfeld Z, Shapiro D, Shteinberg M, et al. Preservation of fertility and ovarian function and minimizing gonadotoxicity in young women with systemic lupus erythematosus treated by chemotherapy. Lupus. 2000;9:401-5.

54. Al-Inany HG, Youssef MA, Ayeleke RO, et al. Gonadotrophin- releasing hormone antagonists for assisted reproductive technology. Cochrane. Database Syst Rev. 2016;4:CD001750.

55. Kåss A, Hollan I, Fagerland MW, et al. Rapid anti-inflammatory effects of gonadotropin-releasing hormone antagonism in rheumatoid arthritis patients with high gonadotropin Levels in the AGRA trial. PLoS One. 2015;10:e139439

56. Huong DL, Amoura Z, Duhaut P, et al. Risk of ovarian failure and fertility after intravenous cyclophosphamide. A study in 84 patients. J Rheumatol. 2002;29:2571-6.

57. Franik S, Eltrop SM, Kremer JA, et al. Aromatase inhibitors (letrozole) for subfertile women with polycystic ovary syndrome. Cochrane Database Syst Rev. 2018;5:CD010287.

58. Morel B, Marotte H, Miossec P. Will steroidal aromatase inhibitors induce rheumatoid arthritis? Ann Rheum Dis. 2007;66:557-8.

59. Laroche M, Borg S, Lassoued S, et al. Joint pain with aromatase inhibitors: abnormal frequency of Sjogren's syndrome. J Rheumatol. 2007;34:2259-63.

60. Bellver J, Pellicer A. Ovarian stimulation for ovulation induction and in vitro fertilization in patients with systemic lupus erythematosus and antiphospholipid syndrome. Fertil Steril. 2009;92:1803-10.

61. Trakakis E, Loghis C, Laggas D, et al. Successful fullterm pregnancies with assisted reproduction supported with prednisolone, acetylsalicylic acid and high progesterone doses in a lupus patient. Clin Exp Obstet Gynecol. 2007;34:212-4.

62. Kratz B, Rasheed A, Holden JP. Luteal phase support for documented failure of placental steroidogenesis: A case report. Case Rep Womens Health. 2016;14:1-3. 


\section{Il punto di vista delle pazienti: la ricerca che accarezza}

e pazienti affette da sclerosi sistemica (SSc) viansia, per sé e per il nascituro. Da una parte, infatti, a causa anche delle informazioni non scientifiche che ormai si trovano ovunque, temono che la malattia possa essere ereditaria e quindi trasmissibile al feto; dall'altra temono che la malattia possa peggiorare durante la gravidanza. Inoltre, l'incertezza dell'outcome della gravidanza stessa (nascite premature, aborti spontanei) crea timore nell'affrontare questo percorso.

Tra le pazienti emerge sempre più la necessità di un percorso educazionale, che veda la futura puerpera (e, laddove possibile il futuro padre) al centro di un processo condiviso da un team multidisciplinare con lo specialista di riferimento per la patologia di base e un ginecologo, per tenere sotto controllo la SSc ed evitare possibili complicazioni. In questo modo si verrebbe a creare l'ambiente più favorevole e tranquillo, che consentirebbe di programmare e monitorare la gravidanza in ogni sua fase e, se la situazione clinica lo richiedesse, posporla o escluderla. In quest'ultimo caso, però, sarebbe fondamentale motivare la scelta (es., una gravidanza sarebbe rischiosa sia per la madre sia per il feto) e fare in modo che la paziente riceva il giusto supporto psicologico. Una gravidanza programmata porterebbe a minimizzare il rischio di esposizione dell'embrione e/o feto a medicinali potenzialmente teratogeni, aumentando la sicurezza e fiducia nella futura madre. Da subito, per evitare eventuali preoccupazioni, la futura madre dovrebbe sapere che, in caso la situazione clinica lo richiedesse, potrebbe ricevere farmaci ma che, comunque, sarà sempre garantito che il beneficio sarà superiore al potenziale rischio, per lei e per il nascituro. Durante la gravidanza, quelli che sono disturbi normali per una donna sana, possono aumentare problematiche già presenti in una paziente sclerodermica (es., reflusso gastroesofageo): sarebbe opportuno non solo un approccio medico, ma anche cercare di rassicurare la futura madre, affinché non pensi a un peggioramento della sclerosi sistemica.

Una volta nato il bambino, la madre deve sentirsi seguita anche durante l'allattamento, per evitare, ad esempio, l'assunzione di farmaci potenzialmente dannosi per il bambino.

Riassumendo, possiamo dire che una donna con la SSc è una donna un po' speciale, che ha bisogno solo di più attenzioni e rassicurazioni nel momento in cui decide di avere un bambino. Bisogna smorzare le sue paure attraverso un lavoro di squadra, in cui lei venga messa al centro. La gravidanza non è una malattia, e come tale dovrebbe essere vissuta, ma la sclerosi sistemica lo è, e può portare a una conduzione più im- pegnativa della fase gestazionale. Alla fine, una carezza al bimbo, ripagherà e cancellerà tutti i timori, sia della madre, sia dei medici che l'hanno accompagnata in questa splendida esperienza.

\section{Ilaria Galetti \\ Gruppo Italiano Lotta alla Sclerodermia (GILS), Milano E-mail:ila.galetti@gmail.com}

T e gravidanze a rischio sono un argomento

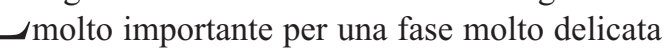
della vita di una giovane donna.

Tenendo conto che le patologie reumatologiche autoimmuni esordiscono con alta prevalenza in giovani donne in età fertile, è assolutamente necessario avere delle attenzioni particolari.

A differenza di un'epoca ormai passata in cui le raccomandazioni erano volte ad evitare una gravidanza per scongiurare un rischio di peggioramento della malattia, ora possiamo guardare ad un futuro più sereno. Possiamo dire che ora, fortunatamente, la ricerca 'accarezza'.

Le giovani donne che intendono essere madri hanno la necessità di sentirsi tutelate, protette e rassicurate.

Lo specialista che le ha in cura ha il dovere di spiegare molto bene quali sono le modalità che possono permettere di affrontare la gravidanza. Un team di specialisti che si parlano tra loro è fondamentale per tranquillizzare la futura mamma anche per quel che riguarda l'immediato post parto.

Il medico saprà comunicare alla paziente l'importanza di porsi innanzitutto come primo obiettivo condiviso quello della remissione di malattia, affinché la gravidanza possa essere affrontata in un momento di stabile controllo dell'attività della stessa.

Molto delicato e meritevole di specifiche attenzioni è anche il rapporto con l'altro futuro genitore. Nel team degli specialisti è necessario avere anche un supporto psicologico per la coppia. Va infine ricordato che vi sono pazienti reumatiche che, pur desiderandola finiscono per rinunciare ad una gravidanza: le ragioni possono riguardare la paura che questa possa provocare una riaccensione della malattia, l'ansia di 'trasmettere' al figlio la propria patologia, così come il timore di non potersi prendere piena cura del nascituro a causa di dolori, terapie e astenia. Un confronto sempre più aperto tra pazienti e clinici, ma anche tra pazienti e pazienti, può aiutare la donna a compiere la sua scelta in modo consapevole e maturo.

Silvia Ostuzzi

ALOMAR Onlus, Milano

E-mail: silviaostuzzi.alomar@gmail.com 


\section{LINEE GUIDA PER GLI AUTORI}

I Quaderni dell 'Italian Journal of Medicine (Quaderni ITJM), costituiscono una collana supplementare solo online annessa alla rivista Italian Journal of Medicine contenente lavori solo in lingua italiana .

I Quaderni ITJM pubblicano:

- Monografie ad hoc individuate dal Presidente FADOI, dal Consiglio Direttivo, dal Board Scientifico o dall'Editor in Chief dell'Italian Journal of Medicine, in funzione del contesto scientifico-istituzionale attuale.

- Monografie ad hoc su temi di particolare rilevanza scientifica a cura della Commissione FADOI Giovani.

- Traduzioni in italiano di alcuni lavori pubblicati sui numeri standard dell'Italian Journal of Medicine, di particolare interesse per la comunità scientifica.

\section{STESURA DEI LAVORI}

I lavori dovranno essere redatti in modo conforme alle linee guida sotto riportate:

- I manoscritti devono essere scritti interamente in lingua italiana, su documento di Word, con carattere Times New Roman/Arial, dimensione 12, formato A4, interlinea doppia e margini $2,54 \mathrm{~cm}$

Parole totali: $\max$ 4000; Sommario/Abstract: $\max 250$ parole; Bibliografia: min 40 voci; Tabelle e Figure: $3 / 5$ totali (le tabelle non devono superare n. 1 pagina del documento in Word).

- La strutturazione del contenuto deve attenersi agli standard internazionali per la Rassegna (Review): i) Abstract riassuntivo dell'intero lavoro; ii) Introduzione al tema trattato; iii) Criteri e strumenti di ricerca (criteri di inclusione/esclusione, banche dati consultate, ...); iv) i successivi paragrafi devono illustrare le più recenti scoperte scientifiche nel settore; v) Conclusioni; vi) Bibliografia.

- La prima pagina deve riportare: i) titolo (in stampatello minuscolo), senza acronimi; ii) nome e cognome per esteso di ciascun autore; iii) affiliazione(i) di ciascun autore, numerate con numeri arabi iv) eventuali ringraziamenti; v) nome e indirizzo postale completi dell'autore corrispondente, corredati da telefono, fax, e-mail; vi) da 3 a 5 parole chiave, separate da virgola. La seconda pagina può riportare: i) contributi degli autori, e.g. informazioni relative a contributi sostanziali delle persone coinvolte nello studio (http://www.icmje.org/\#author); ii) dichiarazione relativa a potenziali conflitti d'interesse; iii) ulteriori informazioni (e.g. fondi, esposizioni durante conferenze...).

- In caso di utilizzo di tabelle, queste devono essere tutte numerate con numeri arabi e citate nel testo in ordine consecutivo (e.g. NON nominare le tabelle come Tabella $1 \mathrm{~A}, 1 \mathrm{~B}, \ldots$ o $1.0,1.1, \ldots)$. Le tabelle devono essere presentate in formato editabile. Ciascuna tabella deve essere corredata da una breve didascalia; in caso di abbreviazioni, riportare una nota a piè di CIASCUNA tabella che spieghi TUTTE le abbreviazioni presenti in ognuna.

- In caso di utilizzo di figure, queste devono essere inviate in formato tiff o .jpg, allegate al manoscritto in singoli files, secondo le seguenti specifiche:

i) a colori (salvate in modalità CMYK): minimo 300 dpi di risoluzione;

ii) in bianco e nero: minimo $600 \mathrm{dpi}$ di risoluzione;

iii) minimo $17,5 \mathrm{~cm}$ di larghezza.

Ciascuna figura deve essere corredata da una breve didascalia.

$N B$ : In caso di Tabelle/Figure riprese e/o modificate da altri lavori già pubblicati, sarà cura degli autori accertarsi se tali materiali siano o meno coperti da copyright e procurarsi i permessi necessari per la riproduzione. Tali permessi dovranno essere allegati alla versione definitiva del lavoro. L'ufficio editoriale si riserva la facoltà di rimuovere Tabelle/Figure coperte da copyright, se sprovviste dei necessari permessi.

- In caso di utilizzo di abbreviazioni, la prima volta che esse sono citate è necessario scrivere per esteso la definizione+abbreviazione tra parentesi tonde [e.g. risonanza magnetica $(\mathrm{RMN})]$, a seguire si dovrà riportare solo l'abbreviazione (unica eccezione: nei titoli e nelle didascalie di tabelle e figure NON si utilizzano abbreviazioni).

\section{BIBLIOGRAFIA}

Le voci bibliografiche devono essere formattate secondo lo stile Vancouver.

Nella sezione Bibliografia, le voci bibliografiche devono essere numerate consecutivamente nell'ordine in cui appaiono per la prima volta nel testo (NON in ordine alfabetico) e, nel testo, devono essere indicate con numeri arabi in apice. Voci bibliografiche riferite a comunicazioni personali o dati non pubblicati devono essere incorporate nel testo e NON inserite tra le voci numerate [e.g. (Wright 2011, dati non pubblicati) o (Wright 2011, comunicazione personale)]. Le voci bibliografiche nella sezione Bibliografia devono tassativamente essere preparate come segue:

i) più di 3 autori, citare 3 autori, et al. Se il lavoro contiene solo 4 autori, citarli tutti e 4 ;

ii) titolo del lavoro in stampatello minuscolo;

iii) nome della rivista, senza punti, abbreviato secondo gli standard internazionali; in caso di dubbi sulla corretta abbreviazione, fare riferimento ai seguenti siti:

a. ISI Journal Abbreviations Index (http://library.caltech.edu/ reference/abbreviations/);

b. Biological Journals and Abbreviations (http://home.ncifcrf. gov/research/bja/);

c. Medline List of Journal Titles (ftp://ftp.ncbi.nih.gov/pubmed/J_Medline.txt);

iv) inserire l'anno di pubblicazione subito dopo il nome della rivista, seguito da punto e virgola;

v) NON inserire giorno o mese di pubblicazione;

vi) citare solo il volume, seguito dai due punti (NON citare il fascicolo tra parentesi);

vii) abbreviare le pagine, e.g. 351-8

Per accertarsi di aver correttamente formattato le voci bibliografiche, confrontarle con le citazioni in PubMed (http://www.ncbi. nlm.nih.gov/pubmed).

Esempi (prestare attenzione anche alla punteggiatura):

Articolo standard su Rivista

Halpern SD, Ubel PA, Caplan AL. Solid-organ transplantation in HIV-infected patients. N Engl J Med 2002;347:284-7.

Proceedings

Christensen S, Oppacher F. An analysis of Koza's computational effort statistic for genetic programming. In: Foster JA, Lutton E, Miller J, Ryan C, Tettamanzi AG, eds. Genetic programming. EuroGP 2002: Proceedings of the 5th European Conference on Genetic Programming, 2002 Apr 3-5, Kinsdale, Ireland. Berlin: Springer; 2002. pp 182-91.

Articoli i cui autori sono Organizzazioni

Diabetes Prevention Program Research Group. Hypertension, insulin, and proinsulin in participants with impaired glucose tolerance. Hypertension 2002;40:679-86

Libri

Murray PR, Rosenthal KS, Kobayashi GS, Pfaller MA. Medical microbiology. 4th ed. St. Louis, MO: Mosby; 2002. (CITAZIONE DEL LIBRO INTERO)

Meltzer PS, Kallioniemi A, Trent JM. Chromosome alterations in human solid tumors. In: Vogelstein B, Kinzler KW, eds. The genetic basis of human cancer. New York, NY: McGraw-Hill; 2002. pp 93113. (CITAZIONE DI UN CAPITOLO)

\section{MODALITÀ D'INVIO DEI LAVORI}

Monografie

Gli Autori dovranno fare riferimento all'Editor-in-Chief o alle persone da lui designate nelle lettere di invito a scrivere gli articoli programmati.

Per gli articoli inviati da giovani internisti, gli Autori dovranno fare riferimento al Dr. Michele Meschi (e-mail:mmeschi@ausl.pr.it)e agli eventuali altri referenti da lei designati, nelle prime fasi di stesura dei manoscritti, revisioni e correzioni. 


\section{QUADERNI}

Il Dr. Meschi raccoglierà poi le versioni definitive dei lavori di ciascuna monografia e provvederà all'invio di tutti i materiali all'ufficio editoriale.

I lavori solo nella loro versione definitiva e approvata dalla Commissione FADOI Giovani dovranno pervenire all'ufficio editoriale già pronti per l'impaginazione e immediata pubblicazione (già corredati da eventuali permessi per la riproduzione di tabelle e immagini redatti secondo le presenti linee guida).

\section{Traduzioni}

Previo invito dell'Editor-in-Chief, gli Autori dovranno far pervenire all'ufficio editoriale la versione tradotta in italiano, al seguente indirizzo e-mail: paola.granata@pagepress.org

Il file in formato Word dovrà essere formattato secondo gli standard editoriali della rivista ufficiale ed essere già pronto per impagina- zione e immediata pubblicazione (corredato da eventuali permessi per la riproduzione di tabelle e immagini).

Si prega di inviare le eventuali tabelle in formato editabile e le figure in alta definizione secondo gli standard sopra riportati.

\section{NOTA PER GLI AUTORI}

I lavori pubblicati sui Quaderni ITJM non verranno indicizzati, ma saranno liberamente disponibili in un'apposita sezione del sito FADOI (http://www.fadoi.org/) e della rivista ufficiale.

Gli Autori i cui lavori siano accettati per la pubblicazione sui Quaderni ITJM e che fossero interessati a vederli pubblicati anche sulla rivista ufficiale, dovranno sottomettere attraverso il sito dell'ITJM (www.italjmed.org) la versione (già tradotta) in inglese e redatta in modo conforme alle linee guida della rivista; seguiranno poi la procedura di selezione tramite peer review e, se accettati, saranno inseriti nel piano editoriale standard.

\section{STAFF EDITORIALE}

Paola Granata, Journal Manager

paola.granata@pagepress.org

Claudia Castellano, Production Editor

Tiziano Taccini, Technical Support
PUBBLICATO DA

PAGEPress Publications

via A. Cavagna Sangiuliani 5

27100 Pavia, Italy

T. +39.0382 .1549020$

F: +39.0382 .1727454$

\section{agepress}

www.pagepress.org info@pagepress.org

\section{QUADERNI - ITALIAN JOURNAL OF MEDICINE}

Tutti gli articoli pubblicati sui QUADERNI - Italian Journal of Medicine sono redatti sotto la responsabilità degli Autori. La pubblicazione o la ristampa degli articoli della rivista deve essere autorizzata per iscritto dall'editore. Ai sensi dell'art. 13 del D.Lgs 196/03, i dati di tutti i lettori saranno trattati sia manualmente, sia con strumenti informatici e saranno utilizzati per l'invio di questa e di altre pubblicazioni e di materiale informativo e promozionale. Le modalità di trattamento saranno conformi a quanto previsto dall'art. 11 del D.Lgs 196/03. I dati potranno essere comunicati a soggetti con i quali PAGEPress intrattiene rapporti contrattuali necessari per l'invio delle copie della rivista. Il titolare del trattamento dei dati è PAGEPress Srl, via A. Cavagna Sangiuliani 5 - 27100 Pavia, al quale il lettore si potrà rivolgere per chiedere l'aggiornamento, l'integrazione, la cancellazione e ogni altra operazione di cui all'art. 7 del D.Lgs 196/03.

https://www.italjmed.org/index.php/ijm/quad 


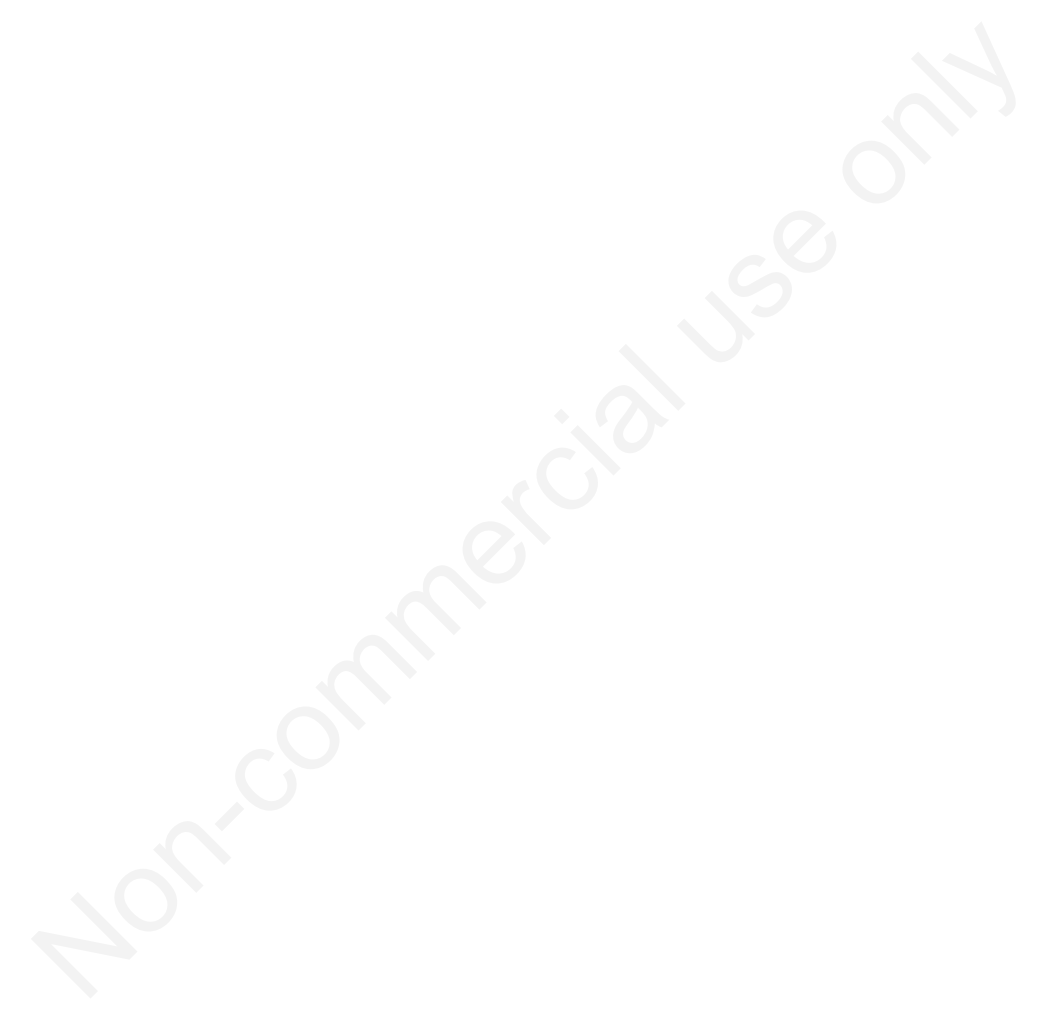


PAGEPress - Scientific Publications

Via A. Cavagna Sangiuliani, 5 - 27100 Pavia - Italy

Phone +39 $03821549020-$ Fax +390382 1727454

www.pagepress.org 